\title{
THE PSYCHOLOGICAL BASIS OF ECONOMIC BEHAVIOUR
}

\section{YU. YA. OLSEVICH}

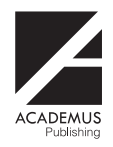

Academus Publishing 2015 


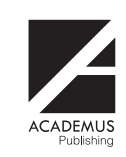

Academus Publishing, Inc.

1999 S, Bascom Avenue, Suite 700 Campbell CA 95008

Website: www.academuspublishing.com

E-mail: info@academuspublishing.com

(C) Publisher, Academus Publishing, Inc., 2015

The right of Yu.Ya. Olsevich is identified as author of this work.

\author{
ISBN 10: 1494600021 \\ ISBN 13: 9781494600020 \\ DOI $10.12737 / 10433$
}

\begin{abstract}
All rights reserved. No part of this publication may be reproduced, stored in a retrieval system, or transmitted in any form or by any means, electronic, mechanical, photocopying, recording or otherwise, without the prior written permission of the publisher. This book may not be lent, resold, hired out or otherwise disposed of by way of trade in any form of binding or cover other than that in which it is published, without the prior consent of the Publisher.

All trademarks used herein are the property of their respective owners. The use of any trademark in this text does not vest in the author or publisher any trademark ownership rights in such trademarks, nor does the use of such trademarks imply any affiliation with or endorsement of this book by such owners.
\end{abstract}




\section{Table of Contents}

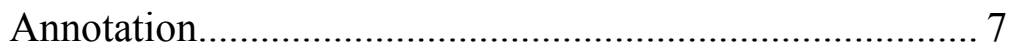

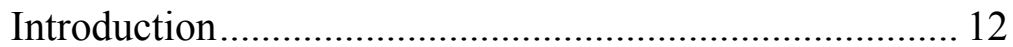

Social Sciences on the Verge of Youth........................ 12

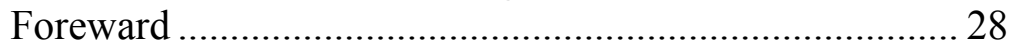

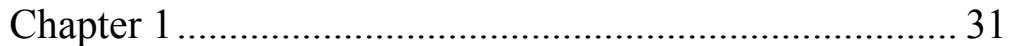

The Psychology about the Structure and Types of

Human Psyche .............................................................. 31

1.1. Philosophical Approaches to Psychological

Structure ..................................................................... 32

1.2. Typologies of the Psyche ................................ 41

1.3. The Reasons for Disagreements..................... 65

1.4. I.P. Pavlov on Instincts and the Role of Institutions $(«$ Rules») ................................................ 78

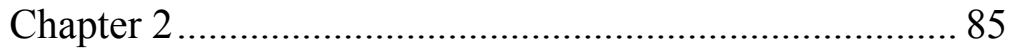

The Role of the Psyche in the Economic System: N.D.

Kondratiev, T. Veblen, V. Pareto, V. Sombart, A.

Marshall, and J. M. Keynes

2.1. N.D. Kondratiev: the Psyche as a Reflection and Regulator of the Satisfaction of Requirements .. 86 2.2. T. Veblen: The Psychic Bases of Capitalism 98

2.3. V. Pareto: the Psychology of the "Elite" as a Source of Economic Progress and Stagnation ........ 108

2.4. W. Sombart: the Deheroisation of the «Capitalist Spirit»

2.5. A. Marshall: a Semi-Marxist View of the Psyche 129

2.6. J.M. Keynes: «The Psychology of the Market» 134

Chapter 3 141

The Human Psyche from the Point of View of New

Economic Nobel Laureates 
3.1. The Contemporary Crisis of Mainstream Axiomatics ............................................................ 141

3.2. Two Views on the Psychological Bases of Economic Choice: D. McFadden and A. Sen ......... 146 3.3. The Psyche and Informal Rules of Economic Behaviour:........................................................... 156

3.4. «Bifurcation» of Economic Knowledge:

Daniel Kahneman and Vernon Smith ...................... 164

Chapter 4

Psychogenomics: the Start of a New Stage in Studying Economic Behaviour.

4.1. Questions that Economic Theory Cannot Answer ................................................................ 175

4.2. A Permanent Basis of Behaviour - Heredity 179

4.3. The Environment: Instilled Instincts, Adaptation, and Habits.

4.4. The Unresolved Problem of the Mechanisms

of Memory and Training ........................................ 192

4.5. Rationality: Abstract or Evolutionary? ....... 198

Chapter 5

The Structure and Types of Psyche: from the

Socioeconomic Point of View 207

5.1. Inborn Requirements, Abilities, and Instincts 209

5.2. The Instilled and Developed Properties of the Psyche, Adaptation, and Habits ................................... 213

5.3. The Role of Consciousness - Cognitivism. 218 5.4. The Constituent «Blocks» of the Psyche and its Social Types

5.5. The «Homo Economicus» and the «Real»

Person: Does Everyone Wish to Become a Capitalist? 231 
5.6. The Psyche of the «Elite» and the Psyche of

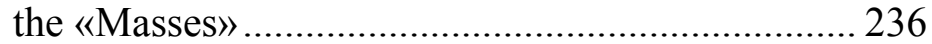

5.7. The Psyche of Extremists............................. 242

5.8. Psyche and Religion..................................... 245

Chapter 6

Underlying Psychological Background of Institutions and Organisations

6.1. Institutions, Organisations, and Typologies of the Psyche 255

6.2. Shifts in the Psyche and the Transformation of

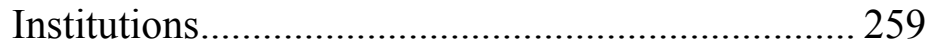

6.3. The Psyche and «Human Capital» .............. 262

6.4. The Market and Organisations: Two types of

Relations

6.5. Questions Regarding «Proto-Institutions».. 269

6.6. Structures of the Psyche and Social-Economic Systems 275

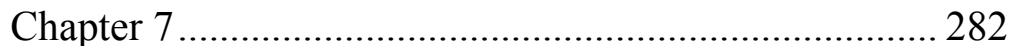

Market Categories: the Psychological Aspect ............ 282

7.1. The Institution of Trust and the Trust Instinct 282

7.2. Wage Psychology........................................28 288

7.3. Does the Instinct of Thrift Exist?................. 293

7.4. Psychological Aspects of the Securities Market 297

Chapter 8 301

Psychological Foundations of the General Interrelation of Markets 301

8.1. Partial Markets in a System of General Market Equilibrium ............................................................ 301

8.2. The Standard of Living and the Self-

Preservation Instinct................................................. 306

8.3. The Boundaries of Interchangeability......... 309 
8.4. The Psychological Determinants of the

Structure of Demand ................................................ 311

8.5. Social Requirements and the Markets of Social Goods 316

8.6. Types of Psyche and Forms of Competition319

Chapter 9

Modern Innovations: the Conflict of Different Types of

Entrepreneurial Psyche

9.1. N. Kondratiev's «Waves» and R. Foster's

«Eras» 327

9.2. Conservatism and Innovation in American

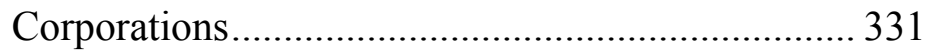

9.3. Conservatism and Innovation in Science .... 339

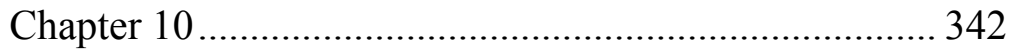

The National Psychology and the National Economy 342

10.1. Understanding the National Psyche ........ 342

10.2. The Genetic Roots of the National

Psychology: A. Marshall and J. Priestley 350

10.3. Capitalistic and Non-Capitalistic

Nationalities - W. Sombart..................................... 361

10.4. Modern National Models of the Economy in

the West - the Psychological Aspect ........................ 370

Chapter 11 382

The Specificity of the National Psychology in Russia 382

11.1. History of the Country and the

Contradiction in the National Psychology ............... 382

11. 2. The Elite and Non-Elite: the Genetic Roots

of Psychological Alienation....................................... 389

11.3. .Specific Features of the National Psyche and the

Economic Behaviour of Russians ........................... 396

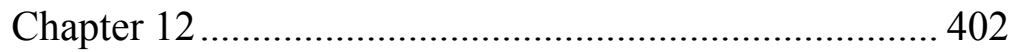


Psychological Factors of the Institutional Transformation and Economic Development of the USSR .................. 402

12.1. Pitirim Sorokin on the Psychology of the

Revolution of 1917 ................................................. 403

12.2 Extremism as the Prepotent Psyche of the

State's Socialist Transformations ............................ 408

12.3. Dynamics of the Psyche and Institutional

Adaptation in the Economy of the USSR after the

Second World War..................................................... 417

Conclusion 


\section{Annotation}

This book proposes and proves a general hypothesis: social and economic evolution and modern society are the result of the expansion in time and space of genetic bases of the human psyche.

The decoding of the molecular structure of the human genome and the identification of many genes, responsible for its psyche, mark a new stage in the development of the science about human behaviour. Geneticists have established that behaviour is $50 \%$ defined by hereditary factors and the remaining $50 \%$ by upbringing, experience, and consciousness. Psychogenomics - a science about the genes governing the psyche - has provided me with the starting point for revealing the structure of the human psyche and for the allocation of the invariant types of the psyche of participants in economic activities. Such an approach allows me to explain in a new way the structure and functioning of social and economic systems in the book: in particular, the direction of the evolution of the market capitalist economy, the rise and collapse of state socialism, modern global crises, and the prospects of national economies.

In the book, the attempts of the most well-known psychologists and economists, including recent Nobel Laureates in economics, to account for the independent role of the psychological factor in social and economic development, are illustrated. In this context, one can divide psychologists and economists into three groups. The first group recognises the genetically caused features of the psyche, but treats them in a simplified and one-sided way. The second group considers the human psyche as something completely derived from the «environment». The third group has come closest to the truth. These psychologists and economists consider the complex, genetic-social nature of the psyche, and its heterogeneity in different groups of individuals. However, as psychogenomic data was not available to them, they therefore could not explain the division and interaction between elements that were genetically inherited from those that were obtained «from outside» of the psyche of participants in the economy. Nevertheless, in the works of this group of authors, a vast layer of knowledge has been accumulated, and the first three chapters of this book are devoted to a brief analysis of their points of views. 
In the following two chapters (chapters 4 and 5), a comparison of these views with the achievements of psychogenomics has allowed me to fill the division of the psyche accepted in psychology between the unconscious (genetic memory), preconsciousness (long-term and operative memory), and consciousness, with specific content, directly linked with social-economic activities. They allocate genetically inherited existential requirements, abilities, and instincts, on the one hand, and requirement and instincts, instilled since early childhood, on the other hand, as well as habitual forms of thinking and behaviour.

This essentially new approach, which is defined throughout the rest of the analysis, consists of the allocation of three groups of requirements and instincts in the psyche of each person: (1) Individualism (directed towards the survival of the individual); (2) Sociality (directed towards the survival of kin); (3) Developments: In this way, unilateral characteristics of human nature as «individualistic» or «collectivistic» are refuted. In the psyche of the majority of people, the allocated groups of requirements and instincts counterbalance and supplement each other. At the same time, during millions years of evolution have also led to the development of such types of the human psyche, which, deviating from «equilibrium», were called on to contribute flexibility and variety to primitive society. These are the types of the psyche directed along one way, dominated by requirements and instincts of individualism, sociality, or development.

In the book, the differentiation of types of psyche from the point of view of inborn and instilled requirements and instincts is combined with differentiation according to the character and level of the inborn and developed abilities - both general (intelligence, will, psychic energy, memory, attention, etc.) and specific.

The interaction of people with different types of psyche, level, and character of abilities, allows one to explain both the genesis of the market capitalist system and its modern institutional structure.

The combination in the inborn psyche of the majority of people of requirements and instincts - individualistic, on the one hand, and socialitarian, on the other hand, as well as requirements for development - has resulted, through their economic interaction over the course of thousands of years, in a combination of market (not personalised) and non-market (personalised) forms of exchanges of activities and distribution of goods and services. 
The concentration of individuals with an individualistic type of psyche, dominated by requirements and instincts of appropriation, accumulation, and aggression, in combination with high psychic energy potential and organisational abilities, has led to the formation of a class of businessmen. Large sums of capital, firms, and enterprises have emerged. Psychogenomics has provided the general foundation for the systematisation of different types of businessmen, characterised by T. Veblen, J. Schumpeter, W. Sombart, V. Pareto, J. M. Keynes, and other economists. In the book four basic types of capitalist-businessmen have been allocated: (1) The predatory type, accumulating wealth through the redistribution of wealth that had been saved up by others; (2) The innovator, creating new effective combinations of factors of production, technology, and products, and discovering new resources and markets; (3) The slave to routine, following the existing norms of management, technologies, and methods of production; (4) The opportunist, aspiring to benefit in any possible way, including through the infringement of rules and contracts.

In order to protect their existential requirements from the aggressive pressure of businessmen, hired workers, the majority of whom consists of people with a balanced psyche, unite for the purpose of concluding agreements on the restriction of the length of the working day, wage increases, and improvements in working conditions. As a rule, movements for the introduction at enterprises of these social institutions, resisting the institutions of profit and private appropriation, are organised and headed by people with a dominant socialitarian psyche. For this type of people there is also another important field of activity - the management of organisations in the social sphere, in which social norms and rules are given priority over institutes of private appropriation (public health services, education, science, culture, the mass-media, social security, etc.).

In chapters 6,7 , and 8 it is shown that on the basis of informal (and, in the end, also formal) institutions of the market capitalistic economy, their combination in the framework of the market system, makes up the interaction of the different types of psyche of market participants. This defines the heterogeneity of the partial markets, and the discrepancy and instability of the general market equilibrium. 
From the analysis of psychogenetic and psychosocial typology, it follows that in a normal social-economic system, the following should apply:

1. Individuals with an individualistic psyche, aspiring to profit and accumulation, should head organizations in the commercial sphere; social norms and rules in this sphere have a «protective» limiting character.

2. Individuals with a socialitarian mentality should head organizations in the social sphere; here, institutions (norms and rules), focused on private benefit, should play the limiting role.

If organisations in the commercial sphere turn out to be in the control of individuals with a socialitarian psyche, guided primarily by social aims, it will undermine profitability; if individuals, aspiring for private benefit, are at the head of organisations in the social sphere, it leads to the degradation and even destruction of the given sphere.

For the preservation of social-economic balance, it is vital that the legislative, executive, and judicial authority is held by persons with a balanced psyche, ready to counteract any specific «distortions» within organisations in both spheres.

At the same time, psychogenetic and psychosocial analysis has shown that the structure of «the body of businessmen» is critically important for the dynamic development of a nation; only the fact that is dominated by «innovators» ensures steady progress. In order to push aside the «predators» and «opportunists», one needs to block all the paths of enrichment available to businessmen, except for technical-organisational progress. These predators and opportunists should be pushed aside through tax and antimonopoly laws, support for trade unions, environmental protection, stimulation of science, innovations, and venture capital projects.

In the book, chapter 9 is devoted to the psychology of technicaleconomic innovation, revealing the leading part played by leaders of large corporations in the organisation of mass innovation activities in corporations and in their environment (consumers, suppliers, competitors, etc.).

In chapters 10,11 , and 12, a new approach is proposed regarding the concept of a nation, national psychology, and its influence on the development of the national economy. The identification of the essence of the nation with historical factors (geographical, economic, political, etc.), which have shaped it, is rejected. This identification 
leads to an erroneous understanding of modern globalisation as a process of the liquidation of national economies. The specificity of the national-institutional systems of the economies of the United States, Western Europe, and Russia is considered from these positions. By considering psychological factors of the economic transformation of the former Soviet Union and Russia, special attention is given to the role of the extreme (extremely dominant) psyche of the governing kernel of the party in power. The psychological roots of the universal «disease», called the «cult of personality», and its dangerous influence on economic and social development, are investigated.

In the conclusion, I have noted that the current crisis has sharply revealed the structural psychogenetic and psychosocial discrepancy between the current ruling elite of Russia and the tasks of economic development in Russia. Attention was drawn to this problem in the Presidential message to the Federal Assembly of the Russian Federation, where it was specified that neither business nor the administration has justified the hopes of the Russian citizens. The problem of the regulation of the structure of the ruling elite is the most important and the most complex challenge faced by any democratic nation.

The book helps us to understand the underlying psychological background of the current financial and economic crisis: in conditions of excessive liberalisation, controlling positions in global financial institutions were grasped by individuals with an extreme and predatory psyche, which led to the destruction of the financial markets.

As the book contains a fundamentally new statement of a series of basic problems of the social-economic structure of the economy and society, it will be of interest to teachers, researchers in science, and journalists in the economic sector, social psychology, philosophy, and other humanities.

It is written in a simple and lively style and contains a systematic consideration of a wide range of actual problems of social development, and will be useful to students, studying social science. 


\section{Introduction}

\section{Social Sciences on the Verge of Youth}

Man's potential for adaptation seems to be unlimited. He is capable of surviving in the deserts of Africa, in Arctic conditions, in wild jungles, in high tech cities, in mountains, in swamps, in submarines and space shuttles. People become accustomed to living in small hovels and luxurious palaces, to a peaceful mode of life and to war, as well as to hard work and idleness. In everyday life they have to adapt their behaviour to social norms, to federal laws, and to company and institutional rules. Finally, people have to constantly adapt to each other everywhere - at home and at work.

This has given rise to the opinion that the human psyche is extremely supple, that it can change depending on changes in natural, technological and social conditions. If these conditions change cardinally, then man himself changes cardinally, if not immediately, then over time. Therefore, one can hope that with the establishment of specific ecological and technological preconditions and the construction of the required social system «the New Person» can also appear; that is, a person, who in his behaviour acknowledges only principles of freedom, equality, brotherhood, fairness, humanity, progress, and peace.

However, there exist many other observations. In all the endlessly different conditions, in which people from different parts of the world live and to which they adapt, their behaviour has inherently common characteristics. Almost everywhere, people try to cooperate with each other and at the same time exploit each other, desire freedom for themselves but want to rule others, value peace, however, are prepared to go to war in order to solve disputes. These contradictory general traits are inherent in the psyche of people, regardless of whether they live in Amazonian jungles, New York or Chukotka.

Furthermore, the basic parameters of the psyche of people change little over thousands of years. This can be seen in the endless repetition of historical themes and types of historical figures and in the mass reactions to economic, political and ideological events by sectors 
of society. Modern man, reading the works of authors that were written two or three thousand years ago (the Old Testament, the Mahabharata, the poems of Homer, and the works of other ancient Greek and Roman authors), understands perfectly the motives behind the deeds of the characters in these works and empathises with them as he recognises his deep psychological link with them. The New Testament, which is about two thousand years old, contains norms of acceptable behaviour, extracted from the experience of ten thousand years of civilisation, which are generally accepted (although often infringed) in the modern world.

Does this mean that man outwardly adapts to any change and changes his behaviour accordingly, however, at the same time, remains unchanged inside?

There exists a third series of facts, which imply that not only people's habits can change, but also their inflexible individual characteristics related to their internal psyche. Depending on the conditions in which the genesis and evolution of a specific nation takes place, in the psyche of its members, certain traits may be reinforced, others weakened, and certain specific characteristics may appear. However, these changes occur extremely slowly over centuries and generations.

The psyche of individuals varies. Philosophers, psychologists, sociologists and economists have made considerable efforts to separate the types of people's psyche and illustrate the role of each type in society. However, opinions vary widely on this issue, as scholars have not yet been able to express a definitive opinion on the nature of man's psyche. This is why there are different opinions on the structure of the psyche of society and on the factors concerning the mass behaviour of people in different spheres of life.

At the same time, there are no shortages of attempts at constructing a theory about the psyche of man and of society as a whole. These attempts are based on the historical sciences such as history, archaeology and anthropology; on the research of the contemporary behaviour of people carried out in sociology and social and economic psychology; and on the research in psychology and psychiatry.

All these theories have a common weakness: their authors are forced to make conclusions on the internal nature and on the structure of the human psyche based on people's behaviour and their opinion about themselves. This appears to be a very strong foundation. 
However, people's behaviour is contradictory, varied, and changeable. In order to explain it, it is not enough to simply describe and systematise facts about people's behaviour. One needs to supplement them with knowledge about psychophysical processes and about the mechanisms of man's higher nervous function. In this way, we can understand why, under the same circumstances, some people act in one way and others in a completely different way, and the reactions that can be expected when the initial conditions change quickly or slowly.

Ivan Sechenov's research as well as the studies of the Nobel Laureate (1904), Ivan Pavlov, on the link between the signalling system in complex reflexes (instincts) and the functioning of different parts of the human brain contributed significantly to the progress made in the science of the internal mechanisms of the higher nervous function. They were applied in neurophysiology with the use of methods used in electroencephalography and biochemistry.

However, the true revolution in the research of the internal mechanisms of the human psyche began at the end of the $20^{\text {th }}$ and the beginning of the $21^{\text {st }}$ centuries, as a result of works on decoding the molecular structure of the human genome and the determination of the functions of separate genes. A new branch of genetics called psychogenomics was formed. This branch is engaged in revealing the genes that control various aspects of the human psyche and studying the biochemical interaction that takes place in this «management» process.

Only knowing the natural (genetic and neurophysiologic) basis of a person's psyche, enables one to understand the influence of external (natural, technogenic, and social) factors on this basis, and thereby understand the formation of the human psyche as a whole.

Economists (like any other social scientists) are interested in the human psyche primarily from two fundamental points of view: firstly, the relation (interaction, link) between the structure and dynamics of people's psyche, on the one hand, and the formation and transformation of the system of social (primarily, economic) institutions, on the other; secondly, they are interested in the role of the psyche in decision-making (and in behaviour as a whole) within the limits of the given institutions. In other words, they are interested in the relation between psychodynamics and institutional dynamics, on the one hand, and the relation between the psyche and rational 
goal-oriented behaviour, in conditions of relative institutional inertia, on the other hand.

Regarding the first fundamental position, one of the great Russian economists, Nikolai Kondratiev, formulated the following general law: "Although the influence of social conditions in life on the psychophysical organisation of a person is both considerable and deep, nonetheless it has its limits. What a person is not capable of achieving on the basis of his natural organic conditions, clearly, cannot be achieved under the influence of social conditions. Conversely, events that are inevitable in the course of the life of a person by virtue of the same natural-organic conditions cannot be prevented by the conditions prevalent in social life. In this sense, nature places maximal and minimal limits on the influence of culture and public conditions on a person and accordingly on the amplitude of the course of social life itself. That is why, in considering society as the real totality of people and in analyzing a person as an element of society, one needs to consider strictly the dual natural and social nature of a human being.»1

Thus, the amplitude of social life has maximal and minimal limits, which are defined by the psychophysical organisation of a person. The maximal limit regarding the influence of culture and social conditions on this organisation is limited by the natural-organic potential of a person. The minimal limit is determined by the fact that the psychophysical organisation of a person makes demands on society and its institutions, which have to be implemented. Thus, the dynamism of the progress of social institutions is limited from above by the degree of elasticity of the psychophysical organisation of a person, and from below by the stability of his natural and organic nature and his demands regarding social conditions. In other words, there exists a maximum possible degree of culturalisation of a person, beyond which his natural basis collapses, and a minimally admissible degree of culturalisation, below which a human being's behaviour ceases to differ from his savage ancestors.

${ }^{1}$ N.D. Kondratiev, "The Basic Problems of Economic Statics and Dynamics: A Preliminary Sketch." M., "Nauka", 1991, p. 33. This work has been written by Kondratiev in 1930-1932 in Butyrskaya Prison where N.D. Kondratiev was being held and questioned on a forged charge of the Peasant Labourers' Party. It was published for the first time 60 years later. 
My primary task in this book consists in (where possible) specifying the given psychophysical structure of a person (and as people differ in this respect, in also specifying the psychophysical structure of society). It involves, on this basis, specifying those demands, which this structure makes on the institutional economic system and on society as a whole in varying technical, ecological, demographic, and cultural conditions, and finding (if possible) mechanisms to implement these requirements.

The next problem in this series is to answer how different types of the psychophysical structure of a person appear specifically in the behaviour of people in different institutional systems of various branches of the economy, and how they affect the efficiency, stability, and dynamism of these systems.

The second series of tasks addressed in this book, concerns specific ways of influencing social (primarily economic) institutions on the formation and dynamics of the human psyche, and the direction and limits of this influence.

From the 1970s to the 1990s, in economic science and economic policy, the market fundamentalist approach was favoured, which forced out Keynesian and classical institutionalism as well as Marxism. Moreover, using the instruments of methodological individualism, this trend has extended to sociology, psychology, law, political science and history, considering any sphere of human activity as a market where rationally operating subjects, maximizing their individual benefits, compete. This scientific expansion has been termed «economic imperialism».

However, since the 1990s a strong movement has been observed going back to sociology, psychology, law, and history. This not only rejected the approach of methodological individualism in research areas but, moreover, resulted in increasingly convincing proof that non-market institutions constitute the basis of the market itself. In other words, it called into question the methodological foundation of market fundamentalism. To a significant extent this was due to the disastrous consequences of its application in the reforms in Russia, the CIS, and Argentina and its rejection by China and Brazil.

One of the main questions that needs to be addressed by research in social studies consists of the following: is it possible to isolate the behaviour of a person in the economic sphere from his behaviour in social, political, ideological, and cultural spheres? Is the psyche of a 
given person in a single system, or is it so fragmented or flexible, that it is possible to speak of an economic person in the economy, and a different social, political and ideological person outside economics; i.e., to recognise, that one and the same person in different fields of activity possesses different types of psyche and behaviour?

Psychology and sociology are increasingly resolutely and successfully being used to explain the behaviour of economic subjects. For their research in this field only in the last few years, Nobel Prizes in economics were awarded to George Akerlof and Joseph Stiglits (2001) and Daniel Kaneman and Vernon Smith (2002). Through laboratory and field research they managed to prove that a greater part of the knowledge used by humans, as well as their ability to make decisions, belongs to the subconscious.

However, the internal mechanism of this subconscious knowledge and decision-making process has still not been discovered, and to date «neuroeconomics» has achieved the best results in terms of understanding the psyche economic decision-making; through functional encephalography, the essential activation of certain parts of the brain in reaction to gains and losses in gambling, and to monetary compensation in general, has been established.

I believe that for the first time in history a real opportunity to penetrate this mechanism has been made possible by the decoding of the human genome and the appearance of a new branch of genetics, psychogenetics, which reveals the genes responsible for various aspects of the nature of the human psyche, and by the research on the activation mechanism of these genes. The term, psychogenomics, and the characteristics of this branch of knowledge were proposed by Dr. Vyacheslav Zalmanovich Tarantul. Psychogenomics has already achieved significant successes, having discovered the genes of leadership, aggression, uneasiness, happiness, search of novelty, sociability, motherhood, etc., and having proved that they function in different ways in the organisms of different people, and in some people, a part of them can be missing.

Psychogenomics claims to be able to explain $50 \%$ of the behaviour of people, leaving the remaining $50 \%$ to be explained by the influence of the surrounding conditions.

Until now the building of sciences, studying human behaviour was constructed from the roof downwards. The contribution of psychogenomics can be considered as the first blocks laid in the 
foundation of this building. In due course, the entire building will be completed and reconstructed on this foundation. It seems to me, that, after taking into consideration the data of other sciences (including history, economy, sociology and psychology), we can now depict only the contours of this future building.

- The development of psychogenomics will lead to the distinction of the basic psychogenetic types of personality (which is what literature, the theatre, and the arts have already been engaged in for thousands of years).

- This will enable research to be carried out at a genetic level on the mechanisms of action of individual and collective instincts (with which not only psychologists, but famous western and Russian economists and sociologists, have operated) and the construction of an equilibrium dynamic model of the psyche at this level, taking into consideration both the interaction of different groups of instincts (of individualism, sociality, and development), and the change in dominant impulses;

- On this basis the system of the instilled instincts, norms, and values, including international, national, group and individual will be investigated; the instilled psyche does not overcome, but refines and partially supplements the natural one. The third floor of the building of human behaviour contains the habits acquired through experience, imitation and adaptation.

- The «penthouse» of this building is occupied by rational thinking, which is mediated by the influence of the psyche as a whole in the selection and evaluation of information and in the implementation of rational decisions. 
This realistic model of human behaviour, based on the data derived from psychogenomics, psychology, and sociology will help economic science answer a number of general and specific questions, including the following:

- What are the demands made by people's psyche on economic institutional structures and how unexpected events mature in this structure?

- How are distinctions correlated between psychogenetic types, on the one hand, and social and economic stratification and professional specialization, on the other hand?

- How international distinctions in the structure, level, and rate of economic development are related to distinctions in the national psyche, and whether such distinctions in globalisation processes are being smoothed out?

Mistaken ideas about natural and social laws of human behaviour have played an important role in the tragic events that resulted from the attempt at «raising the new human being» in the USSR and in the no less tragic episode of the long-term consequences of the economic shock therapy provided to Russia. Today, the consequences of this misunderstanding include the failed monetisation of social privileges, the destructive social reforms, the continuation of the decline in the population, and, importantly, the preservation of the oligarchic system of capitalism, which has blocked the Russian nation's path towards survival and civilised progress and is thus preparing the psychic preconditions for the next explosion.

I believe that only by relying on the development of psychogenomics, will it be possible to constructively answer the question asked in the Presidential message of 2006: why have Russian employers and the state bureaucracy not justified the hopes which were placed on them by the Russian population?

Structural shifts and revolutions in the systems of economic institutions are closely connected with revolutions in all social orders. Furthermore, such revolutions often follow wars. Throughout the 
world there are always scientists, politicians, and political parties, who constantly predict social catastrophes in the near- or long-term future, on a national, regional or global scale. The forecasting of catastrophes can be considered as an expression of a sincere belief, a specific character, self-advertisement, or as an instrument of political warfare.

The tragicomedy of the situation is that forecasts of catastrophes sooner or later come true, and do so in a more ominous form and on a larger scale than imagined by their forecasters.

However, they always come true unexpectedly: not at the time or place, where, according to scientific and practical considerations one would expect them to occur, and not with those forces and consequences, which the forecasters had predicted.

However, evolutionary periods of economic and political history also constantly lead to such shifts and changes in developing trends, which are impossible to foresee. Powerful social and economic tendencies are like currents on the ocean, which appear on the surface, only to again plunge deep into the ocean.

As a result, history, in general, and economic history, in particular, remains unpredictable. The theories explaining history are focused on the past. It is always possible, in one way or another, to (retrospectively) theoretically explain historical events and processes that have already taken place. However, when these theories, based on past events, are applied to the future, they turn out to be groundless.

Usually, the unpredictability of the future is explained by too many interrelated factors of different types. However, in fact, there are not that many factors: demography, the environment, equipment, technology, and human behaviour. Therefore, the difficulty does not lie in the number of factors, but in the uncertainty included in each of them.

In modern demography and Earth Sciences, population dynamics and the development of economic resource bases are comprehensively forecast for a decade ahead. However, one cannot say this about the development of science and technology, and, especially, the behaviour of people.

Here, I am not speaking about the external forces, influencing people's behaviour. I mean that, even when these forces are wellknown, it is difficult to predict human behaviour, and often it is simply not possible to do so. In other words, I am referring to human behaviour as a source of fundamental uncertainty. 
The difference in people's reactions to the same external shocks during different historical periods or in different countries during the same period can be explained (again, retrospectively) by the evolution of their psyche or in terms of national traits. However, how can one explain rapid changes in the basic characteristics of the behaviour of large masses of people? Do these changes contradict our thesis about the invariability of the bases of the human psyche?

In order to answer these questions, one needs to clarify the structure and functioning of the system of psyche, both of individuals and society. This is the central theme of this book. Not wishing to anticipate the answer, I shall try to state my general conclusion in the form of an analogy.

Similarly to the magma, on which the earth's core is formed, the unstructured force of life (animal spirit) and the nervous energy incorporated in each person form the basic foundation of the psyche. Floating plates of the lithosphere have passed by, approached, and collided on this magma. Similarly to these plates, complexes (modules) of genetic memory in the form of inherent needs, instincts, and deposits of abilities form the mobile base of the psyche. Their composition has been determined and finalised. Therefore, people not only biologically, but also biopsychically, form a certain type. Similarly to lithospheric plates, psychogenetic modules are in a mobile state and are capable of changing their position relative to each other and their role in the psychic system of a person.

The second structured layer of the psyche (based on «plates») is its cultural and institutional layer, consisting of the instilled instincts and the norms and rules of behaviour, which are organically acquired by preconscious memory. It is the upper part of the lithosphere, the earth's crust of the «Psyche Planet», which is its most inert cover (from the point of view of a relatively short time interval). The surface layer (landscape) is the set of habits acquired by people in the process of adaptation to the changing (specific) conditions of life. Habitual thinking and behaviour lies in the interaction of consciousness with preconsciousness (operative memory) and unconsciousness (genetic memory).

The paradox of the human psyche consists of the fact that precisely its deepest structured bases are the potential sources of its sharpest shifts. Shifts in the correlations of psychogenetic modules cause shocks and breaks in the cultural and institutional membranes of 
society, just as collisions of plates of the lithosphere result in breaks of the earth's crust and events triggered by them - earthquakes, volcanoes, and tsunamis.

Theoretical hypotheses explaining the movement of plates of the lithosphere and its interaction with the earth's crust exist. However, do theories exist that explain the structural processes in the genetic bases of the human psyche (both the individual and the mass) and their interaction with processes in cultural, institutional and adaptable layers of the psyche?

Such dynamic hypotheses still do not exist, although psychologists already started developing scientific models of the human psyche a long time ago. My analogy with the movement of the earth's lithosphere is no more than a metaphor; it was used only to emphasise the basic orientation and central theme of this book: an attempt to promote an understanding of the psychological mechanism of the formation, functioning, and changes in the social and economic systems. $^{2}$

There is no sense in denying the fact that the cardinal and unexpected shift in the mass psyche of the USSR, which led to the collapse of the country, and the breakdown of one institutional system

${ }^{2}$ The explanations of historical movements by Karl Marx, Pitirim Sorokin, and Arnold Toynbee did not touch on changes in the genetic bases of the human psyche. Marx connected such movements with the conflict of new productive forces and old methods of production. Toynbee treated them as an answer to those calls, which are made on an existing civilisation by changes in the surrounding natural and public environment. Sorokin explained these movements in terms of the conflict between the culture of a society and human nature: culture develops cyclically from religious to idealistic, to sensual, and then back again to religious stages, and only a transitive, unstable, and idealistic culture, being a synthesis of the first and the third cultures, corresponds to the dual nature of man.

${ }^{2}$ A fundamentally different approach was taken by Lev Gumilyov. He divided people on the level of their natural biopsychic energy into three different types: passionary, harmonious, and subpassionary personalities. Changes in the biosphere of the Earth, causing mutations in the hereditary features of the population of certain regions, lead to a "passionary explosion" and to the unwinding of the ethnogenetic process. Gumilyov was the first to specify spontaneous changes in the genetic bases of the psyche of races as a fundamental cause of mass historical movements. 
of society and its replacement by a principally different system, served as the shock, which induced me to such a fundamental statement of the problem about the psychological mechanism of society (in conditions, when scientific representations about the human psyche are still in their infancy). I note: changes that have not been prepared by an obvious economic and social crisis, widespread propaganda, and the organisational and political activities of underground and other parties. Changes that were unexpected and not acknowledged by the overwhelming majority of the population, but «for some reason»" accepted by it (even though without enthusiasm, but at the same time without resistance). This «for some reason» needs to be explained.

It is time for social sciences to investigate the processes occurring in the depths of the human psyche.

Older Russian readers are likely to ask why there is no chapter (or even paragraph) included in this book on Marx. When I wrote these lines (2008), I was approaching 80, and for almost 50 years, I, together with my generation of Soviet economists, was heavily influenced by Marxist theories. Thus, I am far from indifferent to Marx. However, in this book there is no place for him, because here only those scholars, who (at least partially) acknowledge and take into consideration the genetic bases of economic behaviour, and who also do not recognise or seriously doubt the possibility of raising (educating) «the New Person», are considered.

Marx belongs to the majority of thinkers, who, contrary to the entire history of the human race, proclaimed and tried to prove the possibility, and even the inevitability, of the coming of a man-made paradise on Earth.

It would be unproductive to examine the arguments of these thinkers in the 21 st century. It is much more important to study the thoughts of those who tried to understand and explain why the history of «homo sapiens sapiens» is moving in such an irrational way.

However, nonetheless, a brief note on Marx's views on questions of interest to us will be useful. In Marx's opinion, the development of civilization had pushed the instincts into the subconscious, so that the behaviour of people had become entirely defined by consciousness. Consciousness can be ordinary, ideological, and scientific. Ordinary consciousness is guided by daily practical interests. For the working class it signifies the struggle for economic rights. Ideology (false consciousness) is imposed by exploiter classes and reflects their 
interests. Scientific consciousness (socialism) cannot be developed in the bowels of the working class; it demands a critical generalisation of the entire historical experience of mankind, which is a task for scholars. Scientific consciousness was brought into the working-class movement from the outside; it was acquired at first by a narrow group of avant-garde workers and revolutionaries and then spread by them to the working-class masses. The basic element of this consciousness lies in the understanding that workers will never fundamentally improve their position whilst «capitalist slavery» is maintained and that their historical mission is to win political power and construct a socialist society. For this, workers will probably have to go through decades of civil wars, until their own mentality fundamentally changes and they become people, worthy of a new classless society. In the works of Marx and his followers one searches in vain to find explanations of what exactly is capable of motivating workers to fight in a long-term and bloody war, if they are truly guided by reason, instead of blind instincts of class hatred. Marxists believe that this force is the «revolutionary consciousness» (the «revolutionary consciousness» in this work is considered as an extreme type of the psyche).

As we can see, Marxists, considered as materialists, allocate a role of force to («scientific») consciousness, radically transforming society and people for a time when, according to scientist-revolutionaries, material conditions will be ready for this purpose.

In fact, revolutionary Marxism attaches a much greater role to consciousness and its independence (in relation to «matter») than any form of idealism. All materialism of Marxism is reduced to a recognition of the fact that matter is primary, and consciousness is secondary, and that consciousness is a product of the development of matter. However, from the moment of the appearance of «scientific consciousness», it already flies above matter and also moves to dominate it (the famous philosopher Charles Popper placed Marx at the same level as Plato and Hegel). Moreover, having captured the masses, scientific consciousness itself became a material force. In other words, by merging with matter, it added a new quality to matter.

This beautiful phrase, unfortunately, lacks meaning and is empty. Consciousness (including scientific consciousness) always was and will remain an organic part of the psyche, as the aggregate of unconsciousness, preconsciousness, and consciousness. Consciousness cannot be the simple reflection of the external world; 
as a part of the psyche it is literally penetrated and bound by its roots, originating from the depths of the unconscious and preconsciousness, and without these roots it cannot exist. Thus, the first requirement of any real scientific consciousness is to recognise and investigate this link. In order not to be lost in the illusion that something besides terrestrial «diseases» - like philosophical self-flattery, religious or revolutionary ecstasy, love, and poetic delirium - is capable of «lifting» us above the terrestrial reality.

However, it is not so simple. In Marx's works, we repeatedly come across allusions to «human nature», both in connection with the development of productive forces and in connection with human needs, and especially frequently in questions regarding the contradiction in capitalist production relations. This means those primitive instincts, which the class society (civilization) has pushed back into subconsciousness.

Marxism understands primitive instincts as instincts of collectivism (as they are the instincts of an ancient tribal system). The class consciousness of the proletariat, followed by socialist consciousness, destroys the shell of bourgeois consciousness («ideology»), separating the false consciousness of a person from its true internal nature and from its collectivist instincts, so that the scientific (socialist) consciousness unites with the natural collectivist psyche of people.

It is interesting that not only Marx and Engels, but also their antipode Frederick von Hayek, imagined the basic role of the socialist consciousness in precisely the same way. Hayek must have agreed with the conclusion of Engels' famous work, "The Origin of the Family, Private Property and the State», stating that socialism had been called upon to revive the collectivism of primitive tribes (described by the ethnographer Morgan), but on a new basis.

The difference consists in the fact that Hayek sees in consciousness, developed for thousands of years in a market civilization, the only hope for mankind, and the merging of collectivist instincts with socialist doctrines as the greatest threat of destruction to any civilization.

In my opinion, both these positions are based on unacceptable simplifications: primitive human nature was never exclusively «collectivist», and the consciousness and culture of civilization were never exclusively «individualistic». Therefore, both these extreme positions represent a threat to humans and to civilization: both the 
position, which recommends suppressing individualism, and the position, which insists on banning socialism.

Over 30 years ago, Andrey Anikin wrote «The Youth of Science», one of the best books of the Soviet period on the history of economic thought. It covered the period up to and including the beginning of the 19th century. Almost a century prior to Anikin, Alfred Marshall characterized the modern (from his point of view) condition of economic science as being in its infancy.

Let us not judge Anikin too severely, as he simply could not name his book differently. In the USSR, rigid ideological standards prevailed: Adam Smith and David Riccardo were the direct predecessors of Marx; while Marx's theory represented the indisputable «maturity» of political economy; and, only «youth» can precede «maturity».

However, according to Marshall, in the period covering the end of the $19^{\text {th }}$ and beginning of the $20^{\text {th }}$ centuries, economic science had not only not matured but was still in diapers - and we do not have grounds not to trust him. The leading representative of the neoclassicists, unlike many of its modern leaders, was free from self-conceit and complacency and tried to be cautious and realistic in his valuations.

In the 20th century, economic science undoubtedly grew up. However, to what extent and which direction did it take? One of the leading modern American economists, William Baumol, carried out a comparative research of the levels of economic science at the beginning and end of the 20th century. He came to the conclusion that meaningful progress was made only in the applied areas, such as statistics, mathematical devices, interbranch analysis, pricing, etc. As far as theory itself is concerned, some advances were made (mostly towards the end of the century) in microeconomics, with much more modest progress in macroeconomics.

It is indicative that Baumol selected Marshall's «Principles ...» as the book personifying the level of economic science at the beginning of the 20th century. So, there is some justification in continuing Marshall's metaphor: during the course of the 20th century, economic science grew out of infancy and by the end of the century entered childhood. Therefore, future historians, looking back, will be justified in naming their books on the development of economic science in the first half of the $21^{\text {st }}$ century (or even of the entire $21^{\text {st }}$ century) as the «Childhood of (Economic) Science». 
In this book, especially in the first half, I have used many long quotations. This is contrary to the style prevalent today, where there are no quotations in the text, however, at the end of almost each sentence there is a source reference, and a long list of sources at the end of the book. This is probably done for several purposes: to convince the reader of the erudition of the author; that the given phrase is supported by an external authority; that he pays due tribute to others' scientific achievements, so that his work will also not fail to be mentioned; that the theme is actual and his work lies in the main stream of scientific research; and that the list of sources is so detailed, that the publication is worth buying for everyone interested in the topic, even if the book (article) itself is essentially only an appendage to the list of the literature contained in it.

My emphasis on using quotations corresponds to the turning-point towards which economic theory, in terms of understanding the economic behaviour of people, is approaching. I would like the reader to convince himself that economic science has come a long way on its journey to this critical juncture, and the journey is far from finished. 


\section{Foreward}

Based on the conclusions of outstanding psychologists and economists, including modern Nobel Laureates, the author offers an essentially new point of view on the structure, functioning, and evolution of economy - from the position of the real, rather than, fictitious human psyche, whose genetic bases have only recently been discovered as a result of the achievements of psychogenetics.

The differentiation of genetically and socially determined types of psyche (of businessmen and other subjects of the economy) has allowed one to explain in a new way the phenomena of development and backwardness, technogenic growth, exploitation and cooperation, and competition and cooperation. It has also led to the rejection of primitiveness in the approach to institutions in private and state ownership, to organisations in the commercial and social sphere, and also to an understanding of market equilibrium and factors that violate it.

The role of psychological factors in the rise and collapse of the system of state socialism is shown.

\section{Dear readers!}

This is an unusual book, which must be read.

Its unusualness consists of the fact that it contains new ideas in the sphere of theory, primarily, economic theory.

Here, one wants to exclaim: «At last!» We have become disaccustomed to any semblance of novelty and originality in economic science.

In the 1990s, in this area, in Russia the tone was set by strident imitators of monetarism, deplorable imitators of a deplorable market fundamentalism. However, this is why an imitator is an imitator, who merely repeats the ideas of his mentor, only in a weakened and vulgarised form.

From the beginning of the current decade, in Russian economic literature, significant research studies have emerged of separate aspects and problems of economic life, including studies with reference to Russia. However, in the sphere of general theory, no progress has been made: the basis for the research of Russian 
economists remained either western neoclassical mainstream, or the neoinstitutionalism related to it, or the former theoretical material of the classical school and Marxism.

I can confirm with confidence that unlike other books, Yu.Ya. Olsevich's book marks an essential step forward in the general theory of economy and, at the same time, broadens our knowledge, which is significant for all world economic thought.

In itself the theme - «What is a human being? What determines his economic behaviour among other people?» - has accompanied social studies since their inception. However, the author, Professor Olsevich, considers it, based on the most recent achievements in natural science and, in particular, on the revolution in genetics, connected with the discovery of the human genome in the beginning of the $21^{\text {st }}$ century.

Furthermore, as a starting point in the statement of his own position, the author uses the richest material from the history of economic studies. As Olsevich explains, the problem of the psychological bases of economic behaviour was interpreted already by A. Marshall, V. Pareto, N.D. Kondratiev, J. M. Keynes, and other leading figures of the past. It also excites the best modern minds, as can be seen from the contents of the inaugural lectures of Nobel Laureates in economy - D. McFadden, A. Sen, J. Akerlof, J. Stiglitz, and D. Kahneman.

Nevertheless, in the expansion of this theme much more remains to be learnt. The monograph offered to the reader has been called on to fill this gap.

Olsevich's own concept about the so-called human nature and about the psychological bases of economic behaviour of people is complex and multilayered. It would be thankless and vain of me to try and state it instead of the author. Those, who wish to make progress in this area, need to be patient and should study the book independently. I note only the following: in order to value innovation and the theoretical and practical importance of the concept, about which we are speaking, it is sufficient to address an aspect of it, such as the psychological bases of modern innovative activity. In my opinion, the position of the author on this point lays the foundation for the economic theory of innovation, designed to become the key to the progress of all economic science of the $21^{\text {st }}$ century.

The contents of the book convey a great deal about the personality of the author himself. The author of this scientific work is a 
courageous researcher, who loves theory not «for its own sake», but as the key of knowledge of life, is clearly erudite, pays a tribute of respect to his predecessors, is a connoisseur of history and the current state of world scientific thought, is a skilful writer and teacher, stating complicated questions logically and clearly, and a citizen, who feels a personal responsibility for the destiny of Russia.

I have had the good fortune to be amongst the first to read Olsevich's monograph; however, it seems that the feeling of gratitude, which I feel towards the author after reading it, can soon be shared with a countless number of readers, not indifferent to the destiny of Russian science.

Doctor of Economics, Professor A.G. Hudokormov

Head of the Department of the History of National Economy and Economic Studies,

Faculty of Economics,

Lomonosov Moscow State University 


\section{Chapter 1}

\section{The Psychology about the Structure and Types of Human Psyche}

The human psyche (as already mentioned in the introduction) as a biosocial entity is formed by hereditary genetic factors, a person's upbringing, and standards and rules of behaviour learnt during childhood and adolescence, and habits developed from every-day life. A person's psyche includes his consciousness. A person's consciousness and the values included in it, intellect and knowledge together with inherited and consciously developed qualities of the psyche that are capable of regulating behaviour, are functions of the psyche's mechanism. However, this regulator cannot substitute the strength or direction of a person's behaviour.

The nature (psyche) of a person is of interest to an economist, as it appears as an independent factor of his behaviour in production and distribution, the exchange and consumption of goods and services, the formation of social norms and laws, and the organisational forms of this behaviour. Regardless of how a scholar values the correlation in the psyche (that is, the nature) of a person of the elements that are inherited or developed, both consciously and unconsciously, during the period of its activity, this psyche can be seen as a specific concept and as the «nature» of a particular person. This «nature» may differ from the practical behaviour of a person, which contains not only the stable core of his psyche, but also its potential for adaptation and its limited elasticity. This does not mean a change in a person's nature, but his ability to adapt his behaviour to external circumstances, which are contrary to his nature and accept these circumstances within specific boundaries and for a defined period of time.

Consequently, the economic behaviour of a person depends on the nature of his psyche and its potential to adapt.

At first glance, the problems that are researched and discussed by psychologists are not directly related to the economy; to a great degree they are associated with philosophy and sociology. However, these are 
really the same questions, which are posed in a different form and relationship in economic theory.

\subsection{Philosophical Approaches to Psychological Structure}

The general state of the modern psychology of personality and its achievements and problems have been researched in the internationally acclaimed book written by Larry Hjelle and Daniel Ziegler on «Personality Theories» $\left(3^{\text {rd }}\right.$ English edition, 1992). ${ }^{3}$ The authors consider the conceptions on human nature of the 15 most prominent psychologists of the $20^{\text {th }}$ century - from Sigmund Freud and Karl Jung to Abraham Maslow and Carl Rogers - from the point of view of the characteristics of this nature. The authors formulate these characteristics in nine pairs of «diametrically opposed concepts». According to them, human nature is characterised as follows:

1. Freedom or determinism;

2. Rationalism or irrationalism;

3. Holism or elementalism;

4. Constitutionalism or environmentalism;

5. Changeability or Inflexibility;

6. Subjectivity or objectivity;

7. Proactivism or reactivism;

8. Homeostasis or heterostasis;

9. Cognisant or not cognisant.

Hjelle and Ziegler write that the fundamental theme of their book is that all personality theories are based on specific philosophical

${ }^{3}$ L. Hjelle, D. Ziegler, "Personality Theories. Basic Assumptions, Research, and Applications.", "Petersburg", Moscow, SPB and others, 2005 (translation from English). 
positions of a person's nature. ${ }^{4}$ This position can be interpreted in different ways; however, its direct meaning is that different philosophical concepts serve as the basic source of the initial ideas of different psychological conceptions. Keeping the broad range of contradictory philosophical doctrines in mind, such an interpretation also helps explain the contradictions between psychologists. If this had been true, it would have been immediately accused of being a misconception of psychologists. This is because philosophy as a science, by definition, cannot serve as the basis of psychology, economy, sociology, or history. Philosophy itself has to rely on these sciences for its own support.

Fortunately, Hjelle and Ziegler's book contains considerable material, which shows that psychology is not based on philosophy, but on the observance of behaviour, on clinical experience, on laboratory and field research, on the physiology of the higher nervous functions, and on genetic data. The generalisation of a person's nature, as concluded by psychologists, can touch philosophical questions (freedom, necessity, development, rationality, irrationality, etc.); however, the value of these generalisations is determined by the extent to which they are based on facts.

Hjelle and Ziegler show that most well-known psychologists (based on whom, entire scientific schools of thought have been established) have diametrically opposed positions according to the alternatives listed; although some of them may take a more moderate position on separate points. This means that in modern psychology, instead of a single prevailing point of view with respect to a person's nature, there exist numerous contradictory and even mutually exclusive concepts.

For economic science, how real, sufficient, and relevant are the diametrically opposed concepts of the authors regarding a person's nature? In order to answer this question, one needs to clarify the psychological thought that is contained in these concepts.

An understanding of «freedom or determinism». This refers to the level of internal freedom, which people have in choosing their thoughts and actions, and also controlling their behaviour.

If one infers from this tautology that freedom is «a subjective feeling of freedom», etc., then it begs the question: To what degree is

\footnotetext{
4 The same as above, p. 434.
} 
people's behaviour determined by factors, which partly or fully remain at a level outside their consciousness? Here, strangely enough, the question turns out to be Marxist in nature: freedom is the acknowledgment of necessity.

Hjelle and Ziegler quote two different positions on this issue. They state that Carl Rogers confirmed that a human being is not simply a machine, he is not only gripped by unconscious motives but is also a personality, which is in the process of forming itself, which is creating sense of its own life, and enjoying a certain level of subjective freedom.

Note that Rogers considered the psyche not to be cognisant and therefore there was no need to ask him about the origin of «subjective freedom», and on which grounds the «meaning of life» is formed.

As if in response to Rogers, Beres Skinner sharply declared that an autonomous human being is an invention, which is used to explain things that could not otherwise be explained. ${ }^{5}$

I am dissatisfied with both positions. Internal freedom exists; however, it does not deny unconscious motives but relies on them. A person's internal level of freedom depends on the following abilities of an individual:

1. To be conscious of his alternative wishes (motives);

2. To wilfully (consciously) choose a variant that he will follow in the near future;

3. To choose the most appropriate means of implementing this variant.

Consequently, internal freedom is the ability to choose (determine) between ones internal thoughts and actions, and it is inseparable from the conscious suppression of some instincts in favour of others. For all three points, the internal and external choices interact with each other. (Note that psychologists are not interested in external freedom in the same way that (to date) economists have not shown any interest in internal freedom.)

${ }^{5}$ See L. Hjelle and D. Ziegler, p. 41. 
An individual's degree of internal freedom corresponds to the level he can fully control his feelings. If he rejects all his feelings (for example, as required in Buddhism) he suppresses the person inside himself and in that case one can no longer speak of human freedom.

What is the nature of will? Clearly, in the overall sense, will is not simply the ability to be able to control ones feelings and actions, but the ability to subordinate ones behaviour to such motives, which steer ones behaviour away from the usual path, which are not connected with arousing feelings of pleasure, with the instincts of imitating others, with the herd instinct, or with adaptation to external influences. In fact, will is the exertion of a certain motive or group of motives (stimulated by habit or external signals), which blocks the action of other (dominating) motives and which leads to an individual behaving in a risky or ambiguous way (resulting in the attainment of remote aims). (Here, we are not speaking about the will required to overcome the lack of will; we are speaking of will, which raises an individual's normal behaviour above the level of his usual behaviour.)

The statement of the problem of «internal freedom» by psychologists considerably differs from the biopsychic statement of this problem, which is closely connected with the actions of the inborn instinct of freedom. Each living being and, especially, human being, feels the ineradicable need to overcome the barrier limiting their ability to live and develop. This could be an external barrier created by natural, technological or social conditions, or an internal barrier, caused by deformations in psychogenetic traits and retarded abilities. In the cases where the instinct for freedom is suppressed by an external barrier or by psychic deformations, a person's ability to live and develop is limited and becomes deformed. At the same time, in order for the action of this instinct not to acquire a destructive character, it should be limited by informal norms, establishing an optimal (instead of maximal) degree of freedom in specific spheres of life.

In the economic sphere, freedom is the real opportunity to choose ones line of work, the possibility to manage ones own property, be allowed to work as an entrepreneur, and enjoy consumer choice. It is obvious that the higher the level of economic development, prosperity, and culture of the population, the more developed the market institutions, and the more stable the economy, the greater the economic freedom of the individual. 
If the behaviour of a human being is strictly determined by external factors (as the behaviourist, Skinner, believes), then so is his economic choice determined; if a human being is free and capable of «creating himself» (as Rogers has stated), then the choice becomes especially uncertain.

Rationality or irrationality. If Sigmund Freud believed that the behaviour of people is determined unconsciously and consequently is irrational, the majority of other psychologists consider this behaviour rational irrespective of whether it is determined or not. What is meant by the «rational» concept? George Kelly assumed that each person is «a scientist» and a researcher, and intellectual processes have paramount value for the behaviour of a person. Freud confirmed that an individual is inherently not aware of psychic processes. He wrote that only vanity prevents humans from recognising the fact that they might not be fully in control of their own brains. 6

Hjelle and Ziegler, as a matter of fact, reduce the concept "rational" to the concept «realised». They consider that if people realise the motives of their own behaviour they are acting rationally. In other words, it is enough to realise motives to act rationally.

Stating the question in this way is barely comprehensible not only to an economist, but also from the point of view of common sense. For example, Medea killed her children, realising that in this way she will be taking revenge on her husband, Jason. However, at the same time, "awareness" does not mean that reason has control over feelings. The public prosecutor may consider that if a person is aware of his actions and the reasons for them, it means that he is acting rationally. However, in this case, feelings govern, own, and direct reason, and the person acts illogically, contrary to standard norms, harming his own existence and, consequently, as a result, is irrational. This is not in the least a «mistake of reason», but the result of its subordination to instincts.

The first two pairs of alternatives (freedom-determinism and rationalism-irrationalism) are used to reveal the positions of psychologists concerning the question on what dominates the psyche of a person, consciousness and will or the «unconscious beginning» (inherited and acquired instincts and stereotypes).

${ }^{6}$ See Hjelle, Ziegler, p. 42. 
The third pair, holism or elementalism, assumes alternative answers to the question on whether the psyche of a human being is one, indivisible system, or whether it is a set of independent elements, which should be studied separately. From the point of view of «holists», in a person's behaviour in any field of activity and in any situation, his psyche appears as an interconnected and mutually dependent unit. If one approaches the psyche in the same way as an aggregate, made up of independent elements, then one and the same person in different fields of activity will act as different persons. (One can refer to "one-dimensional" concepts of the «economic person»" maximizing income, the «political person» as the subject of power relations, the «institutional person» following norms and rules, etc.). «Elementalists» declare that only the elementalist approach allows one to gain exact information on the psyche.

Here, one needs to distinguish between an understanding of the essence of the psyche and methods for studying it. On the one hand, a person's psyche (as we shall see further) is multidimensional and very contradictory, and, on the other hand, different methods of studying it can supplement each other. However, the latest discoveries in genomics (as shown in the third chapter) allow one to confirm that the natural basis of the psyche as a unit system is set genetically.

The fourth pair, constitutionalism or environmentalism, offers alternative answers to the question on what plays a defining role in the formation of the psyche, internal, inherited (biological) factors, or factors of the surrounding (social) environment. In particular, which position is more correct: do people form an economic system that corresponds to their psyche, or does the social and economic system form people's psyche?

Psychologists emphasise the interaction of biological and social factors in the formation of the psyche, however the mechanism of this interaction (which is studied in social psychology) in the economic sphere has not been discovered and, therefore, the question of selecting the defining factor remains open.

The fifth pair, changeability or stability, is also connected with this; and, as Hjelle and Ziegler emphasise, here, the issue concerns the limits that an individual is capable of fundamentally changing during the course of his life. How much can the basic structure of personality 
really change? Is deep change an indispensable component of evolution or development of a person?7

Clearly, the answer to this question depends on the answers to the previous questions, and, above all, on the structure of the genetic basis of the psyche, the structure that psychologists call the «unconscious origin». Here, the diversity of opinions amongst economists is as broad as it is amongst psychologists - ranging from the invariability of the psychological bases of behaviour of a person (according to neoclassicists), to the ability of a person being able to fundamentally change these bases several times during the course of his life (according to some institutionalists) ${ }^{8}$.

The sixth question concerns subjectivity or objectivity: is a person's behaviour defined by inherited qualities and the accumulation of his internal life's experiences, or is it directly related to external influences? Rogers, a representative of the phenomenological (subjective) branch of psychology, wrote that the internal world of an individual, probably, exerts greater influence on a person's behaviour than the external stimulus provided by the environment.

The leading behaviourist, Skinner, proposed following the path laid out in physics and biology, studying the link between behaviour and the environment directly, and neglecting the intermediary role of consciousness. ${ }^{9}$

I believe that, for studying economic behaviour, both these approaches are insufficient in themselves, for they ignore features that are common to the psyche that are transferred genetically or culturally. Clearly, the answer to the question asked depends on the content and understanding of «experience», "consciousness", «the internal world of an individual», and «the subject as a physical system». For economic science, genetics, experience, consciousness, and external influences that impact on decision-making and their implementation are of paramount value in the explanation of people's behaviour.

The seventh question, proactivism or reactivism, concerns the source of the activeness of a person: is it inside a person (proactive) or

${ }^{7}$ See L. Hjelle, D. Ziegler, p. 45.

${ }^{8}$ See, for example, B. Seligman, "Main Currents of Modern Economics". M., 1968, pp. 531-532.

${ }^{9}$ See L. Hjelle, D. Ziegler, p. 47. 
outside him, so that a person only reacts to external influences (reactive). The famous theorist of the «humanitarian» branch of psychology, Abraham Maslow, in relation to proactivism has stated that the future of a human being is inside him, and (this future) at any given moment is dynamically active. Skinner, in contrast, has declared that what occurs inside the body of a person is not significant and that the behaviour of a person can be explained independently of our knowledge of it. However, Skinner should add that it can be explained only in retrospective, as it is always possible «to explain» a person's past behaviour, but we can only sometimes predict a person's behaviour without knowing what is happening «inside a person».

In economics, only those industrialists, who have studied the psychology of related groups of agents in a versatile manner and not just their habitual behaviour, can predict the reaction of consumers, competitors, employees, and contractors of new invoices and conditions (new institutions, new production, technologies, organisation, etc.).

The eighth psychological alternative, homeostasis or heterostasis, has a direct relationship with economic theory as it seeks to answer questions regarding the motives of human actions. Some psychologists consider that these actions are aimed at easing pressure and restoring psychological balance (homeostasis), broken by unsatisfied needs. Others believe that the psyche of a person is focused on its development, the search for new stimuli, and selfrealisation (heterostasis).

Economic practice says that such a contraposition (as well as some of the previous ones) is applicable only to some types of persons and to separate real-life situations, since, as a rule, both factors operate simultaneously or serially.

Finally, the ninth dilemma concerns the cognisability or uncognisability of the psyche of personality. While behaviourists are convinced of its full cognisability (through regular supervision and research experiments), representatives of the phenomenological branch believe that each individual experiences a constantly varying subjective experience and, consequently, it is comprehensible only to the subject. Such an approach in general removes the question of psychology as a (theoretical) science and about its place in the system of social studies. 
I believe that one can look at the alternative characteristics of the psyche, through which Hjelle and Ziegler describe the positions of scientists and psychologists, from a completely different point of view - from the point of view of the different types of human psyche.

In their classification of alternatives, Hjelle and Ziegler proceed on the unspoken basis that there is a certain «normative» type of psyche, whose contents are treated differently by scientists in different branches of psychology. However, further in their books they include a lot of material, from which it is clear that a number of well-known psychologists distinguish the types of psyche that cardinally differ from one another. Furthermore, each such type can be either «normal» or «defective».

Distinguishing amongst the various types of human psyche and revealing the social consequences of such distinctions is, in my opinion, a key issue in psychology and other social sciences. The solution of this problem (applied to economic activities) will be the central theme of this book. Here, I shall illustrate the themes mentioned above, and I shall try to construct specific abstract models of two extreme types of the psyche on the basis of Hjelle and Ziegler's «alternatives».

One such «extreme» type will be characterized in terms of internal freedom, rationality, integrity, volatility, subjectivity, and internal motivation for action and development.

The other type will be internally determined by genetics, will be irrational, inconsistent, constant, disposed to react to external impulses, and gravitate towards a balanced psyche instead of towards development.

One can also design certain «intermediate» models of the psyche, which will also have speculative characteristics.

How does the psyche of an «economic person» in neoclassical theory look from the point of view of these characteristics? It is internally free, rational, and subjective. However, at the same time it is constant and possesses internal motivation towards action and development. This person is «one-dimensional» and, therefore, one can consider neoclassicists as a special version of «elementalists».

People in institutional theories have different types of psyche; however, they also possess features in common: internal determinancy by informal norms and rules, integrity, volatility, dependence on the surrounding environment, and a desire for development. 
Note that in chapter four we will essentially offer a different approach to the types of psyche presented in the capitalist markets.

\subsection{Typologies of the Psyche}

Now, I shall discuss how (according to Hjelle and Ziegler) various prominent scientists and psychologists understand the human psyche, paying particular attention to the types of psyche distinguished by them.

A. Genetic determinant - Freud, Adler, and Jung: Sigmund Freud's (1856-1939) general theory concerning the defining influence on the psyche of sexual instincts and sexual development at an early age is the basis of the distinction of the types of psyche.

Freud distinguishes four types of psyche in adults: three of them can be considered flawed and the fourth, "ideal".

Flawed types ("characters") are formed by virtue of the fact that in one of the stages of sexual development, it becomes fixed (stops) due to frustration (prohibition) or permissiveness and, therefore, does not continue to a higher stage, and remains at this stage for life.

An oral character differs either through a combination of passivity, dependence and trustfulness (oral - passive type), or, on the contrary, negativism, by a desire to exploit others and sarcasm (oral - sadistic type); in other words, passive-trustful on the one hand, and exploitative-sadistic on the other hand.

An anal character is composed of a combination of avarice, obstinacy, and thriftiness (anal-withdrawn type), or a combination of animosity, disorderliness, and roughness (anal-aggressive type). Here, too, one group consists of avaricious and obstinate types, and, in contrast, the other group consists of harsh and aggressive types.

A phallic character combines insolence, exhibitionism, excessive pride, and rivalry. Here, there is one group of insolent and arrogant types.

A genital character is an ideally healthy type with a normally developed sexuality and who productively cooperates with other people. That is, people, whose sexuality has developed normally and, 
consequently, they are capable of cooperating productively, are the «ideal» types. 10

According to Freud, deviations from psychic norms basically occur along the lines of pliable passivity on the one hand and obstinate aggression on the other hand. From the economic point of view, «abnormal» tendencies noted by Freud towards avarice, acquisitiveness, exploitation, and aggression on the one hand, and «normal» to productive cooperation on the other hand, are especially important. The third group is represented by people with qualities such as passive trustfulness and dependence on another's will.

It is important to note that, according to Freud, negative character traits are formed in the first six to seven years of a child's life. (Then, there is a latent period up to the age of 12-13, which is followed by sexual maturity, the «genital period».) We note that Freud does not point out the genetically inherited negative deposits of the psyche for specific individuals. He probably assumed that genetically inherited primary instincts, sexuality and aggression are transferred in a «normal» condition, and only after the birth of a child undergo deformations.

However, according to Freud, the link between the type of a person's psyche and the character of his actions is neither straight forward nor simple, as it is mediated by processes of the «sublimation of instincts» and the «displacement of activity». He argued that the key to understanding the dynamics of the energy of instincts and its expression in the choice of objects lies in the concept of displaced activity. Displaced activity occurs, when for some reason, the object required for the satisfaction of an instinct is not available. ${ }^{1}$

Displaced activity allows one to free the energy of frustrated instincts and remove the internal psychological conflict. The protective mechanism of a person's psyche - giving the possibility, for adaptation purposes, of changing ones impulses so that they could be expressed by means of socially comprehensible ideas and actions is the sublimation of instincts.

According to Freud, the primary (inborn) instincts are the sexual instinct and the instinct for aggression. Freud confirmed that the

\footnotetext{
${ }^{10}$ L. Hjelle, D. Ziegler, pp. 154-156.

${ }^{11}$ Hjelle, Ziegler, p. 118.
} 
sublimation of sexual instincts served as the main catalyst for great achievements in Western science and culture. ${ }^{12}$

In essence, all aspects of civilisation, including its culture and religious, political, economic, and other institutions were explained by Freud by means of the concept of «displaced activity», that is, the satisfaction of ones instincts by the displacement of activity from an inaccessible object to an accessible one. In particular, Freud explained racial prejudices and wars by the displacement of the instinct of aggression. (This means that the object of aggression becomes not «ones own», but «someone alien».) In the absence of the opportunity to take pleasure directly and immediately, people have learned to displace their energy on other people, other subjects and other activities, instead of those, intended for the direct discharge of the tension. Complex religious, political and economic institutions are formed in this way. ${ }^{13}$

That is, any activity is caused by the direct or «displaced» action of two primary instincts from their sources (the requirements of an organism) to their purpose (pleasure from the satisfaction of needs) through objects of influence (objects or people) by means of a stimulus (the required quantity of energy for the achievement of the purpose).

In essence, this is the psychological interpretation of hedonism. It ignores not only the complex system of inborn needs and instincts (reducing them to two), but also all conditioned reflexes and, at the same time, the entire history of civilisation, as institutions are primarily forms of historical memory.

Freud's theory leads to the following conclusion: the more the primary instincts are suppressed, the greater is the need for «displacement», the greater the potential of «sublimation», the potential for the development of culture and institutions, on the one hand, and racism and wars, on the other hand. At the same time, such a sublimation occurs primarily through people with psychic deviations, both creative as well as destructive. (Freud's observations are justified, but I shall try to give a different theoretical interpretation, based on the same observations).

\footnotetext{
12 In the same place, p. 132.

${ }^{13}$ Hjelle, Ziegler, p. 118.
} 
The Austrian psychologist, Alfred Adler (1870-1937), developed a concept, in which a person's natural propensities and instincts develop (change in some way or another) during his lifetime, especially at an early age in childhood. The following is related to these natural bases:

- Feeling of inferiority and helplessness with which a child is born, and his attempts to compensate this feeling during his subsequent life;

- Connected with this, an aspiration for superiority, as the main motivational force;

- A social instinct and the social interest connected with it, signifying an aspiration to cooperate and value the interests of society as a priority;

- Aspiration towards creativity and self-development;

- Aspiration to be goal-oriented (including both real and fictitious goals);

- Activity level (psychic energy).

Already at the earliest age, a child, unconsciously, develops a form of behaviour that fulfils his natural propensities and instincts; Adler called this form «life style» and drew the conclusion that it is fully formed already at the age of 4-5 years, and from then on merely develops. The life style of a specific person is individual, it depends both on a special combination of natural traits and on the social environment. Each person in his own way aspires to superiority, perfection, and integrity (p.173). At the same time, Adler distinguished four types of personalities, each of which is characterised by its own «life style»:

1. Controlling type: Self-confident, active, energetic, with insignificant or no social interest. Aims for superiority. Basic tasks in life (work, friendship, love, etc.) are 
resolved in a hostile, antisocial manner. Examples used by Adler: young offenders and addicts.

2. User type: Set up to be a parasite; no social interest; low activity level.

3. Avoiding type: Shows no social interest and is not interested in activities. Avoids making decisions on important issues.

4. Socially useful type. An embodiment of maturity; a high level of social interest and interested in activities. Considers social duties to be of paramount importance.

In this way, Adler compares two types, forming two extremes of the psychosocial structure of a society: the socially-harmful «controlling type» and the «socially-useful type»; in other words, for Adler as for Freud, the criterion for differentiating between useful and harmful types of psyche is «social». According to Adler, the determination of the type to which an individual belongs depends on family circumstances, the number and order in which children are born, and a person's early upbringing. This begs the question, if types (life styles) vary to such an extent, already at the age of 4-5 years, whether the natural bases of the psyche deduced by Adler are truly general for all people? Or are children born with different psychic bases?

At the heart of the theory of another outstanding Austrian psychologist, Carl Jung (1875-1961), lies the doctrine about collective and personal unconscious beginnings. The collective unconscious, which, according to Jung, contains «the entire spiritual heritage of human evolution, which is inherent in the structure of the brain of each individual», represents the common (to all human 
beings) «storage of genetic traces of the memory of mankind and even our humanoid ancestors» 14 .

The archetypes («primary models»), constituting the collective unconscious, include the following: Anima (the female beginning, whose symbols are the Virgin Mary and the Mona Lisa); the Person (a social role, with the symbol of the Mask); the Shadow (unconscious contrast to positive consciousness; its symbols are Satan, Hitler, Hussein, etc.); Self (integrity and harmony, adjustable centre of the personality, the Mandala); the Sage (wisdom; symbol, the Prophet); God (the psyche, concentrated on the external world; symbol, the Solar Eye); and others.

Personal unconsciousness_comprises complexes and the accumulation of emotionally charged ideas, feelings, and memories, originating from past personal experience or from birth, hereditary experience (for example, power complexes, dependence on parents, the power of money, sex, etc.).

\begin{tabular}{|c|c|c|}
\hline Extrovert & Functions of the psyche & Introvert \\
\hline $\begin{array}{l}\text { Mobile/volatile } \\
\text { Sociable } \\
\text { Driving force - } \\
\text { external factors }\end{array}$ & $\begin{array}{l}\text { Rational (active) } \\
\text { functions: } \\
\text { 1. Thinking (logic, } \\
\text { arguments) } \\
\text { 2. Feeling (information } \\
\text { in the language of } \\
\text { emotions) } \\
\text { Irrational (passive) } \\
\text { functions: } \\
\text { 3. Sensation («records } \\
\text { and photographs» events in } \\
\text { the outside world) }\end{array}$ & $\begin{array}{l}\text { Contemplative } \\
\text { Restrained, reserved } \\
\text { Aspires to solitude } \\
\text { Immersed in a private world } \\
\text { of ideas, feelings and } \\
\text { experience. }\end{array}$ \\
\hline
\end{tabular}

${ }^{14}$ Hjelle, Ziegler, pp. 200-201. 


\begin{tabular}{|l|l|}
\hline 4. Intuition (grasps the \\
essence of events, relying \\
on guesses and \\
premonitions, reacting to \\
unconscious images, \\
symbols, and hidden \\
meanings)
\end{tabular} \mid

Personal (especially, individual) complexes are probably imposed on collective archetypes, giving some of them a certain character, and merging with them (for example, a sexual complex, Don Juan; a complex of the power of money, for example, a financier; etc.).

One may assume that Jungian archetypes and complexes are not exclusively psychological concepts, but represent a certain mixture psychology, philosophy, and sociology with images of art and history.

According to Jung, based on the orientation of their psyche, people can be divided into extroverts (outwardly oriented) and introverts (inwardly oriented) - see Table 1.1.

\section{Two Orientations of the Personality and Four Psychological Functions according to Jung}

Table 1.1

According to Jung, the combination of these two «orientations» and four «functions» gives eight types of personalities:

1. Extrovert, cogitative: a cold and dogmatic person living by the rules (for example, Sigmund Freud)

2. Extrovert, sensual

3. Extrovert, feeling

4. Extrovert, intuitive

5. Introvert, cogitative 
6. Introvert, sensual

7. Introvert, feeling

8. Introvert, intuitive: Eccentric, unsociable, and indifferent to those around him (for example, Jung himself)

In Jung the role played by the collective and personal unconscious in the formation of types of personalities remains unclear.

According to Hjelle and Ziegler, in Jung's concept, each person is endowed with all four psychological functions. However, as soon as one personal orientation (extroversion or introversion) becomes dominant, it is realised; in the same way, only one function from the rational or irrational pair usually prevails and is realised. The other functions are pushed into the unconscious and play an auxiliary role in the regulation of a person's behaviour. Any function can be the dominant one. Accordingly, conceptual, sensuous, feeling-based, and integrated types of individuals are observed. According to Jung's theory, an integrated or «individualised» personality uses all the contrasting functions to deal with real-life situations.

From here it is clear, that, according to Jung, the «unconscious» is a «storehouse» of both «orientations» and all four functions of the psyche. However, only one «orientation» and one «function» are realised by the individual and become dominant in his behaviour. Such a selection is probably defined both by the relative strength of hereditary complexes and the environment. Jung's achievement lies in his attempt to present the unconscious as the basis for modelling certain initial types of psyche and abstract concepts. However, he was not entirely successful in his attempts at specifying the «genetic traces of memory».

Firstly, in the «genetic memory» it was necessary to separate those elements of the psyche that are common in humans and some other species of living beings; in «rational man» and his humanoid ancestors; and in «rational man» from the Stone Age and his ancestors. Then, we would have received, at least, three different layers of a human being's «genetic memory»: «prehuman», «early human», and the layer belonging to «savages».

${ }^{15}$ Hjelle, Ziegler, p. 204. 
Secondly, the concept «unconscious» is much wider, than «genetic memory», since it also covers that memory, which is contained in preconsciousness and includes the culture and personal experience acquired by individuals. If «genetic memory» and the memory from ones culture and experience are united and create certain «archetypes», then, how does one distinguish what they contain from each type of memory? For Jung, archetypes of the psyche clearly bear marks of culture; however, specific «traces of genetic memory» are not designated to them.

Thirdly, the definition of «collective» has a double meaning. It can mean «inherent in all», and can also mean «connecting all». The instincts that are «inherent in all» (for example, instincts of feeding, appropriation, aggression, sex, etc.) cannot always unite all, but they can separate them. For Jung «collective» probably means «common/uniting». However, in that case, «archetypes» should reflect not the universal, but the ancient tribal, psyche. There could hardly be an archetype of a single God at the genetic level, even at the level of vague instincts.

Nonetheless, I believe that the main achievement of Jung is the promotion of the hypothesis about the collective and personal unconscious as a «storehouse of genetic traces of the memory of mankind and even of our humanoid ancestors».

B. Social determinant: Fromm, Horney, Allport, and Maslow. From the point of view of social and economic problems, the social typology of personality, developed by Erich Fromm (1900-1980), the German psychologist and the sociologist, who worked in 1934-1965 in America, deserves special attention. He distinguished five social types of character. Fromm characterized the first four types (that, in his opinion, prevail in modern societies) as unproductive (unhealthy), and only the last type as productive (healthy). However, this fifth ideal type is still just an ultimate goal in the development of the human being 16. Thus, according to Fromm, the five types of psyche are as follows:

1. Receptive type: These people are passive, dependent and trusting; they see the source of all good in their life

${ }^{16}$ Hjelle and Ziegler, p. 253. 
outside of themselves. They are capable of optimism and idealism.

2. Exploiting type: Such types of people use all the strength and ingenuity of others, are not capable of being creative themselves, and aspire to appropriate others' ideas. They are aggressive, self-confident, and egocentric. They are sure of themselves, possess self-respect, and are impulsive.

3. Accumulating type: This category includes those who aspire to possess the maximum material benefits, power and love, and jealously protect what they accumulate. These people are suspicious and obstinate. Unlike the first two types, they are afraid of novelty. They are provident, loyal, and reserved.

4. Market type: They are convinced that everything (including people) can be sold or favourably traded. Their motto is, «I am as you wish to see me.» Their key character traits are dispassionateness, opportunism, a lack of integrity, tactless, unscrupulous in their methods, and can be ruinous. At the same time, they are open, inquisitive, and generous.

5. Productive type: They have an independent, honest, and quiet character. They are loving, creative, and socially useful. Their ability to think productively and logically releases them from self-deception, and their ability for productive love leads them to care for all forms of life on 
Earth; and their aspiration for creative self-expression leads to material and other benefits that are necessary and desirable in life.

According to Fromm, the presence of the social types of characters and the domination of the «unhealthy» types (that were mentioned above) are caused by the conflict between the «existential needs of a person» and the social system. In order for the «healthy type» of person to prevail, social reform and a transition to a «humane communal socialism» are necessary.

Fromm distinguished five basic existentialist needs, incorporated in human nature, which are the most powerful motivational forces in life.

1. Need to communicate («productive love» towards people; in its absence, egoism and mistrust prevail).

2. Need to overcome animal passivity by means of creation (the alternative is destructiveness).

3. Need for roots (the feeling of being in touch with the world, similar to sensations of safety, stability, and durability).

4. Need for identity (recognition of ones individuality).

5. Need for a systematic view (objective and rational understanding of the complexities of the world) and loyalty (dedicating oneself to a higher goal or to God).

The fulfilment of these needs requires certain social and economic conditions. Since the end of the Middle Ages, the struggle for personal freedom has led to the partial realisation of some of these needs, but has undermined others, primarily, safety requirements. The developed market capitalist system, through its contradictions, has resulted in a «flight from freedom» (under the «protection» of authoritative and totalitarian systems). The interaction of these needs and systems has resulted in the formation of constant types of human characters. The opportunities for satisfying existential needs, which are present in any 
specific society, form the structure of the person (according to Fromm, they are the basic «orientations» of character). Moreover, according to Fromm, as well as Freud, the orientation of the character of a person is considered as stable and not varying in time ${ }^{17}$.

Fromm's description of psychological types is quite realistic and in many respects is similar to Freud's description of types. It is significant that both Fromm and Freud consider that a person's belonging to a certain type of psyche does not vary during the course of his lifetime.

However, while Freud unequivocally explains the existence of various «unhealthy» types of psyche by various kinds «frustrations» in childhood, Fromm, aspiring to deduce these types from the social and economic conditions of the market capitalist system, gets entrapped in a series of contradictions.

If certain types of psyche are stable and are formed by the social system, that is, correspond to it and are generated by it, then the system is also stable in the long term, despite its contradictions and conflicts. Furthermore, after stable types of psyche of people are formed, the question on «who defines whom» loses its meaning. The social system becomes dependent on the stable structure of psychic groups to the same degree that this group is dependent on the social system (that is on the system of formal institutions). This contradiction is partially inherent also in Marxism. Marxism, in trying to extricate itself from this, refers to the inevitability of an aggravation of class contradictions (which can be presented as a conflict between social and psychic types; as they become more aggravated, the psyche of one of the classes, the proletariat, changes qualitatively and becomes revolutionary).

Fromm explains historical dynamism by the human psyche's internal conflict. Existential needs lead to a conflict between the desire for freedom and the desire for safety, this «universal and inevitable trait of human nature», which represents «the most powerful motivational force» in people's lives.

Up to the end of the Middle Ages (the end of the $15^{\text {th }}$ century), people lived in conditions of rigid social, political, economic and religious restrictions. In conditions of a struggle for survival, the need for safety was a priority. However, subsequently, the social,

${ }^{17}$ Hjelle and Ziegler, p. 252. 
economic, and political systems changed under the influence of the struggle for freedom. As a result, freedom was gained at a cost of the alienation and loss of the feeling of safety and personal importance.

The reaction to a social system, providing personal freedom, but depriving feelings of safety and importance and generating a sense of estrangement, was a "flight from freedom» and the suppression of ones own individuality. Fromm describes three forms of such «flight»: authoritarianism, destructiveness, and conformism. In the first case, a person aspires to overcome a feeling of his own inferiority, by attaching himself to someone or something external; in the second case, by subordinating and suppressing others; and in the third case, by his own absolute submission to social norms.

This may be an explanation of the establishment of totalitarian regimes in the 1920s-1930s in terms of these forms of «flight from freedom» within the framework of Fromm's concept.

Fromm opposes negative, destructive freedom, which generates totalitarianism with «positive freedom», in which people feel independent and unique and, at the same time, maintain a bond with other people and society, and gaining a sensation of safety. The recipe of achieving «positive freedom» is simple and lies in developing «spontaneous activity» through love and work. It is probably also the way to a «humane communal socialism» and the formation of the «ideal person», discussed above.

However, the four social and psychological types described by Fromm, who dominate over the free market capitalist system, can hardly be the flag bearers of social dynamics. It is unlikely that the internal conflict between the desire for freedom and the need for safety will bother them in the least. (I note again that the main feature of the first type is passivity; of the second type, the aspiration to exploit; of the third type, accumulation of material riches; and the fourth type, trading). This is the case as long as we do not consider that steady (lifelong) social and psychological types are only social mimicry, and only psychic forces such as an aspiration for safety and freedom, act at a deep natural-genetic level. It is obvious that at the level of knowledge of human genetics, which was prevalent up to the end of the $20^{\text {th }}$ century, it was impossible to definitively answer which qualities of the psyche are transferred genetically and which are formed by a person's environment. Fromm's concepts and those of 
some other psychologists asked these questions, but were not able to give convincing answers to them.

The American psychologist, Karen Horney (1885-1952), distinguished three types of interpersonal behaviour: (1) Oriented on people (compliant type); (2) Oriented away from people (isolated type); (3) Oriented against people (hostile type).

According to Horney, the aspiration to achieve a feeling of safety in the surrounding environment lies at the heart of all forms of human behaviour. This aspiration is shown through ten requirements: (1) Through love and approval; (2) Through controlling a partner; (3) Through precise restrictions in life; (4) Through power over others; (5) Through exploiting others; (6) Through social recognition; (7) Through self admiration; (8) Through ambition; (9) Through selfsufficiency and independence; (10) Through faultlessness and irrefutability.

People fulfil these requirements in different degrees and combinations, primarily, depending on whether they have a healthy or neurotic psyche. A person becomes neurotic as a result of experiencing feelings of vulnerability and anxiety about his existence in early childhood. As a result, throughout his life, there remains an excessively high need for a feeling of safety, which manifests itself in different ways in all three types of behaviour. "The compliant type» is guided by irrational belief that if he concedes, he will not be harmed. A compliant type needs to be needed, loved, protected and supervised. However, behind the politeness, there can be a hidden and suppressed need to behave aggressively. Although it seems that such a person is embarrassed in the presence of others and prefers to remain in the background, often feelings of animosity, rage, and fury are hidden beneath this behaviour. 18

«The isolated type» is guided by the erroneous belief that if he isolates himself, everything will be alright with him. Such people go through life without passion in love, work, and rest.

For the «hostile type», domination, animosity, and exploitation are characteristic; this type of person proceeds on the illusory belief that he is powerful and nobody will be able to harm him. The hostile type considers that all other people are aggressive, and that life is a struggle of everybody against everybody. Therefore, he considers any situation

${ }^{18}$ See Hjelle and Ziegler, p. 260. 
or relationship from the position of his potential benefit. The hostile type is capable of acting tactfully and in a friendly manner, but his behaviour is always aimed at finding a way of gaining control and power over others, the satisfaction of his need for exploitation, and gaining prestige.

These three strategies are used by each of us at some time or other. Moreover, according to Horney, these three strategies find themselves in a state of conflict both in the healthy and in the neurotic person. However, in the healthy person this conflict does not result in such strong emotions as in the case of a neurotic person. A healthy person is more flexible and can change his strategy to suit the circumstances. In contrast, a neurotic person is not in a condition to make the correct choice and uses only one of the three strategies, regardless of whether it suits the given conditions or not. ${ }^{19}$

The strength of Horney's concept is that not only positive requirements (love, acknowledgment, faultlessness, etc.), but also negative requirements (power over others, exploitation, narcissism, etc.), are considered as the needs of all people, both psychically normal and neurotic. Horney asserts that both these groups resort to identical forms of behaviour (friendly, isolating, and aggressive). The difference lies in the excessive needs and the «fixation» on one of the forms of behaviour in the case of neurotics, and in the weaker negative requirements and flexibility in selecting the appropriate forms of behaviour in the case of normal people.

The weak side of Horney's concept lies in its inability to explain the appearance of negative requirements and negative forms of behaviour in psychologically normal people. While Horney explains this for neurotics as the result of exposure to an adverse social environment in early childhood (which is also Horney's explanation for neuroticism itself), its occurrence in normally developing children remains unexplained.

That is, Horney was able to describe general types of behaviour; however, she was not able to explain the behaviour of normal people in this context. The reason, probably, lies in the fact that Horney aspires to deduce an entire set of requirements from one inborn requirement for safety, and to attach an exclusively social

${ }^{19}$ In the same place. 
interpretation, i.e., an interpretation ignoring genetics, to a variety of requirements.

It is worth bearing in mind that Horney developed her concept in the 1930s-1940s, when clearly neurotic and aggressively ambitious persons, such as Hitler, Mussolini, Franco, and Stalin (whom the wellknown psychiatrist, Vladimir Bekhterev, diagnosed with schizophrenia in 1927 after a check-up after Stalin had complained of headaches) were in power.

The excessive love of power of such persons, their need to exploit others for their own interests for the acknowledgment of their own faultlessness and irrefutability, their fixation on one specific manner of behaviour makes them, according to Horney's concept, ineffective. Probably, this is true only for the early stages of the careers of such leaders. Later, under conditions that are favourable for them, a defect can be turned into a strength, in two ways. Firstly, such neuroticism increases psychic energy, and its rigid one-directional nature promotes the advancement of the given person in power. Secondly, the neuroticism of a leader can turn into a tool of hypnotic influence over the masses. Aggression and fixation are then perceived by the masses as a display of staunch will power, purposefulness, and reliability.

The American psychologist, Gordon Allport (1897-1967), has distinguished six core value orientations of people, whose different combinations characterise a «mature person» and are inherent (in different measures) in everybody 20 .

1. Theoretical: A person with such an orientation is primarily interested in finding the truth. $\mathrm{He}$ is characterised by rationalism, criticism, and empiricism in his approach to life. Such a person is intellectual and inclined to work in the fields of fundamental science and philosophy.

2. Economic: «The economic» person above all appreciates usefulness and profitability. He is exclusively «practical»

${ }^{20}$ See Hjelle and Ziegler, pp. 301-302. 
and strongly adheres to the stereotype of a successful American businessman. These types of people are extremely interested in how to make money; they consider knowledge that cannot be specifically applied is useless. Many brilliant achievements in engineering and technology have been achieved as a result of the fulfilment of the scientific requirements of people of an economic disposition 21 .

3. Aesthetic: Such a person most appreciates form and harmony and values significant events according to their appeal, symmetry, and relevance. He considers that life is a process, which everyone enjoys for their own sake and, in this respect, is inclined to egoism.

4. Social: For the social type of person, the highest value is love of people. For such a person, theoretical, economic, and aesthetic approaches are not humane, and love is the only acceptable form of mutual relations. His social position is altruistic and is connected with religious values.

5. Political: For a political type of person, power and influence are of primary importance. This is associated with leaders in any field of activity (not only politics). If the power motive is expressed openly, it repudiates all

${ }^{21}$ See Hjelle and Ziegler, pp. 301-302. 
other motives and a «thirst for personal power, influence, glory, and fame» remains. 22

6. Religious: This leads to an understanding of the world as one, with a higher sense. Some religious persons assert themselves by actively participating in life (immanent mystics), as opposed to others (monks), who search for a higher reality, through isolation from life (transcendental mystics).

Allport's reservation that the given classification applies only to the «mature person» is very relevant, as the overwhelming majority of people do not count themselves in the listed «fundamental orientations». They are not «theorists», «money makers», «aesthetes», «altruists», «masters», or «mystics». Even if one does notice the existence of one of these traits in them, none of them individually or in aggregate are likely to be a core characteristic in an ordinary person. It turns out that the majority of the population are excluded by the «maturity» requirement and drops out of Allport's sphere of typological analysis. However, Allport's analysis, conclusions, and tests were probably not intended for the masses; it seems that this psychologist focused on «mature» individuals. Probably, he believed that precisely such individuals define the structure and development of society.

Allport's analysis reflects an important element of reality; namely, it traces the link between the inborn psyche and acquired values, on the one hand, and a person's abilities and professional calling, on the other hand.

The American psychologist, Abraham Maslow (1908-1970), has gone even farther than Fromm and Horney in explaining the psyche in terms of social and economic factors. Formally, Maslow does not have a concept of the types of psyche and typologies of behaviour, as, in his opinion, everyone has the same basic psyche. However, actually, Maslow does have such a concept and I will try to highlight it

${ }^{22}$ In the same place. 
(although I acknowledge that Maslow himself would hardly agree with this).

According to Maslow, a person has five groups of requirements, all of them either inborn or «instinctive», and they are «by nature» organised according to a hierarchical system of priorities or domination.

Physiological requirements (hunger, thirst, etc.) should be sufficiently satisfied before the demands related to the second, «higher», group», display themselves, are realised, and transformed into a stimulus for action;

Requirements for safety and protection (long-term survival and the stability of fundamental conditions); these requirements (together with the previous ones) should be satisfied, to a certain degree, before the requirements of the third group appear and demand satisfaction;

Requirements for belonging and love (joining and acceptance); the satisfaction of the requirements of these three groups arouses the needs of the fourth group;

Requirements of self-esteem (value, competence): after the satisfaction of these requirements, we come to the fifth group;

Requirements of self-fulfilment (requirements for personal improvement and the fulfilment of ones creative potential).

As the transition to a higher group of requirements begins already when the requirements of the previous group have still been only «sufficiently» (and not completely) satisfied, a person can simultaneously realise the requirements of different priority levels as motives for his behaviour. Maslow assumed that the average person satisfies these requirements in approximately the following degree: $85 \%$ of the physiological requirements, $70 \%$ of the safety and protection requirements, $50 \%$ of the requirements for love and belonging, $40 \%$ of the requirement for self-esteem, and $10 \%$ of the requirement for self-fulfilment ${ }^{23}$.

As we saw, for the «average person» (apparently, this refers to the average American in the 1960s), according to Maslow, the highest requirements (in terms of self-fulfilment) are least satisfied. Furthermore, people do not feel and do not realise the poignancy of this discrepancy. What is the reason of this contradiction? Probably, from Maslow's point of view, the given (fifth) form of requirements is

${ }^{23}$ See Hjelle and Ziegler, p. 487. 
weakly manifested, as the two previous groups of requirements $(50 \%$ of the requirements were satisfied for the third group and only $40 \%$ for the fourth group) are not satisfied adequately.

Self-fulfilment is inseparable from creativity; the latter is, according to Maslow, the most universal trait of human nature, inherent in all people. It does not require special talents. However, this trait is suppressed by the acquired culture of the majority of people. It is one of the reasons why the overwhelming majority of people do not feel the need for self-fulfilment. (This refers to the standardization of spiritual needs at a low level in the course of a person's upbringing, education, and everyday life.)

Thus, Maslow has essentially formulated, in his own way, a universal law of raising requirements as the law of the development of the psyche by the transition of a dominating role from the lowest group of inborn (instinctive) requirements to the highest group. As a universal law, such a movement of the psyche, in the long-term plan, is probably justified.

However, it would also be worth considering the inborn, genetically determined system of requirements from another structural point of view. Then, it will be seen that in one, and, perhaps, the most numerous, part of the population, physiological requirements are clearly dominant. Moreover, this is not at all because the people in this group are starving, homeless, and lack other required material benefits; but, because its representatives use gains in their incomes, primarily, to qualitatively and quantitatively increase their consumption.

The other part of the population predominantly cares about health services, education, social security, and the preservation of law and order.

The requirements regarding «belonging and love» and self-esteem are inherent in all people; however, they can be dominant only for a clear minority at any level of material prosperity.

Finally, the natural requirement for self-fulfilment is also inherent in the majority of people; however, it can hardly be treated as the most vague requirement (as a person's aim - to fulfil his potential); it is worthwhile to consider self-fulfilment in the context of all the important activities of a person as its creative beginning.

Thus, from the concept of Maslow, in my opinion, it follows that according to the criterion of a dominating group of inborn 
requirements, the population in each given period can be divided into following groups:

1. Focused on personal consumption;

2. Focused on the development of a social sphere;

3. Focused on moral values;

4. Focused on status;

5. Focused on creativity.

If this is the case, then it implies that people genetically possess not only an identical set of instinctive requirements (as Maslow suggests), but that different people within the limits of this set are born with different dominant requirements. The question remains whether such a hypothesis has been empirically proven to be true? Or are dominant requirements a function of levels of income? In the USSR, the sphere of social requirements was far from a source of discontent in the 1980s.

B. Determinant of consciousness: Kelly. At the end of the 20th century there was a shift in psychology, which was even called the «cognitive revolution». Its aim was to give the human consciousness the main role in the formation of the human psyche.

This shift was prepared in the works of the American psychologist, George Kelly (1905-1967). Kelly believed that the focus of psychologists on unconscious motives and the past experience of a person was mistaken, as a person, through the course of his life, is focused on the future and consequently collects information and processes it in order to predict the future. According to Kelly, each person, like a scientist-researcher, develops for himself various cogitative personal designs through which he interprets reality and different specific situations, and «predicts» the future. Chains of these «designs» also form cognitive «channels», which make up the unique psyche of a specific individual. Personal designs are deeply individual, therefore the perception of the world and events are ambiguous; social dialogue is possible only in conditions when the counterparties are capable of learning and considering the specificity of each other's cognitive processes.

Kelly's maximalism, rejecting the role of past experience and motivation, based on a position of extreme relativism, was replaced by 
compromise approaches which, however, maintain the defining role of consciousness in the formation of the psyche. "Scheme» concepts are widely used; in which the "scheme», i.e., the hypothetical cognitive structure, is used for the perception, organisation, processing, and use of the information about the world.

Central to these concepts is the «me-scheme», consisting of properties which we consider most representative in relation to who we are. It includes physical signs, characteristic aspects of our mutual relations with people that are significant for us, the recognised features of personalities, motives, values, and purposes. The «me-schemes» can be subjected to change as a person reinterprets his behaviour in the present and in the possible future ${ }^{24}$.

The basic postulate of the cognitive paradigm consists of the fact that processing the «me-relevant» information controls both the reasons and consequences of external behaviour. Experiences that are incompatible with the existing «me-structure» are not symbolised or are symbolised in a distorted perception.

In other words, if a person has convinced himself that his behaviour is absolutely normal in a given situation, then he does not take notice of other people's comments, implying that he is excessively avaricious, dishonest, lazy, rigid, etc. Although such a person can become irritated and upset, his consciousness and (hence) psyche do not, on the whole, react adequately.

The basic postulate of the cognitive theory has been supported by a number of experimental researches, which have confirmed that people, as a rule, have a fairly clear subjective idea about the features of their own personality, motives, values, purposes, and their relationship with the surrounding environment - in other words, the «me-scheme». Experiments have revealed the following about people:

- Quickly express judgments and take decisions about themselves, if the question concerns the «me-scheme»;

- Quickly recollect or reconstruct episodes from their past, which correspond to their «me-scheme»;

- Often perceive others through a prism of their scheme;

${ }^{24}$ See Hjelle and Ziegler, p. 582. 
- Reject information which does not correspond to their «me-scheme» ${ }^{25}$.

In other words, cognitive psychology has established the fact that the individual psyche of a person is a fairly specific and rigid construction; that the psyche actively influences a person's perception of the surrounding world; that it is ready to deflect external attempts to «attack» it; and, that it is not inclined to change elastically under external «pressure». None of this is new. However, the confirmation by cognitive psychologists that the system of the psyche is created by consciousness, by the conscious processing of information, is new.

We believe that cognitive psychology has proposed (and proved) two important principles that help in understanding real behaviour. One is that the various elements of an individual psyche, starting from the psychophysical properties (general and specific) of a specific organism, including properties of the subconsciousness and consciousness, form «chains»; and, the personality of a person is made up of the system formed by these chains.

According to the second principle both in the formation of these «chains» and the system of the individual psyche as a whole, consciousness plays an active role in selecting, developing, and using the information received both from the organism and from the external world.

At the same time, «cogitative» (i.e. «identifying», «realising» and «rationalising») psychology, in giving a defining role to consciousness in relation to other elements of the psyche, appears not to be in a condition to answer a number of important questions:

- What are the origins of the criteria and the purposes, which guide the «pure» consciousness in selecting and processing the information and decision making?

- Why does the selection and processing of information by separate people result in the formation of different personal psychic systems?

${ }^{25}$ See Hjelle and Ziegler, p. 593. 
- Why does the consciousness of individuals vary?

- Why was consciousness, through historical development, not able to form a psyche of individuals that was free of the defects inherent in it?

Kelly's theory can be used as an example of what happens when the psychologist is excessively attached to a certain philosophical doctrine. This example is especially interesting in that it concerns the founder of modern cognitivism, which (as we will see in chapter 3) has had a significant impact on modern economic thought.

The «cognitivism» of Kelly is based on the philosophical doctrine proposed by him in his philosophical doctrine, «constructive alternativism», connecting (to a certain extent) subjective relativism with pragmatism. Hjelle and Ziegler write that as a doctrine, constructive alternativism proves that the modern interpretation of the world needs to be revised and replaced. According to it, nothing is sacred and nothing leaves an indelible trace. There are no politicians, religions, economic principles, social privileges, or even foreign policies in relation to Third World countries, which are absolutely and indisputably «right». All will change, if only people look at the world from another point of view. Kelly asserted that there is nothing in the world, concerning which there cannot be two opinions. Objective reality, of course, exists, but different people perceive it differently. Hence, nothing is constant or final. Truth, like beauty, exists only in the consciousness of a person.

As facts and events (like all human experience) exist only in the consciousness of a person, there are different ways of interpreting them. $^{26}$

In other words, the founder of «cognitivism» explained the psyche of the person, proceeding from the subjective-relativistic doctrine, especially empirically: the specific living conditions of a person define his consciousness, and the consciousness forms the psyche. However, «cognitivism» (like Marxism) is not able to explain essential distinctions in the psyche of people living under the same fundamental conditions.

${ }^{26}$ See Hjelle and Ziegler, pp. 434-435. 


\subsection{The Reasons for Disagreements}

From their analysis of the development of theories of personal psychology in the $20^{\text {th }}$ century, Hjelle and Ziegler reached an uncomfortable conclusion. They wrote that as the short history of personology has shown, there is no limit to the number of different theoretical models of mankind that scientists can invent. The greater the number of minds, the greater is the number of alternative concepts of man. In turn, in the future, there will probably be new concepts and directions ${ }^{27}$.

What are the reasons for such deep divergences? One can name some general reasons, some of which are mentioned by Hjelle and Ziegler. One of them is the specificity of the disposition of the psyche of the theorist, another is the historically specific social and professional environment in which the theory was developed and the third is the philosophical views of the personolog.

At least two important reasons still remain. Firstly, the questions which, openly or implicitly, the personolog asks himself, and uses the theory developed by him to answer them. Some worry primarily about the question regarding the roots of psychological diseases, others worry about the sources of totalitarianism and democracy, a third group worries about social contradictions and conflicts, a fourth group worries about the possibilities of education, and raising children and young people, a fifth group worries about the potential of the development of a person, etc. Accordingly, each theorist suggests different aspects and factors of the psyche as the defining aspects.

Secondly, the theory is influenced by the specificity of reference groups, with which individual personologs have dealings, and in general by that group of people, whose behaviour he observes and to which he addresses his arguments. As a rule, each field of activity is dominated by a certain psychological type (or types), on whose behaviour a given theory can be based.

The reasons listed are more than enough to come to the conclusion, which Hjelle and Ziegler actually made: the greater the number of minds, the greater is the number of alternative concepts of man. This probably means that until now psychologists and theorists do not have a general initial axiomatic base and, consequently, there is no general

${ }^{27}$ See Hjelle and Ziegler, p. 589. 
theory. However, if such a base had appeared, then various, even mutually exclusive, concepts of a person could have been considered as material for complementary «blocks» of a more general approach. (In the later chapters of this book, I will try to reveal such a base and develop such a general approach with reference to behaviour in the social and economic spheres).

Hjelle and Ziegler created the following table (Table 1.2) in order to illustrate the opposing positions of groups of leading psychologists and theorists regarding the decisive points of the concept of a human being.

The table emphasises the difference of opinions between groups (directions) of theorists in each of the nine considered problems.

At the same time, one can raise the following question: which positions are prevalent among the leading group of personologs, concerning the nine problems on the nature of the human psyche, raised by Hjelle and Ziegler at the beginning of their book? Table 1.3 is based on the summarised table of Hjelle and Ziegler (Table 1.2), but has been reconstructed to distinguish the positions of each separate theorist on the entire complex of the problems considered.

My table focuses on the closeness of the link between the positions of each of the theorists on each of the nine issues that Hjelle and Ziegler have included in the table. It is noticeable that those psychologists, who consider that the behaviour of people is internally free, also consider it to be rational (i.e., aware), subjective, and proactive, and consider the psyche of a person as a single whole, focused on development (heterostasis). However, in some of the positions taken by this group of psychologists, the link between features of the psyche appears to be different. Some of them consider the psyche of a person as invariable, others consider it to be variable, some consider it to be cognisant, and others consider it to be not cognisant.

The views on other issues of those psychologists, who believe that the behaviour of people is predetermined, can differ to an even greater extent, than those who believe in the psychological freedom of individual behaviour. This can be seen in the way that Freud and Erikson take opposing positions on five of the nine issues discussed above. 
A review of the positions of leading theorists on the fundamental positions, concerning human nature (Hjelle and Ziegler, p. 576)

\begin{tabular}{|c|c|c|c|c|c|c|c|c|}
\hline & Strong & $\begin{array}{l}\text { Moderat } \\
\mathrm{e}\end{array}$ & eak & $\begin{array}{l}\text { A } \\
\text { ve } \\
\text { ra } \\
\text { ge }\end{array}$ & $\begin{array}{l}\text { Wea } \\
\mathrm{k}\end{array}$ & $\begin{array}{l}\text { Modera } \\
\text { te }\end{array}$ & Strong & \\
\hline $\begin{array}{l}\text { Freedo } \\
\mathrm{m}\end{array}$ & $\begin{array}{l}\text { Adler } \\
\text { Maslo } \\
\text { W } \\
\text { Rogers }\end{array}$ & & & & & $\begin{array}{l}\text { Erikso } \\
\mathrm{n}\end{array}$ & $\begin{array}{l}\text { Freud } \\
\text { Skinne } \\
\mathrm{r}\end{array}$ & $\begin{array}{l}\text { Determ } \\
\text { inism }\end{array}$ \\
\hline $\begin{array}{l}\text { Ration } \\
\text { ality }\end{array}$ & $\begin{array}{l}\text { Allport } \\
\text { Bandur } \\
\text { a } \\
\text { Kelly } \\
\text { Maslo } \\
\text { w } \\
\text { Rogers }\end{array}$ & $\begin{array}{l}\text { Adler } \\
\text { Eriks } \\
\text { on }\end{array}$ & & & & & $\begin{array}{l}\text { Fre } \\
\text { ud }\end{array}$ & $\begin{array}{r}\text { Irra } \\
\text { ionality }\end{array}$ \\
\hline Holism & $\begin{array}{l}\text { Adler } \\
\text { Erikso } \\
\mathrm{n} \\
\text { Maslo } \\
\mathrm{w} \\
\text { Rogers }\end{array}$ & $\begin{array}{l}\text { Freu } \\
\text { d } \\
\text { Allpo } \\
\text { rt } \\
\text { Kelly }\end{array}$ & & & & $\begin{array}{l}\text { Bandur } \\
\text { a }\end{array}$ & $\begin{array}{l}\text { Skinne } \\
\mathrm{r}\end{array}$ & $\begin{array}{l}\text { Elemen } \\
\text { talism }\end{array}$ \\
\hline $\begin{array}{l}\text { Constit } \\
\text { utionali } \\
\text { sm }\end{array}$ & & $\begin{array}{l}\text { Freu } \\
\text { d } \\
\text { Kelly } \\
\text { Masl } \\
\text { ow } \\
\text { Roge } \\
\text { rs }\end{array}$ & & $\begin{array}{l}\text { A } \\
\text { dl } \\
\text { er } \\
\text { Al } \\
\text { lp } \\
\text { ort }\end{array}$ & & & $\begin{array}{l}\text { Bandur } \\
\text { a } \\
\text { Erikso } \\
\mathrm{n} \\
\text { Skinne } \\
\mathrm{r}\end{array}$ & $\begin{array}{l}\text { Enviro } \\
\text { nmenta } \\
\text { lism }\end{array}$ \\
\hline $\begin{array}{l}\text { Variabi } \\
\text { lity }\end{array}$ & $\begin{array}{l}\text { Erikso } \\
\mathrm{n} \\
\text { Skinne } \\
\mathrm{r} \\
\text { Bandur }\end{array}$ & & & $\begin{array}{l}\mathrm{Al} \\
\mathrm{lp} \\
\text { ort }\end{array}$ & & $\begin{array}{l}\text { Kel } \\
\text { ly }\end{array}$ & $\begin{array}{l}\text { Fre } \\
\text { ud } \\
\text { Adl } \\
\text { er }\end{array}$ & $\begin{array}{l}\text { Invaria } \\
\text { bility }\end{array}$ \\
\hline
\end{tabular}




\begin{tabular}{|c|c|c|c|c|c|c|c|}
\hline & $\begin{array}{l}\text { a } \\
\text { Maslo } \\
\text { w } \\
\quad \text { Rog } \\
\text { ers }\end{array}$ & & & & & & \\
\hline $\begin{array}{r}\text { Sub } \\
\text { jectivit } \\
y\end{array}$ & $\begin{array}{c}\text { Adl } \\
\text { er } \\
\text { Kel } \\
\text { ly } \\
\text { Ma } \\
\text { slow } \\
\text { Rog } \\
\text { ers }\end{array}$ & & $\begin{array}{l}\text { Freu } \\
\text { d } \\
\text { Allp } \\
\text { ort }\end{array}$ & $\begin{array}{l}\mathrm{Ba} \\
\text { nd } \\
\text { ur } \\
\mathrm{a}\end{array}$ & $\begin{array}{l}\text { Eri } \\
\text { kson }\end{array}$ & $\begin{array}{l}\text { Ski } \\
\text { nner }\end{array}$ & $\begin{array}{r}\text { Obj } \\
\text { ectivity }\end{array}$ \\
\hline $\begin{array}{l}\text { Proacti } \\
\text { vity }\end{array}$ & $\begin{array}{l}\text { Adler } \\
\text { Allport } \\
\text { Macloy } \\
\text { Rogers }\end{array}$ & $\begin{array}{l}\text { Freu } \\
\mathrm{d} \\
\text { Eriks } \\
\text { on }\end{array}$ & & $\begin{array}{l}\mathrm{Ba} \\
\text { nd } \\
\text { ur } \\
\mathrm{a}\end{array}$ & & $\begin{array}{l}\text { Skinne } \\
\mathrm{r}\end{array}$ & $\begin{array}{l}\text { Reactiv } \\
\text { ity }\end{array}$ \\
\hline $\begin{array}{l}\text { Homeo } \\
\text { stasis }\end{array}$ & $\begin{array}{l}\text { Fre } \\
\text { ud }\end{array}$ & & & & $\begin{array}{l}\text { Erikso } \\
\mathrm{n}\end{array}$ & $\begin{array}{l}\text { Adler } \\
\text { Allport } \\
\text { Maslo } \\
\text { w } \\
\text { Rogers }\end{array}$ & $\begin{array}{l}\text { Heteros } \\
\text { tasis }\end{array}$ \\
\hline $\begin{array}{l}\text { Cognis } \\
\text { ability }\end{array}$ & $\begin{array}{l}\text { Freud } \\
\text { Skinne } \\
\mathrm{r} \\
\text { Bandur } \\
\mathrm{a}\end{array}$ & $\begin{array}{l}\text { Erikson } \\
\text { Allport }\end{array}$ & & & & $\begin{array}{l}\text { Adler } \\
\text { Maslo } \\
\text { w } \\
\text { Rogers }\end{array}$ & $\begin{array}{l}\text { Uncogn } \\
\text { isabilit } \\
\mathrm{y}\end{array}$ \\
\hline
\end{tabular}

Table 1.2

\begin{tabular}{|l|r|r|r|r|r|r|r|r|r|r|}
\hline $\begin{array}{r}\mathrm{H} \\
\text { uman } \\
\text { natur } \\
\mathrm{e} \begin{array}{r}\text { is } \\
\text { chara }\end{array}\end{array}$ & eud & dler & $\begin{array}{r}\text { Er } \\
\text { ikson }\end{array}$ & $\begin{array}{r}\mathrm{A} \\
\text { llpo } \\
\mathrm{rt}\end{array}$ & $\begin{array}{r}\mathrm{Sk} \\
\text { inner }\end{array}$ & $\begin{array}{r}\mathrm{Ba} \\
\text { ndura }\end{array}$ & $\begin{array}{r}\mathrm{K} \\
\text { elly }\end{array}$ & $\begin{array}{r}\mathrm{M} \\
\text { aslow }\end{array}$ & $\begin{array}{r}\mathrm{R} \\
\text { ogers }\end{array}$ & $\begin{array}{l}\mathrm{C} \\
\text { onc } \\
\text { lusi } \\
\text { on } \\
\text { reg }\end{array}$ \\
\hline
\end{tabular}




\begin{tabular}{|c|c|c|c|c|c|c|c|c|c|c|}
\hline $\begin{array}{l}\text { cteris } \\
\text { ed by }\end{array}$ & & & & & & & & & & \begin{tabular}{|l} 
ardi \\
ng \\
the \\
9 \\
aut \\
hor \\
s
\end{tabular} \\
\hline $\begin{array}{l}\quad \mathrm{Fr} \\
\text { eedo } \\
\mathrm{m} \quad \text { or } \\
\text { deter } \\
\text { minis } \\
\mathrm{m}\end{array}$ & $\begin{array}{c}\mathrm{D} \\
\text { eterm } \\
\text { inism }\end{array}$ & $\begin{array}{r}F \\
\text { reed } \\
\text { om }\end{array}$ & \begin{tabular}{|} 
De \\
termi \\
nism
\end{tabular} & $\begin{array}{r}F \\
\text { reed } \\
\text { om }\end{array}$ & $\begin{array}{c}\text { De } \\
\text { termi } \\
\text { nism }\end{array}$ & th $\mathrm{Bo}$ & oth & $\begin{array}{l}\text { Fr } \\
\text { eedo } \\
\text { m }\end{array}$ & $\begin{array}{l}\text { Fr } \\
\text { eedo } \\
\text { m }\end{array}$ & $\begin{array}{r}F \\
\text { r. 4; } \\
\text { Det } \\
\text { 3; } \\
\text { Bot } \\
\text { h 2; } \\
? \\
0\end{array}$ \\
\hline $\begin{array}{l}\mathrm{R} \\
\text { ation } \\
\text { ality } \\
\text { (awar } \\
\text { eness } \\
\text { ) or } \\
\text { irr } \\
\text { ation } \\
\text { ality }\end{array}$ & $\begin{array}{l}\text { Irr } \\
\text { ation } \\
\text { ality }\end{array}$ & $\begin{array}{l}\text { R } \\
\text { atio } \\
\text { nali } \\
\text { ty }\end{array}$ & \begin{tabular}{|}
$\mathrm{Ra}$ \\
tional \\
ity
\end{tabular} & $\begin{array}{l}\mathrm{R} \\
\text { atio } \\
\text { nali } \\
\text { ty }\end{array}$ & $?$ & \begin{tabular}{|}
$\mathrm{Ra}$ \\
tional \\
ity
\end{tabular} & $\begin{array}{r}\mathrm{R} \\
\text { ation } \\
\text { ality }\end{array}$ & $\begin{array}{r}\mathrm{R} \\
\text { ation } \\
\text { ality }\end{array}$ & $\begin{array}{r}\mathrm{R} \\
\text { ation } \\
\text { ality }\end{array}$ & \begin{tabular}{|l|}
$\quad$ R \\
at. \\
$7 ;$ \\
Irra \\
t. 1; \\
Bot \\
h $0 ;$ \\
$\quad ?$ \\
1
\end{tabular} \\
\hline \begin{tabular}{|l}
$\mathrm{H}$ \\
olism \\
(whol \\
eness \\
) or \\
$\quad$ el \\
emen \\
talis \\
m
\end{tabular} & $\begin{array}{r}\text { W } \\
\text { holen } \\
\text { ess }\end{array}$ & $\begin{array}{r}\text { } \\
\text { hole } \\
\text { ness }\end{array}$ & \begin{tabular}{|} 
W \\
holen \\
ess
\end{tabular} & $\begin{array}{r} \\
\text { hole } \\
\text { ness }\end{array}$ & $\begin{array}{r}\text { El } \\
\text { ement } \\
\text { alism }\end{array}$ & $\begin{array}{r}\text { E1 } \\
\text { ement } \\
\text { alism }\end{array}$ & $\begin{array}{r}\text { W } \\
\text { holen } \\
\text { ess }\end{array}$ & $\begin{array}{r}\text { W } \\
\text { holen } \\
\text { ess }\end{array}$ & $\begin{array}{r}\text { W } \\
\text { holen } \\
\text { ess }\end{array}$ & \begin{tabular}{|l}
\multicolumn{1}{r}{} \\
ol. \\
$;$ \\
El. \\
$2 ;$ \\
Bot \\
he $0 ;$ \\
$?$
\end{tabular} \\
\hline $\mid \begin{array}{c}\mathrm{C} \\
\text { onstit }\end{array}$ & $\underset{\text { onstit }}{\mathrm{C}}$ & oth & $\begin{array}{c}\text { En } \\
\text { viron }\end{array}$ & oth $B$ & $\begin{array}{c}\text { En } \\
\text { viron }\end{array}$ & $\begin{array}{c}\text { En } \\
\text { viron }\end{array}$ & $\underset{\mathrm{C}}{\mathrm{C}}$ & $\underset{\text { onstit }}{\mathrm{C}}$ & $\underset{\text { onstit }}{\mathrm{C}}$ & ons \\
\hline
\end{tabular}




\begin{tabular}{|c|c|c|c|c|c|c|c|c|c|c|}
\hline $\begin{array}{l}\text { ution } \\
\text { alism } \\
\text { or } \\
\text { envir } \\
\text { onme } \\
\text { ntalis } \\
\text { m }\end{array}$ & $\begin{array}{l}\text { ution } \\
\text { alism }\end{array}$ & & $\begin{array}{l}\text { menta } \\
\text { lism }\end{array}$ & & $\begin{array}{l}\text { menta } \\
\text { lism }\end{array}$ & $\begin{array}{l}\text { menta } \\
\text { lism }\end{array}$ & $\begin{array}{l}\text { ution } \\
\text { alism }\end{array}$ & $\begin{array}{l}\text { ution } \\
\text { alism }\end{array}$ & $\begin{array}{l}\text { ution } \\
\text { alism }\end{array}$ & $\begin{array}{r}\text { t. } 4 ; \\
\text { Env } \\
. \quad 3 ; \\
\text { Bot } \\
\text { h 2; } \\
? \\
0\end{array}$ \\
\hline $\begin{array}{l}\quad \mathrm{V} \\
\text { ariabi } \\
\text { lity } \\
\text { or } \\
\text { invari } \\
\text { abilit } \\
\text { y }\end{array}$ & $\begin{array}{r}\text { In } \\
\text { varia } \\
\text { bility }\end{array}$ & $\begin{array}{r}\text { I } \\
\text { nva } \\
\text { riab } \\
\text { ility }\end{array}$ & $\begin{array}{l}\mathrm{Va} \\
\text { riabili } \\
\text { ty }\end{array}$ & oth & $\begin{array}{l}\mathrm{Va} \\
\text { riabili } \\
\text { ty }\end{array}$ & $\begin{array}{r}\mathrm{Va} \\
\text { riabili } \\
\text { ty }\end{array}$ & $\begin{array}{r}\text { In } \\
\text { varia } \\
\text { bility }\end{array}$ & $\begin{array}{l}\quad \mathrm{V} \\
\text { ariabi } \\
\text { lity }\end{array}$ & $\begin{array}{l}\quad \mathrm{V} \\
\text { ariabi } \\
\text { lity }\end{array}$ & \begin{tabular}{|l} 
ar. \\
$5 ;$ \\
Inv \\
ar. \\
$3 ;$ \\
Bot
\end{tabular} \\
\hline $\begin{array}{l}\mathrm{Su} \\
\text { bjecti } \\
\text { vity } \\
\text { or } \\
\quad \mathrm{O} \\
\text { bjecti } \\
\text { vity }\end{array}$ & $\begin{array}{l}\mathrm{Su} \\
\text { bjecti } \\
\text { ve }\end{array}$ & $\begin{array}{l}\text { S } \\
\text { ubje } \\
\text { ctiv } \\
\text { e }\end{array}$ & $\begin{array}{l}\quad \mathrm{O} \\
\text { bjecti } \\
\text { ve }\end{array}$ & $\begin{array}{l}\mathrm{S} \\
\text { ubje } \\
\text { ctiv } \\
\mathrm{e}\end{array}$ & $\begin{array}{l}\quad \mathrm{O} \\
\text { bjecti } \\
\text { ve }\end{array}$ & th & $\begin{array}{l}\mathrm{Su} \\
\text { bjecti } \\
\text { ve }\end{array}$ & $\begin{array}{l}\mathrm{Su} \\
\text { bjecti } \\
\text { ve }\end{array}$ & $\begin{array}{l}\mathrm{Su} \\
\text { bjecti } \\
\text { ve }\end{array}$ & 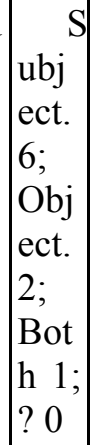 \\
\hline \begin{tabular}{|l}
$\quad P r$ \\
oacti \\
vity \\
or \\
reacti \\
vity
\end{tabular} & $\begin{array}{r}\quad P r \\
\text { oacti } \\
\text { vity }\end{array}$ & $\begin{array}{l}P \\
\text { roac } \\
\text { tivit } \\
y\end{array}$ & $\begin{array}{l}\quad \operatorname{Pr} \\
\text { oactiv } \\
\text { ity }\end{array}$ & $\begin{array}{l}\mathrm{P} \\
\text { roac } \\
\text { tivit } \\
\mathrm{y}\end{array}$ & $\begin{array}{l}\mathrm{Re} \\
\text { activi } \\
\text { ty }\end{array}$ & th & $?$ & $\begin{array}{r}\text { Pr } \\
\text { oacti } \\
\text { vity }\end{array}$ & $\begin{array}{l}\quad P r \\
\text { oacti } \\
\text { vity }\end{array}$ & $\begin{array}{l}\quad \mathrm{P} \\
\text { roa } \\
\text { ct. } \\
6 ; \\
\text { rea } \\
\text { ct. } \\
1 ; \\
\text { bot } \\
\text { h 1; }\end{array}$ \\
\hline
\end{tabular}




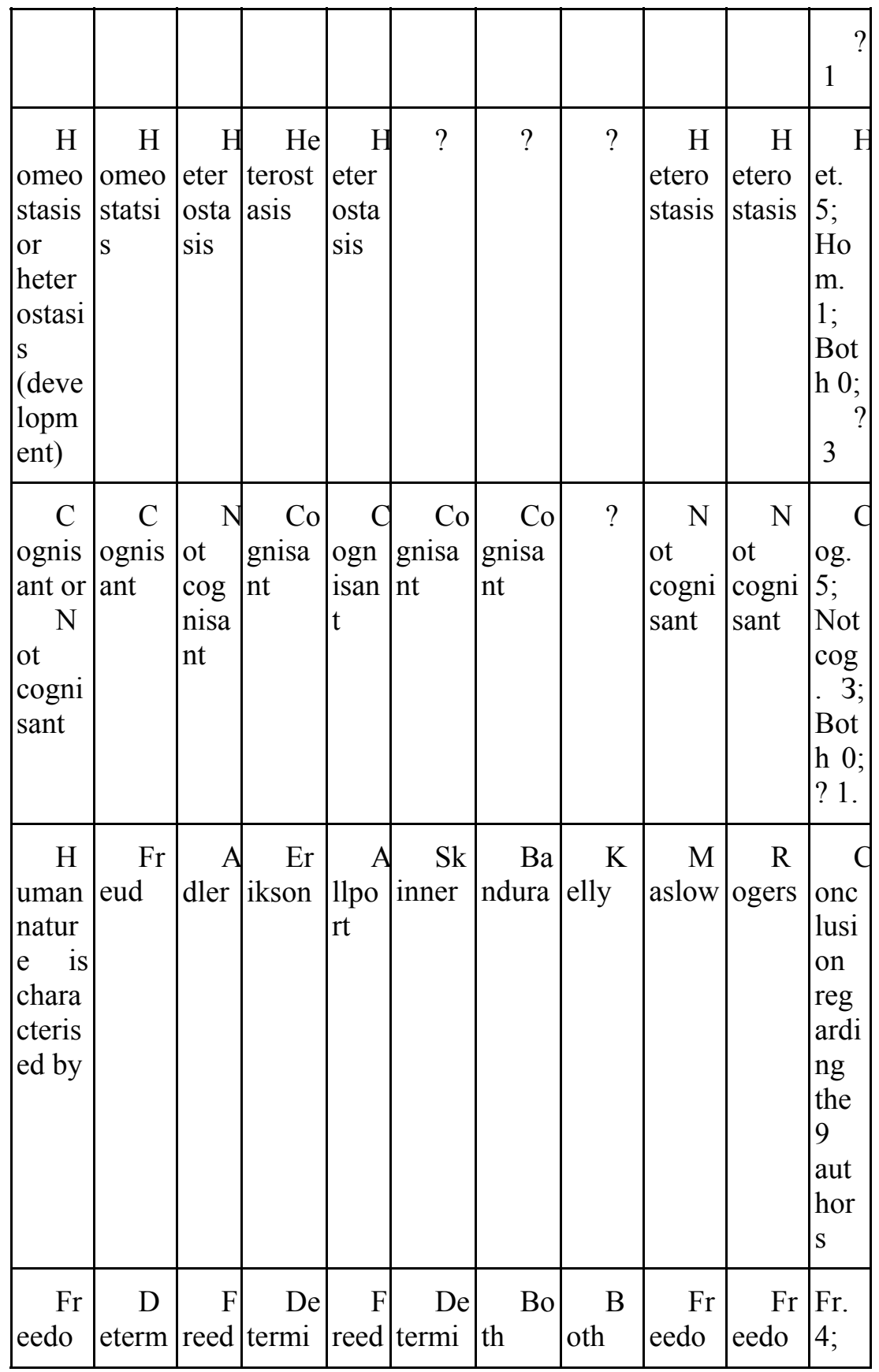




\begin{tabular}{|c|c|c|c|c|c|c|c|c|c|c|}
\hline $\begin{array}{ll}\mathrm{m} & \text { or } \\
\text { deter } \\
\text { minis } \\
\mathrm{m}\end{array}$ & inism & om & nism & om & nism & & & $\mathrm{m}$ & $\mathrm{m}$ & $\mid \begin{array}{l}\text { Det. } \\
3 ; \\
\text { Bot } \\
\text { h 2; } \\
\begin{array}{l}? \\
0\end{array}\end{array}$ \\
\hline $\begin{array}{l}\text { R } \\
\text { ation } \\
\text { ality } \\
\text { (awar } \\
\text { eness } \\
\text { ) or } \\
\text { irr } \\
\text { ation } \\
\text { ality }\end{array}$ & $\begin{array}{l}\text { Irr } \\
\text { ation } \\
\text { ality }\end{array}$ & \begin{tabular}{|l}
$\quad R$ \\
atio \\
nali \\
ty
\end{tabular} & \begin{tabular}{|l} 
Ra \\
tional \\
ity
\end{tabular} & $\begin{array}{l}\quad \mathrm{R} \\
\text { atio } \\
\text { nali } \\
\text { ty }\end{array}$ & ? & \begin{tabular}{|}
$\mathrm{Ra}$ \\
tional \\
ity
\end{tabular} & \begin{tabular}{|l}
$\mathrm{R}$ \\
ation \\
ality
\end{tabular} & $\begin{array}{r}\mathrm{R} \\
\text { ation } \\
\text { ality }\end{array}$ & $\begin{array}{r}\mathrm{R} \\
\text { ation } \\
\text { ality }\end{array}$ & 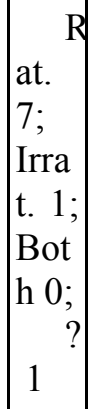 \\
\hline \begin{tabular}{|l}
$\quad \mathrm{H}$ \\
olism \\
(whol \\
eness \\
) or \\
\multicolumn{1}{c}{ el } \\
emen \\
talis \\
m
\end{tabular} & $\begin{array}{r}\text { W } \\
\text { holen } \\
\text { ess }\end{array}$ & $\begin{array}{r}V \\
\text { hole } \\
\text { ness }\end{array}$ & $\begin{array}{r}\text { W } \\
\text { holen } \\
\text { ess }\end{array}$ & $\begin{array}{r}V \\
\text { hole } \\
\text { ness }\end{array}$ & $\begin{array}{c}\text { El } \\
\text { ement } \\
\text { alism }\end{array}$ & $\begin{array}{r}\text { E1 } \\
\text { ement } \\
\text { alism }\end{array}$ & $\begin{array}{r}\text { W } \\
\text { holen } \\
\text { ess }\end{array}$ & $\begin{array}{r}\text { W } \\
\text { holen } \\
\text { ess }\end{array}$ & $\begin{array}{r}\text { W } \\
\text { holen } \\
\text { ess }\end{array}$ & \begin{tabular}{|l}
\multicolumn{1}{r}{} \\
ol. \\
$;$ \\
El. \\
$2 ;$ \\
Bot \\
h $0 ;$ \\
$?$ 0
\end{tabular} \\
\hline \begin{tabular}{|l}
\multicolumn{1}{c}{$C$} \\
onstit \\
ution \\
alism \\
or \\
envir \\
onme \\
ntalis \\
m
\end{tabular} & $\mid \begin{array}{c}\mathrm{C} \\
\text { onstit } \\
\text { ution } \\
\text { alism }\end{array}$ & oth & \begin{tabular}{|l}
\multicolumn{1}{|c}{ En } \\
viron \\
menta \\
lism
\end{tabular} & oth & \begin{tabular}{|l}
\multicolumn{1}{|c}{ En } \\
viron \\
menta \\
lism
\end{tabular} & \begin{tabular}{|l}
\multicolumn{1}{c}{ En } \\
viron \\
menta \\
lism
\end{tabular} & $\begin{array}{c}\mathrm{C} \\
\text { onstit } \\
\text { ution } \\
\text { alism }\end{array}$ & \begin{tabular}{c}
\multicolumn{1}{c}{$\mathrm{C}$} \\
onstit \\
ution \\
alism
\end{tabular} & \begin{tabular}{c}
\multicolumn{1}{c}{$\mathrm{C}$} \\
onstit \\
ution \\
alism
\end{tabular} & $\begin{array}{r}\quad \\
\text { ons } \\
\text { t. } 4 ; \\
\text { Env } \\
\text {. } 3 ; \\
\text { Bot } \\
\text { h 2; } \\
? \\
0\end{array}$ \\
\hline$\underset{\text { ariabi }}{\mathrm{V}}$ & $\begin{array}{r}\text { In } \\
\text { varia }\end{array}$ & nva & $\begin{array}{r}\mathrm{Va} \\
\text { riabili }\end{array}$ & oth & $\begin{array}{r}\mathrm{Va} \\
\text { riabili }\end{array}$ & $\begin{array}{r}\mathrm{Va} \\
\text { riabili }\end{array}$ & $\begin{array}{r}\text { In } \\
\text { varia }\end{array}$ & $\underset{\text { ariabi }}{\mathrm{V}}$ & $\underset{\text { ariabi }}{\mathrm{V}}$ & ar. \\
\hline
\end{tabular}




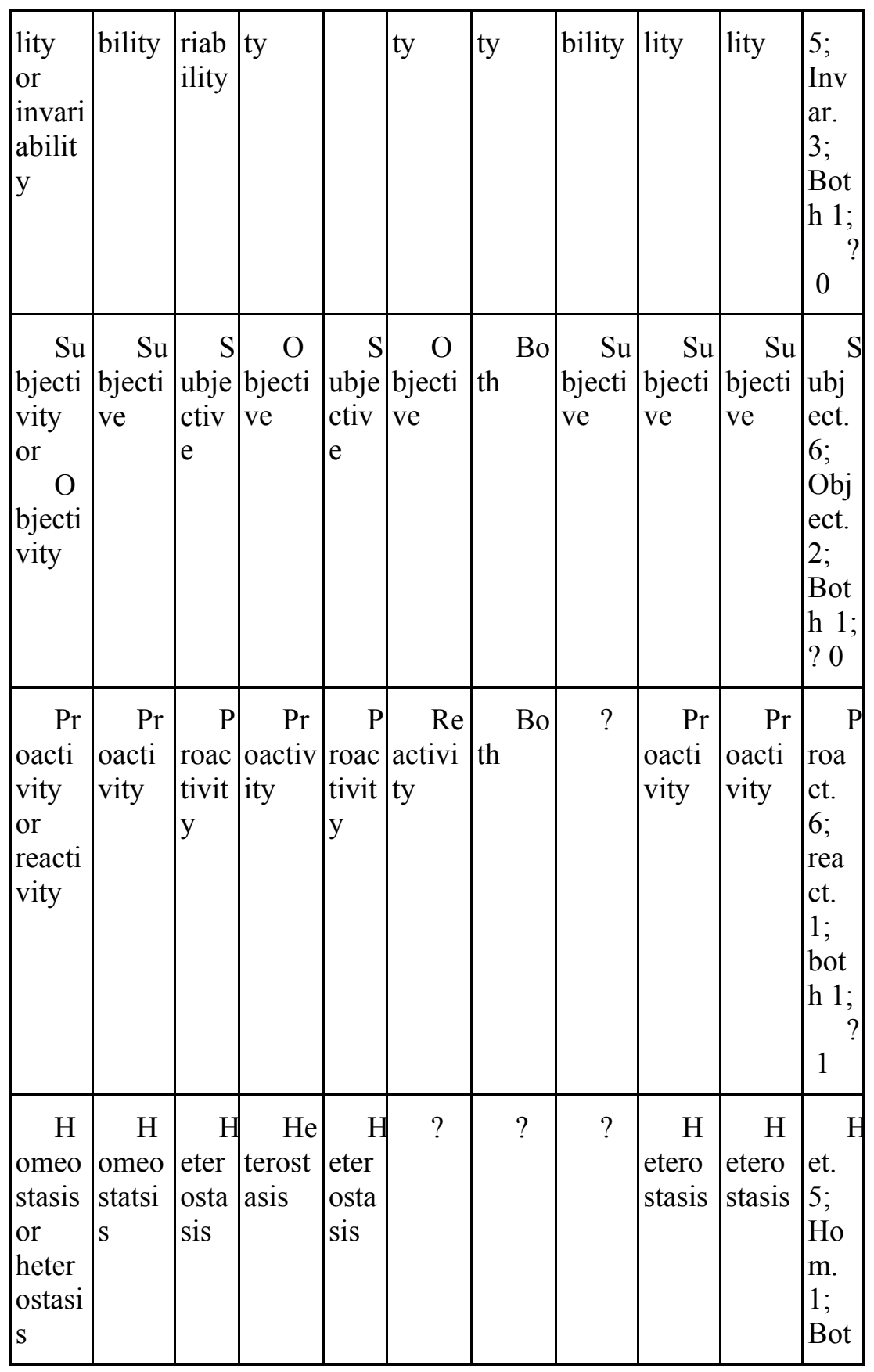




\begin{tabular}{|c|c|c|c|c|c|c|c|c|c|c|}
\hline $\begin{array}{l}\text { (deve } \\
\text { lopm } \\
\text { ent) }\end{array}$ & & & & & & & & & & $\begin{array}{r}\text { h } 0 ; \\
? \\
3\end{array}$ \\
\hline \begin{tabular}{l}
$\quad \mathrm{C}$ \\
ognis \\
ant or \\
\multicolumn{1}{c}{$\mathrm{N}$} \\
ot \\
cogni \\
sant
\end{tabular} & $\begin{array}{l}\quad \text { C } \\
\text { ognis } \\
\text { ant }\end{array}$ & $\begin{array}{l}\quad \mathrm{N} \\
\text { ot } \\
\text { cog } \\
\text { nisa } \\
\text { nt }\end{array}$ & $\begin{array}{l}\text { Co } \\
\text { gnisa } \\
\text { nt }\end{array}$ & $\begin{array}{l}\text { C } \\
\text { ogn } \\
\text { isan } \\
t\end{array}$ & $\begin{array}{l}\quad \text { Co } \\
\text { gnisa } \\
\text { nt }\end{array}$ & $\begin{array}{l}\text { Co } \\
\text { gnisa } \\
\text { nt }\end{array}$ & $?$ & $\begin{array}{l}\quad \text { N } \\
\text { ot } \\
\text { cogni } \\
\text { sant }\end{array}$ & \begin{tabular}{l}
\multicolumn{1}{c}{$\mathrm{N}$} \\
ot \\
cogni \\
sant
\end{tabular} & $\begin{array}{l}\quad \text { } \\
\text { og. } \\
5 ; \\
\text { Not } \\
\operatorname{cog} \\
\text { Bot } \\
\text { Bot } \\
\text { h } 0 ; \\
? 1 .\end{array}$ \\
\hline
\end{tabular}

Table 1.3

Note: «?» means that the position of the theorist on this point in question is not designated by Hjelle and Ziegler.»Both» means that the theorist has taken an intermediate position. In the given table the «strong» and «moderate» positions, which differ in the initial table of Hjelle and Ziegler, do not differ.

This gives grounds for concluding that if each theorist considers their own positions on the nine specified problems to be internally in agreement, then he is obliged to consider the positions of the majority of the others to be internally inconsistent. Furthermore, the greatest disagreements are caused by the alternatives, freedom versus determinism, and, constitutionalism versus environmentalism, and the least discrepancy by, rationality versus irrationality.

If one could justify making an overall «portrait» of these separate characteristics of a person's psyche, for each of which the simple majority of the nine theorists named in the table «voted», then the psyche would appear as follows:

- Freedom (m.);

- Rational; 
- Holistic;

- Constitutional, i.e., defined by internal factors (m.);

- Variable (m.);

- Subjective;

- Proactive;

- Focused on development (heterostasis);

- Cognisant (m.).

(The sign (m.) means that on the given point the «majority» is minimal.)

The specified «majority» under separate characteristics is extremely non-uniform. In some points it is overwhelming and in others, minimal.

One may assume that the majority of psychologists mentioned above would support those general characteristics of human behaviour, with which institutional economists agree.

At the same time, a minority of the psychologists and theorists considered above (who believe that determinism, elementalism, rationality, invariance, reactivity and homeostasis is inherent in the psyche of people) would support the views on human behaviour, inherent in neoclassic economics.

Psychology can help explain the structure and functioning of society only to the degree that it is capable of revealing not abstract, but real, types of the human psyche. At the same time, the detection of these types in a real structured public environment, in the process of different activities is also necessary for psychology itself. Without a real «typification» of the psyche, the questions posed by Hjelle and Ziegler will never receive well-founded answers.

Leading psychologists do not have a common position on the question of human nature or on the typology of the psyche. At the same time, I believe that on both these issues it is possible to choose positions, with which the majority of them agree. Here, I will focus on the positions that are relevant to the theme of my research. (See Figure 1.1, «Types of Psyche»).

The majority of leading psychologists agree that a person's psyche, to a significant degree (ranging from $33 \%$ to $50 \%$ ), is genetic in 
nature, i.e., inherited. Such conclusions are based on the observation of people's behaviour (in particular, twins and siblings); however, it is not quite clear what psychologists mean by «genetic nature» predisposition or the functioning of instincts, or both.

This majority as a natural basis of the psyche specifies the human requirement for safety and protection (which can be understood as the action of the instinct for self-preservation).

The prevalent position is that a person according to his own nature is internally free. Unlike social scientists, who interpret the absence of external restrictions as freedom, the majority of psychologists understand freedom as the absence, primarily, of internal restrictions and psychic «complexes». As the latter cannot mean that a person in decision-making is «free» from his own psyche, a person's freedom refers to his ability, based on reason and will, to be able to choose the psychic impulses (instincts, inclinations, feelings, and values) by which he is guided in a given situation.

Figure 1.1

\begin{tabular}{|c|c|c|c|c|c|c|}
\hline Freud & Adler & Jung & $\begin{array}{l}\text { Fromm } \\
\frac{\text { Types of }}{\text { psyche }}\end{array}$ & Homey & Allport* & $\begin{array}{l}\text { Maslo } \\
\text { W }^{\star *}\end{array}$ \\
\hline $\begin{array}{l}\text { Oral } \\
\text { (dependent } \\
\text { or } \\
\text { exploitive) } \\
\text { Anal } \\
\text { (retaining or } \\
\text { aggressive) } \\
\text { Phallic } \\
\text { (insolent, } \\
\text { competitive) } \\
-------- \\
--- \\
\text { Genital } \\
\text { (productively } \\
\text { cooperative) }\end{array}$ & $\begin{array}{l}\text { Goveming } \\
\text { Taking } \\
\text { Avoiding } \\
\text { Socially- } \\
\text { sseful }\end{array}$ & $\begin{array}{l}\text { Extrovert } \\
\text { - cogitative } \\
\text {-sensual } \\
\text { - feeling } \\
\text {-intuitive }\end{array}$ & $\begin{array}{l}\text { Receptive } \\
\text { Exploitive } \\
\text { Accumulative } \\
\text { Market- } \\
\text { oriented } \\
-{ }_{-} \\
\text {Productive }\end{array}$ & 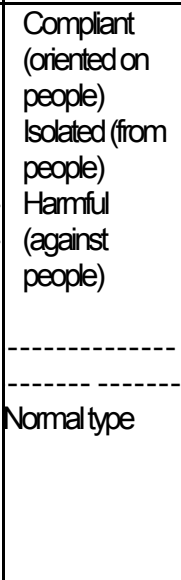 & $\begin{array}{l}\text { Theoretical } \\
\text { Eoonomic } \\
\text { Aesthetic } \\
\text { Social } \\
\text { Political } \\
\text { Religious }\end{array}$ & $\begin{array}{l}\text { Consume } \\
r \\
\text { Social } \\
\text { Ethical } \\
\text { Status- } \\
\text { oriented } \\
\text { Creative }\end{array}$ \\
\hline
\end{tabular}




\begin{tabular}{|c|c|c|c|c|c|c|}
\hline & & $\begin{array}{l}\text { Introvert: } \\
\text { - cognitive } \\
\text { - sensual } \\
\text { - feeling } \\
\text {-intuitive } \\
\end{array}$ & & & & \\
\hline \multicolumn{7}{|c|}{ Genetically inherited requirements, instincts, characteristics, aspirations } \\
\hline $\begin{array}{l}\text { Sexual } \\
\text { instinct } \\
\text { Instinct of } \\
\text { aggression }\end{array}$ & $\begin{array}{l}\text { Feeling of } \\
\text { helplessne } \\
\text { ss } \\
\text { Aspiration } \\
\text { to } \\
\text { superiority } \\
\text { Social } \\
\text { instinct } \\
\text { Aspiration } \\
\text { to creativity } \\
\text { Aspiration } \\
\text { to goat } \\
\text { setting } \\
\text { Level of } \\
\text { activity }\end{array}$ & $\begin{array}{l}\text { Collective } \\
\text { unconsciou } \\
\text { s } \\
\text { (archetype } \\
\text { s) } \\
\text { Personal } \\
\text { unconsciou } \\
\text { s } \\
\text { (complexe } \\
\text { s) }\end{array}$ & $\begin{array}{l}\text { Aspiration to } \\
\text { freedom } \\
\text { Aspiration to } \\
\text { safety } \\
\text { Existential } \\
\text { requirements: } \\
\text {-in } \\
\text { establishing } \\
\text { communicatio } \\
\mathrm{n} \\
\text {-in } \\
\text { overcoming } \\
\text {-in roots } \\
\text {-inidentity } \\
\text {-infaithrulness }\end{array}$ & $\begin{array}{l}\text { Aspiration to } \\
\text { safety } \\
\text { Natural } \\
\text { requirements: } \\
\text { - in love } \\
\text {-in } \\
\text { management } \\
\text {-in constraint } \\
\text {-in power } \\
\text {-in exploitation } \\
\text {-in } \\
\text { adknowledgm } \\
\text { ent } \\
\text {-in self- } \\
\text { admiration } \\
\text {-inambition } \\
\text {-in } \\
\text { independenœe } \\
\text {-in } \\
\text { fautlessness } \\
\end{array}$ & $\begin{array}{l}\text { Intellect } \\
\text { Temperam } \\
\text { ent } \\
\text { («Genetic } \\
\text { factors } \\
\text { define half } \\
\text { ofhuman } \\
\text { behaviour») }\end{array}$ & $\begin{array}{l}\text { Requirem } \\
\text { ents: } \\
- \\
\text { physiologi } \\
\text { cal } \\
\text {-in safety } \\
\text {-in } \\
\text { belonging } \\
\text { and in love } \\
\text {-inself- } \\
\text { esteem } \\
\text {-in self- } \\
\text { realisation }\end{array}$ \\
\hline
\end{tabular}

* Types of «value orientations» of behaviour;

** Types of psyche, based on Maslow's concepts (that are, however, absent in Maslow's works).

Some psychologists consider that the «skeleton» of a person's psyche is formed in childhood and then does not change, while others consider that the psyche can change significantly during the course of a person's life, or from the impact of changes in the surrounding environment.

The majority of theorists believe that all the components of a person's psyche form a single whole, and internal contradictions in the psyche's system are considered either as a pathology or as a tragic conflict. 
On the whole, from the point of view of issues in social and economic research, one can consider the division of the factors defining behaviour, into genetic and social factors, and also the attempt to distinguish between types of psyche as the most significant general achievements in psychology.

From the same point of view, the main failure in this field has been the inability of researchers to establish a connection between the genetically-determined and socially-determined types of psyche.

As will be seen further on, the unresolved problems of establishing a link between the psychogenetic and the psychosocial sides of the personality and the distinction on this basis of the social-genetic types of psyche interfere with the development of realistic initial axioms of economic theory.

\subsection{I.P. Pavlov on Instincts and the Role of Institutions («Rules»)}

The paragraph below is based on the shorthand copy of two lectures, read by Pavlov in 1913 and 1919, which were published for the first time in $1999 .^{28}$

In the first lecture, on «suicides», the great physiologist discusses a subject, which he considers to be "far from (his) speciality», but at the same time, a subject which he had thought about at length and for which he had selected material. The second lecture is called «The Cultural Bases of Animals and the Human Being», and as is evident from the name itself, it weaves a thread between the psyche of humans and animals, a subject that directly concerns his speciality. (I note that the scientist himself objected to the use of the term «psychology», believing that the «physiology of higher nervous activity» would be a more appropriate term.)

One can state that Pavlov's conclusions on human instincts, in these articles, on the one hand, are supported by the logical analysis of

\footnotetext{
${ }^{28}$ Source: Russian Academy of Sciences, vol. 69 № 1, 1999. Further in this paragraph, references to the pages of this source will be given in the text in brackets.
} 
human behaviour in specific historical conditions, and on the other hand, by the methodological research of the scientist in the field of physiology of higher nervous activity.

The logic of the first lecture is the following: from observations of the lives of animals and people, it follows that one can distinguish two connected instincts: an «instinct for life» and an «instinct for achieving ones purpose».

«The instinct of any living entity pushes it to live as long as possible (p. 58).» In another place: «I am convinced that in the human organism, besides the well-known instincts, for example, to live etc., there is also an aspiration, badly formulated, little noticed, but extremely important. This aspiration (this instinct) I name as the instinct for achieving ones aim.»

Furthermore, in this case, I believe it important to note the following: Pavlov's speech is not referring to a person (or an animal) acknowledging (or feeling) his various requirements as the aims of his actions, but to the special, separate requirement of an organism to set and achieve an aim. Accordingly, the human being or animal is constantly under a certain nervous tension. Thinking of the aim, probably, supplies the nervous system (and through it the entire organism) with the directed impulses. «Something pushes an animal (or human being) to reach its aim, once it has been set. It is the same need, as the need for food, sexual intercourse, etc. ... In the organisms of humans and animals, there is an instinct for achieving their aim (p.60).»)

The inclination to commit suicide is unnatural, as it contradicts the action of two proven instincts. However, such an inclination arises there, where this action encounters specific barriers.

Pavlov considers a nervous breakdown or an illness of the nervous system as the first such barrier. "Our century is a nervous century», but in the Russia of 1913, having endured two sharp critical shifts in its way of life over a period of 50 years (the end of serfdom and the revolution in 1905), the burden on the nervous system of the population was especially great. At the same time, in Russia, unlike Europe, there were no «rules for easing the tension on the nervous system, so that a person could receive fewer and weaker shocks (p. 59)». 
As the first group of such rules for «easing the nervous system», Pavlov cites tolerance to other people's views and being accustomed to multiple opinions.

In Russia, in contrast to Western Europe, a difference in convictions is a «source of spiteful feelings (p. 59)».

«Thus, the reasons (leading to an increase in suicides -0) are the crises endured by us and the absence of rules regulating every minute of life (p. 59).»

Physical work and sports are related to the second group of rules for «easing the tension in the nervous system» and preventing nervous diseases. "We have inherited a very highly developed physiological life... Our ancestors lived under different living conditions in the form of animals. Their nervous activity... was always expressed through the workings of their muscular system. Hence..., the muscular system should be the natural base. While our nervous activities without muscular activities are unknown in the zoological world. It is wellknown that in the lower classes, as long as their work does not become excessive, there are few nervous illnesses. These are illnesses of the higher classes. Also, there are many cases of observations that show the degree to which a return to the primary, muscular, activity of an organism results in curing the problems related to nervous activity ( $\mathrm{p}$. 59).»

Thus, in order for the nervous system to be in a healthy state, in which the natural instincts can function normally, the social conditions need to meet the following requirements:

- The absence of public crises that could have an impact on this system;

- The existence of social rules of behaviour, easing the burden of a crisis on the nervous system;

- The general involvement of the population in physical work and sports;

- The absence of excessive physical burdens.

One can consider that if these conditions are (fundamentally) infringed, a significant part of the population suffers from painful nervous tension; moreover, nervous illnesses and suicide cases, in 
particular, are only the tip of the iceberg, the extreme display of a mass neurosis, which weakens the functioning of the «instinct for life».

Do these thoughts of Pavlov have any value for economic theory? I believe that their impact is at least as significant as the ideas of Keynes (discussed in chapter 2) on «cheerfulness» as a basis of business (stated more than two decades after Pavlov's publications).

More specifically, we consider that the «life instinct» is the basis of the economic aspiration, which theorists refer to as the «maximisation of well-being». It is obvious that the force of this aspiration for a specific individual is directly dependent on his inborn life instinct and on the social conditions, in which this instinct operates. Hence, the moving force of the desire to maximise well-being in different people, in different countries, and in different historical stages can differ greatly.

However, even amongst people with healthy nervous systems, cases of suicide are not uncommon. This leads Pavlov to disclose one more instinct and the mechanisms for implementing it. Pavlov considers the loss of purpose in life as the "root of this tendency» towards suicide amongst healthy people. «In this case, I again turn to physiology. Although, this has not yet become part of physiology, nonetheless, to me it is clear that it involves physiology (p. 60).» He continues: «I am convinced that in human nature there is also an instinct to achieve ones aims, and consciousness of this instinct and its correct practice is one of the objectives of life and one of the conditions required for happiness (p. 60).»

The instinct of achieving ones aims, present both in human and in animal organisms, is fulfilled through the achievement of ones aim in parts and through movement to an ultimate goal in stages. At the same time, obstacles give impulses to this movement. "If there are no obstacles, then a person is insufficiently irritated and does not receive the impetus to work. This is the very proof of instinct. The greater the obstacles, the better the instinct functions (p. 60).»

Noting that in Russia this instinct is «very weak», Pavlov explains: «It is clear that this instinct, due to various historical circumstances, was not able to develop here. However, now our life is starting to take shape. Serfdom, thank God, has been destroyed. The constant interference of bureaucracy has also started to fade away (p. 60).» 
Pavlov also expresses hope for radical changes in the educational system.

The thoughts stated by Pavlov concerning this instinct can be generalised by three conditions: in order for any natural instinct to function actively, it is necessary to (1) acknowledge it, (2) nurture independence and initiative in people, and (3) create institutional conditions favourable for the functioning of this instinct.

In other words, social (including economic) conditions should be subordinated to the requirements of those natural instincts, which give substance and purpose to human life.

«I find that if one addresses the root of the problem, the tendency to commit suicide is represented by the waning of the instinct for achieving ones aim. This is based partly on historical conditions and partly on the absence of thoughts that such an instinct exists and, which needs to be acknowledged and protected; (then, it would make both a person's personal and social life unbelievably richer).

I also think that if a person will always live and maintain a purpose and aim in life, which has to be attained, then, he will not be disappointed in life (p. 61).»

Note that, in this case, Pavlov does not oppose natural instinct and consciousness; instead he considers the awareness of instinct as a condition for functioning normally in life.

While in his lecture in 1913, that is, prior to the First World War and the Revolutions of 1917, Pavlov focuses his attention on the harmful consequences of the suppression of natural instincts by reactionary institutions and the subjugation of the nervous system by the social crises, in his lecture in 1919, read after these events and at the height of the civil war, he emphasises the «dampening» role of institutions (both formal and informal) in restraining the stimulation of the nervous system and the free functioning of instincts. Essentially, in the first lecture he defines the conditions in which instincts can function positively and constructively; and in the second lecture, he defines the ways and methods of restricting negative and destructive displays, which take place under unlimited freedom of action of the instincts.

In the second lecture (1919), the central themes are stimulation and inhibition, and freedom and discipline. The lecture is called «The Cultural Bases of Animals and Humans»; thus, the relationship, link, and interaction between stimulation and freedom on the one hand, and 
inhibition and discipline on the other hand, are projected by Pavlov in this lecture as characteristics of the condition, in which the bases of human culture lie. Here, essentially, it is a question of contrasting the instinct for freedom with deliberately established restrictions. "The most progressive races - the Germans and the English - basically attach the same significance to inhibition, holding in check, as they do to a display of activity, freedom. It is clear that the legal limits of freedom are found next to inhibition (p. 62).»

According to Pavlov, «inhibitions» are most developed in England and Germany. «These inhibitions are presented, firstly, in religion, then in law, by the authorities, supervision, upbringing, customs, and habits. These are all inhibitions (p. 61).»

Moreover, not only the important laws and customs, but also the small disciplinary restrictions, including formal restrictions, matter. «In this way (one) supports the practice of nervous activity and exercises inhibitions. That is why formalism matters... (p. 62).»

In Russia, by allowing and permitting everything to the child in the course of its upbringing, one «makes the child a slave to its internal inclinations and desires. The child will not have any authority over itself, because it does not have the ability to inhibit itself, as it was not developed in the child. We do not understand this... We create a boat without a rudder and without a helmsman (p.69).»

Pavlov opposes the softness of Russian laws and the practice of their application.

«Russians have not yet found out that life consists of two halves, freedom and discipline, and irritation and inhibition. To refuse one half of it means that one is doomed to a life of shame.

The degree to which this is life's law can be seen in our revolutionary times. It is both a magnificent and an awful illustration. What is revolution? It is a release from all the inhibitions that I have mentioned, it is a complete lack of restraints and curbs. There were laws, customs, etc. Now, they are all gone. The past no longer exists; the future has still not come into being. Inhibitions have been abolished, and there is only stimulation left. It is the origin of all sorts of excesses in the field of desires, thoughts, and behaviour (p.63).»

In summing up Pavlov's two lectures on fundamental ideas concerning the bases of human behaviour (from the point of view of their meaning in terms of economic theory), I come to following conclusions: 
- Free action and development of ones natural instincts is the basis of a normal existence and development of a person (and this also applies to the development of an economy);

- Unlimited freedom of ones instincts leads to chaos and a breakdown of social order and economic equilibrium, and as a result to a breakdown in development;

- Economic development under balanced conditions requires a harmonious combination of freedom in the functioning of ones instincts and discipline, inhibiting their negative manifestation.

These lectures are also important from the point of view that they refute the view, affirmed in the Western literature, according to which Pavlov is considered almost as the founder of behaviourism and the predecessor to Skinner, who denies the independence of the human psyche. The inborn instincts, the instincts of life, purpose, freedom, the social mechanisms of their action, stimulation, and inhibition, already considered in these two lectures of Pavlov, show that he clearly understood the genetic bases of the higher nervous activity.

In Pavlov's lectures the question about the typology of the psyche is not raised directly, but they contain the criteria for working out such a typology. These criteria are the following: vitality, purposefulness, love of freedom, sociability, the presence of a will, and a focus on social interests and order. On such a scale one can draw the characteristics of the psyche of separate individuals, social groups, and nations. 


\section{Chapter 2}

\section{The Role of the Psyche in the Economic System: N.D. Kondratiev, T. Veblen, V. Pareto, V. Sombart, A. Marshall, and J. M. Keynes}

In this chapter I do not analyse the historical development of the views of economists on the role of the psyche in economic processes; the order of the text below is dictated by logical, not chronological, principles.

In my opinion, Kondratiev has given the widest and deepest «synthesising» methodological statement, regarding psychic processes in the social system in general and in the economy in particular (to the extent possible for a political prisoner confined to a prison cell by Stalin's regime). Therefore, his work ${ }^{29}$ is considered as the first on this topic, although it was written from the end of 1930 to the beginning of 1932, and published only 60 years later (in 1991).

He is followed by Veblen, Pareto, and Sombart, who in their works at the end of the $19^{\text {th }}$ century and the beginning of the $20^{\text {th }}$ century paid particular attention to the psychic bases of class structure and the predominant system in society, based on market-capitalistic principles and, in this respect, analysed inherently-social types of psyche.

Further, the points of view of Marshall, as the founder of the neoclassical tradition, who (in the 1890s) formulated his position concerning the psychic bases of the functioning of the marketcapitalistic system, and his main antagonist, Keynes, who developed an alternative position (in the 1930s), are considered.

The stand-off of the psychic bases of the market-capitalistic economy on the Veblen-Marshall axis, which was very acute at the end of the $19^{\text {th }}$ and beginning of the $20^{\text {th }}$ centuries, began to fade into

29 N.D. Kondratiev, "Fundamental Problems of Economic Statics and Dynamics: A Preliminary Sketch." Moscow, "Nauka", 1991. In this chapter all of Kondratiev's references are from this publication; the pages are specified (in brackets) in the text. 
the background in the 1930s, whereas the stand-off on the MarshallKeynes axis became more acute and appeared in new guises at the end of the $20^{\text {th }}$ and beginning of the $21^{\text {st }}$ centuries. ${ }^{30}$ The latter can be seen in the works of the Nobel Laureates in economics, who are considered in chapter three.

At the same time, Kondratiev's general systematic approach has maintained its methodological value in the modern stage of research in the psychic aspects of economic processes.

\subsection{N.D. Kondratiev: the Psyche as a Reflection and Regulator of the Satisfaction of Requirements}

In this section, I consider Kondratiev's views on the human psyche as one of the bases of economic activities. In order to allow the reader to become acquainted with these views at first-hand, I have used detailed quotes, limiting myself to the statement of questions and brief comments.

Kondratiev's opinions were guided by the state of psychology in the first quarter of the $20^{\text {th }}$ century (in particular, by Pavlov's works in the field of the physiology of higher nervous activity and Bekhterev's works on social psychology). These opinions were basically confirmed by subsequent developments in this field, including developments in the last few years. However, subsequent events have not only confirmed, but also significantly added to and developed Kondratiev's ideas. I have also added a brief comment below.

A. Is it possible for the inborn psyche to exist without a social component? First of all, Kondratiev raises the question on the similarities and distinctions of the psyche of «natural» and «social» persons. «Clearly, the human psyche, considered as a product of its natural-organic evolution, is barely differentiated and syncretic; however, nevertheless, in embryo form it reveals the roots of all basic psychic abilities, characteristic of an already social person (p. 35).»

30 The question of the stand-off on the problems of the psyche between the classical and neoclassical schools, on the one hand, and historical and newhistorical schools, on the other hand, is briefly considered in the chapter devoted to the national psyche. 
The question concerning the border between a «natural» and a «public» person is extremely complicated. According to modern genetics, anthropology, and archaeology, the human being separated from the higher primates 5-6 million years ago. Already, at that time, the initial form of «human society» had appeared. One needs to bear in mind that the higher primates had existed before (and continue to exist in nature today) in groups, organised hierarchically on bloodrelated principles. Throughout most of history (for 5-6 million years, excluding the last 20-30 thousand years), the human being has lived in a tribal system.

Hence, the animal ancestors of the human being and human beings themselves were exposed to a very strict natural selection process, in which one of the main requirements was the development of the internal requirement and ability of individuals to survive not alone, but within an autonomous joint group. Those individuals, whose genetic code lacked the need and ability for group «cooperation», simply did not survive. We have come to a preliminary conclusion that the psyche of a «natural person» is an initial, primitive model of the psyche of a «social person». Natural selection complicated and developed the human psyche as a set of inborn properties, a considerable part of which can be revealed only through upbringing in society. At the same time, it seems that for millions of years the inborn human psyche has evolved qualitatively and structurally (which is not possible to achieve genetically within a period of a few thousand years).

On the evolution of the psyche, Kondratiev wrote: «According to Aristotle, a human being is a social animal and lives in society. Furthermore, whereas a human being is the initial atom of society and without his psychophysical properties it would not be possible to understand social life, on the other hand, the psychic structure of a human being varies under the influence of the conditions of social life (p.38).» He continued: «A natural person or, a person from birth, as the history of society has shown, represents an being with huge potential for psychophysical development and improvement, very much like a blank slate on which the right conditions can reveal a product of complex contents, having transformed it into a device of very subtle and diverse activities... Social conditions, undoubtedly, also exert, within certain limits, an influence on the biological properties of a person (p. 39).» I can add that the question on these 
«certain limits» is the main unresolved issue in social science and the main «unknown» factor in the equation.

Over the course of millions of years, environmental changes - due to the geographical movements of people, ice ages, and natural catastrophes - have played a crucial role in the changes of the «psychophysical structure of a person», as well as in changes in «society» as a whole. In addition, the possible merging of different branches of Homo sapiens also played a significant role.

With the regular preparation and application of implements of production in a triangle of mutually cooperative and commonly evolving factors (the psyche, nature, and society), there appeared a fourth factor, technogeny. This generated a number of cardinal changes.

Firstly, the direct dependence of the psyche on the environment began to weaken, as humans gradually learnt to deal with obstacle that occurred and to use their strength effectively.

Secondly, the human psyche had to adapt to the varying techniques and technologies of production.

Clearly, the process of natural selection also had to accelerate, but in rapidly changing conditions, it could not do so through the evolution of the structures of genes. The evolution of the psyche has proceeded on the path of the development of such biochemical «derivatives» surrounding the genes, which increased the flexibility and adaptability of the inherited psyche to the changing social and technological conditions.

At the same time, at a relatively late stage of the development of production, the natural environment began to degrade quickly, having again turned into an active factor, influencing the formation of the psyche, however, this time, in a different sense.

B. Needs, aims, and stimuli: does consciousness control behaviour? Kondratiev establishes a link between needs and the psyche and reveals two essential differences in requirements in humans from those of «other animals»: (1) Whereas, in the latter, needs arise only in their organisms, in humans, needs arise also in the nervous system; (2) All major requirements of humans are conscious needs.

«We will designate the state of a broken correlation of the balance between separate parts of an organism (or their functions) or between an organism and its environment, and the condition emerging from it 
in search for ways of restoring this balance, as the general meaning of need (p. 36).» He continues: «For a human being «requirements occur not only as a result of the breakdown in the balance between his organs or his functions, but also in his psychic nervous system. They occur, not only as a result of the infringement of the balance between his organism and the environment, but also as a result of the impact of this environment on his psyche. Therefore, the range of his requirements is wider than that of other organisms. This is the fundamental difference between a human being and other organisms. Moreover, regardless of the grounds on which a human being's separate requirements arose, the majority of them (or at least all significant requirements), due to the internal unity of an organism are reflected in his psyche, are accompanied by an infringement of its balance and are, therefore, conscious requirements (p. 37).»

Here, the most difficult and debatable of Kondratiev's questions concerns the fact whether the presence of a need is always connected with an infringement of the psyche's balance, and whether the satisfaction of a need is always linked with the restoration of this balance.

If the requirements are not an expression of the physiological functions of an organism, but the inborn properties of the psyche, then the presence of such requirements should be considered as the permanent, normal state of an individual. For example, the need for personal contact, creativity, justice, etc., are inborn properties of the psyche and their presence is not an indication of psychic disbalance. Certainly, the external suppression of these requirements can cause psychic stress, whereas stimulation can lead to their additional development.

Kondratiev sees the role of consciousness in the fulfilment of needs, primarily in the formation of the purpose of activity. The part of an act of behaviour that is carried out automatically, without passing through consciousness, is «habitual behaviour». As far as conscious acts are concerned, Kondratiev divides them into «teleologic» (goal-seeking) and «consecutive» («alogical»). Goalseeking acts are further divided into (a) utilitarian (pursuing benefit); (b) hedonistic (pleasure-seeking); and (c) objective (where the purpose is to achieve scientific, technical, artistic, etc., goals).

«Consecutive» acts are divided into the following: (1) Imitative; (2) Not goal-oriented, but based on principles; and (3) «core» acts 
(enacted on the basis of powerful primitive emotions, such as fear, hunger, jealousy, etc., contrary to purposes and principles).

It is not difficult to see that needs, either physiological or psychic, stand behind each of the acts of behaviour classified by Kondratiev. The difference is that in some cases the act of behaviour is aimed directly at satisfying specific requirements and, in other cases, they appear as the end purpose, which is attained by passing through an intermediate purpose.

«Requirements may or may not be acknowledged ... In this respect, all acts of behaviour can be divided into conscious and unconscious acts. The group of unconscious acts are related to an uncountable number of acts of behaviour but, essentially, as a rule, they are ordinary acts that do not significantly affect the daily flow of a person's life. Moreover, they include both various reflex actions and actions, which were once conscious, but then, through force of habit, became unconscious. Equally, actions, which were unconscious, due to a complication of the course of their usual habitual conditions, can reach the consciousness and become conscious actions (p.41).»

In conscious acts, «the character of the control of consciousness in the occurrence and influence of requirements, and accordingly, motives of behaviour is far from uniform. Sometimes, the satisfaction of these or other requirements is represented as a clearly acknowledged specific task. In this case, the act of behaviour is enacted according to the «in order to» scheme and motivation has a teleologic character. Furthermore, by their very nature, the goals, which are set here, can be utilitarian, for example, obtaining the maximum economic benefit; or hedonistic, for example, the obtaining of pleasure; or purely objective, for example, fulfilling a scientific, technical, artistic, etc., aim. The nature of the aim set can be complex in character; i.e., can include a sequence of utilitarian and hedonistic considerations, or hedonistic and objective reasons, etc.

However, no less often, and, strictly speaking, perhaps more often, the satisfaction of a need is not acknowledged as a specific, clearly set aim. In this case, the act of behaviour is enacted not under the «in order to» scheme, but under the «because» scheme. Such a motivation scheme can be called - as opposed to teleological - consecutive or even alogical. The latter, in turn, is not homogeneous and can be broken down into subgroups. Firstly, acts of behaviour on the basis of various requirements can be enacted in such a way, rather than 
differently, as a result of imitation or social pressure. Thus, quite often people buy a fashionable dress, have a particular type of hairstyle, and even join certain political, religious, and aesthetic trends, not as the result of clearly realised purposes or convictions, but because others act in this way, and it is fashionable, modern, it corresponds to the spirit of the age, etc. These subgroups of consecutive motivations are extremely widespread and can be especially clearly observed when crowds gather and at times of epidemics, revolutions, wars, etc. One can call this subjective motivation. Secondly, conscious acts of behaviour are quite often enacted irrespective of their benefits, pleasure, and objective effect, and are motivated only by duty, honour, sense of justice, etc. This subgroup of consecutive motivation is called principled motivation.

Thirdly, in many cases, conscious acts of behaviour take place not on teleological grounds or reasons of principles (and frequently despite such considerations), but on account of imperative and insuperable circumstances and motives. These are acts that are performed, contrary to goal-seeking and principled motives, on account of fear, hunger, envy, jealousy, weariness, laziness, etc. Evidently, in this case, the acts are (in the end) based on the most powerful emotions experienced by a person. This subgroup of consecutive motivation can be called the core subgroup (pp. 42-43).»

How can one interpret Kondratiev's statement about «controlling the consciousness in the occurrence and impact of needs and accordingly of motives of behaviour»?

From the text, it follows that consciousness is not in a position to control not only the unconscious, habitual acts of behaviour, but also the «consecutive» acts; it can only record the latter group, but cannot interfere with such acts. This means that only «teleological» acts remain. However, then, on which basis should consciousness control these acts? Should it be from the achievement of a certain psychic balance between «benefit», «pleasure», and «objective results»? (The latter can mean, for example, the aim to maximise life expectancy.)

However, is consciousness capable of defining whether such a balance has been reached? If so, how can one co-ordinate this with the part of consecutive behaviour, which is backed by requirements for imitation, following principles, and for the satisfaction of the most powerful primitive feelings? 
Kondratiev does not answer these questions; however, this text as a whole implies that Kondratiev assigned a very limited role to conscious control over human behaviour. Moreover, in this, he anticipated long ago the views of some modern Nobel Laureates in economics (who are considered by us in the following chapter).

C. Psychic communication and the collective psyche. When studying Kondratiev's work, one needs to constantly bear in mind the scientific epoch and specific conditions in which it was written. While the epoch imposed restrictions on the knowledge of the internal structure of the human psyche, the specific conditions of a prison cell and the vigilant supervision over him as a political prisoner did not allow him to write about social types of psyche and the relations amongst them. Therefore, it seems that Kondratiev was limited to «horizontal» communication on the basis of labour processes (and narrower still, on the basis of physical work), and universal aspects of the social psyche.

Nonetheless, even those ideas, which Kondratiev was able to develop in a prison's torture chamber, are courageous, deep, fruitful, and necessary for the explanation of the relationship between the psyche and the economy.

In the beginning, Kondratiev raises the question on the sources of the common features of the psyche of people. On the one hand, this generality is created by labour processes (joint work in factories, and the division and cooperation of labour in society); and, on the other hand, common psychic features have biopsychic foundations in the human organism and its nervous system.

«However, communication and interaction in collaboration are not only material in character. The very fact of collaboration creates a new environment and new conditions, which affect the psyche of each participant. The process of collaboration itself affects it, as well as the movements, gestures, words, and expressions of associates. All these can also be considered as material factors ... However, here, this second chain (of material communication - 0.) acts ... as a catalyst of specific psychic anxieties in each person involved in the cooperation... Psychic communication and interaction are also established amongst the participants. The facts indicate that this communication psychically draws those that are co-operating closer together. To some extent, their individual traits are smoothed out into an actual psychic condition; common features appear, transforming them as though they 
were a part of some comprehensive whole; and a general rhythm in their work is created, which subordinates them (p. 48).»»

«Direct connections in cooperation are necessary and at the same time contain material, psychic, and ideal aspects (p. 49).»

«Furthermore, in case of long-distance cooperation, we deal with the same three inseparable sides as part of the communication: material, psychic, and ideal. However, one can say, without exaggeration, that a considerable part of the physical work in society (and this sphere is extremely large) depends on cooperation amongst people either located in one place or geographically divided. Hence, all of society is penetrated by these communications as if by thick ropes (p. 51).»

The collective psyche emerges from the basis of a general psyche, i.e., in many respects the same type and interconnected psyche of a great number of people, who react in the same way to «external» disturbances.

«However, the interaction process has not only an ideal, but also a psychological, aspect. Therefore, if we paid attention not to the process and mechanism of the establishment of the communication, and instead took a stream of communications and interactions and produced cross-sectional and longitudinal times along its section, then we would have discovered that together with an ideological row there is also a collective psychological row. This is related to joint notions, feelings, emotions, strong-willed aspirations, etc.

In the conditions of social life it is impossible to challenge the reality of such collective psychic experiences. They become more visible during epochs of heightened nationalism or, on the contrary, during epochs of national declines, in religious festivals, in strong theatrical performances, amongst gatherings of various types of crowds and, in general, anywhere where the influence of mass hypnosis and the herd reaction is found. However, in less striking forms, they are also found in ordinary life as inspiration, infection, and imitation continually find expression in it also.

Basically, the unity of the biopsychic organisation of a person primarily serves as the basis for such collective psychic experiences and, hence, its ability to uniformly react to the relevant irritants... The biopsychical organisation of a person is under the strongest influence of the conditions of social life. Hence, the propensity towards collective experiences takes root of the biophysical organisation of a 
person according to the conditions of collective life. On the other hand, the same social environment in the course of people's interactions places them in the medium of general and strongly operating irritants... In these conditions, reactions also acquire a collective character, initially in the form of experiences, feelings, and emotions, and then in the form of actions under the influence of inspiration and contagiousness from the surrounding social environment (pp. 59-61).»

Further, Kondratiev makes a generalisation, which is extremely important for understanding the origins of the uncertainty and unpredictability of shifts in the social psyche. "While ideas give both an exact and objective confirmation and expression, the same cannot be stated about collective psychic experiences... In studying collective psychic experiences it is simply not possible to differentiate them from individual experiences in any significant way... In the normal conditions of everyday life of a society... collective psychic experiences, although they undoubtedly take place, are imperceptible. They cannot be systematised, precisely described, or linked with other occurrences (p. 61).» The irrationality of individual behaviour is revealed in the unpredictability of the movement of the collective psyche and collective behaviour.

From Kondratiev's analysis it follows that the collective psyche has both a biopsychic and a social-psychic side, is irrational, and reveals itself sharply in extreme situations and weakly, in everyday life. Kondratiev points out the almost insurmountable difficulties connected with studying the collective psyche and the impossibility (under the then existing level of science) of separating it from the individual psyche. Meanwhile, the question of the similarity and distinction between the individual and collective psyche and the border between them is fundamental to the understanding of all social, including economic, processes and institutions (which is discussed in greater detail chapter four). As will be explained later, both the biopsyche and the social sides of an individual's psyche simultaneously contain both individualistic and collectivistic components.

D. The place of the psyche in the structure of society and the economy. In order to define the place and role of psychic factors in society and the economy, Kondratiev constructed a special research matrix (see Table 2.1 below). This matrix contains seven horizontal rows, constituting a society: actional, relational, material, collective- 
psychic, ideological, organisational, and personal. Vertically, the columns represent social categories (including economic categories).

«According to its structure, any society is made up of specific constituents of rows, which are inseparably intertwined: action oriented, relational, material, collective-psychic, ideological, organisational, and personal. ... For the definition of any category of social phenomena, allocated vertically, one can use the features of any of the horizontal rows, constituting society, or a combination of several horizontal rows. We could also arrive at the definition of the economy and economic phenomena in the same way. However, ... the features of one or another horizontal row are not always equally suitable for the definition of vertical categories of social phenomena. It depends on the relative weight, imparted to a particular horizontal row in the given category of social phenomena.

From this point of view, for the category of social phenomena, which according to the research that has been collected, relates to the economic sector, two horizontal rows in the structure of society (are important): the material row and the actional row or the row of mass acts of behaviour in the activity of people. Scientific researchers searched for signs that are characteristic for the economy, mainly within the properties of these two rows, and particularly in the actional row (pp. 88-89).»

\section{Kondratiev's Society Matrix}

\begin{tabular}{|c|l|l|l|l|l|l|}
\hline $\begin{array}{l}\text { Rows } \\
\text { Constituting } \\
\text { society }\end{array}$ & $\begin{array}{l}\text { Categorie } \\
\text { s of social } \\
\text { phenomen } \\
a\end{array}$ & & & & & \\
\hline & $\begin{array}{l}\text { Economic } \\
\text { phenomen } \\
a\end{array}$ & $\begin{array}{l}\text { Knowledg } \\
\text { anight }\end{array}$ & $\begin{array}{l}\text { Religio } \\
\text { s }\end{array}$ & $\begin{array}{l}\text { Politic } \\
\text { s }\end{array}$ & $\begin{array}{l}\text { Famil } \\
y\end{array}$ \\
\hline Actional & & & & & & \\
\hline Relational & & & & & & \\
\hline
\end{tabular}




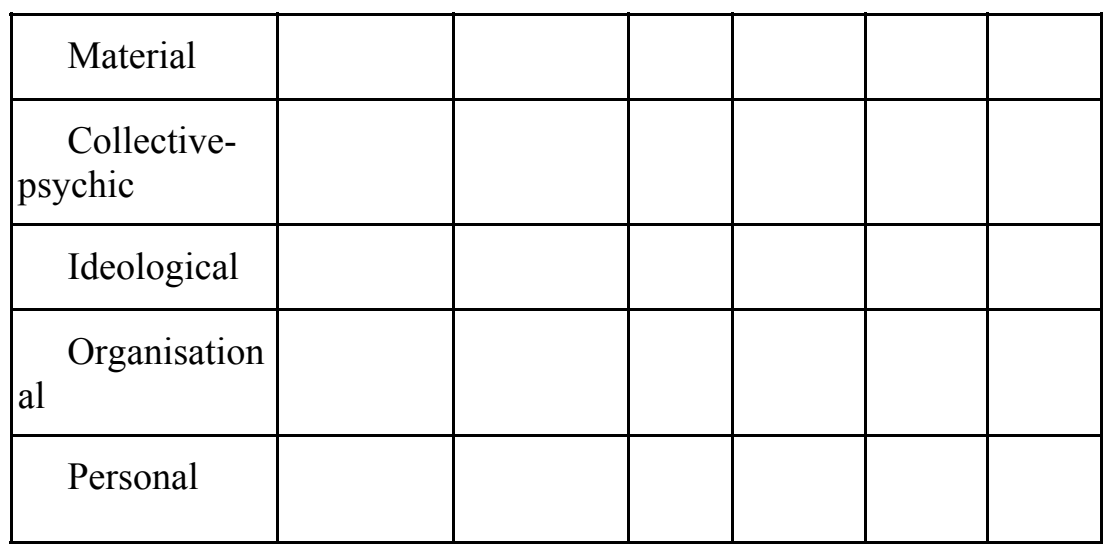

Table 2.1

Source: Kondratiev, «Main Problems of Economic Statics and Dynamics», Moscow, «Nauka», 1991, pp. 31-71, 88-117.

«Society, considered in this way, as a real set of people, whose system of mutual relations is based on their actions, which are aimed at providing the means of satisfying their needs, is the economy, or the economic basis of society. It is already clear from this that the concept of an economy, or the economic system of society, is a certain logical abstraction. In fact, such a set of people, who rely only on activities aimed at the provision of the material means for satisfying their requirements, without the process of the satisfaction of such requirements, does not, and cannot, exist (p. 110).»

«Essentially, the scheme for the construction of a national economy is the same, as for all mankind (p. 112).»

Kondratiev's matrix raises two questions: why is only the collective-psychic phenomenon given in the horizontal row of psychic phenomena? Why are only two horizontal rows, the material and actional row, important for the vertical category of «economic phenomena»?

It seems that the answer to the first question concerns the fact that Kondratiev considered the collective-psychic phenomena as a qualitatively special type of psychic phenomena, possessing relatively «independent» lives and that are of importance in the spheres of politics, religion, and culture. The answer to the second question is contained in Kondratiev's subsequent explanations of the «matrix», from which the following can be seen: 
1. Individually - the psychic factor is included in other «horizontal» rows, primarily, in the «actional» and «personal» rows.

2. The «actional row» (including the individual psyche) is considered by Kondratiev to be closely connected with the «relational row»; and these two rows are merely «different sides» of the economy.

As far as the collective-psychic phenomena are concerned, from the text one cannot conclude that Kondratiev considered them as an important independent factor, «constituting» the economic system. (However, it should be remembered that this factor also plays a part in the formation of an economy, as, according to Kondratiev, both in the economy and in other spheres of life, the same seven types of phenomena are involved, albeit, in different proportions.)

«Statistics... separates the category of the gainfully employed population or personal row of the economy... (in which the participants - O.) are always given a biopsychic structure, which has developed in them at the given time, as a result of their previous organic and social development (p.114).»

«Acts of economic activity are related mainly to conscious activity. By their very existence, as they are not the process for the satisfaction of requirements, but only acts that provide the means of their satisfaction, these acts demand the intervention of the consciousness to differentiate, control, and direct them (p.115).»

«Further, if we saw that conscious acts can proceed under various motivational schemes, then, for economic activities the scheme of teleologic motivation in the utilitarian or target-oriented form is especially characteristic, while in the hedonistic form it is rarer ( $\mathrm{p}$. 115).»

«It is perfectly clear that during each given moment in a society, there exists a system of acts of behaviour and, corresponding to it, a system of social and economic relationships. Consequently, if one can say that on the basis of acts of economic behaviour, there is a system 
of social and economic relationships, then, conversely, one can also say that the system of acts of economic behaviour represents an expression of the existing system of social and economic relationships amongst people. Both rows are only different sides of social-economic life... (p. 117).»

$$
* * *
$$

Thus, in the given work (which is subtitled, "A Preliminary Sketch»), Kondratiev has briefly considered fundamental problems, such as the relationship between the bio-psyche and sociology in the psyche of an individual and in the collective psyche and the place of the psyche in the matrix of social phenomena in general and in economic phenomena, in particular. At the same time, not all the questions raised by Kondratiev in the given paragraph are considered by us (for example, on the relationship between the psyche and ideology; on the two types of economies - centralised and decentralised; and on the specificity of the categories, characterising each of them; and on the relationship of a person to future requirements, etc.). We will return to these statements of Kondratiev in subsequent chapters.

Here, I assume that if it had been possible for Kondratiev to work further on «A Preliminary Sketch», he would probably have specified the contents of the categories of individual and collective psyche with reference to the psyche of social groups (based on professional, sexual, age, and other principles), classes, and nations, and similarly with reference to types of individual psyche.

Without such a specification it is difficult to imagine how the other «horizontal» rows of social phenomena and society, as a whole, function.

\subsection{T. Veblen: The Psychic Bases of Capitalism}

Thorstein Veblen (1857-1929) was the first established economist, who made a serious attempt to unite the natural and scientific concepts of human nature with the influence of a historically changing life environment on human behaviour, and on this basis, to explain the structure, contradictions, and tendencies of the system of institutions 
of society. «Being guided by modern biological science and psychology, we should reform the concept of human nature in terms of habits... these habits, which are a way of life, are too comprehensive in character to be attributed to any late or short-term influence (p. 225).» ${ }^{31}$ Elsewhere in this book, Veblen remarks: «In resolving the question regarding which set of habits that dominate the way of life of an individual, the inherited propensities and properties of character have the same value as the duration of a habit. The prevailing type of inherited propensities, or, in other words, the type of temperament inherent in the dominating layer of any ethnic community, appreciably predetermines the scale and character of its fundamental activities (pp. 138-139).»

In order to understand the strengths of Veblen's concept (allowing it to remain highly relevant over a period of more than a hundred years, despite the constant statements saying that it was «obsolete») and the weaknesses, which have prevented this concept from becoming the main «program» for the development of economic science, one needs to understand Veblen's logical structure.

A. The history of the rise and decline of the "predatory» class. According to its logic, human nature is characterised since ancient times by two deep instincts, namely, an instinct for competition (contests) and an instinct for mastery (useful diligence). In the primitive stage, initially, peaceful living conditions and competition within the community prevailed, promoting the domination of the instinct for skills and the development of work, which was carried out near their lodgings, where women, old people, and children lived. The perfection of tools and hunting techniques led to four interconnected shifts: the transformation of hunting large animals as the main source of food, the domination of men over women, inter-tribal wars, and the intensification of the competition amongst men for superiority within tribes.

With the development of these shifts, there was a transition from the higher stage of savagery to the early stage of barbarism, in which the instinct for competition started to dominate, acquiring an «envious» and «predatory» character. In conditions of continuous

31 T. Veblen, Theory of the idle class, published by "Progress", Moscow, 1984. Hereinafter, after the quotations, the relevant pages of the given edition are specified in brackets. 
inter-tribal wars, the dominant position in tribes was occupied by the strongest and most cunning men, who aspired to confirm their position by capturing slaves (primarily, women) and property belonging to others (cattle, weapons, clothes, etc.), and through the accumulation of private property. From then on, the instinct of workmanship faded into the background and occupied a subordinate position, as useful work was no longer respected as it had been, whereas war, the capture of slaves, property, management, and hunting became worthy and «valorous» occupations. Accordingly, predatory competition became dominant and the predatory instinct started developing in the behaviour of people. The ruling class stepped aside from doing useful work and in this sense became a «leisure class», and aspired to underline and flaunt its «idleness» in every possible way. During the long period of the early stage of barbarism, psychology throughout society changed, as the predatory psychology of the ruling class and its «envious competitiveness» was imposed as the model for imitation on the working classes, whose instincts for skill appeared in a dejected state. He wrote that the predatory instinct, followed by the approval of predatory abilities, had deeply taken root in the mentality of those people, who have been schooled in the predatory culture over a long period of time (pp. 78-79).

In the second, «weakened» stage of barbarism, wars become rarer and direct force as a means of domination and management was used less; however, the possession of property as a tool of domination and a source of income emerged in the forefront. In this stage, the predatory instinct and «envious competition» remained very much as the leading motives of behaviour, however, in a different form: the domination of the «predatory» class turned into a form of financial domination, competition became a form of struggle for the redistribution of property and the higher social classes continued to display their idleness and to consume ostentatiously and prodigally.

The middle and even lower classes of the population were drawn into this race of «demonstrative consumption», as - instead of useful consumer goods - goods and services, including items of luxury, fashion, and superficial novelty were considered «desirable» and prestigious in society. Moreover, the same views were held with respect to idle pastimes. In this, the richest layer of society was helped by the church and universities. 
The relationship to productive work as a «worthless» occupation came into sharp conflict with the interests of social progress, when mankind began the transition from barbarism to civilisation. Veblen considered the machine industry and mass production of goods as the defining factors of this transition.

In the industrial stage, the instinct of workmanship and its users, engineers and industrial workers, became the primary factors of development.

At the same time, the productive forces remained the private property of the «leisure class» and the «captains of industry», whose fundamental principles remained predatory competition in the redistribution of property and «flagrant consumption».

On the whole, each of the social classes of society, not only the top, but also the middle and lower classes, remained strongly conservative, contrary to the dynamism of industry. Veblen argued that the «leisure class» was so well provided for from the incomes of their property that it did not feel the need to increase the efficiency of the production of goods and for changes connected with this in the institutional structure of society.

As far as the middle and lower classes are concerned, they had become accustomed to follow the model of «demonstrative consumption», which was imposed on them by the «leisure class». The imitation of this wasteful model of behaviour had far-reaching social and economic consequences.

Veblen wrote that the propensity towards rivalry and envy is a deeply rooted feature, penetrating all of human nature. In his opinion, except for the instinct for self-preservation, the predisposition to rivalry was the strongest and most persistent economic motive. In an industrial society this predisposition to compete is expressed in monetary terms or in some form of demonstrative profligacy. According to his theory, the need for demonstrative profligacy, would always led to the absorption of any increase in the efficiency of production, as soon as the most elementary material requirements were satisfied (pp. 139-140).

For people belonging to the middle and lower classes, general «envious competition» with their neighbours in terms of ostentatious living demands maximum efforts in earning higher incomes, which are then prodigally spent. As a result, most of the energy of these classes is directed in a channel that is alien to any reforms, which must 
be aimed at the institutional reorganisation of society against the domination of the "leisure class», the suppression of the predatory instincts, and the establishment of the domination of the instinct of skill.

B. Psychic «blocks» of the mechanism of exploitation. Ernest Hemingway selected the following epigraph, from a conversation amongst two friends, to one of his stories: His friend (F Scott Fitzgerald): "Let me tell you about the very rich; they are very different from you and me.» (Hemingway) replies, «Yes, they have more money.» Both Hemingway and other writers have struggled with the question: the rich, who are they? How do they differ from other people? Is it really the case that wealth (like power) spoils people, or, are people themselves the reason of the property gap (as well as political oppression)?

From Marx's theory, it follows that great fortunes in the form of slaveholding economies, feudal estates, trading firms, and industrial enterprises were forms of ownership, corresponding to different stages of progress of the forces of production. Therefore, right up to the middle of the $19^{\text {th }}$ century, the wealthy were - despite numerous exceptions and whole epochs of regression - the force behind economic development. Certainly, for the majority of them, already since the $16^{\text {th }}$ century in Western Europe, monetary profit became the main principle in life; however, at the same time, many showed enormous diligence and ingenuity, or, creative energy. Marx proposed a «two-channel» concept of the rise of capitalism - through force and market stratification of the small-scale economies.

Joseph Shumpeter precisely divided the rich into two categories, innovative businessmen and capitalists, who are slaves to routine. Economic progress is achieved mainly due to the creative activity of innovators, which is the historical justification of the existence of private business as a system.

Maxim Gorky developed an understanding of wealth that was quite close to Shumpeter's interpretation. Gorky was primarily interested in the evolution of capitalist dynasties. In his research/novel «The Artamonov Business»,, Gorky expressed his concept of the degeneration of dynasties, whose founders were courageous creators, whose children were run-of-the-mill exploiters, and whose grandchildren were mere consumers of leisure. 
Unlike the points of views given above, Veblen categorically refutes the idea that great fortunes emerge as a result of or from the stimulus of the creative activity of their owners. He was one of the first to use the opposite argument in favour of the thesis that the concentration of wealth in private hands is the result of the predatory activities of persons with a certain type of psyche and in whom the predatory instinct dominates. (Pierre Prudon, the author of the wellknown thesis «Property is Theft» can be considered to be his predecessor.)

The object of the predatory activity of capitalists is the product created by people with the opposite type of psyche, whose behaviour is dominated by the instinct of skill. These people, whom society frowns upon, are the original creators of progress.

The discovery that the division of the human psyche into two fundamental types lies at the heart of the division of people into economic classes and all institutional structures of society is a great achievement, whose overall significance cannot be diminished by the disputability of many details of this concept, and by the modern development of psychogenomics, psychology, and sociology.

Thus, according to Veblen, the whole pyramid of social institutions at the stage of an industrial system is defined by the fact that it is controlled by a «leisure class» of powerful owners, whose behaviour is dictated by instincts for money-making and aggression, and is characterised by Veblen as «predatory».

This pyramid of institutions imposes a certain way of life on society, which forms specific psychic types of people.

A century of institutional selection led to the separation of two types of psyche, peaceful and aggressive, with the latter prevailing. Therefore, the modern person is at heart a barbarian, for whom the institution of private property defines the fundamental shape of his thoughts, and his purpose in life is to gain control over the surplus of material benefits produced by society. Veblen concludes that human beings, in the conditions of modern civilisation are essentially savages or possess such an unstable character that there is always the danger of an atavistic return to barbarism. ${ }^{32}$

Veblen dichotomises the types of people's psyche into those that are dominated by predatory instincts and those that are dominated by

${ }^{32}$ B. Seligman, p. 68. 
the instinct for skills; he distinguishes between the «leisure class» and the working class and, between «business men» and manufacturers. During an epoch dominated by the engineering industry, the domination of «predators», the «leisure class», and «businessmen» in society has turned into an anachronism and sooner or later will be subverted. When people possessing the instinct of skill (engineers) will become the ruling class, the psychic structure of society will also change: instincts and propensities for money-making, aggression, «prodigal consumption», and envy will cease to dominate.

In other words, technological progress should lead to a radical change of the institutional system, and this change should transform the structure of the psyche and society as a whole.

It turns out that the psyche of a society, which developed over tens and hundreds of thousands of years, is expected to change within several years or decades. However, science is not ruled by optimism (or pessimism).

C . Instincts or institutions? Veblen was aware that he had outlined only the most general contours of the system of institutions of society, that the real picture was much more complex and contradictory and that for its disclosure much more additional scientific data was required; however, this data was not available to scientists at the turn of the 19th and beginning of the 20th centuries and would not be available for a long time to come. I believe this explains why Veblen has asked, but left unanswered, the fundamental question, regarding the degree to which the psyche of a person and his instincts are defined genetically, and the extent to which they are formed by the «environment» and historically varying living conditions. According to Veblen, social institutions are not only the results of a process of selection and adaptation, forming the prevailing or dominating types of relations and psychic positions; at the same time, they are seen as special ways of the existence of a society, which form a special system of social relations and, hence, in turn act as effective factors of selection. Thus, a change in institutions leads in turn to the further selection of individuals with the most adaptable characters and to the adaptation of habits and temperaments of separate people to changes, owing to the formation of new institutions in the environment (p.200). Do institutions really select people according to their psychic type, or do people select institutions? This question can be set aside, if the purpose is to analyse the already 
developed structure of institutions and types of psyche. The link between both is obvious; however, the answer to the question regarding the extent that they influenced each other over the course of evolution requires special analysis.

However, this question will become central if the processes of institutional transformations accelerate and one has to predict future social development. In this case, the question concerning the mechanisms of temporary or steady changes and the shifts in the human psyche acquires fundamental value; and the forecast of the institutional structure of society depends on the answer to it. That the answer to the specified question has not been given in Veblen's research (and, it seems, it was not possible to provide an answer at the time), also served as a warning on the inaccuracy of its forecasts. According to Veblen, in the history of the development of any society, where the population represents a mixture of different ethnic elements, at any given moment of time, one or another of the several widespread and relatively stable types of constitutions and temperaments becomes predominant. Furthermore, the type of person, who has passed through such selection, in order to further develop and continue the institutions inherited from the past, in some fundamental way, will form these institutions according to his own model. However, apart from such a selection, which takes place among sufficiently steady character traits and mentality, this is accompanied, simultaneously, with the process of the selection and adaptation of a mentality within the general sphere of the propensities, characteristic for the dominating ethnic type or types (p. 201).

Seligman considers Veblen's and Freud's views on the relationship between the psyche and the institutions of a society to be very close to each other, as Veblen in his understanding of institutions included psychic substance. At the same time, according to Seligman, Veblen did not share Marx's view, who unequivocally considered institutions as a force defining the psyche and behaviour of people.

Actually, Veblen's views were somewhere between the positions held by Freud and Marx; he essentially refused to determine unequivocally the psyche as the reason and the institution as the consequence (or vice versa); at that time, such a position was the only scientific one. However, to predict social development on such a clearly immature scientific base was also not justified. 
According to Veblen, instincts have an ancient origin, but at the same time they continuously vary in connection with changes in social institutions. Some instincts can be apportioned to different social elements, as has been established in experimental psychology. Consequently, these instincts are not inherited, and possess the character of psychological reactions originating in social experience. However, in order to serve as analytical tools, institutions should be sufficiently stable. According to Seligman, Veblen's instincts are much closer to Freud's Trieb, than to the «firm program» of Mcdougall or the rigid behaviourism of Watson. Veblen's psychology of instincts comes from the physiological researches of tropisms, which were conducted by Jacques Leb.33 However, unlike the theory of tropisms, for Veblen, the instinct is not something spontaneous, but a task-oriented and active factor, which defines the known image of the action of an individual. An instinct is under the influence of the comprehension by an individual of a situation, in which the instinct functions, and possesses the ability to adapt to new conditions. As Seligman has noted, this undoubtedly contains an element of reason, which is especially appreciable in its most developed form, that is, as an instinct of skill («workmanship»). Industrial norms and rules of behaviour are formed on this biological basis. 34

Thus, we learn, firstly, that instincts form a biological basis of norms and rules of behaviour rules and that they have ancient origins and are sufficiently stable. Secondly, we learn that they are not inherited, and change together with changes in social institutions by adapting to them.

${ }^{33}$ Tropisms are growth movements of bodies of plants (a stalk, a root, leaves, etc.), caused by the directed action of any stimulus (light, chemical substances, etc.). Tropism is based on the non-uniform growth caused by the redistribution of phytohormones in a plant - the chemical compounds developed mainly in actively growing fabrics of a plant, which regulate its growth. With reference to the human psyche, "tropism" can mean the nonuniform and irreversible development of various properties of the psyche of an individual or group under the influence of external factors (environment). The forms acquired in the course of "tropisms" are not transferred genetically.

34 T. Veblen, "The Instinct of Workmanship", New York, 1914, p. 39 (B. Seligman, see "Main Currents of Modern Economic Thought", M., 1968, p. 66). 
What are these «instincts», which, forming the biological basis of institutions (customs, ways of thinking, and norms and rules of behaviour) are themselves based on institutions and change together with them?

I will not accuse Veblen of being logically inconsistent, and will instead try to fathom the meaning, which Veblen places on the concept of «instinct». In this way, it becomes clear that Veblen, without understanding it himself, is speaking about two essentially different kinds of instincts. Veblen calls the instincts of workmanship, parental bent, and idle curiosity as the main instincts. Besides, he also relates the following to instincts: the aspiration to self-affirmation, self-love, creativity, and pugnacity.

The «instinct of workmanship» is a complex of inclinations, inducing the processing of natural materials, production improvements, and the creation of useful conditions. Veblen included creative activity, the rational use of economic resources, and the aspiration to increase technological knowledge and to adapt the environment to human needs, in this instinct.

The «natural instinct» and «natural inclinations» that Veblen describes here are actually partly instincts that are instilled (diligence) and partly truly natural instincts (expediency, creativity, and inquisitiveness). However, their association is possible only in specific institutional conditions, including freedom of work, transfer of knowledge, a comparative estimation of efficiency, the link between production and consumption, etc. Historically, such conditions arise and subside periodically.

Veblen interprets the parental bent as looking after ones family, which leads to caring for social well-being and the well-being of mankind, i.e., as an altruistic instinct. As the family was formed quite late and was preceded by the kin, family and parental feelings can only be instilled. In this sphere of life, natural instincts are instincts for the continuation of ones generation and the maternal instinct (which is not the same as caring for a family and, even more so, for mankind). The «parental bent» as caring for a family can arise only in the case of a family taken together as a social institution. On the other hand, the instinct of belonging to a kin can easily develop as a natural instinct; a similar instinct in the higher primates is fully developed. The kin instinct can form the natural basis for the whole system of "social" instincts already at the primitive stage of mankind. 
According to Veblen, the combination of the instincts of workmanship and parental bent predetermines the aspiration for improving material well-being; in other words, they are the main force behind economic development.

This development is also promoted by an instinct for «idle curiosity», which is biologically connected with the instinct of play. Idle curiosity is the basis of all research, both purely scientific and pragmatic; it leads to discoveries and innovations.

Curiosity, as the aspiration to observe and «investigate» new subjects and phenomena in order to find out their useful and dangerous properties, is inherent in many animals. However, the use of knowledge, obtained in this way through labour-creative processes reflects the fact that the aspiration towards creativity is specific to human beings and is a natural, creative instinct, which is also evident in play. (In play a number of other natural instincts are also evident.)

Veblen considers that internal tension in the human psyche is caused by some instincts being resisted by others, which are opposite in nature. Thus, the parental bent (as well as the altruistic instinct) is opposed by the accumulating instinct. The instinct of workmanship is opposed by a «belief in supernatural and religious dogmas».

Above, I have noted Veblen's scientific strengths. The weakness of these concepts lies in the fact that they ensue from the inadequacy of Veblen's concepts about the structure of the human psyche and, in this sense, about the character of the interrelation between the biological bases of the psyche, on the one hand, and the content of economic institutions, on the other hand.

\subsection{Pareto: the Psychology of the "Elite" as a Source of Economic Progress and Stagnation}

A. Initial uncertainty. In economic and sociological literature, the behaviour of people can be divided into «rational» and «irrational» categories. «Rational» behaviour is logical and one can deduce laws for it. «Irrational» behaviour is illogical, and it is not possible to establish appropriate laws for it. Paradoxically, those economists and sociologists, who set «rational» against «irrational» behaviour, have 
also tried to arrange the «illogical» in some logical order and to find natural relations in it.

The most striking example can be found in the works of one of the most outstanding economists and sociologists at the end of the $19^{\text {th }}$ and beginning of the $20^{\text {th }}$ centuries, Vilfredo Pareto (1848-1923). In these works, a comprehensive attempt is undertaken to deduce the psychological structure of a human being from historical and literary material. In other words, from the description and the analysis of the behaviour of large masses of people and separate individuals, Pareto deduces that, which we can call the structure or system of laws of the human psyche. He makes this deduction in order to carry out the procedure in return: i.e, to deduce the structure and laws of the economy and all of society from the structure of the psyche. Moreover, Pareto carries out the first procedure, consisting of the deduction of elements of the psyche from social processes, as something self-evident, which does not require any special proof. However, he pays particular attention to the second procedure, which consists of deducing public structures and laws from the human psyche, and implements it carefully. Nevertheless, «here, it is the first step which is important».

Is it really possible to discover the foundations of the psyche of people by studying their behaviour? Behaviourism asserts that social studies should definitely follow this path, and to a considerable extent it is correct. However, the statement is correct only up to a point, as in the definition of behaviour, besides the named foundations, changing circumstances, compulsions, and rational decisions also play a role.

Therefore, we will accept the postulates of Pareto's theory not as axioms, but as initial (partially justified) hypotheses. One can distinguish three such postulates:

1. Human behaviour is defined mainly by the psyche (i.e. irrational factors).

2. The bases of the psyche (instincts) have a social (instead of a natural) nature.

3. The psyche of people differ deeply.

In the first two initial hypotheses, we see the «vicious circle», mentioned above: society defines the psyche, and the psyche defines 
society. It would seem that a «dead» relation between the psyche and society follows from here. However, this contradicts the hypothesis about the differentiation of the individual psyche. At the same time, this does not explain the origin of this differentiation. If, the origin is again from society, then the «eternal» contradictions, on which Pareto builds his theory of social development, are not clear, as in the long term all these contradictions should have disappeared, and complete conformity of society and the psyche of the individual would be established (according to Marx, Zamyatin, and Hayek).

Researchers of Pareto's work differ in their interpretation of his understanding of the psyche. Selingman wrote that he has established six basic groups of human instincts: a set of instincts or moods of productive character; instincts, expressing the steady character of human relations or between people and things; instincts of selfexpression, for example, religion; social instincts, such as selfsacrifice; instincts and moods, connected with the aspiration towards self-preservation; and sexual instincts. ${ }^{35}$

Note that Pareto related not only instincts to irrational and illogical (i.e. psychic) factors, but also the feelings, interests, and desires of individuals, social strata, and classes. As we will see later, the statement itself about the roles of instincts and their separation from the general psychic structure, both individual and «collective», has deep foundations, but a century ago it was at best merely an assumption, which was disputed by many.

Without discussing specific formulations, I note that the instincts and «moods» (i.e., feelings, interests, and desires) listed by Pareto cover the psyche of an individual (strata, class) are versatile and systematic, like an interconnected set, but qualitatively with different motivations for action. Already with this, Pareto rose significantly above other sociologists and economists, who only proposed the investigation of the problem of the behaviour of a «living person», however, did not further advance their truncated, two-dimensional models.

One should note that Pareto reached such a leading position only in sociology; as an economic theorist he was average. However, as we will see, from Pareto's sociological conceptions (which he developed only after his work in economic theory and which he valued higher),

35 B. Selingman, op. cit., p. 251. 
one can deduce significant conclusions on economic theory that call into question not only Marx's theory (against which they were directly targeted), but also his own economic theory.

B. "Masters" of society. Pareto asserted that the main object of his research was the problem of social balance. However, balance is derived from the structure and the functioning of the system, and this, according to Pareto, depends on the division of society into the dominating elite and non-elite. Therefore, in sociology, Pareto was essentially interested is the question regarding the nature and kinds of social power, as he considered the answer to this question predetermined the entire social and economic structure of society and the conditions of its balance.

According to Pareto, «people differ physically, morally, and intellectually», and these differences are not measured by their potential abilities, but by their actual achievements.

«For the moment, we will not touch on the good or bad, useful or harmful, and laudable or reprehensible characteristics of human nature; we will pay attention only to that level which they possess: low, mediocre, high... Thus, we assume that in each sphere of human activity, each individual is awarded an index corresponding to his abilities... a person who has managed to acquire millions (regardless of whether he achieved this fairly or dishonestly), 10; a person earning a thousand lire, 6; a person who barely avoids dying of hunger, 1; and a person sheltering with beggars, $0 . \gg{ }^{36}$

He continued: «Thus, we will construct a class of people, who have the highest indices in their field of activity, which we will name as the selected class or elite... It is useful to further divide this class into two parts; we will separate those, who directly or implicitly play a significant role in managing society and are part of the ruling elite, and the others, who are not part of the governing elite.»> ${ }^{37}$

Within the ruling elite, Pareto especially separates those, who for various reasons are only nominally present in it and do not possess the qualities required for it, and also those who, possessing such qualities, originate from the non-elite group and, therefore, «bring with

${ }^{36}$ V. Pareto. For general sociology, we recommend "Anthology of Global Political Thoughts". vol. II, Moscow, "Misl”, 1997, pp. 59-60.

${ }^{37}$ In the same place, p. 61. 
themselves, as a rule, certain inclinations, feelings, and predispositions»». ${ }^{38}$

Hence, people are divided into classes depending on the extent to which they have fulfilled their potential, measured in terms of their monetary income, irrespective of the way in which this income is received.

According to Pareto, the level to which they have fulfilled (in monetary terms) their potential is an expression of the level of their characters, i.e., the level of their psychic energy, irrespective of the ethical valuation of their psyche.

Thus, the main distinction between people is the «level of their characters»; the division between «elite» and «non-elite» is defined at this level.

However, how do they affect the division of the differences in the structure of characters?

Pareto called instincts, feelings, interests, and desires of individuals (and also social groups and classes) the «remainders», i.e., that stable psychological constant, which makes up the basis of behaviour. From the six classes of the remainders, Pareto separated the first two, as the ones playing the main role in social behaviour: he called the «remainders» of the first class the instinct of combinations and he called the «remainders» of the second class the constancy of aggregates. When the ruling elite is dominated by the «remainders» of the first class, society develops and changes dynamically. When the influence of the «remainders» of the second class increases in the ruling elite, conservatism and stagnation become prevalent. A normal position, providing social equilibrium, is considered to prevail when among the elite, the «remainders» of the first class are dominant, and among the non-elite, the «remainders» of the second class are dominant. However, eventually the ruling elite weakens and the relative influence of the "dead weight» increases; i.e., the elite contains a higher proportion of people, who do not possess the qualities necessary for government, and it is replenished with people from the «non-elite» class, possessing conservative ideological principles.

${ }^{38}$ In the same place, p. 63. 


\section{The «Circulation of the Elite»}

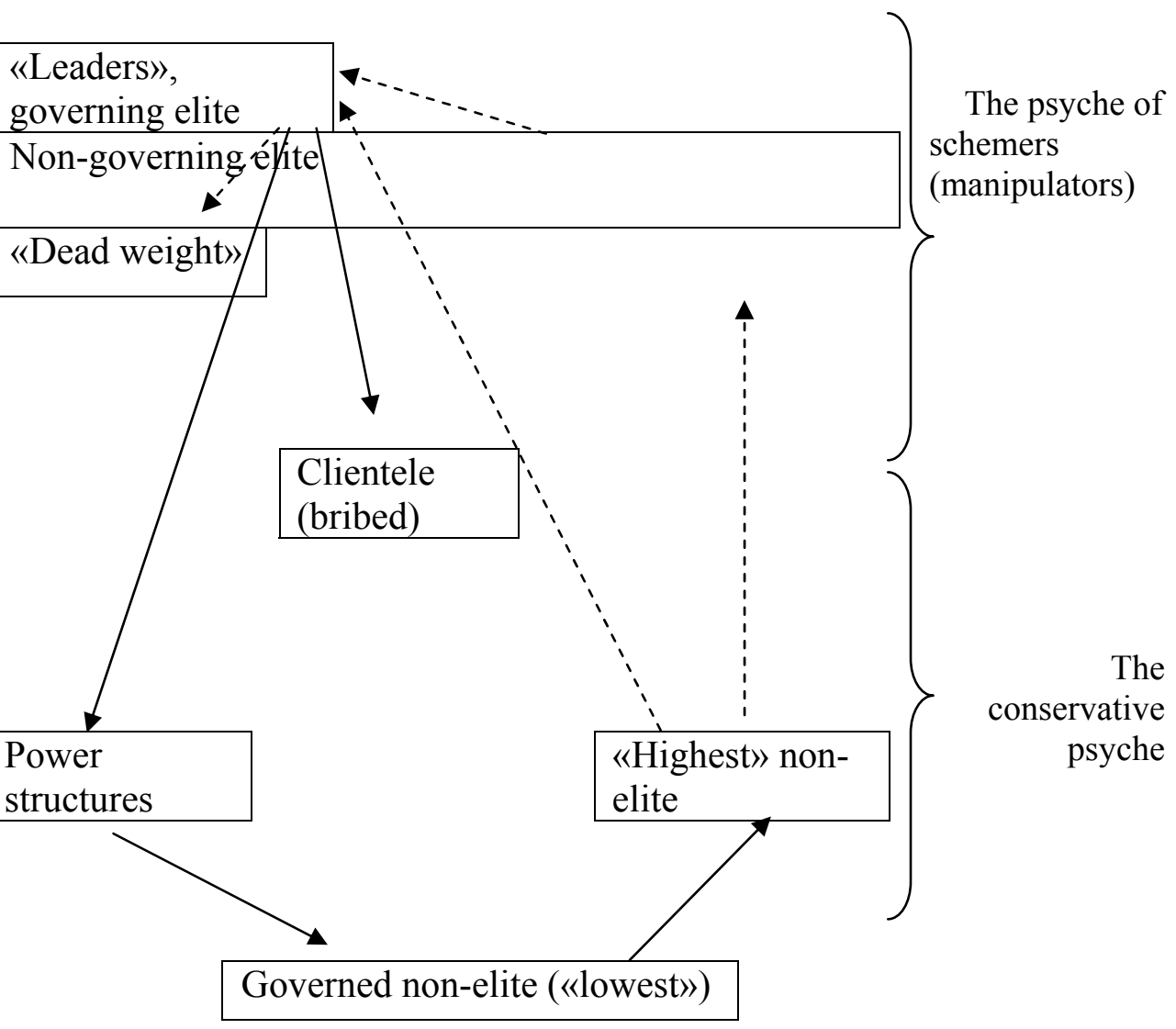

Figure 2.1: The continuous lines refer to actual influence and the dotted lines refer to the possible circulation of the members of the elite. 
Here, I have not set myself the task of logically stating Pareto's views on how the structure of the psyche defines social systems; I have set this task in reverse: in order to establish, how Pareto came to understand the structure of the psyche of people, based on his conceptions of social systems.

Thus, the first principle: The psyche of people is divided into «categories» according to the quality of their actual achievement (their «fulfilled potential»). However, actual achievements depend on the interactions of the following: (1) Specific natural abilities, one of which is the energy of an individual; (2) Various initial conditions; (3) Existing external circumstances; (4) The operating social system. In some people, their natural qualities are displayed in a fast path upwards, and in others, their best qualities are spent in facing up to hardships. As a result, one person «favoured» by nature becomes the president of a bank, while another person becomes a petty thief or small drug dealer.

This means that although the natural inequality of people in terms of their energy and abilities plays a significant role in the formation of classes in a society, nonetheless, it is considerably smaller than the role attributed to it by Pareto.

The second principle: The psyche of people differs in terms of their structure. Pareto distinguished two psychological types: individuals with a predominant instinct for novelty (a «combinational instinct») and those with a conservative frame of mind (a «constancy of aggregates»). The first type of psyche is characteristic for individuals in the «elite» class in general, and especially for those in the "governing elite», while for individuals in the governed «nonelite» class the second type is characteristic. Thus, we already have two features, characterising the psyche of individuals in the «elite» and «non-elite» classes. Individuals in the first group possess a highquality psyche with a combinational structure, whereas individuals in the second group possess a psyche of a lower quality with a conservative structure.

However, Pareto himself questioned such a division, as many historical examples showed when individuals with a conservative, but a «high-quality» psyche, having broken into the «ruling elite» class from the «governed» class, had prevailed there.

All that can be maintained from the second principle is the verification of the fact that different levels of psyche, in terms of 
quality, can be combined with different psychic structures, and active individuals, both with «combinational» and with conservative inclinations, can find ways of entering the ruling elite.

The third principle: This accounts for the factor of «beliefs» and the factor of interests. In the psyche, besides instincts, Pareto also includes beliefs, interests, and desires. Individuals with a «highquality» and «scheming (manipulative)» psyche (making up the majority in an effective ruling elite), as a rule, are free from submission to «beliefs», i.e., religious and ideological doctrines, traditions, and myths, and therefore are very aware of their interests. At the same time, conservative individuals (making up the governed class), as a rule, follow different types of beliefs, which «obscure» their real interests and prevent them from even recognising their real interests. The fact that the ruling elite clearly understands its interests, and the governed class is not aware of its own interests, creates the preconditions for the manipulation of the behaviour of the governed class through the support of any beliefs and prejudices.

The fourth principle: The psyche of representatives of the governing elite does not include generally accepted moral standards. Thus, the «elite» is not even aware when it breaches generally accepted moral norms. When its representatives are convicted of crimes, the elite only pretends that it too is «troubled», but actually, having hushed up yet another scandal, it continues its «routine» practice of violating universal morals.

The fifth principle: The interest of the «elite» consists of its own enrichment by any possible means. The «elite» enriches itself by robbing the «governed non-elite» (or other nations). However, this does not necessarily lead to the destitution of the population, as it suits the «elite» and it is in its interests that the population also participate in the enrichment process; therefore, the elite carries out a policy that allows this to take place.

In this way, we can compose the following list of properties of the psyche, required for an individual to enter into an effective «ruling elite», (a type of «Pareto’s psychological admission permit»):

- An individual should be highly effective in his activities, combining energy, an aspiration towards novelty, and «combinational instincts»; be free from religious and 
other «beliefs» and, at the same time, be capable of manipulating them to his advantage; be immoral; and recognise personal enrichment as his prime target. Thus, an aspiration towards personal enrichment is the main (often hidden) feature of the psyche of a rank-and-file member of the «ruling elite», regardless of whether he is a banker, a politician, a judge, or a general.

It is very revealing that Pareto does not include in this list properties of the psyche, such as love of power, vanity, careerism or «feelings» such as patriotism, populism, and nationalism. This is because as far as the «ruling elite» is concerned, it refers to a fairly large class of people, possessing real power and defining policy, and not the top of this class (the government, party leaders, etc.). Completely different demands are made of the leaders, representing the «official face» of the ruling elite. They can be power hungry or compliant; fair and highly moral; patriots, sharing many beliefs of the «managed non-elite», and even «democrats, socialists, or anarchists». The only demand made by the governing elite on their leaders is not to hinder them from further enrichment and implementing the corresponding policy. Pareto underlines that the ruling elite looks for leaders, who in terms of their psychological type, in many respects are the opposite to the real psychological type of the elite, and are similar only in one aspect: mutual tolerance. It is strange that internally, within the environment of the most «standard» elite (according to Pareto) the relationship towards such «opposite» types is very intolerant. In other words, Zeus (i.e., the leader) is allowed to act in ways that are forbidden to a bull (i.e., an ordinary member of the elite).

The professional structure of the ruling elite changes according to the functions that the ruling elite, in a specific country, needs to carry out at a specific stage. It usually consists of military officers, judges, high-ranking officials, «speculators» (i.e., prominent financiers and traders), and «plutocrats» (i.e., politicians, closely connected with «speculators»). According to Pareto, since the second half of the $19^{\text {th }}$ century, «speculators» began playing a leading role in the ruling elite of England, France, the United States, and Italy. 
C. Circulation of the elite and economic development. For Pareto, the process of the «circulation of the elite» plays a key role in understanding the course of history. Part of the «ruling elite» inevitably degenerates, eventually, i.e., loses the qualities necessary for management, and actually withdraws; therefore, the ruling elite should continuously replenish itself from the ranks of the «elite not in power» and also from the «new elite», which consists of the bestprepared people for this purpose from the «governed non-elite».

If the ruling elite «becomes enclosed in itself» and the circulation process slows down, it loses its ability to govern, and the «governed class» is weighed down by individuals, whose governing abilities have not been fulfilled. This creates the conditions for replacing the old elite by a new one through revolution.

However, such a revolution brings a whole group of completely different psychological types of people to power: capable of governing, but conservative, and attached to doctrines and strict morals. This type of revolution «cleanses» a society morally; however, it leads to economic stagnation, and in the fields of literature and art it even results in regression.

Thus, Pareto did not see a positive link between universal ethical standards (do not kill, do not steal, do not lie, honour your parents, etc.) on the one hand, and economic progress on the other hand (in a narrower sense: between the condition of social ethics and the effective functioning of the market mechanism). Like his ideological opponent Marx, Pareto considered the development of privateownership in the economy and a strengthening of morals to be incompatible. They differed in that Marx considered that capitalism destroyed social morals, and Pareto's view was that the negative morals of the governing class stimulated, and positive morals slowed down, economic development. In other words, for Marx the economic institutions of capitalism played an active role, whereas for Pareto the psyche of the governing elite played an active role.

However, the isolation of the ruling elite, which hinders «circulation», does not always lead to a revolutionary change of the elite. The elite operates through a combination of force and «consent». At the same time, the «speculative» elite uses consent, reached by bribing parties and voters, to a greater extent, whereas the conservative elite relies more on force. In any case, the isolation of the governing is inevitable, while their weakening leads to the real power 
falling into the hands of the «security forces»: the Praetorian Guard in ancient Rome, the Mamelukes in Egypt, and the Janissaries in Turkey. In this way, the ruling elite perishes, and together with it, the nation itself can disappear from the historical stage.

For Pareto the whole concept revolves on the thesis about the identity of the ability to govern and the ability to make a profit. Having recognised that it is not the same, Pareto created a flaw in his simplified logical design, for it opened a way of entering the governing layer, to those who are motivated by love of power, but not love of money. However, it is difficult for marginalist economists to imagine that individuals with a well-developed psyche could be motivated by something other than the thirst for money. His postulate, according to which almost the entire population («non-elite») is in the grip of non-monetary motives, is especially valuable. However, in that case, the other basis of Pareto's conception, namely, the thesis that the «level» of the psyche can be measured by money, also does not hold.

D. To what extent are Pareto's critics justified? Now, I will consider the objections that historians of economic thought have raised against Pareto. Seligman has collected these reproaches together in one place. Pareto was not able to investigate the internal substance of the instincts and feelings of people; he was not capable of undertaking the type of research conducted by Freud. In the same way, he was not aware of the concept of «understanding», which lay at the heart of German sociology. It is possible that Pareto would have rejected this concept for it assumed the recognition of a corresponding system of moral values. As a result, his instincts appeared «ambiguous». Sometimes they act as instincts, rooted in the biological nature of the human being, and in certain cases they differ little from forms of human activity. Their division into six categories is artificial, their selection illustrative, and the material used arbitrary. Pareto's assertion that his social theory is based on comparative analysis is not convincing, as Pareto never conducted a proper analysis of the nature of instincts as demanded by the genetic method.39

Seligman's book was published in 1963, less than two decades after the end of the Second World War and at the height of the «cold war». It is surprising that Pareto's critics could not (or did not wish) to understand the heart of his concept, which he developed during the

39

Ben Seligman, op. cit., p. 252. 
period leading up to and at the start of the First World War. Essentially, Pareto points out that the psyche of the governing class is of primary importance, rather than which class is in power. One can dwell endlessly on imperialism and communism; however, it will still not explain militarism, fascism, Stalinism, or the domestic and foreign policies of such regimes.

Each «charge» made against Pareto by his critics is correct, if considered in isolation. However, history has confirmed (and continues to confirm) the basic validity of his social-psychological approach to social processes.

The psyche of people («the remainders» in Pareto's terminology) defines their behaviour, whereas different types of explanations, substantiations and justifications of this behaviour are not the motives of their actions; at best, they aspire to comprehend behaviour. They are all «derivations» (derived) in relation to the «remainders». They can be embodied in the form of religious doctrines, myths, ideologies, and political and social concepts. (I would like to add - also in the form of economic concepts.)

Regarding the rational side of human activity, in my opinion, neither Pareto nor the researchers and critics of his works managed to distinctly explain, how it differs from these «derivations», (which, are only a reflection and continuation of the «irrational» side of activity). Seligman wrote that the rational side of people's actions reflects their aspiration to think and explain their instincts. Sometimes quite logically, but more often a non-scientific person connects one instinct with others, in order to somehow explain his actions. The rational motives of human actions were grouped (by Pareto - $\mathrm{O}$ ) into four forms: the simple statement; the reference to an authority; the elevation of moods into principles; and, verbal proofs, which are often based on emotions and ambiguities. ${ }^{40}$ It is unlikely that all these «four kinds» can be related to the «rational side of actions», and it is unlikely that Pareto himself thought so.

I believe that in Pareto's understanding the rational side of human actions is based on a different source - not on an «aspiration to think and explain instincts», but on the empirical experience of people. Towards the end of his life Pareto stated: «... human activity covers two basic areas - the area of human feelings and the area of empirical

${ }^{40}$ B. Seligman, p. 252. 
research. It is not possible to exaggerate the importance of the first area. Feelings trigger the impulses that lead to action, dictate morals, define every possible form of human enjoyment, and religion. Human society exists and develops, inspired by ideals. However, the second area, which provides working material for the first area, is important also. The second area of human activity enriches people's knowledge of the productive character of their actions and the advantages of their feelings, which themselves adapt fairly slowly to the environment.» ${ }^{41}$

Here, the «knowledge of the productive character of their actions and the advantages of feelings»» are, according to Pareto, rational knowledge and rational actions, and also the basis of the rational evaluation of feelings, helping people accelerate the adaptation of their feelings to the environment.

In other words, «feelings» make up the driving force and define the moral framework of activity, and the rational knowledge, obtained from empirical experience, allows people to estimate the efficiency of this activity. However, note that Pareto does not speak about the rational regulation of human activity. For scientists and rationalists, this is the most disturbing area in Pareto's position.

D. Veblen and Pareto. I will try to compare Veblen's and Pareto's views on the human psyche. I will start by pointing out the areas where their views supported each other and will then note the areas where their opinions differed. Thus, they both held that the psyche of an individual was a complicated and inconsistent system, and believed that (in different measures) all aspects of this system participated in any field of activity - economic, social, political, or ideological.

Their second common position concerned the recognition of deep distinctions in the psyche of separate individuals, and their aspiration to distinguish psychic types.

The third characteristic common to both their points of view lies in their aspiration to agree on the recognition of the biological roots of the psyche, on the one hand, and an institutional explanation of the psyche, on the other hand. The conditions prevalent in science at that time - the theories of evolution, genetics, psychology, sociology, the economy, etc. - did not allow this question to be raised; attempts to resolve this issue led both authors to tautologies, when institutions were treated as psychological concepts, and the latter as institutions.

${ }^{41}$ B. Seligman, op. cit., p. 252. 
Finally, the last and perhaps the most important common feature between the two authors consists of the fact that the system of the human psyche was researched by both Veblen and Pareto, from a specific point of view - revealing the link between this system and the class division in society.

Both researchers characterise the governing class (the «leisure class» in Veblen and the «elite» in Pareto) as a layer of individuals with specific psychic features, including, clearly criminal (but «highly effective») individuals.

Regarding the differences in their opinions on the psyche, they diverge mainly on the list and characteristics of the elements, forming the psyche - primarily, instincts.

Thus, while Veblen's list of instincts is headed by the «instinct of workmanship», Pareto has no such instinct; however, he uses the term «productivity instinct», with a different meaning. For Pareto, the energy and the will, which focuses this energy to achieve specific aims, is of primary importance in relation to the psyche; in this context, Pareto pays a great deal of attention to combining the qualities of the psyche and the level of intellectual development of individuals.

Veblen does not attach any significant meaning to these aspects of the psyche; however, he underlines the defining role, dominating the psyche of separate groups of people, of the predatory instinct, and contrasts the aggressive and peaceful psyche.

Pareto's historical concept is less optimistic than Veblen's. For Veblen, people with vigorous «combinational instincts» can remain in the ruling class and take advantage (for their personal benefit) of society as long as they want, on the condition that they correctly organise an uninterrupted horizontal and vertical «circulation of the elite».

In the case of a slowdown, or, even more so, of the termination, of such circulation, a cardinal replacement of the elite is inevitable; this leads to the arrival of a «new elite» in power, which is conservative (in terms of the economy) and composed of ideologised former members of the «lower layer», possessing completely different psychic structures and, in any case, different from those, whose psyche is dominated by «combinational instincts».

Pareto was the first among prominent neoclassical theoretician, who openly recognised the basic contradiction between this theory and 
economic practice, and tried to offer an explanation. He declared that the economy is part of social science, dealing with the logical, justified, rational, and natural actions of people.

However, besides rational actions, irrational and spontaneous actions also exist, dictated by the psyche and that cannot be explained logically. Social science studies both rational and irrational actions. In this way, economic theory is a science not about the actual, but only the rational, behaviour of people in the economy, i.e., a conditional (normative) science. Only sociology as a whole, as a science about human beings and society, is capable of studying actual behaviour. In other words, the science related to the real behaviour of humans in the economic sphere is applied sociology (just as human behaviour in political and ideological spheres is studied by other forms of applied sociology).

\subsection{W. Sombart: the Deheroisation of the «Capitalist Spirit»}

Another interpretation of the human psyche, developed by a prominent economist, is presented in Werner Sombart's book (18631941), "The Bourgeois" (1913). Just as Veblen and Pareto, Sombart also investigated the psyche from the point of view of the dominating psychic types of people in society and the behaviour imposed by them on the society that they governed. In Sombart's terms, these are the "bourgeois", the bearers of the «capitalist spirit» (corresponding, in modern terminology, to the «capitalist psyche»). According to Sombart, the capitalist spirit is a combination of the spirit of enterprise and the spirit of the petty-bourgeois. These two elements arise and develop separately at first, and, form the capitalist spirit only after uniting together. "Each of these two compound elements has a complicated nature: the spirit of enterprise is a synthesis of the thirst for money, a passion for adventure, resourcefulness, and many other characteristics; the petty-bourgeois spirit consists of a propensity towards accounting, prudence, discretion, and frugality.» ${ }^{42}$

${ }^{42}$ W. Sombart, "Bourgeois World Economic Thought", M., "Misl”, vol. III, 2005, p. 221. 
A. A blend of business with the petty bourgeois. At times, Sombart defines the same object in very different and contradictory ways. After defining the spirit of enterprise stated above in the second chapter of his book, in the fifth chapter he comes up with a different definition: "We can name the set of all spiritual qualities that are necessary for the successful performance of an enterprise as the spirit of enterprise.» Sombart explains: "We use the term enterprise (in the broadest sense) to mean the existence of any far-sighted plan, which, in order to be implemented, requires the long-term joint action of several people, obeying a single will.» What are its spiritual qualities? «... if he wishes to be successful, a businessman needs to possess the combined qualities of a conqueror, organiser, and trader.»43 In order to be a "conqueror", he needs to possess, besides ideology, spiritual freedom, energy, and persistence, in order to create and fulfil plans. (In other words, he needs to possess a strongly pronounced instinct of freedom and will). In order to be an organiser, one needs to be able to value, select, and (if necessary) unite people, to distribute tasks that suit people's abilities, and to supervise performance. (In other words, an organiser needs to possess the qualities of a leader). According to Sombart, a «trader» is a skilful «negotiator», capable of agreeing and establishing the necessary relationships, in other words, a sociable, communicative, and authoritative person.

As for the «petty-bourgeois» making up the capitalist psyche, its essence lies in diligence and moderation aimed at the accumulation of riches. In other words, it is a combination of the instinct of diligence with the instincts of appropriation and thrift.

«Undoubtedly, all forms of the display of the capitalist spirit, as well as all states of mind and psychic processes in general, are rooted in certain «predispositions», i.e., in the initial inherited properties of an organism, «as a result of which the ability and the propensity to execute certain functions, or the predisposition to acquire a fortune, are placed and prepared in it.» ${ }^{44}$

One needs to stress that, according to Sombart, all forms of displays of the capitalist psyche are rooted in the inherited properties of an organism. The term «are rooted» is fairly vague and does not mean «predetermination», as different features of the psyche can be

\footnotetext{
${ }^{43}$ In the same place.

${ }^{44}$ W. Sombart, Essays, p. 227.
} 
«rooted» in the same human organism. In Sombart's time, human genetics was a new field and he could not construct a division between inborn and acquired instincts, and thus considered all instincts to be inborn. «If we understand instincts to include accumulated experience, which lives in the subconscious, "having become the automatic strong-willed and instinctive actions of many generations» (Wundt), nevertheless, the circumstance that they should be reduced to known inherited and hereditary «predispositions» plays a critical role in their occurrence, which means that they cannot be conceived without being rooted in blood.» ${ }^{45}$

Sombart stresses that, from this point of view, deep distinctions between people can exist: some people have «inclinations to capitalist thinking and the desire not to belong to universal predispositions, while in others they are absent. Or, at least, they can be present in some individuals in such a weak degree that they can practically be considered nonexistent, whereas others possess them in such a strongly pronounced form that it makes them differ sharply from their colleagues». ${ }^{46}$

Sombart considers that only a minority of people possess the entrepreneurial or even the «petty-bourgeois» psyche, and an absolutely insignificant minority possess "fully" the psychic properties required to turn them into a «capitalist spirit».

«Undoubtedly, many people possess only an insignificantly small predisposition to become robbers, organise thousands of people, be skilled at stock exchange operations, think quickly, save and allocate their time, and lead a generally ordered way of life. Of course, an even fewer number of people possess many or all of these predispositions, from which various components of the capitalist spirit arise. $>{ }^{47}$

In conclusion, according to Sombart, a capitalist is a person, who combines the qualities of a conqueror, an organiser, and a trader, with diligence, money-making and thrift.

Recall that Veblen characterised a capitalist as a predator, who was demonstratively idle (and, far from «diligent», «thrifty» or capable of doing any type of creative work); and, for Pareto, capitalists are at the heart of the «ruling elite», and their main characteristic is money-

\footnotetext{
${ }^{45}$ In the same place.

${ }^{46}$ W. Sombart, Essays, p. 228.

${ }^{47}$ In the same place.
} 
making, which they achieve through the use of their scheming (manipulative) talents and administrative abilities.

Joseph Shumpeter's book, «The Theory of Economic Development», was published in 1912 (a year prior to Sombart's book, "The Bourgeois" (1913)), in which the businessman-innovator is sharply opposed to the capitalist- slave to routine, i.e., the psyche of the businessman, focused on progress, is opposed to the pettybourgeois psyche of the capitalist focused on profit. Lenin considered that in an epoch of financial capital, the tone was set by conmen. Finally, in the 1970s, the well-known economic historian, Brodel, showed that the real capitalist is a person, who profits through close connections with the political establishment rather than through his own diligence and thrift.

Whose view is closer to reality? Clearly, here, different types of capitalists are discussed, and each of them is real. The capitalist class is multifaceted, mobile, fluid, elastic, and quickly adapts to varying conditions in order to extract profit. However, the psychic qualities of this class very heavily influence the economy and society, as a whole, according to the principle, «judge the flock by its priest». Therefore, national and religious types of capitalism are types of psyche of corresponding groups of the population and, primarily, of dominating groups of capitalists.

«Regarding the foundation of the capitalist spirit, there exist special types of bourgeois natures (a mixture of the entrepreneurial and petty-bourgeois natures), i.e., people, whose predisposition enables them to develop the capitalist spirit faster than others; when influenced by an external reason or stimulation, these people acquire capitalistic aspirations quicker and more intensively, and more willingly accept petty-bourgeois virtues; they acquire economic abilities easier and more fully than people with other, different types of natures. Of course, there remains an immeasurably broad gap for transitive steps between entrepreneurial and petty-bourgeois geniuses and those natures, which are absolutely alien to capitalism. $\rangle{ }^{48}$

B. «Transitive» and «non-capitalistic» natures. One in a thousand is capable of embodying the capitalist spirit. Which type of psyche do the rest of the people (making up almost the entire population) possess? In his book, «The Bourgeois», Sombart does not

${ }^{48}$ W. Sombart, Essays, p. 233. 
even ask such a question, which is the main weakness of his theoretical structure, which is left hanging in midair.

However, in this book, Sombart contrasts entrepreneurs, pettybourgeois, and other followers of the «capitalist spirit» with some opposite types of psyche: the psyche of artists, handicraftsmen, rentiers, aesthetes, scientists, moralists, bon vivants, etc.

The businessman has a far from harmonious personality. «... people with entrepreneurial natures have strongly pronounced intellectual gifts and powers of persuasion, which they need to possess to an excessive degree, in order to perform great deeds, and with an exhaustive sensual and spiritual life...» ${ }^{49}$

Sombart considers the psyche of capitalist businessmen to be close to the psyche of statesmen and commanders, and cardinally different from the psyche of artists: their souls are in stark contrast: «the former are target oriented, the latter are opposed to setting goals; the former are intellectual, the latter are full of feelings; the former are firm, the latter are soft and gentle; the former know the ways of the world, the latter are alien to the ways of the world; in the former, their attention is focused externally, in the latter, their attention is focused internally; therefore, the former know people, and the latter know the human being.

Our entrepreneurial natures are also as little related to handicraftsmen, rentiers, aesthetes, scientists, bon vivants, moralists, etc., as they are to artists.» ${ }^{50}$

In order to define the petty-bourgeois psyche, Sombart distinguishes «two basic types of human beings in general, (or, at least, amongst Europeans). People are either givers or takers and either spendthrift or economical in all their behaviour. The basic human feature, whose contrast was well-known even in ancient times and to which scholars attach crucial importance, is luxury versus avarice. People are either indifferent to their internal and external benefits and freely give them away in recognition of their own riches, or they save, protect, and look after them carefully and strictly account for the income and the expenditure of their spirit, strength, property, and money. I will try to note, perhaps, the same contrast, which Bergson wishes to express in the terms: open home and closed home.

\footnotetext{
${ }^{49}$ W. Sombart, Essays, p. 229.

${ }^{50}$ W. Sombart, Essays, p. 230.
} 
Both these are fundamental types: givers and takers, seigniorial and petty-bourgeois natures (for, needless to say, that I see one of the basic types in the petty-bourgeois nature) standing against each other, as sharp contrasts, in any real life situation. They value the world and life differently: for one group the higher priorities are subjective and personal; for the other group, they are objective and material; the former are by nature inclined to enjoy life, the latter are inclined towards duty; the former are individuals, the latter have a herd mentality; the former are personalities, the latter are materialistic; the former are aesthetical, the latter are ethical; the former are like flowers, which fill the world with their fragrance without any personal gains, the latter are like medicinal herbs and edible fungi.

Even this contrasting predisposition is then expressed in a radically different estimation of human pastimes and general activities: the former recognise only that activity to be worthwhile, which raises the human being, as a person; the latter declare all employment to be the same, as they only serve general welfare, i.e., «are useful».

... At the same time, those that do not belong to the bourgeois travel all over the world, living, contemplating, and reflecting, while the bourgeois have to organise, raise children, and teach. The former dream, the latter think.

... Deep down, the distinctions between both these basic types have to be based on the contrast in their love life. For it, clearly, defines all human behaviour as the supreme, invisible force. The petty-bourgeois and erotic natures are diametrically opposed.» 51

«Both sensual natures and natures that are not sensual, which both adapt perfectly to the petty-bourgeois nature, are equally remote from the erotic nature. Sensuality and eroticism are almost mutually exclusive contrasts. Both sensual natures and natures that are not sensual subjugate themselves to the petty-bourgeois requirement for order, but erotic natures never subjugate themselves in this way.»

«Xenophon: «Those in love are not suitable for housekeeping.»«

«In the end, the ability of capitalism is rooted, nevertheless, in the sexual constitution and, which is a problem, «love and capitalism», also from this point of view, stand at the centre of our interest.» ${ }^{52}$

\footnotetext{
${ }^{51}$ W. Sombart, Essays, pp. 230-231.

52 W. Sombart, Essays, p.232. 52
} 
Here, Sombart interrupts his analysis of the petty-bourgeois element of the psyche of the capitalist. It is easy to find traces of Freudian influence in this analysis.

C. Capitalistic spirit and development. Now I will compare, on the one hand, Veblen and Pareto's points of views on the psychic bases of the economy, with Sombart's, on the other hand.

For all three, the main object of the analysis is the psyche of the members of the ruling class. However, the question is stated in a cardinally different way; whereas, Veblen and Pareto are interested in discovering through which qualities of the psyche, members of the «leisure class» or «dominating elite» manage to maintain power and property, Sombart focuses on the psyche of capitalists as a force for social development. Veblen and Pareto, each in their own way, underline the common features of the psyche of all members of the governing class. Sombart, who considers that the capitalist spirit is the combination of the «spirit of conquest» (aggression, oriented on new goals, neglecting norms, etc.) and the «petty-bourgeois spirit» (prudence, accumulation, and observance of rules), compares capitalists to statesmen and military leaders, in whose psyche «conquest» is inherent, and «narrow-mindedness» is absent. On the other hand, according to Sombart, the «petty bourgeois» as such cannot become capitalists, nor force their way into the governing class, as «conquest» is alien to their psyche.

Clearly, Sombart has no doubts at all regarding the question whether genetics or the social environment plays the defining role in the formation of the "capitalist spirit» in a person: according to Sombart, without possessing the required set of inborn psychic qualities, a person cannot acquire the capitalist spirit, regardless of his social environment.

Therefore, I believe, for Sombart it was easy to explain the means through which people endowed with the «capitalist spirit» dominate. Veblen explained this domination through the exploitation by the «leisure class» of the natural instinct of imitation and «envious consumption». Pareto referred to the deceit and purchase of the population by the immoral «elite». From Sombart's concept, it follows that only capitalists, who make up an insignificantly small share of the population, possess the necessary set of inherited psychological qualities that are required for managing a modern economy. Other social groups of the population, such as officials, the intelligentsia, 
handicraftsmen, and rentiers (not to mention workers, peasants, and servants) simply do not possess such qualities (as groups).

\subsection{A. Marshall: a Semi-Marxist View of the Psyche}

The psyche is a product of the activity of many contradictory factors. Marshall preferred concepts that were as close as possible to reality. Therefore, he saw no contradiction in considering that the character of a person is formed by the economy, however, for the economist a «person's nature» remains enigmatic; that, not greed, but clear-headed calculation, characterises the «modern epoch», however, nonetheless, money provides the stimulus for activity; and, that capitalism has both harmed and improved the human psyche.

A. The economy forms the character of a person. According to Marshall, economic science on the one hand, constitutes a research of wealth, and on the other hand, forms part of the research of a human being.

Marshall argued that religion and the economy were two great forces that shaped the world's history. According to him religious motives are stronger than economic motives, but their direct influence is seldom so widespread. He stated that employment, which helps a person earn a living, fills his thoughts during the overwhelming majority of the time that his mind is functioning effectively; during this time, his character is formed and affected at work by how he uses his capabilities, the thoughts and feelings he experiences, and the relations that develop with fellow workers, employers or his employees. $^{53}$

The economy forms the character of a person not only through labour processes and relations, but also through distribution processes and relations. According to Marshall, very often, the influence exerted on the character of a person by the amount of his income is barely less than the influence exerted by the way in which the income was earned. The conditions accompanying extreme poverty, especially in

53 A. Marshall, "Principles of Political Economy", vol. 1, Moscow, 1983, p. 56. 
overpopulated areas, can kill the best qualities. Those people, who are called the «dregs of society» in large cities, have very little possibility for friendship, domestic life does not exist for them, and religion is often not accessible to them. Marshall conceded that physical, intellectual, and moral defectiveness may partially be generated also by other reasons, besides poverty, but he maintained that poverty remains the main reason. ${ }^{54}$ Marshall pointed out the influence of the severe working conditions and poverty on both the inborn and instilled psychic qualities and instincts of people, on their habits, and on the informal institutions of society.

According to Marshall, poverty is not the only, but the main, reason for a "defective" psyche, i.e., essentially of a special social type of psyche. I find it difficult to agree with this.

People, who grow up and live in poverty (as well as in luxury), acquire specific conditioned reflexes, values, and habits, but one cannot consider their psyche as «defective». It is normal for the given environment, although from the point of view of the development of the personality, it is deformed in both these cases. (The same can also be said of the psyche of people, working in many niche professions, although this deformation has a different aspect and character.)

B. Difficulties regarding the «quality of human nature». Later, without noticing it himself, Marshall contradicted his original position by stating that the merits of the human being have been proclaimed and defended by Christianity, with increasing passion throughout the past century, but the value of this expression had only recently started to be fully appreciated, due to the broad expansion in education that had taken place. Marshall argued that, as a consequence, one could realistically question the inevitability of the existence of the so-called «lower classes»; in other words, is there a necessity for the existence of a set of people to be doomed to arduous toil from birth, in order to enable other people to live in a refined and cultural way, whereas their own poverty and exhausting work deprived them of the possibility to receive their share of the benefits, or at least a part of them, in this life. 55

Marshall went on to claim that the answer to this question could not be based only on economic science. It partially depended on the

\footnotetext{
${ }^{54}$ In the same place, p. 57.

55 A. Marshall, Essays, p. 58.
} 
moral and political possibilities of human nature, and the economist had no special means for revealing these qualities. He, like others, had to resort to guesses. However, at the same time, the answer, to a great extent, depended on factors and conclusions based on economic science, and this is what made up the main and higher aim of economic research. $^{56}$

Here, I will briefly summarise Marshall's point of view, thus far. He wrote that the character of a person is formed, mainly, by the place occupied by a person in production and distribution. Based primarily on this, the psyche of the «lower classes» is "defective". Under the influence of Christian morals and the spreading of education, the demands to make decent living conditions available to the masses have strengthened, and the prospect of the elimination of the «lower classes» is being taken seriously.

However, is this possible? Marshall answered this question in two parts as it depends on the following: (1) the «moral and political possibilities of human nature», and (2) economic «factors and conclusions».

Regarding the first part, one can only guess. Hence, one cannot expect a definitive answer regarding the question of the inevitability of the existing class structure, as the given «nature» remains an «an object in itself». However, this is not on account of the economy. The economically determined aspect of human nature is studied and measured by economic science. Hence, one could expect an answer to the second part of the question. Moreover, Marshall gave an answer in the sense that, in this aspect, human nature does not create obstacles to overcome (or, at least, significantly narrow) the gulf between the higher and lower classes of society. (I note that, at the same time, this implicitly assumes that not only the lower, but also the higher classes, are ready to overcome this gulf (to the degree that the character of their members is economically determined).

C. Is the psyche improving with the development of capitalism? Marshall considered that «modern industrial life» had improved people's behaviour. He opposed those, who believed that the main displays of the fundamental features of modern industrial life were competition, egoism, and profiteering. He argued that in reality the main trends of industrialisation led to the following: the appearance of

${ }^{56}$ A. Marshall, Essays, p. 58. 
a certain independence and tendency for people to choose their own way and believe in their own strengths; discretion and, at the same time, speed in making decisions and judgments; and the tendency to foresee the future and define a course of action, taking into account long-term goals. He conceded that these factors often induced people to compete with each other but, on the other hand, they also pushed people to cooperate and create all types of organisations, both commercial and charitable.

He considered that the term «competition» had excessively negative connotations; it had come to be associated with egoism and indifference towards the well-being of other people. However, in his opinion, sober consideration, rather than self-interest, is the distinguishing feature of the modern epoch. ${ }^{57}$

Marshall considered that «in a modern society» (in comparison with the past), the relationship of a person with his relatives and neighbours had deteriorated, but intra-family relations had become stronger and relations with «strangers» had also improved. He stated that in trading between relatives and neighbours, the standards of fairness and honesty had deteriorated in comparison to the standards that had existed among primitive people, but they had become much higher than in transactions with strangers. Thus, only relationships with neighbours had deteriorated, and family connections in many respects had become stronger. According to Marshall, relations towards strangers had become consciously fairer than they had been in the past. ${ }^{58}$

Marshall wrote that modern trading methods included principles of trust, which had become a habit, on the one hand, and the ability to resist the temptation to deceive, which is not characteristic of backward people, on the other hand. ${ }^{59}$

However, Marshall warned against overestimating the value of the positive shifts that had occurred in the human psyche and ignoring the imperfections that were still characteristic of human nature.

According to Marshall, history in general and the history of socialist experiments in particular, has shown that ordinary people are seldom capable of showing purely ideal altruism over the long-term;

\footnotetext{
57 A. Marshall, Essays, p. 60.

58 In the same place, p. 61.

${ }^{59}$ In the same place, p. 62.
} 
the only exceptions are cases, when the unrestrained zeal of a small group of religious fanatics turns material cares into nothing in comparison with a higher belief. ${ }^{60}$

That is why Marshall believed that economic science should avoid extreme measures and not favour either altruism or egoism, and should be based on the principle of «material compensation for work», or, more broadly for «economic activities». He argued that economic science should be engaged in studying how people exist, develop and what they think in their everyday life. However, the subjects of its researches are mainly those incentive motives, which most strongly and most steadily influence a person's economic behaviour. Marshall argued that each person of any worth uses his best qualities for economic activities, and, just as in other areas, he is subject to the influence of personal attachments, ideas about obligations and fidelity to high ideals. However, despite all this, the most persistent stimulus to conducting economic activities is the desire to receive payment for such activities, representing material compensation for the work done. It can then be spent on egoistical, altruistic, noble or unworthy purposes; here, one sees the multifaceted character of human nature. However, a certain amount of money acts as the incentive for such behaviour. This specific and exact monetary measurement of the steadiest of stimuli has allowed economic science to outperform all other sciences in human research. ${ }^{61}$

It is worth noting the cardinally different approach taken by Marshall to the human psyche from Veblen's, Pareto's, and Sombart's approaches. Firstly, Marshall did not focus on the psyche of the governing class, but on the psyche of hired workers. Secondly, he was interested in the socially-determined qualities of «human nature» and not its «inborn» characteristics. Thirdly, he aspired to reveal the historical evolution of the psyche of the masses under the influence of the development of capitalism. Fourthly, unlike Veblen and Pareto, Marshall aspired to present inter-class conflict not as a clash of different psychic types, but as a clash of the different levels of development of the human psyche, caused primarily by the gap in income levels. Marshall's position was close to the positions of social psychologists, rather than geneticists.

\footnotetext{
${ }^{60}$ In the same place, p.64.

${ }^{61}$ A. Marshall, Essays, p. 69.
} 


\subsection{J.M. Keynes: «The Psychology of the Market»}

Unlike Marshall, who stated his opinions on the human psyche and how this psyche was formed and appeared in economic activities, Keynes (1883-1946) left no such account of his views. Nevertheless, in his works, a number of detailed statements confirm that on a number of fundamental positions, his views are directly opposite to those of his teacher, Marshall.

Preferring not to stray away from directly observable reality, Marshall asserted that the psyche of a person is formed mainly in the manufacturing and distribution sphere, and consists primarily of the aspiration to rationally maximise his monetary income in order to satisfy various requirements; however, Keynes believed that economic activity had a deeper psychic basis, which is inherent in a person due to his natural thirst for activity. He wrote that man's inborn thirst for activity was the driving force of the world; the rational half of man's ego was engaged, in whichever way it could find, in the selection of alternatives, and wherever possible in calculating them; however, quite often it was in the power of man's whims, moods, and desires to try his luck. ${ }^{62}$

In other words, the rationality of economic agents is far from being the main principle of their behaviour, but only a subordinate means of selection of alternatives, which is used only when possible; however, it is by no means universally used.

The «inborn thirst for activity» can take both a constructive, socially useful direction and a destructive direction that is dangerous to society. This is related to the fact that people have both positive and negative (dangerous) inclinations (in particular, cruelty, love of power, self-exaltation, etc.). Keynes wrote that the economic system should be constructed in such a way that negative (dangerous) inclinations are directed towards useful, or, at least, harmless channels. Thus, Keynes was inclined to consider that the economic system was derived, primarily, from the psyche of its agents.

62 J.M. Keynes, “General Theory of Employment, Interest and Money”, from Keynes's selected works. Moscow, 1993, p. 350. 
He believed that there were well-known social and psychological justifications for the considerable inequalities in incomes and riches, however, not for a gap as big as the one which existed at that time. He wrote that the successful implementation of certain necessary kinds of human activities required mercantile interests and the general conditions of private property. Moreover, he argued that it was possible to direct dangerous human inclinations towards relatively harmless channels, where there are prospects of «making money» and accumulating personal riches. He warned that the same inclinations, if they were not satisfied in such ways, could emerge in forms of cruelty, reckless aspiration for personal authority and influence, and other forms of self-exaltation. Keynes wrote that it was preferable for society if a person tyrannised his current accounts than his fellow citizens. $^{63}$

Thus, it is not the consumer, who pulls an economy forward through his needs, but the person «thirsting for activity», who pushes it forward and, who, at the same time, is capable (if permitted) of severely oppressing and recklessly tyrannising his fellow citizens.

For how long will the human «thirst for activity» be combined with human «inclinations», which demand the use of a market capitalist economic system? Keynes warns that one needs to distinguish between two different tasks: the «transformations of human nature» and the «management of people» (he means people as they are).

According to Keynes, the task of transforming human nature should not be confused with the management of people. Although in an ideal society, people may be trained or brought up, without being interested in profit, nevertheless, pragmatic heads of state should ensure that the established rules and restrictions are observed, so long as the average person or at least a significant part of society, remain subject to the passion of «making money». ${ }^{64}$

Clearly, Keynes was influenced in his thinking by the events that were taking place at the time, in the early 1930s. A global crisis had struck and the free market had been gradually suppressed in Germany, Italy, and Japan by centralised regulation, and in the USSR it had been completely displaced by the planned economy (while, at the same time, the successful formation of the «New Person» was declared).

\footnotetext{
${ }^{63}$ Keynes, Essays, p. 511.

${ }^{64}$ In the same place.
} 
If one speaks about the USSR and other socialist-state countries, the crash of this system at the end of the $20^{\text {th }}$ century has left unanswered, for the time being, the question posed by Keynes: is it possible to break the habit of the «average person» from the «passion to make money»? Or, in other words, which of the two statements is closer to the truth: the planned economy has failed, because it is inefficient in general; or has it failed because it was not possible to raise the «New Person», free from «commercial» inclinations?

Against a planned economy, two series of arguments have been put forward. The first consists in its inability to financially stimulate work through due differentiation of salaries. This argument has turned out to be invalid as the differentiation of salaries in socialist states is no less than in market capitalist economies.

The second series of arguments for Marshall's followers has turned out to be the main one: a planned economy is not capable of revealing the relative deficiency in production and resources and of correctly setting their prices, and, therefore, of defining an optimum production structure. The market creates the conditions so that each consumer and each manufacturer can establish for himself an optimal balance of expenses, income, and consumption according to his individual preferences and possibilities.

Keynes argues that since a significant part of people's actions are positively inclined, they are usually based on a spontaneous feeling of optimism rather than on detailed calculations of moral, hedonistic, or economic motives. Probably, the majority of people's decisions of a positive character, whose consequences will become fully apparent only after the lapse of many days, are taken under the influence of only one factor, namely, cheerfulness; this spontaneously arising determination to act, instead of sitting, with folded arms, is not in the slightest the result of calculating the arithmetic average of those or other quantitatively measured benefits and weighing the probability of each of them occurring. Businessmen need to carry out only that activity, which appears to be aligned with their basic motives, formulated in their own plans for the future, however sincere and truthful they may be. Keynes considered that business was based on exact calculations of the expected income, only to a slightly higher degree than an expedition to the South Pole. Therefore, when cheerfulness fades, it destroys optimism, and, when people are left to rely on mathematical calculation alone for estimating future income, 
business decays and dies, even if the fears of losses are as superficial, as the hopes of profit had been earlier. ${ }^{65}$

Thus, it is not calculations of estimated future expenses, results, and profits and losses that are the moving force of the market capitalist system, but the «inborn thirst for activity», «spontaneous cheerfulness» and «optimism» of its agents. It is in this that both its strength and its weakness lies.

However, it is also in this, it seems, that the strength and weakness of a planned economy lies. When the «inborn thirst for activity», «cheerfulness», and «optimism» were present in its members, primarily in the leaders at all levels of the planned economy, despite its inherent defects, quite good results were achieved. However, eventually the system became bureaucratic and the quality of its leaders changed: careerists, conservatives, sceptics, and overcautious people gained control: «cheerfulness faded», «optimism was shaken», and despite all the optimally planned calculations and stimuli, the system «decayed» and «died».

Moreover, it not only did not limit, but even encouraged the «dangerous inclinations» (as defined by Keynes) of the human psyche, such as the love of power, cruelty, self-exaltation, etc.

Hence, according to Keynes, the question is not, which system is better in accounting for, distributing, and providing financial stimulation, but which system supports the «inborn thirst of activity», «spontaneous cheerfulness», and «optimism» stronger and more reliably in society; and, which, at the same time, is capable of effectively and constructively transforming the «dangerous inclinations», inherent in energetic people.

Clearly, the core of Keynes' theory centres on «the psychology of the market», the doctrine about the interaction of psychological forces, defining economic booms and recessions.

At the heart of these forces, as already noted, lies the «inborn thirst for activity» that directs and strengthens «spontaneous cheerfulness» and «optimism». These psychic forces are subjected to the influence of different factors, both economic and not economic, including «the dangerous inclinations» inside the human psyche itself. If events in general develop negatively, «cheerfulness fades», «optimism is

${ }^{65}$ Keynes, Essays, p. 349. 
shaken», and the thirst for activity «dies» and activity is replaced by apathy.

Resting on such an unsteady «base», the real (instead of abstract) and unregulated market is characterised by general uncertainty, and the «psychology of the market» by a complete lack of confidence. This should be kept in mind, when considering any category of Keynesian theory and its general logic.

Naturally, those who take part in economic activities do not consume their entire income at once, but put aside a part of it in savings for large acquisitions in the future, for use in case of unemployment, illness, old age, passing on as an inheritance, etc. However, the psychology based on a general lack of confidence encourages saving up as much as possible for an «insurance reserve», without decreasing the developed consumption level. For this purpose, people put aside a greater share of their increased income in savings. The psyche of a lack of confidence in the future is manifested by a growing propensity of the population to save and a decreasing propensity to consume.

The next question concerns the form in which to hold savings. The market offers different ways of saving: cash, bank deposits, securities, etc. Due to the same lack of confidence, the saver prefers liquid assets, cash, bank deposits, or highly liquid stocks and bonds. He mostly avoids placing his savings in non-liquid assets. Keynes called this property of the psyche of a saver as a «preference for liquidity».

«The sacred Trinity» of the psychology of income earners, an increasing propensity to save, a decreasing propensity to consume, and a preference for liquidity, is closely connected with a fourth component, forming part of Keynesian market psychology, namely, the «inducement to invest».

The general psychology of uncertainty and the lack of confidence, characteristic for the market, are especially visible in the investment sphere. Unlike the first three «propensities», within which Keynes does not distinguish different types of market psyche, in the framework of an «inducement to investment», he accurately outlined two contrasting types: the «speculator» and the «industrialist».

The speculator is prone to risk taking and, who, through the stock exchange, professionally manipulates the savings of the population invested in securities, while, at the same time, relying on the aforementioned components of the «market psychology», the 
«preference for liquidity», and a feeling of uncertainty and lack of confidence, which are reflected in the continuous price fluctuations of stocks and bonds. His ability to earn money is based on his ability to «guess» faster than others the mass reaction of holders of securities to global events, influencing market prices.

On the one hand, stock market speculation plays a negative role in society as it increases the uncertainty and lack of confidence in the economy; however, on the other hand, without stock exchanges it would be difficult to attract the savings of people, who are inclined to risk taking and «money making», in investments in securities. According to Keynes, the stock exchange is necessary, as long as there are alternative forms of savings, such as cash and deposit accounts.

The psyche of a speculator on the stock exchange contrasts with the psyche of an industrialist, who invests money for the long-term, regardless of the fluctuations of the market. According to Keynes, in the eyes of the public, he is considered an eccentric, as he acts contrary to the general pursuit of highly liquid assets. The industrialist concentrates on the income, which he should receive from the property that he acquired or created, throughout its useful life. In order to find objects for long-term investments and be able to receive the income anticipated from them under conditions of general uncertainty, one needs to possess outstanding mental faculties, much higher than for speculation in the stock market. However, above all, one needs to possess a «thirst for activity», «optimism», and «cheerfulness», without which one cannot be involved in industry. However, «the market psychology» is such that that an industrialist is forced to operate in an environment, which dampens the «inducement» for long-term investment.

Here, I am not asking the reader to remember the basic theses of Keynes' economic theory; my aim is to «highlight» the underlying psychological reason of this theory. The economic result of the interaction of psychic factors, «propensities», «preferences», and «incentives» on a general basis of uncertainty and lack of confidence, is a lack of effective demand and chronic underemployment of resources. Such conditions form a favourable environment for the «inborn thirst for activity» of persons with «dangerous inclinations», including «the madmen in power, who hear voices from the heavens». By aspiring to solve the social and economic problems of their country 
at the expense of other countries, these persons «with dangerous inclinations» exploit the «natural aggressiveness of nations».

(It is typical that in his book, «The Economic Consequences of the Peace», written in 1919, 15 years prior to «The General Theory of Employment», Keynes named the «unbalanced psychology of the working and capitalist classes» among three factors, which predetermined the instability of Europe's position before the First World War. ${ }^{66}$ )

Keynes draws the conclusion that the state needs to introduce certainty and confidence in the psychology of the markets through its policies regarding consumption, savings, and investment. He argues that it is necessary to create a stable psychic environment, in order that an industrialist with average abilities can implement profitable longterm capital investments.

${ }^{66}$ J. M. Keynes, Essays, p. 519. 


\section{Chapter 3}

\section{The Human Psyche from the Point of View of New Economic Nobel Laureates}

\subsection{The Contemporary Crisis of Mainstream Axiomatics}

Contemporary economic science is in a paradoxical position. On the one hand, it is developing quickly and, on the other hand, it is increasingly being accused of being in crisis and unable to answer even basic social and economic issues in a rapidly changing world. This dilemma can be seen even in the Royal Swedish Academy, which has been compelled to award Nobel Prizes to economists, holding mutually exclusive theoretical positions.

The crisis theory does not begin when facts are gathered, which contradict it - this is a necessary but insufficient condition. The crisis begins, when these facts are constructed in an alternative competing hypothesis, related to the same object. The defining line of crisis theory is the detection of the absolute, or a relative, lack of justification of its initial premises, i.e., its axiomatics. The absolute groundlessness of its axiomatics is understood to mean its unfitness during any periods of history in any country; relative groundlessness refers to its discrepancy in relation to facts, during separate periods in specific countries.

The fact that the market capitalist economy (with all the diversity and autonomy of its components, stages of non-uniform development, complexity of structures, functions, and subjects) forms a system is represented to us as an indisputable fact. If there is a system, then a general theory (model) of this system should also exist. This leads to the following question: which elements of this system are assigned on the basis of this theory as its initial axioms (taken not from the theory, but from «practice»)? Communications and interactions in an economic system are always (directly, or, eventually) interactions 
between people. Therefore, the initial axiomatics of any economic theory, explicitly or implicitly, are a concept about human nature and behaviour taken from practice (including historical practice).

Both classical and neoclassical theory and their derivatives (within the limits of mainstream theory) start with the «axiom» about the economic person rationally maximising individual welfare (interpreted as monetary income or wealth). From the very beginning, the historical school (both the old and new) and institutionalism rejected this initial premise, and proposed completely different interpretations of human nature and behaviour. They were even able to (more or less realistically) explain the basis of the institutional structure of a market capitalist economy, but they were at a complete loss in trying to explain its functioning as systems. Keynes' «general theory» was based on his own representations about the psyche of market participants, rejecting both their rationality and their focus on maximising their welfare. Characterising these «actors» (market participants) as carriers of propensities, preferences, and motives, as well as aggressive and protective reactions, which, at times, led them to a collective panic and, at other times, to euphoric optimism, Keynes constructed a functional model of the unstable market, which gravitated to partial employment.

As a rule, neoclassical theory has been criticised for a long time (and without any apparent result) for the fact that it is based on a state of equilibrium of the market capitalist system. However, no system is capable of existing over the long-term if it does not contain a «point of equilibrium», around which fluctuations occur. The nature of this equilibrium - and the level, cost, and forces, which support it - is an entirely different question. Market equilibrium primarily consists of the balance between supply and demand in two interconnected markets - goods and services, on the one hand, and production factors, on the other hand. However, which forces, standing behind supply and demand, are included in the theory of the model, and which are not taken into consideration? This is what differentiates the theories of the market capitalist system (the neoclassical and the neoinstitutional, on the one hand; the Keynesian, neo-Keynesian, and post-Keynesian, on the other hand; with the Marxist and neo-Marxist, making up the third group).

Regarding the theoretical concepts of the historical school and traditional institutionalism, they have not developed to a level, where 
the theory of the market capitalist system could be applied to them; although attempts were made by the institutionalist, Wesley Mitchell, and by the successor of the ideas of the historical school, Walter Eucken.

I believe that both the defects of the already existing theories of the market capitalist system and the inability of alternative theoretical concepts to become systemic can be explained by the limitation, inaccuracy, or uncertainty of their axiomatics, i.e., the initial concepts about the nature and behaviour of the participants in the capitalist market.

Over half a century ago, Milton Friedman proposed the thesis, according to which the criterion of the scientific character of any theoretical hypothesis lies in its adequacy in forecasting the reaction of the economic system to external influences. In this way, he transferred the focus of discussions about the relevance of the theory from the viability of its initial axioms to checking its practical conclusions.

Sometimes such a transfer of the focus is taken to mean the belittling of the value of the axiomatics of the theory by Friedman, which does not tie up with the long-term research practice of this historian of the monetary system and statistics. I believe that Friedman's approach should be understood as a recognition by him of the extreme complexity and discrepancy of the economy and of the basic necessity (for building a theory) of its sharp simplification by selection of some its key characteristics as initial axioms. In the end, the prognostic possibilities of the theory, built on selected axioms, is proposed as the validity criterion of such a selection.

Depending on the selection of the initial axioms, one receives different theoretical designs, based on which different prognostic estimations will be deduced for the same «external» influence. Friedman was primarily interested in the effect of changes in the monetary policy on the level of employment. The axioms selected by him (are reduced to the fact that market participants aspire to maximise their income - not only monetary income - from a total of five forms of wealth, namely, material capital, human capital, shares, bonds, and money) led to an anti-Keynesian (monetarist) theoretical hypothesis, according to which active monetary policy, in the end, is powerless in changing the «natural» unemployment rate, but is capable of causing «stagflation». According to Friedman's principle 
position, if this theoretical forecast proves to be true in practice, then, the degree to which the initial assumption corresponds to reality - that the majority of market participants possess five specified forms of wealth and, thus, aspire to maximise their cumulative income from them - has no meaning.

However, the point is that the conclusions of Friedman's theory concurred with the reality, precisely because the initial premises of this theory for the given historical period appeared realistic: towards the 1970s, in the United States and Western Europe, a powerful middle class had been formed. However, later (in the 1980s and 1990s), its relative weight in the economy as a whole began to fall, and social polarisation in the distribution of all forms of wealth started to increase. Moreover, it seems that it was not merely coincidence that, when the monetarist bill on zero inflation was proposed in the United States Congress, it was rejected on the (obviously not monetary) basis that blocking price growth would lead to an increase in unemployment and a decrease in economic growth rates.

Thus, it turned out that monetarist theory had prognostic capabilities concerning the behaviour of the economic system - but only for some indicators and a certain type of external influence on this system.

In principle, the same can also be stated about the Keynesian theories, whose initial axiomatics consisted of well-known collective psychological «propensities», «preferences», and «motives» of the market participants. This theory partially considered the presence of «two classes» and nations in the world markets and predicted the consequences of their behaviour - however, as it later became clear, only for a certain historical situation.

Both monetarism and Keynesianism ignored the corporate structures of the market, due to their specific practical focus, on the one hand, and their initial axiomatics, on the other hand. Ronald Coase's theory of transactional costs was used to fill this gap. (Coase acknowledged that he was pushed into developing this theory after coming across Lenin's well-known thesis about a «factory unit».

Coase criticised the initial premise of neoclassicism (and monetarism) about the stimulus of maximisation of individual welfare, but he himself could not overcome this premise. According to Coase, people enter corporations in order to minimise transactional costs. In fact, the efficiency and dynamism factor, both for large manufacturing 
and intra-corporate institutions (partially considered in Leibenstein's concept of X-efficiency), is more important. On the whole, Coase's theory does not answer why more than half of employment, even in the developed countries, is linked to small enterprises.

The examples stated above indicate that economic theory is not uniform; it does not consider the economy as a developing system; it ignores the interrelation of some basic aspects and problems and has no general axiomatic base. This conclusion can be supported by the position of many well-known modern scientists.

Thus, W. Baumol has confirmed the absence of the theory of technogenic economic growth, having a microeconomic base; Akerlof has called for a revision of macroeconomic theory on new psychological and social bases; Amartya Sen believes that neoclassical premises cannot form the basis of the theory of social choice; Vernon Smith suggests replacing the premise about conscious rationality with an axiom about «ecological rationality»; etc.

Certain notions about the psyche of people, as the mechanism defining their behaviour, have always lain at the heart of economic theory (explicitly or implicitly).

The specificity of the current state of economic science consists of the fact that its efforts are directed at bringing theoretical models into accord with the real behaviour of people in an economy, both on the micro and macro levels. The preconditions for such an orientation are created by numerous failures of abstract theoretisation, on the one hand, and the accumulation of information of the empirical research of economic behaviour, on the other hand.

The lectures of six Nobel Laureates considered here - Amartya Sen (1998), Daniel McFadden (2000), George Akerlof (2001), Joseph Stiglitz (2001), Daniel Kahneman (2002), and Vernon A. Smith (2002) - are not devoted specifically to research on the human psyche, but they include the psychological and sociological interpretation of economic events (sometimes in detail and at other times in summary or partially). ${ }^{67}$ I will try to «reconstruct» and compare their conceptions about the human psyche, based on these interpretations.

67 The lectures have been published in a five-volume edition, "World Economic Thought", volume V, book 2, "Moscow", 2005. Further in this chapter, references to this source will be given as (WET). 
According to J.K. Galbraith, in scientific narration, as opposed to deductive reasoning, the result can be declared at the beginning. My result can be reduced to four points. Firstly, four of the six Laureates named above consider refuted the concept of the classical and neoclassical theories that, in the centre of economic processes, there is an individual consciously maximising individual utility; and two have left the question on motives of economic behaviour open. Secondly, all of them refuse to consider that decisions made by individuals are capable of leading to an effective («market clearing») equilibrium. Thirdly, the model of the universal psyche, towards which each of the Laureates is (implicitly) inclined, is fundamentally distinct from the others; thus, in criticising the neoclassical model, they do not propose a common alternative. Fourthly, in the lectures of the Laureates, it is extremely puzzling that the question on the types of human psyche is not even raised; moreover, even the statements of this question, which had been made in the works of Keynes, Marshall, Veblen, Pareto, and other scientists, were not mentioned.

After all, in this direction lies the thread, which leads to disentangling the clew of structural and functional problems of the markets, researched by these Laureates.

\subsection{Two Views on the Psychological Bases of Economic Choice: D. McFadden and A. Sen}

In this section, two contrasting approaches are considered in the interpretation of the economic choice of the Nobel Laureates, Daniel McFadden and Amartya Sen. Both approaches seek to serve as the theoretical basis for the development and estimation of the programs of social and economic policy. However, the authors start with a sharply contrasting understanding of the human psyche and, naturally, come to different conclusions.

A. The biological and genetic roots of the «rational model». McFadden aspires to prove the thesis about «the sovereignty of the consumer», as this thesis is the main support not only of the neoclassical theory of the market, but also of the entire philosophy of market democracy. Is it possible to influence the choice of the consumer «from the outside» or to subordinate the behaviour of the 
consumer to state propaganda or advertising in such a way that he voluntary changes its preferences? If this is possible, the market ceases to be the regulator of the economy, and the consumer, its defining figure (as claimed in traditional institutionalism).

In order to disprove such a possibility, McFadden connects the sovereignty of the consumer with the genetic bases of the human psyche. According to McFadden, the core of the standard or rational model of economic science is the idea that consumers aspire to maximise their inborn preferences and are stable concerning the quantities and signs of the goods that they consume. The power of the consumer is an important feature of this theory, according to which, in any situation, the preferred choices are predetermined and do not depend on the alternatives available. In short, desirability takes precedence over availability.

McFadden goes on to state that this standard model contains an implicitly expressed biological aspect. Preferences are defined by a genetically programmed reference set of tastes. In the majority of applications of the standard model, dependence on experience is excluded, and the strength of this model consists in its ability to explain the character of economic behaviour, without reference to experience or perceptions. ${ }^{68}$

McFadden considers it necessary to soften the severe constraints of the «standard» model, having placed preferences in functional dependence not only on a genetically programmed «reference set of tastes», but also on past experience, on characteristics of the consumer, on the consumption level, and on the labels of goods. Consumers are heterogeneous according to their «unobservable characteristics» (according to their «reference sets of tastes», according to individual mechanisms of the formulation of perceptions, etc.)

At the same time, although psychological factors such as motivation, affect, purpose, etc., influence the formation of perceptions (beliefs) and decision-making, according to McFadden, they play a supporting role.

McFadden proposes the following scheme, in which «minor» factors «are inserted» in the expanded «standard» model of choice.

68 Daniel McFadden, "The Problem of Economic Choice", WET, vol. V, book 2, p. 401. 


\section{The Selection Process - Daniel McFadden ${ }^{69}$}

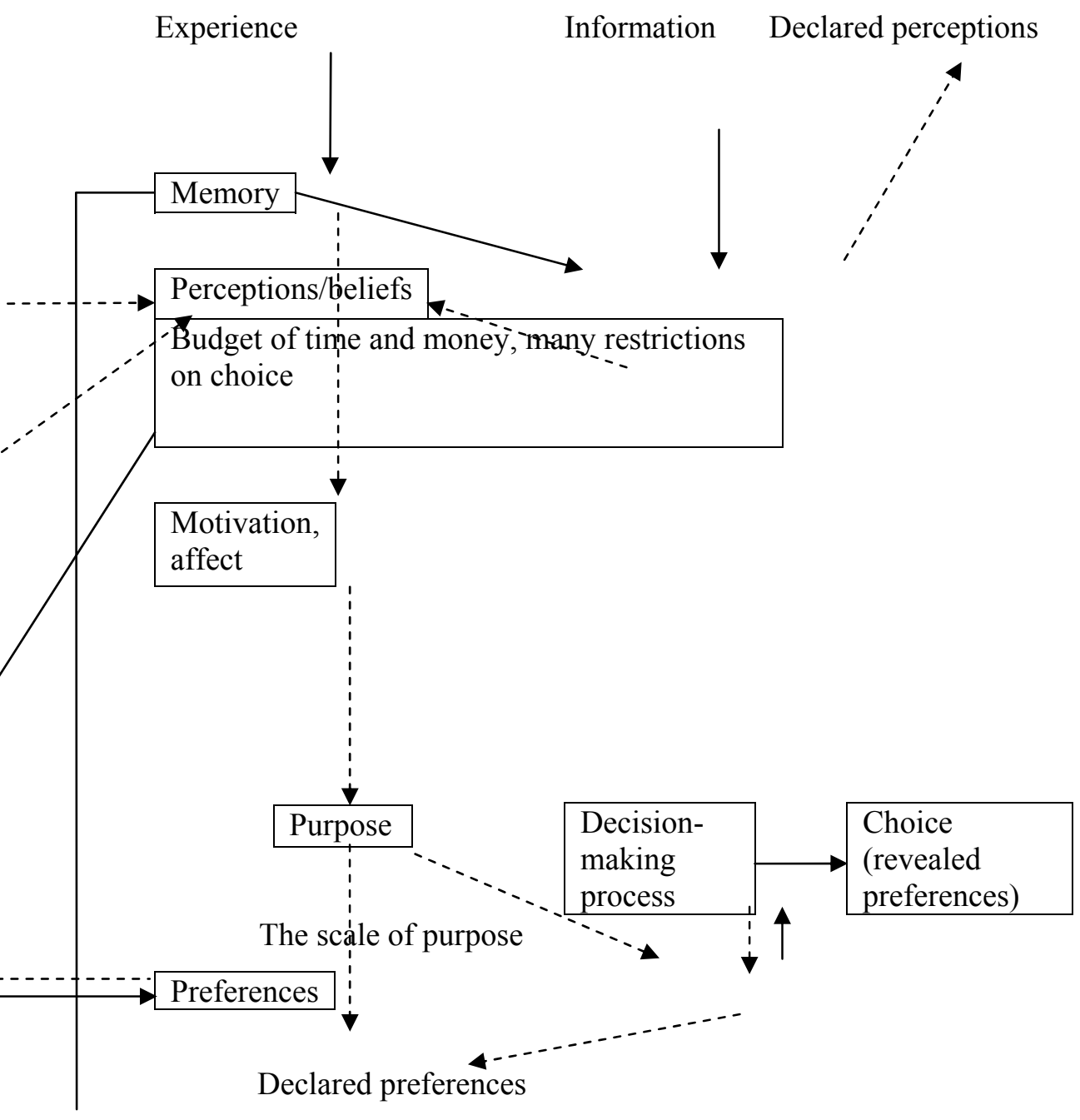

${ }^{69}$ WET, vol. 5, book 2, p. 401. 
Figure 3.1: The continuous lines with arrows correspond to the traditional (standard) model of economists' selection process and the lines with dashes and arrows correspond to the psychological factors, involved in the decision-making process.

McFadden received the Nobel Prize for developing the theory and methods of analysis of a discrete choice. This method consists of the fact that the preferences revealed are presented as continuous functions of the characteristic of the signs of the consumer of goods. Consumer characteristics are divided into those that are observed and those that are not observed. The latter are non-uniform for different consumers and include: (1) «the reference sets of their tastes» (which are genetically determined) and (2) the mechanisms for the formation of perceptions. The conditional assumption is that the consumer characteristics that are not observable continuously depend on the observable characteristics (for example, on age). McFadden wrote that in its initial formulation, the Random Utility Maximization model (RUM) - the model for the maximisation of utility in the presence of elements of chance - was the behavioural hypothesis, which was based on the standard model, in which chance was related to the nonobservable (implicit - O.) heterogeneity in tastes, past experience, and information on signs of alternatives. ${ }^{70}$ As noted, McFadden includes the conditional assumption of the dependence of the distribution of the observed heterogeneity from the unobserved. According to him, the revealed consumer preferences are functions of their genetically programmed reference set of tastes, past experience, and the nonobservable component. McFadden represents preferences as a form of continuous functions of consumer characteristics, the consumption level, and the signs of goods. Consumers differ according to characteristics that are not observable, such as the reference sets of their tastes and the mechanisms, which help them form their perceptions. For example, the tastes and perceptions of an individual are directly connected with his age, as long as there are no fundamental shifts in his observable characteristics. McFadden assumes that the conditional distribution of the characteristics that are

70 “WET”, vol. V., book 2, p. 402. 
not observable will continuously depend on observable characteristics. $^{71}$

This offers the chance to indirectly define the revealed preferences as functions of observable consumer characteristics.

This still leaves the question on the correlation between the role of genetically programmed «tastes», on the one hand, and the role of «mechanisms of perceptions», on the other hand, in the formation of preferences.

B. A strange contrast: genetics against psychology. At the same time, McFadden decisively contrasts psychological and economic theories of choice, as the former increasingly compete for leadership in this sphere of research. He wrote that in the psychological theories of the process of choice, an individual is presented as much less organised, and his behaviour is seen to be more adaptive and imitative, than in the standard economic model. The psychological descriptions of the process of decision-making are simultaneously both colourful and intuitive. Attitudes play a major role in how consumers set a decision-making task. In 1977, Kahneman wrote that the economist works with preferences and the psychologist, with attitudes. Affects and motivation are key determinants of installations; they also influence the perception, from which the link stretches out to the processing of the choice (see the dashes with arrows in the diagram given above). From the point of view of these theories, the calculation of utility estimations, carried out by economists, along with the maximisation of utility, represents the reduction of the diverse environment of decision-making to only one of the numerous factors operating in the environment, and the influence of this factor is very often overcovered by the effects of the general background, emotions, and errors in perception and judgments. Experimental evidence and self-reports on decision-making support the view that heuristic rules are the closest stimulants of people's behaviour. 72

Although, in the theory of choice, McFadden also takes into consideration changes in the external (in relation to inborn preferences) factors, such as psychological factors (perceptions, motivations, and affects), and institutional factors («rules»), he, nevertheless, definitely declares his adherence to the basic postulate of

\footnotetext{
${ }^{71}$ In the same place, pp. 402-403.

72 "WET", vol. V, book 2, p. 414.
} 
the traditional theory - that the deepest foundation of human behaviour does not consist of these factors, but of inborn preferences and of the genetic focus on their rational maximisation.

McFadden noted that the existence of preferences at the heart of behaviour is a vitally important scientific question for economists. If one can answer this affirmatively, then the evidence of the decisionmaking process, based on cognitive psychology, proposes only that economists should learn to see through a smoke screen of rules and distinguish the deeper level of preferences, which is necessary for estimating the productivity of economic policy. Personally, I am a cautious optimist and I hope that this question has an affirmative reply. The first reason for this optimism consists of the fact that a significant part of behavioural deviations from the standard model of economists can probably be explained by the illusions of perception and errors in information processing, than a more fundamental collapse of the definition of the concept of «self-interest». The second reason consists of the fact that the majority of rules, which we use, have an essentially protective character, protecting us from the choice of poor alternatives and, furthermore, the rules merely «codify preferences» $^{73}$.

Thus, McFadden states the following:

(1) Consumer preferences are inborn;

(2) These preferences are defined by a «genetically programmed reference set of tastes»;

(3) The system of preferences is predetermined and does not depend on the available alternatives;

(4) The rational choice among alternatives consists of the maximisation of ones «own interest».

Taken together, this means «consumer sovereignty».

In his lecture, McFadden does not explain what is meant by «a reference set of tastes» and by the rational maximisation of ones «own interest»; it seems that it is not possible to form a specific definition here, as consumers are not uniform, both in terms of their «reference tastes» and their individual mechanisms for forming perceptions.

${ }^{73}$ In the same place, pp. $414-415$. 
Similarly, it is just as difficult to specify «self-interest»; at least, until studies on the functioning of the human brain give an adequate representation of the cognitive mechanism (p. 417).

McFadden considers the core of the stated standard or rational model of economic science correct, but introduces a number of additions and restrictions to it, which I will discuss further. Here, I will underline the main point: McFadden boldly and resolutely emphasised the genetic nature of the central category of modern economic theory - of «preferences». In this way, he recognised the indissoluble link between modern economic theory and genetics. Moreover, the global scientific community recognised this by awarding the Nobel Prize to McFadden. (From here, in my opinion, it would be logical to conclude that the «standard» economic theoreticians need to urgently study the most recent achievements in genetics and neurophysiology).

Having noted McFadden's fundamental contribution, I also feel compelled to add some criticism. As can be seen from the material in chapters 1 and 2, the genetic nature of «preferences» has been noted not only by psychologists, but also a number of prominent economists, including Marshall, Keynes, and Kondratiev - however, in different terms. In fact, what is the «set of tastes» and «preferences»? They are requirements, «built» in a certain system of priorities, correlated with the set of available alternative ways of satisfying them. Inborn requirements are set together with the psychological mechanisms of their realisation, which are natural instincts (complex reflexes). Every human organism, along with general properties, also has specific inborn characteristics, which results in the distinctions in the requirements and actions of instincts. All this has been known for a long time, however, it seems that only now has it begun to be taken into consideration by «standard» economic theory.

Now, I will address the additions and restrictions that were introduced by McFadden in the «standard» model. First, he proposes that «past experience» should be taken into account, without explaining what he means by this. This can be the experience that is transferred through upbringing from generation to generation, and it can be the experience of an individual, which has become a habit. In the former case, it can be the «instilled» requirements and instincts, which result in «preferences» that are as rigid as inborn «reference tastes»». 
In other words, McFadden does not have a clear idea about the structure of the human psyche and about the correlation in this structure between genetics, education, experience, and consciousness. In McFadden, this results in the opposition between genetics and the psyche, on the one hand, and the psyche and institutions, on the other hand. McFadden himself indirectly recognises this lack of understanding, when he makes the reservation that «the standard model» will remain as the basis of economic policy only until the time, when studies of the functioning of the brain come up with adequate concepts about the cognitive mechanism.

McFadden wrote that as long as studies of the functioning of the human brain cannot adequately explain the cognitive mechanism in the selection of a wide spectrum of economic decisions, the standard model, with the added feature of taking into consideration regular illusions of perception, will remain the best basis for estimating the productivity of the majority of the programs of economic policy.

In conclusion, McFadden quotes a wider list of factors that influence preferences. He was convinced that in future the basic RUM, the theory of decision-making, which assigns a much bigger weight to the role of experience and information in the formation of perceptions and in the expression of preferences, and also takes into account the use by carriers of preferences of certain rules, may be able to basically describe behaviour regarding economic choice in the markets, in questionnaires, and in laboratory experiments.

Obviously, one needs to perceive this list not so much as a description of the theoretical system of choice, as much as an appeal for the creation of such a system, taking into account the listed factors, but with one condition: that «self-interest» remains the genetic basis of choice.

C. Amartya Sen: ethics against «mental conditions». Preferences are a category, closely connected with the category of welfare; the maximisation of welfare for the individual, according to neoclassical theory, is attained by the realisation of his preferences.

As we saw, preferences were at the centre of McFadden's attention, when he developed the theory of choice; in the same way, they were also at the centre of attention of another Nobel Laureate,

\footnotetext{
74 "WET", vol. V, book 2, p. 417.

75 Quotations, essays, p. 437.
} 
Amartya Sen, when he was engaged in developing the theory of public welfare. However, contrary to McFadden, who believed that individual preferences reveal the deep genetic bases of economic behaviour, Sen does not consider this to be the case. Pleasures, desires, values, utility, etc. (everything that, according to McFadden, makes up the genetic basis of preferences), Sen diplomatically calls «mental states», which, in his opinion, probably reflect accustomisation to a certain social status and way of life, rather than the true welfare of an individual.

According to Sen, one needs to characterise the welfare of an individual, based primarily on universal ethical principles and rational social judgments; subjective evaluations should be used as additional information. It is the same approach, which McFadden in his lecture ironically called «the maximum happiness for the greatest number of people».

However, Sen argues effectively to substantiate his approach. To a significant extent, this argument is reminiscent of Marshall's argument (given in chapter 2), where the latter defines the psyche of workers as a variable, depending on their work conditions, on the one hand, and the level of their incomes, on the other hand.

Sen wrote that interpersonal comparison of personal welfare, or individual benefits, should not be based only on the comparison of mental states. According to him, reasonable ethical bases can actually exist in order that one does not unduly concentrate on the comparison of the mental conditions of pleasure or desire. Utility can be sometimes very subject to the influence of constant deprivation. A poor and hopeless man, who does not have a way out; the crushed worker, living in conditions of exploitation; or an enslaved housewife, in a society with a deep-rooted inequality towards women; or a citizen subject to tyranny in a severely authoritarian society - can all become used to their deprivations, they can take pleasure in small achievements, and can change their desires according to the degree of their achievability (thereby, increasing the probability of their execution). However, their success in adapting in such a way will not relieve them of their deprivations. The measurement of pleasures or desires in certain cases appears to be absolutely inadequate in 
reflecting the degree of the real deprivations, experienced by an individual. $^{76}$

Sen believes that for the definition of such a degree it would be better to consider not individual evaluations and preferences, but the real requirements of incomes, or sets of goods, or resources.

Sen was truly convinced that individual advantages (preferences O.) should be estimated from the point of view of the possibilities of individuals to live in a way, which they have reason to appreciate. He argued that such an approach focuses attention on independent freedom, which people possess, instead of being limited to end results, which they receive. The use of interpersonal comparisons can only be partial and is quite often based on a mixture of various points of view. However, the use of such types of partial comparisons can significantly change the informational basis of rational social judgments.

However, if one does not value the welfare of an individual, according to his subjective outlook, but from the position of a generally-accepted standard of ethics and «rational social judgments», then the principle of «the sovereignty of the consumer» and the structure of «the standard economic theory» are undermined. Wishing, probably, to ease this conflict, Sen introduces a complex concept of «the possibility of individuals to live in a way, which they have the basis to appreciate» as the base for evaluating preferences. In other words, Sen proposes imputing to individuals certain «sociallyrational» and ethically defensible sets of preferences, and considering that individuals appreciate these sets of preferences as the expressions of their «independent freedom», which are suitable for them.

At first glance, Sen is trying to combine the incompatible individualism and the social approach in valuing individual welfare. However, later in this book, we shall see that both these approaches are not only compatible but are also genetically placed together in the human psyche. Unfortunately, Sen treats this contradiction insufficiently deeply, relating both the actual mentality of individuals and ethical socially-rational evaluations to socially-political phenomena.

\footnotetext{
76 Amartya Sen, "The Possibility of Social Choice", "WET", book 2, p. 270.

${ }^{77}$ In the same place, p. 271.
} 
McFadden's approach to preferences is deep, but narrow; Sen's approach is broad-ranging, but superficial.

\subsection{The Psyche and Informal Rules of Economic Behaviour: George Akerlof and Joseph Stiglitz}

In the previous section two contrasting views on subjective evaluations of utility were presented: according to one of them, these evaluations are the natural rational-economic basis of choice, whereas «external» influences represent only «hindrances», and according to the other view, which gives priority to a socially-ethical choice, and assigns a subordinated position to subjective value judgments, thus, practically depriving them of their right to be considered rational.

In this section, the points of view of two economists - who call into question the thesis that the behaviour of market participants is rational and egoistical and that it pursues the aim of maximising their personal benefits (or the maximisation of anything else) - are considered.

A. Wild lions and «behavioural macroeconomics». George Akerlof interprets as «wild lions» the psychic and social factors of economic behaviour, which, in his opinion, were originally discovered by Keynes. Earlier, in chapter 2, we saw, how Keynes represented the psychic bases of consumption, savings, cash reserves, investments, and how the psyche of market participants can lead to a deficiency in effective demand, decline of investments, and involuntary unemployment. The Keynesian recipe for «taming the lions» consisted, primarily, in the policy of monetary expansion.

Although it was effective in the 1950s and 1960s, in the 1970s this policy no longer stimulated employment, but urged on inflation. On this basis, the «monetarists» declared the Keynesian theories bankrupt. In the new conditions, it turned out that solvent demand grew and unemployment did not fall; in other words, unemployment was not a consequence of the deficiency of «effective demand», as Keynes confirmed. In that case, what generated the unemployment?

Monetarism does not answer this question, but «removes» it, declaring that chronic unemployment is «voluntary», and its existing level is «natural». 
Akerlof's position is directed not only against monetarism, directly denying Keynesianism, but also against «neoclassical synthesis», uniting Keynesianism with «neoclassicism» (and assuming that laws of market equilibrium will again come into force, as soon as the state's monetary policy provides sufficient «effective demand»).

To date, Keynes' "General Theory» has made the greatest contribution to behavioural economy. Almost everywhere, Keynes explained market failures in terms of psychological propensities (consumption) and irrational behaviour (speculation on the stock markets). Immediately after its publication, economists (various supporters of the «neoclassical synthesis» - O.) «tamed» Keynes' theory. They tamed it, by transferring it into smooth mathematical formulas of the classical economy (Akerlof's Notes: Hicks, 1937, Patinkin 1956 - O.).

Akerlof characterises the human psyche by the set of features, received not by abstract reasoning, but on the basis of the analysis of the real phenomena of the market economy, which neoclassical (including monetarist) theory, based on the psychology of rational egoism and the maximisation of individual utility, was not able to explain.

Reciprocity, justice, self-identification, money fetishism, a disinclination to sustain losses, the herd instinct, and procrastination help to explain the essential distinctions of the real economy from the general equilibrium model of perfect competition. According to Akerlof, it follows from this that macroeconomics should be based on similar behavioural views ${ }^{78}$.

According to Akerlof, there are at least six essential differences in the macroeconomic sphere of the real economy from the economy, which is depicted by «the general equilibrium model». He wrote that «the new classical macroeconomics» (i.e. «monetarism») faced great difficulties in evaluating at least six macroeconomic phenomena:

- The existence of involuntary unemployment;

- The influence of monetary policy on production and employment;

${ }^{78}$ WET, vol. V, book 2, pp. 475-476. 
- Preventing the acceleration of deflation under a high rate of unemployment;

- The wide prevalence of not fully funded pension funds;

- Exceptional instability of share prices in comparison with their real profitability;

- The steady presence of self-destructive lumpenproletariat. ${ }^{79}$

Monetarism («the new classical macroeconomics») appears incapable of explaining these phenomena, precisely because it is based on microeconomic foundations, which are contrary to reality.

Note the contrast in the method of the interpretation of the economic behaviour of market participants, supporting the neoclassical approach, on the one hand, and Akerlof, on the other hand.

If the former reduce all the various displays of this behaviour to only one feature of the psyche, namely, to the aspiration to maximise individual welfare, on the contrary, the latter explain each such separate display by a specific set of a series of features of the human psyche.

Thus, the establishment of the level of wages, according to Akerlof, is defined by features of the psyche, such as the ones given below:

1. Labour morals (i.e., the habit for fair and diligent labour, the presence of a sense of responsibility for the results of ones labour, the habit of working discipline, etc.);

2. Justice (i.e., the inborn ability and habit of both employers and employees to adhere to the standard informal norms and rules in a given society in the distribution of work and the income received for ones work);

3. Insiders (i.e., the psychic predisposition and preference, offered, both by the employer and employees, to those who are already working in the firm, in preference to «strangers», i.e., those who have only applied for a position to work in the given firm);

79

See quotations, essays, p. 446. 
4. Asymmetric information (i.e., the fear of the risk of hiring new employees, about whom the employer knows much less than he does about the employees already working at the firm).

The developed models have shown that factors such as labour morals, justice, insiders, or asymmetric information, essentially give employers the grounds to pay employees more than the minimum salary, as a means of attracting them. Such an incentive payment is above the labour market's clearing wage; therefore, workplaces are rationed, and some workers cannot receive them. These are the workers, who find themselves forced out of work. ${ }^{80}$

Based on the listed features of the psyche of workers, the employer pays them higher wages, than the wages, for which new employees with the same qualification would be ready to work, since the employer counts on reciprocity from his staff, in terms of efficiency, quality, and work discipline.

Why do firms pay more than a firm lower limit? According to Akerlof, a psychological and sociological explanation of the given phenomenon is the most convincing. The three most important reasons are: reciprocity (see the anthropological concept of an exchange of gifts), justice (see the theory of the formation of groups in psychology and the reference group theory in sociology) ${ }^{81}$, and also the encouragement of work discipline.

Akerlof notes that the alternative version of the theory of the incentive payment, based on asymmetric information, considers superfluous earnings as a disciplinary measure. In the Shapiro-Stiglitz model, firms pay «high» wages in order to reduce the desire of an employee to evade (minimise) work.

According to Akerlof, the «Theory of Work Discipline» satisfies the standard economic logic to a greater degree, than the approach based on sociology and psychology. However, the sociological and psychological approaches, including the «insider-outsider», rely on factors outside the standard set of economic factors and probably, on the whole, explain the phenomenon of involuntary unemployment better. $^{82}$

\footnotetext{
${ }^{80}$ WET, vol. V, book 2, pp. 450-451.

${ }^{81}$ WET, vol. V, book 2, p. 452.

${ }^{82}$ Op. cit., p. 453.
} 
The distinction in the approaches of Akerlof and Shapiro-Stiglitz consists of the fact that the former assumes the initial presence of a cooperative psyche both in the employer and in the employees, whereas the latter considers that workers are initially disposed to «shirk» work, i.e., have no internal moral stimulus to work fairly and it is necessary to interest them in it financially. To a certain degree, they are both correct, as the psyche of individuals (including the psyche of employers) is not uniform. However, both these approaches can basically be characterised as "co-operative»; they differ from the neoclassical, according to which both the psyche and material interest of the employer are aimed at minimising wages, and the psyche and interest of employees are aimed at maximising wages. In this case, a «struggle for power» (strikes and lock-outs) are the usual way of «regulating» wages, and egoism and mutual aggression are its psychic basis. Here, again «the neoclassical» approach is close to the Marxist approach. (With the difference that for the former, such an order of affairs is eternal and «natural», and for the latter, it is inevitable for capitalism, but historically it is transitory).

For Akerlof, Shapiro, and Stiglitz, an overestimated level of wages (in comparison with the market-clearing wage) is the «natural» result of the interaction of psychic, social, and informational factors; and, consequently, the reverse side of this relation, the involuntary unemployment of those, who are left out of operating companies, is equally «natural».

The conclusion that arises in the presence of the preconditions, described by Akerlof, in conditions of growing solvent demand, employers will try not to expand employment, but raise the price of their goods and, simultaneously, the salaries of their employees. Thus, inflation turns out to be interconnected, through overestimated wages, with involuntary unemployment.

Here, we are dealing not only with a criticism of monetarism, but also with a significant correction of Keynes' position, which explained the phenomenon of involuntary unemployment in an entirely different way.

I have dwelled only on the first of the six points («charges») made by Akerlof against monetarism, namely, its inability to explain involuntary unemployment. The remaining «charges» will be considered in subsequent chapters, in connection with the analysis of the interrelation between the psyche, on the one hand, and specific 
economic institutions, on the other hand. As far as unemployment is concerned, this example illustrates how Akerlof represents the psychic basis of economic behaviour.

I have again listed the psychic characteristics of economic behaviour given by Akerlof: work morals, reciprocity, justice, insiders, self-identification, the fetishism for money, disinclination to sustain losses, the herd instinct, procrastination, and asymmetric information. All these characteristics can be easily reduced (fully or partially) to those inborn existential requirements and instincts, written about by psychologists, to acquired requirements and instincts, and to habits in behaviour and thinking.

In particular, this refers to the instinct of self-preservation, the requirement for trust and protection, the requirement for belonging, and the requirement for self-realisation, and also to the fact that in the natural human psyche, the mechanisms of due care about the future are not inserted (as in the case of some animals, birds, and insects) and that inertia and deformations of perception are inherent in the human psyche.

Different elements and aspects of the human psyche in different forms of economic behaviour operate as various «complexes», as interconnected (as a result of repetition) combinations of certain requirements, instincts, and skills (realised abilities). In Akerlof's list, psychic «complexes» such as «institutions», operating as habitual forms of behaviour, are named.

It is typical that Akerlof does not name such forms of behaviour, in which egoism and aggression are shown, both of employers and employees (lock-outs, strikes, strike busters, systems of penalties, contract infringements, etc.). One should not forget that such forms of behaviour were widespread up to the Second World War, which could not but affect Keynes's theory.

At the same time, Akerlof writes about a «counterculture», which is essentially an aggressive reaction of a part of the representatives of ethnic minorities to an (essentially) equally aggressive rejection of these minorities by the dominating national «culture». The "counterculture» institution, on whose basis lies the conflict of psychological «complexes», became a significant factor in the labour market in a number of countries.

B. Asymmetric information: link with the «psychology of the market». If psychological and social factors of economic behaviour 
are of primary interest to Akerlof, another critic of the theory of market balance, the Nobel Laureate (2001), Joseph Stiglitz, concentrates on the asymmetry of information, in which conditions the market functions and which the market itself generates. Under such an asymmetry, market participants cannot make decisions, supporting market equilibrium.

In other words, the classical and neoclassical theories, explaining the behaviour of market participants, proceeding from a principle of equilibrium, are incorrect. Each market participant behaves according to the information accessible to him and, at the same time, aspires to minimise the arising uncertainty and risk.

In his «Nobel lecture», Stiglitz stated that he hoped to show that information economics represents a fundamental change of the paradigm, dominating economic science. ${ }^{83}$

According to Stiglitz, not accounting for the «information» factor has caused both the vulnerability of Keynesian theory and the inconsistency of monetarism in its attempts to construct a neoclassical macrotheory.

Stiglitz argued that in the 1970s, economists sharply strengthened their criticism of Keynesian ideas, partially because the latter did not have a sufficiently rigorous microeconomic base. Attempts to construct a new macroeconomic doctrine on the basis of traditional microeconomics, which assumed smoothly functioning markets, were doomed to failure. ${ }^{84}$

Stiglitz bases his thesis that the asymmetry of information causes a basic unbalance of the market on a number of data.

Firstly, the lack of reliable information about clients does not allow one to differentiate properly the interest rate on credit, corresponding to the level of risk, and in that way support equilibrium in the capital markets.

Secondly, the asymmetry of the information in the labour market forces employers to resort to paying incentive salaries and to limiting demand for work. Psychological factors, such as the state of a person's morale, caused by the feeling that a person is receiving fair wages, can affect the efforts made by workers and, in certain cases, are a

83 Joseph E. Stiglitz, "Information and a Change of the Paradigm in Economic Science", WET, vol. V, bok 2, p. 235.

${ }^{84}$ In the same place, p. 537. 
convincing argument in favour of the theory of incentive wages. The persistence with which economic theorists ignore factors, which are not only in the centre of everyday life but even included in business school programs, is extremely surprising. ${ }^{85}$

Thirdly, the asymmetry of information is generated by a change of the strategy of firms with a change of management, whereas the «equilibrium» theory assumes an invariable strategy.

Fourthly, market participants consciously create problems with information for their competitors and clients as an element of the use of their «market strength». The most fundamental reason that markets with incomplete information differ from those with full information disclosure is that actions (including choice) transfer information, and market participants know this, which, in turn, influences their behaviour $^{86}$.

Furthermore, in addition to the problem of the presence of authentic and accessible information, there is the problem of the perception and processing of the information, and also the problem of choice, based on preferences. All these problems are connected with the psyche of the market participants and their influence on each other.

The asymmetry of the information is connected to the fact that in conditions of development, not only technologies and knowledge, but also preferences, aims, and ways of thinking, change.

The standard theory starts with the supposition that technologies and assumptions are fixed. However, changes in technology, research, and development form the core of capitalism. The new information economics, expanded to include changes in knowledge, has at last started to systematically study these bases of the market economy.

Reflecting over development problems, Stiglitz also increasingly came to the conclusion on the inadequacy of the assumption of the fixity of preferences. He criticised the development strategy of the Washington consensus partly because they understood development only as the accumulation of capital and the correction of economic disproportions. Stiglitz considered that development was a much more fundamental transformation of society, including a change of «preferences» and aims, the acceptance of the necessity of changes,

\footnotetext{
${ }^{85}$ In the same place, p. 603.

${ }^{86}$ WET, vol. V, book 2, p. 554.
} 
and the refusal of many traditional ways of thinking. Stiglitz noted that many modern economic theorists accepted the additional assumption that judgments (opinions), to some degree, are rational. However, many aspects of economic behaviour are barely compatible with this hypothesis ${ }^{87}$.

There is no doubt about what Vernon Smith has in mind, in particular, about the concept of «ecological rationality», which is considered by me in the following section. Stiglitz rejects it, probably because Smith starts with the concept of market equilibrium, which Stiglitz considers fundamentally flawed. However, do all rational (including intuitively rational) solutions lead to market equilibrium? Moreover, do all irrational («intuitive») solutions disturb this balance?

\section{4. «Bifurcation» of Economic Knowledge: Daniel Kahneman and Vernon Smith}

The specificity of the views of these scholars consists of the fact that the cognitive process of the subject (i.e., the process of the perception and processing of information and of decision-making) is considered by them not as one, but as a «double» process, proceeding within the limits of two relatively independent systems of the psyche the intuitive and the conscious. Moreover, depending on the character of the initial information («stimulus») and the features of the perceiving subject, either one of the systems can function, or both simultaneously, correcting each other.

According to these authors, it is characteristic that economic behaviour in most cases is governed by intuitive «cognitions», and rational thinking is used only for correction. These conclusions in many respects concur with the analysis of economic behaviour, carried out by Kondratiev 70 years earlier (see chapter 2).

Through these works, economic science discovered the fact (already known to psychologists for a long time) that a person's perception of reality through his sensual organs occurs not only through consciousness and is processed into active reactions not only through thinking, but also directly through the preconsciousness and

${ }^{87}$ WET, vol. V, book 2, p. 602. 
the unconscious sphere (i.e., the sphere of inborn instincts). In other words, all spheres of the system of the psyche are capable of reacting to the impulses, arriving «from the outside» (and «from within» the psyche itself) both simultaneously, and separately.

This explains many «irrational» phenomena in the economy, but at the same time makes the task of its theoretical and logical modelling extremely complicated.

A. The system of intuition and the system of reasoning. The psychologist, Daniel Kahneman, who, for many years investigated (together with Amos Tversky and others) economic behaviour, specified that recently scientists working in this area were able to come to an agreement, regarding which characteristics form the basis of the distinction of two types of cognitive processes, named «System $1 »$ and «System 2».88

\section{Two Types of Cognitive Processes: System 1 and System 2}

\begin{tabular}{|l|l|l|l|}
\hline PERCEPTION & $\begin{array}{l}\text { INTUITION } \\
\text { System 1 }\end{array}$ & $\begin{array}{c}\text { REASONING } \\
\text { System 2 }\end{array}$ \\
\hline
\end{tabular}

\begin{tabular}{l|l|l} 
P & Speed \\
R & $\quad$ Simultaneity \\
O & $\quad$ Automatism \\
C & Absence of significant efforts \\
E & $\quad$ Associativity \\
S & $\quad$ Slowness in learning
\end{tabular}

Slowness

Sequence

Controllability

Labour-intensive

Orientation to the norm

Flexibility

88 Daniel Kahneman, "Maps of Bounded Rationality: a Perspective on Intuitive Judgment and Choice", WET, vol. V, book 2, p. 633. 


\begin{tabular}{|l|l|l|l|}
\hline $\mathrm{d}$ & Perception & & Judgments with notions \\
$\mathrm{g}$ & Current stimuli & & Accounting for the past, present, and future \\
$\mathrm{N}$ & $\begin{array}{c}\text { The link to the } \\
\text { Can be aroused by language }\end{array}$ \\
$\mathrm{T}$ & stimulus & & \\
$\mathrm{N}$ & & & \\
$\mathrm{T}$ & & & \\
$\mathrm{S}$ & & & \\
\hline
\end{tabular}

\section{Figure 3.2}

As Figure 3.2 shows, perceptions and intuitive processes of System 1 generate impressions concerning the signs of objects of perception and reflection. According to Kahneman, these impressions are not subject to the will of the people and do not require verbal expression. On the contrary, judgments are always obvious and bear their intended character, irrespective of whether they are stated openly or not. Thus, System 2 refers to all judgments, irrespective of where they arise, from notions or from well considered conclusions. The characteristic is applied «intuitively» to judgments, directly reflecting impressions. ${ }^{89}$

The weakness of System 2 opens the path to the prevalence of intuitive judgments. One of the functions of System 2 is to monitor the quality of thought processes and obvious behaviour. Usually, monitoring has a languid, uncertain, and flexible character, including the monitoring of false judgments. ${ }^{90}$ Intuitive judgments prevail to a greater degree the more their object is represented as being accessible without understanding.

According to Kahneman, the accessibility and the ease with which specific cogitative content comes to mind are the key concepts of the modern analysis of intuitive judgments and preferences. The defining property of intuitive judgments is that they come to us spontaneously,

89 Daniel Kahneman: "Maps of Bounded Rationality: a Perspective on Intuitive Judgment and Choice", WET, vol. V, book 2, p. 632.

${ }^{90}$ In the same place, p. 634. 
like perceptions. ${ }^{91}$ The availability concept means the notions of the expressiveness of the stimulus (of the stimulating influence), selective attention, and activation of the (primary) response. ${ }^{92}$

For the theory of economic choice, it is important to conclude that in the presence of experience and the deficiency of time «System 2» does not work at all, and decisions are accepted intuitively: the fundamental discovery of research in the field of intuitive decisions has been that individuals, experienced in decision-making and working under the pressure of events, such as, for example, heads of fire services, seldom require a choice between different alternatives, as in most cases only one of them enters their mind. The rejected variants are simply not represented to them. Doubt represents the phenomenon, encountered in System 2.

At the same time, Kahneman recognises that the concept of the internal mechanism of the acceptance of intuitive decisions has not been understood. The factors defining accessibility are known; however, a general theoretical approach to it is still lacking; also, the prospect of obtaining such an approach in the near future is also missing. At the same time, he states that in the context of the research of judgments and decision-making processes, the absence of the theory practically does no harm and does not exert an influence on the utility of the concept.

However, the mechanism of accounting for the interaction between «System 1» and «System 2» has been developed and checked empirically. ${ }^{93}$ Kahneman's reasoning has been built by developing a single general idea, according to which the highly accessible impressions, generated by System 1, operate judgments and preferences, until they are transformed or rejected by the conscious processes taking place in System 2. The chosen model has predetermined the research program: in order to understand what represents judgment and choice, one should study the factors, defining the high degree of accessibility and the conditions, in which System 2 dominates over or corrects the results of the activity of System 1, and also the rules of the introduction of the corresponding amendments. ${ }^{94}$

\footnotetext{
${ }^{91}$ In the same place, p. 626.

92 WET, vol. V, book 2, p. 639.

${ }^{93}$ WET, vol. V, book 2, p. 639.

${ }^{94}$ WET, vol. V, book 2, p. 674
} 
What are the conclusions that have been drawn as a result of the research conducted under this program?

According to Kahneman, the model offers four variants for the development of events in the processes of judgments or decisionmaking:

(i) The intuitive reaction is absent and the judgment is born in the heart of System 2;

(ii) The intuitive judgment or general idea appears and,

(a) it is supported by System 2;

(b) it forms a basis for introducing the amendments, corresponding to the other characteristics of the situation;

(c) it is considered to be incompatible with the subjectively well-founded and adequate rules and it is blocked, without receiving obvious expression. ${ }^{95}$

Which of these four mutually exclusive (completely or partially) variants should be considered as prevalent?

Kahneman argues that the relative frequencies of the given outcomes cannot be precisely established; however, random observation leads one to consider the existence of the following order (from the most to the least frequent):

(iia) - (iib) - (i) - (iic)

Kahneman wrote that in most cases, human behaviour is intuitively qualified (i.e., assumes the presence of specific knowledge, skills, and abilities), and is obvious and successful. In certain cases, there is the perception of the need to correct intuitive judgments and preferences; however, judgment remains tied to the intuitive impression. In such cases, the correction is most probably insufficient rather than excessive (superfluous). The widespread conservative point of view consists of the fact that the variables ignored by intuition, remain underestimated also in thought out judgments. ${ }^{96}$

\footnotetext{
95 In the same place, p. 676.

${ }^{96}$ WET, vol. V, book 2, p. 675.
} 
Despite all the cautiousness and vagueness of Kahneman's general conclusion, its fundamental meaning has not raised any doubts: according to him, research has shown that human behaviour is defined more often by intuition (in essence by reflexes), and only then, on this basis, by calculations. At the same time, Kahneman specifies two gradations of this general rule (iia) and (iib), without attaching them to different types of psyche. He does the same for variants (i) and (iic), which completely drop out of this general rule.

The scientific merit of Kahneman's concepts lies not only in the fact that they have partially proved the hypothesis about the domination of intuitive decisions over rational decisions in behaviour, but also in the fact that they have explained a number of typical errors of intuitive decisions.

The domination of intuition is explained by the fact that intuitive decisions are reactions to aspects of a reality more accessible to perception. However, distortions are inherent in such a «simplified» perception also:

- The similarity of objects is accessible to perception easier than distinctions;

- It is easier to perceive the change of objects than their absolute value;

- Average values are easier to perceive than sums;

- More accessible values are given a greater relative density than less accessible values (the effect of «standing out» and «attachment»).

However, Kahneman does not answer the main question: why is intuitive behaviour successful? He does not even raise this question. This is probably, because the answer would require discovering the internal structure of the psyche. This structure would allow one to simultaneously answer the question on the success of intuitive behaviour and the question about its mistakes. In this aspect, Kahneman merely states that in general, the field of the psychological theorisation of the status of factors of accessibility is similar to the status of factors of the grouping of perceptions. In both cases, there is no general theory; there is only a set of powerful empirical 
generalisations, which are a strong base for the construction of experimental forecasts and models of the phenomena of a higher level. Unlike the gestalt principles, which were listed a long time ago, work on a universal list of factors, influencing and mediating accessibility still needs to be carried out in the future. The list will be long, but many of its elements are already known. ${ }^{97}$ (The factors, influencing «accessibility», which Kahneman has in mind here, are listed above).

For now, Kahneman's empirical research leads to the conclusion that System 1(rather than System 2) is the basis of decision-making by an individual because it is more effective than System 2. It is more effective in the sense that it provides satisfactory decisions for a person with an average level of abilities and preparations, whereas System 2 would result in heavy losses and mistakes for the same person, if he does not resort to intuition. Kahneman in his «model of judgments» - variant (i) - assumes the possibility of the absence of an intuitive reaction. I believe that such a possibility can exist only when «judgments» are formed under a specially made program, from which parameters and variables, capable of reflecting the influence of the intuition of those who form them, are excluded in advance. The functioning of System 1 (rather than System 2) merely requires correction by System 2. It turns out that Kahneman, and not Stiglitz, raises the question of the introduction of a new scientific paradigm. However, the prevalence of intuition over reasoning can also be considered as a reaction to the asymmetry of the information, which lowers the value of logic in comparison to experience.

B. Constructivist and ecological rationality in market and social exchanges. If the mechanism of market equilibrium cannot operate in conditions of limited and asymmetric information and in the even more limited possibilities of its rational «processing» with subjects of the market, then how is such an equilibrium nevertheless reached? According to Vernon Smith's concept, it is reached empirically by means of «trials and errors» in the course of cultural and biological evolution. This evolution consists in the «emergent» (i.e., carried out necessarily) development, in families and in society, as a whole, of rules, traditions, and moral principles, which underlie economic institutions (property rights in a market exchange and social

${ }^{97}$ WET, vol. V, book 2, p. 675. 
rules in «the personified» exchange between persons known to each other).

By means of this system of institutions there is an aggregation of the dispersed asymmetric information on supply and demand and «effective prices, clearing the market» are formed. Smith warns that the real process of the aggregation of the dispersed asymmetric information cannot in principle be fully understood by definition.

One needs to consider as the main methodological thesis of Smith's concept its firm position that in human behaviour it is impossible to oppose rational and irrational behaviour as there are two kinds of rationality, the conscious («constructivist») and the unconscious («ecological») rationality. According to Smith, Cartesian constructivism uses reason for designing the rules of actions of individuals and institutions, providing optimal outcomes for society. It creates a standard model of a social and economic science. However, most of the knowledge used by us and our decision-making ability has an unconscious character. Our brain protects attention resources as well as conceptual and symbolical thinking, as they are scarce, and delegates the majority of the work on decision-making to independent processes (including emotions), which do not demand conscious attention. The emergent social mechanisms even if they were initially constructivist, should possess the features of survival, including the ability to account for the costs of missed possibilities and calls of the environment, remaining invisible to constructivist modelling. This leads to an alternative concept of rationality, to ecological rationality, according to which the emergent order is based on processes of trials and errors of cultural and biological evolution. These processes lead to the development at the family and social levels of rules of action, traditions, and moral principles, which form the foundation of property rights in a depersonalised exchange and social rules in an exchange between separate persons known to each other. As a method of studying economic rationality, Smith used rational reconstruction; for example, the principle of reciprocity or a system of preferences considering the interests of others, and investigated through this method individual behaviour, the emergent order in human culture and public institutions, and their stability, variety, and evolution in time. 
Experiments allowed him to verify the statements, received on the basis of rational reconstruction. $^{98}$

What have the experiments yielded? They do not provide the «ultimate truth», but a «working hypothesis».

During these interactions of individuals in the market between many minds with the mediating role of rules, a process of aggregation of the dispersed asymmetric information takes place, more or less leading to the rapid convergence to conditions of competitive balance, if such conditions exist.

Each experimental market has its own unique character with a dynamic trajectory distinct from others.

This information is concentrated in a static or dynamic social and economic environment, where the supply and demand are formed; it should be aggregated to provide effective prices, clearing the market. According to Smith, one can never fully understand how this process occurs in the real world as it demands information, which is given to a separate mind, and is not accessible to it. ${ }^{99}$

The total order is invisible to its participants unlike its fruits, when they ripen. Market participants find out, what they need to know, in order to attain optimal results for themselves within the restrictions, which are outlined by others.

Rules arise as a spontaneous order; they are found, instead of projected intentionally with the help of a calculating mind. A so-called mind of society emerges, which solves difficult organisational problems without cognitive consciousness. ${ }^{100}$

According to Smith, this process organises a compromise between transactional costs, servicing, supervision, and efficiency of distribution in such a manner that the institution itself generates order in the economy, corresponding to the problem, which it is trying to resolve.

Smith goes on to state that reciprocity, trust, and the reputation of the person deserving trust are very important in the personalised exchange, where the formal markets do not justify the costs associated with them, however, nevertheless, it is necessary to profit from the

98 Vernon L. Smith, "Constructive and Ecological Rationality in Economic Science", WET, vol. V, book 2, p. 755.

${ }^{99}$ In the same place, p. 756.

${ }^{100}$ WET, vol. V, book 2, p. 756. 
exchange. They also play an important role in the conclusion of contracts, as it is impossible to foresee all the loopholes to benefit at the expense of the other side.

Smith states that people do not have to be selfish. The markets should not in the least destroy that base, on which they have probably arisen, namely, the social exchange between members of a family, friends, and partners. ${ }^{101}$

In a community, individuals should be active participants in social exchange and at the same time vigorous traders in the market; however, as follows from Hayek's concept about «two worlds», the ecologically rational coexistence of the personalised and nonpersonalised exchange is not constructive in the Cartesian sense of design. Therefore, there is always a danger that the rules of a «personalised exchange» will be illegitimately used to manage the expanded order of the markets or to change it. In the same way, there is a danger that the rules of a non-personalised market exchange can be used illegitimately in relation to the network of social interaction.

Thus, Smith partially answers Douglass North's recognition that in evolutionary neoinstitutionalism (which he represents) «there is no theory». Smith «inserts» the process of spontaneous institutional evolution in the system of a dynamic market balance as a basis of the latter. At the same time, the subject of the market should necessarily be a carrier of "ecological rationality», which essentially means the following: (1) To be the carrier of the norms, rules, and traditions that are developed and checked in practice; (2) To perceive information through them; (3) To make decisions intuitively on the basis of ones own experience; (4) To clearly see the border between the norms and rules of the personalised and non-personalised exchange.

According to Smith, the general system of basic norms and rules constitutes the foundation of both a competitive market and a «social exchange»; in either case, «ecological rationality» controls behaviour. However, the basic distinction consists in the fact that in the second case these norms and rules are realised directly, and in the first case, through the supply and demand mechanism, market prices, and formal contracts.

\footnotetext{
${ }^{101}$ WET, vol. V, book 2, p. 757.

${ }^{102}$ In the same place, pp. 757-758.
} 
The conclusions from the materials of this chapter are presented in the short introduction to this chapter. Here, I will repeat them in another form.

Firstly, it is considered proved that (contrary to the neoclassical tradition) the economy is not a sphere, where the subjects of economic activities can make decisions, based on rational (in the Cartesian sense) thinking. Moreover, this also applies to the sphere of «the social exchange». Cartesian (purely logical) thinking can serve only as an auxiliary, correcting mechanism within the limits of the general psycho-rational system of the development of economic judgments. This is also connected to the conclusion that the thinking of economists-theorists also should not be Cartesian (where a chain of formal and logical conclusions is drawn based on a few premises).

Secondly, the nature of the behaviour of the subjects of the economy is defined by the genetic (inborn) bases of their psyche, and by acquired social norms, rules, values, and habits (i.e., institutions). Their actions are defined not by the aspiration to maximise utility, as is considered in the neoclassical tradition, but by the desire primarily to maintain the status quo, and avoid risk and uncertainty.

Thirdly, a market system, in which decisions are made by its subjects intuitively, proceeding from diverse psychosocial criteria, cannot be in equilibrium and gravitate to an optimum, as it inevitably contains asymmetric information, uncertainty, involuntary unemployment, and inefficiency. The accumulation of tension in such a system is prevented by the evolutionary, adaptive development of institutional systems and the state's social-economic policy.

This undermines not only the «neoclassical», but also the «neoinstitutional» mentality (as presented by Coase and Williamson) and favours the «post-Keynesian» and «evolutionary» theories. 


\section{Chapter 4}

\section{Psychogenomics: the Start of a New Stage in Studying Economic Behaviour}

\subsection{Questions that Economic Theory Cannot Answer}

Until now the character and structure of the inborn bases of human behaviour have not been scientifically established and the border between inherited and environmentally-caused (past and present) features of the psyche has been washed away. This did not allow for the possibility of answering Kondratiev's fundamental question about the limits defined by natural human nature on the social and economic transformations of a society and the acceptable forms of development of this society that do not cross over these limits, and, hence, the viable forms of development.

The unresolved fundamental problems of the human psyche (which are evident in the differences of opinions considered in the previous chapters, both among psychologists and among economists) interfere with the research on the behaviour of people in the economic sphere. The proposed economic theories rely, as a rule, on differently selected and specifically interpreted features of the human psyche. This was discussed in chapters II and III. In these theories, the human psyche is presented no less contradictorily, than in the concepts of psychologists.

Economists of different schools start with various initial assumptions relative to the following:

1. The direct purpose (motive) of economic activities: maximisation of monetary income, maximisation of well-being (usefulness), and the preservation of the level reached in either case;

2. The ability or inability of people to find consciously optimal (the most effective) decisions; 
3. Whether people are guided by principles of collaboration (cooperation) or competition (exploitation);

4. Whether, in terms of economic interests, people consider only their individual interests or both their own interests as well the interests of society;

5. The presence or absence of economic trust between counterparties;

6. Whether a focus on past experience, the imitation of current tendencies, or rational forecasts of future tendencies dominates economic decision-making?

It is clear that a different understanding of the human psyche lies at the heart of the divergences on these and other questions of economic theory.

The discoveries in genetics in the second half of the $20^{\text {th }}$ century and, in particular, the decoding of the structure of the genome, have opened a new epoch in the study of the natural foundations of the human psyche. Through the process of disclosing the functions of genes, «managing» various aspects of human behaviour, the ambiguities in the understanding of its natural foundations will be gradually narrowed. Already in the early 1990s, i.e., almost a decade prior to the decoding of the genome, Hjelle and Ziegler underlined the basic value of behavioural genetics, biochemistry, and neurophysiology to the «decisive changes» in psychology. According to Hjelle and Ziegler, the present stage of development of science will probably be noted as the century of biology and as a period when the achievements in behavioural genetics, biochemistry, and neurophysiology had an impact on the considerable and decisive changes in theoretical constructions and methods of psychological research. Nevertheless, except for Freud, Cattell, Eysenck, Maslow, and Rogers (the only five theorists mentioned in their book, who really recognise and underline the biological basis of behaviour), personologs traditionally only verbally recognised studying the neurophysiological, biochemical, and genetic components of a person's behaviour. Fortunately, today, the majority of personologs agree that individual distinctions are partially rooted in biological processes and genetic predispositions (Rowe, 1989). As our knowledge of the biological basis of behaviour and psychic processes increases together with the development of complex research projects, 
it seems that resistance to understanding personality in biological and genetic terms will be broken. ${ }^{103}$

The situation in modern economic theory, as we saw in chapter 3 , is significantly similar to the situation in psychology. The value of genetics in understanding economic behaviour has been acknowledged by only a few economists, and even then, in the most general and vague form. In this chapter, I will try to summarise the modern conclusions of genetics, directly concerning people's behaviour, and compare them with the treatment of the psychic bases of economic behaviour in the main branch of modern theory, mainstream economics.

Similarly to Euclidean geometry, based on two fundamental axioms, the basic direction of modern economic theory constructs complex mathematical sky-scrapers on the narrow base of two assumptions about behaviour: the individual as a rule acts rationally and generally aspires to maximise his well-being. But unlike the Euclidean axioms that rely on practical experience of construction and land surveys, the mainstream axioms are constantly called into question. The rationality postulate has been confirmed only by some data, and in the majority of cases it is contradicted by them, either completely or partly. The concept of the «well-being» of an individual has no standard interpretation; therefore, any actions of a person can be interpreted to be directed at maximising his well-being.

In reply to criticism, supporters of mainstream economics initially drew a basic line, differentiating between aims and means. The selection of an aim is defined by individual preferences, is irrational, and consequently cannot be the object of economic science; the aims of economic activities for an economist are parameters that are set externally. However, the means of achieving the externally set purposes are selected by a person absolutely rationally. Thus, in mainstream economics, a person acts as if he were two different persons: he irrationally sets certain aims for himself as one person, and he fulfils them absolutely rationally, as another person.

The further development of mainstream economics has proceeded in two directions.

103 Hjelle and Ziegler, "The Theory of Personality", "Piter", Moscow, St. Petersburg and others, 2005, p. 597. 
Firstly, attempts are being undertaken to rationally explain the structure of the priorities (aims) and its modification in the process of economic growth. ${ }^{104}$

Secondly, attempts are being made to limit the postulate of rationality in order to bring the theory closer reality. In this context, one needs to mention, first of all, the concept of «limited rationality» of the Nobel Laureate, Herbert Simon, according to whom economic decisions cannot be completely rational because of the lack of reliable information and the inability of an individual mind to process even the amount of information that is available.

The main reason, which prevents the acceptance of rational decisions, is the «asymmetry of the information» (as demonstrated by the Nobel Laureate, Joseph Stiglitz). Different agents in the market and in firms do not have identical access to the information. «Opportunistic behaviour» is related to this in buyer-seller relationships (Oliver Williamson) or principal-agent relationships (George Akerlof and others).

As a result, Richard Nelson and Sidney Winter, the authors of «An Evolutionary Theory of Economic Change» came to the conclusion that «routines» not «rationality», lie at the heart of the decisions taken by firms: each «routine» is a certain stable set, developed on the basis of experience and intuition, of methods and techniques of the solution of economic and other problems, inherent in a specific firm, in other words, some kind of hereditary «gene». Moreover, even when the situation cardinally changes and the firm has to be restructured, it does not search for original decisions, and instead uses the already developed «routine of restructuring». In other words, contrary to the assumptions of most economists, firms aspire to avoid the search for «rational decisions» and compete on the basis of «routines». As a result of market selection, the most effective «routines» survive.

Deviations from the axiom of mainstream economics have raised the following questions:

Is the assumption of a «split personality» of a person as an irrational goal-setter, on the one hand, and rational actor, on the other hand, justified?

${ }^{104}$ Here, it is worth noting the use of the concept of transferring from the elementary stage of requirements to a qualitatively higher stage of humanitarian needs of Maslow. 
If market participants operate on the basis of «limited rationality», what is the respective relative weight occupied by «rationality» and its «restrictions» in their decisions?

If the actions of these market participants are in general defined not by rationality, but by «routines», then what is the content of the foundation, on which routines are formed?

In this respect, let us consider what the genetics of a person can tell us.

\subsection{A Permanent Basis of Behaviour - Heredity}

Economic theory is primarily a science about the behaviour of people in the sphere of economic relations and is directly linked to psychology (as well as sociology, political science, linguistics, history and other sciences about society). The most valuable research of this relationship of economic theory has been highlighted by Daniel Kahneman, the Nobel Laureate in Economics in 2003 for a series of researches on economic behaviour.

Psychology, in turn, is closely connected to biology in general and with genetics in particular. ${ }^{105}$ The revolution in genetics began in 1953 with the opening of a «double spiral» DNA, the heredity carrier, and was celebrated in 2001 by the decoding of the molecular structure of the human genome, which is of fundamental importance in social science. The «deciphering» of the genome and research of the chemico-molecular mechanisms of the «work» of its numerous links is still in the initial stage, however, the results already attained by scientists, allow us to hope that genetics will help find the answer to the following key question of social development: to what extent is the behaviour of people determined by heredity, and to what extent is it determined by the changing conditions of their existence. A special

105 As pointed out in A.V. Oleskin's article, "The Political Potential of Modern Biology", biologic-social (biologic-humanitarian) sectors such as, socio-biology, biolinguistics, biosemiotics, social ethology, biopolitics, etc., are developing quickly in the West and in Russia. ("The Bulletin of the Russian Academy of Sciences”, №1, 1999, pp. 35-37.) 
branch of genetics has already been established, which has started to provide specific answers on psychogenomics. ${ }^{106}$

Tarantul specifies in his book mentioned above: «According to modern estimations, indicators such as life expectancy, a person's health, ... are primarily connected with genetic factors, whose role is estimated to be $65-70 \%$ (p. 217).» It is not surprising that the basic efforts of genetics are directed towards discovering sources of hereditary diseases and finding ways of treating them. Hundreds of «defective» genes have already been discovered, gene «surgery» is developing rapidly, and a number of effective medicines have been produced.

According to the estimates of scientists, the psyche and behaviour of a person are half defined by hereditary properties. «Firstly, as a rule, not one, but a set of genes is responsible for our spiritual characteristics. They interact between themselves in a complex and at times very ambiguous way, whose effect depends on a set of different factors. Secondly, according to the majority of scientists, the psyche and behaviour are only about $50 \%$ defined by genes. Society, the environment, and education, in other words, the surrounding media, play an equally important (if not an even more significant) role in defining them (pp. 210-211).»

With the help of reservations such as «only» and «sometimes», the author, an expert in molecular genetics, steers us away from the oppressive conclusion that a person's destiny is predefined at birth. Nevertheless, the verdict of genetics is clear: people who have grown up and been raised in the same environment, behave differently depending on hereditary properties. Moreover, we have seen that when the general environment changes, some people strive to become oligarchs, politicians, and stars in show business, and others, no less gifted and educated, in contrast, fall to the bottom of the social and economic ladder.

106 The term was introduced by V.Z. Tarantul, the author of the book, "The Human Genome: An Encyclopaedia Written in Four Letters", Moscow, 2003. In this chapter, I will refer to this work, which is estimated by experts in genetics as a highly competent statement and systematisation of the latest global achievements in human genetics. (Page references to this book are given in the text of this chapter in brackets.) 
On which specific experimental data are the conclusions of psychogenomics based? I will list some of them.

The hereditary origin of features of behaviour, such as «leadership», in relation to which the term «leadership gene» (pp. 207-208) is applied, has been experimentally proved.

The «gene of genius» has also been identified.

It has been established that the feeling of well-being and satisfaction with life («happiness») depends 50 percent on genetics (i.e., excluding a person's financial position, age, and education), and depends only on the remaining 50 percent on the «regrets and pleasures of the previous hours, days, and weeks», in other words, on the «environment» (see, p. 216).

Genes and the chemical-molecular mechanism defining the hereditary propensity of some people towards disturbing behaviour and depression have also been identified (pp. 208-209).

The dopamine receptor gene, regulating the activity of the nervous "centre of emotions and pleasures» has been identified. One form of this gene (long allele) causes aggravated craving in people with this form for pleasures and new impressions; in contrast, people with another form (short allele) of this gene are passive. «People with a long allele are more inclined to search for new impressions, and this aspiration to novelty is shown in all spheres of life. This gene has been aptly named, «the novelty-seeking gene». It is probably not a coincidence that the dopamine long allele receptor gene is encountered 25 times more often in Americans, than, say, in people living in Southern and Eastern Asia. Historically, we know how America was populated with Europeans. Clearly, the people who travelled into the unknown in search of riches and glory were, primarily, vigorous, curious, and impulsive people, inclined to adventurism. They brought the long allele «novelty-seeking gene» to the modern American population (pp. 209-210).»

In other words, if a country in Southern and Eastern Asia constructs the same economic and political system as in America and takes other effective measures, the general level of business will, all the same, remain many times lower. This give us, Russians, something to think about. After all, according to the stereotype, «we are lazy and lack inquisitiveness». At the same time, as history has shown, we are genetically «social», talented, and patient. However, these qualities can turn into a powerful force only under adequate social organisation. 
As they say in sports, «organisation beats class». Moreover, «the general organisational science» (known as «the theory of systems») was created for the first time by the great Russian thinker, economist, philosopher and physiologist, Alexander Bogdanov. Furthermore, if we do not wish to lag hopelessly behind America, we have no choice but to compensate the genetic difference in the level of activity in the economic and political systems, through other stimulating measures.

The genetic predisposition to divorce, alcoholism, and drugs has also been established (p. 216).

Recently, two genes, linked to the «maternal instinct» (which are transferred along paternal lines), have been discovered in the human genome. Experiments with similar genes in mice have shown that in the case of mice-mothers lacking «maternal instinct» genes, only 8 percent of their litter survived compared to 80 percent for normal mice-mothers (p. 210).

The «aggression gene» has also been discovered. It turned out to be «the monoamine oxidase gene, of the enzyme, involved in transmitting nervous impulses» (p. 210).

In 2002, «a criminality gene» was identified (pp. 326-327).

At the same time, Tarantul considers that this is only the beginning of the development of psychogenomics. «However, the hereditary mechanism itself and the genes that are responsible for temperament, inclinations, and predilections have still not been discovered... However, recently, thanks to huge successes in genomics, significant progress has been made in this field also. One can refer to the science, which has recently emerged as a mixture of genetics and psychology, psychogenomics, analogously to Freudian psychoanalysis. The primary goal of psychogenomics consists of «hunting for the genes» that form the personality, psyche, and behaviour of a person (p. 208).»

Studies that have already been conducted by geneticists and psychologists provide me with the grounds for the following statements.

Firstly, genetic inheritance makes up the relatively invariable (let us call it «permanent») basis of human behaviour (as a gene changes only over a period of thousands of years and, even then, insignificantly). This applies to human behaviour in all spheres of activity, including the economic sphere.

Secondly, not only the general features of human behaviour, but also the fundamental psychic distinctions among people, are 
genetically transferred. This is due to the fact that although the genome is 99.9 percent structurally identical in all humans, the same genes in different individuals can function differently, causing distinctions in their physiques and in their behaviour. This seems to be connected primarily with mutations in the genome of their ancestors, as well as being caused by bacterial and viral intrusions into the genomes of individuals (pp. 106, 114, 118, 122, 130).

Thirdly, the degree of the genetic conditionality of different aspects of behaviour revealed by experiments fluctuates from almost 90 percent to approximately 10 percent. $^{107}$ (Note that the average degree of genetic conditionality of behaviour is estimated by geneticists at approximately 50 percent.)

In other words, in order to understand the behaviour of people in any field of activity, including the economic sphere, one needs to proceed not from some abstract formula, but, primarily, from the real genetic basis of their psyche.

Let us note that those economists and theorists, who insist that behaviour is dictated by the principle of the rational maximisation of well-being, can use two arguments: unlike other fields of activity, in the economic sphere, people are guided primarily by reason and least of all by their psyche; moreover, in the economic sphere, the tone is set by certain types of people, whose psyche is aimed at searching for rational ways to maximise their own well-being.

However, before considering such an argument, one needs to answer a series of questions. What is the relationship of the link established by geneticists between genes and the behaviour of a person, on the one hand, and, the structure of the inborn instincts of a person that has been investigated for a long time in psychology, on the other hand? If heredity defines 50 percent of behaviour, and the «environment» the remaining 50 percent, how should one understand the concept of the «environment»? Where does the rationality factor fit in this «environment»?

107 Different aspects of a person's psyche are defined by his genotype in varying degrees. So, whereas the activity of a person is 89 percent genetically determined, and his irritability 85 percent, his sociability is only 10 percent genetically determined [p. 216]. 
In Tarantula's book, the concept of «instinct» is used seldom, and, even then, in brackets. Meanwhile, in psychology it is one of the basic concepts, which is also used by many economic theorists.

Genetics is an analytical and very exact science, it analyses biological processes at a molecular level. Until now, psychology has relied on the physiology of the higher nervous activity, psychiatry as a branch of medicine and on peer-group researches and experiments. Economic theory tries to rely on the contradictory generalisations of economic history, economic statistics, economic practice, and introspection (self-analysis).

The inborn instinct is a complicated reflex, a type of «automatic» task-oriented reaction of the nervous system to certain «internal» and «external» signals. We already know that besides «the first» signal system, there also exists a second signal system. For example, the selfpreservation instinct can be aroused into action not only by a direct threat, but also as a result of a mental conclusion (correct or mistaken) from the analysis of some indirect information concerning a potential danger. Having been aroused, the self-preservation instinct incites the entire nervous system of a person to undertake protective measures. Which measures are taken, depends on a number of inborn properties of a specific person and all other conditions (including the ability of a person to foresee the consequences of his own actions).

That inborn instincts are connected with the genome of a person is easy to see. However, it seems that the conditionality of the separate instincts by specific genes has not yet been discovered and the chemical-molecular mechanism of instinctive impulses still needs to be investigated.

Experts have named a number of prospective genetic tasks, which can be grouped into four «classes».

Firstly, it is necessary to specify the total number of genes of all kinds; and, secondly, to define the functions of all genes that have already been discovered.

Currently, geneticists still do not have a common opinion on the total number of different genes in the genome of a person, with estimates fluctuating from 28,000 to 150,000 . "Thus, a definitive estimate of the number of genes in a person will probably not be arrived at soon. Currently, scientists are aware of the functions of only about eight to ten thousand genes. Moreover, detailed information on the mechanisms of their regulation is even scarcer (p. 106).» 
According to geneticists, it may take a hundred years to comprehensively define the functions of all genes (p. 330). Meanwhile, the specificity of the human organism is covered only in the mechanisms of the operation and regulation of genes. «In the human being, reigning in nature, unlike other organisms existing on our planet, there is a high complexity of proteome, the total number of functional proteins in a cell, which is provided not simply on account of the large size of the genome or large numbers of genes, but due to all the possible innovations, connected with the functioning of genes and the formation of proteins ... (p.106)».

From here, the third task is to investigate the mechanisms of the interaction of genes with each other. Fourthly, one needs to investigate the mechanisms of the interaction of genes amongst themselves (which occupy up to $97 \%$ of the length of each «spiral» of the genome), primarily, to detect «devices» in them, which regulate the work of genes and their interaction.

One assumes that in the process of resolving these and other issues in genetics, the role of the genome in relation to instincts will also be clarified.

However, even today, some conclusions, which are important for economic theory, have arisen on the basis of the dependences that have already been discovered, of some aspects of the human psyche, on certain genes and their specificity to separate groups of people.

The general conclusion is that mechanisms for the functioning of inborn instincts are «imposed» on the functioning of the genes, defining the individual properties of the psyche.

As noted above, the genes responsible for the following characteristics of behaviour have already been determined:

1. Level of «anxiety» and «depression»;

2. Level of «happiness» (satisfaction in life);

3. Ability to feel pleasure;

4. Degree of activity, inquisitiveness, and «adventurousness»;

5. Leadership ability;

6. I.Q.

7. Presence (or absence) of the «motherhood instinct»; 


\section{Presence (or absence) of the «family instinct»; \\ 9. Aggression level.}

In separate groups of individuals, different hereditary characteristics (mentioned above and others) of aspects of the psyche can be combined differently; as a result, people can have fundamentally different types of psyche, despite having common genetic origins. We name them «psychogenomic types» (based on the term «psychogenome», introduced by Tarantul).

Now, I will address universal inborn (i.e., genetically inherited) natural instincts. I will consider only some of them here, having conditionally divided them into three groups (with subgroups within them): «instincts of individualism», «instincts of sociality», and «development instincts». One can include instincts of selfpreservation, nutrition, reproduction, appropriation, hunting, and aggression in the first group; instincts of communication, hierarchy, empathy, cooperation, and imitation in the second group; and, instincts of freedom, expediency, inquisitiveness, game playing, creativity, and competition in the third group. (These instincts, excluding the creative instinct, are also inherent in many representatives of fauna.)

Universal human instincts, «being imposed» on different genetic types of psyche, lead to fundamentally different actions. (I will not consider these distinctions here.)

Let us refer to an example used by psychologists, which shows different types of reactions to threats: the reaction could be an active or passive form of defence, aggression, flight, an onset of depression, etc.

The aroused instinct of appropriation in people of a certain genetic type can result in a craving for the aggressive redistribution of property in favour of themselves, and in people of a different genetic type it could lead to an aspiration to accumulate this property through productive efforts.

All people are subject to the action not only of instincts of «individualism» but also of instincts of «sociality» and creativity. However, if the psychogenomic disposition of some people offers a wide basis for the interaction of all three groups of instincts, for other people, the «sociality» instincts come across rigid barriers. (I recollect the conviction of a Russian ex-oligarch that conscience is a category, 
applicable to intrafamily, and not social, relations). On the other hand, the hierarchical instinct, if its action is «imposed» on the psychogenomic type, combining leadership and aggression, is capable of conflicting with the instincts of freedom, creativity, and competitiveness.

From the aforesaid, it is clear that different psychogenomic types of people cannot have an identical approach to fundamental values, to the meaning of the concept of «well-being», and to the importance of the principle of «maximisation» of this well-being. For some types (for example, in the case of the combination of a genetically high level of «happiness» with a genetically low level of activity), this principle, in general, will have little significance.

However, we should not forget that in addition to genetic factors, other factors are available that define $50 \%$ of the behaviour of a person.

\subsection{The Environment: Instilled Instincts, Adaptation, and Habits}

The distinction between psychogenetic types, leading to the fact that the same inborn instincts manifest themselves in different behaviours, is capable of confusing the functioning of a herd, a clan, a tribe, and any active community, including nations. If, in the face of a threat, some attack, others wait, and others take flight, then, such a «community» will probably die. If some people seek to construct and accumulate property and others try to confiscate it, then, such an «economy» will collapse; any organisation, containing too many people with a «free rider» psychology, is doomed to disintegration.

Therefore, any human community develops norms of behaviour, which, starting from the period a mother breast feeds her child, take root in the preconsciousness of a child, long before he is capable of thinking independently. These «externally» imparted norms obtain the force of «internal» instincts, but they are not genetically inherited. This includes the instinctive distinctions between «good» and «evil», «ones own» and «another's», diligence, honesty, «feeling of debt», patriotism, ambition, fear of reproach, respect for seniors, etc. They are passed on from generation to generation in thousands of ways, 
consciously, and, in the majority of cases, unconsciously (through the example of ones own behaviour, estimations of people and events, images of fairy tales and legends, songs, turns and intonations of speech, etc.). Thus, the psyche of a nation - which, in a concentrated way, reflects its history over a period of centuries - is formed in this way, and itself influences this history. Clearly, these «instilled» instincts can change, but only over the course of several generations.

The specificity of the national psyche is defined both by long-term «external» conditions, in which the given nation is formed and develops, and by the psychogenetic types that make up the nation.

The conclusion of geneticists that the American «population» incorporated into itself the European emigrants, possessing genes of activity, inquisitiveness, and risk, has already been cited above. Similarly, one can assume that nations living in zones of permanent conflicts, not only develop norms and aggressive conditioned reflexes, but «attract» aggressive (in terms of their psychogenomic type) people from everywhere.

Hence, although the national psyche is mainly composed of a set of raised instincts, which are borne by people, belonging to different psychogenomic types, nonetheless, the link between the psyche defining the nation and the raised concentration in it of representatives of a specific psychogenomic type is not merely by chance.

A nation is non-uniform; therefore, along with the common features of a national psyche, making up the classes of a nation, sustainable social, ethnic, and local communities also have their own «raised» instincts, that are quite often not very compatible with each other.

The habits of an individual, as the result of the consolidation of his daily experiences, form the most superficial layer of the psyche. Habit is the adaptation of the entire set of genetic properties of a person's psyche, as well as his inborn and instilled instincts, to a relatively stable fundamental environment.

Note that habitual behaviour does not necessarily mean the monotonous repetition of the same actions. Such behaviour does not exclude changes within the context of a limited set of actions; it even includes the possibility of a new choice, if the differences in the new objects have no basic value (for example, changes in fashion).

Geneticists consider that the genome as a whole is not simply the set of genes connected among themselves, but an «intense» system of 
balanced interaction. ${ }^{108}$ One assumes that within the framework of this general system, the genes «managing» the psyche will themselves form some kind of subsystem. Although psychogenetic types also differ from each other, each of them is characterised by a certain balance, which, if it is regularly breached, implies a psychic pathology. Accordingly, inborn instincts also form an «intense» system, in which «individualism» is opposed by «sociality», and «conservatism» is opposed by «development».

The «instilled» instincts and habits also have a «system-defined» character; it is the historically developed subsystem of the psyche, called on to correct and regulate the action of the systems of the genetically inherited psyche. The «balanced» psyche does not in the least assume any type of «standard». Each psychogenetic type has its own «balance». Besides, the national system of «instilled» instincts also does not even out individual genetic distinctions; it only sets certain frameworks for these differences. Therefore, faced with similar situations, people are capable of taking both the same and, fundamentally different, «decisions» and acting accordingly; however, in both cases, they are driven primarily by instincts.

People with a different individual psyche can act in the same way under the influence of a collective instinct (a «crowd instinct») in critical situations, especially when a «crowd» has «leaders». (Similar «co-ordinated» actions can be observed in shoals of fish, flocks of birds, swarms of insects and herds of animals.) In the economy «collective» reactions are especially characteristic in (but not limited to) the financial sphere. (George Soros built his multi-billion dollar fortune on his ability to resist such collective impulses and use them for his personal benefit. Theoretically, he based his practice on the fact that he had «solved» the essence of the mechanism of the financial world: it is moved by the interaction of «mistaken» decisions and «reflexive» processes. However, Soros did not delve deeply into the analysis of the essence of the collective psychology of the community

\footnotetext{
108

The argument against "rational maximisation" from the point of view of psychology is given in the book of the English institutionalist, G. Hodgson, "Economic Theory and Institutions", Moscow, 2005, pp. 166-181. However, Freudism, cognitivism, or post-Freudism, in themselves, do not create a basis for developing a theory of solutions as an alternative to "rational maximisation". I believe that only in connection with psychogenetics will psychology be capable of creating such a basis.
} 
of individuals, which made up the basis of the «mistaken» decisions and «reflexive» processes).

In this case, is it possible that the actions of people are determined not by their psyche, but by a different factor, «pure rationality»?

Only that behaviour - which is not dictated by psychogenetics, instincts (both inborn and instilled), or habits, but only by the logic of achieving a specific aim with the given resources (as is assumed in economic theory) - can be considered rational. How much «room» remains for such behaviour taking into account everything that was mentioned above?

Let us recall that the genome defines approximately $50 \%$ of behaviour. Let us assume that of the remaining $50 \%$, which is allocated to the influence of the «environment», at least $40 \%$ needs to be allocated to «instilled» instincts and habits. Then, no more than $10 \%$ (or less) of the aggregate factors influencing behaviour remains for allocation to «pure rationality». However, is purely rational behaviour, in general, and in the economy, in particular, possible?

The psychology of a person (his psychogenomic type and inborn and instilled instincts and habits) forms a «program», based on which his consciousness perceives and processes information arriving «from the outside» and takes «decisions». Naturally, this is a contradictory and disputed process, as the «impulses» emitted from the genes, which regulate various aspects of a person's psyche, from different instincts and habits «compete» with each other, and result in a struggle for priority. For example, nutritional, maternal, appropriation, selfpreservation, etc., instincts can find themselves in sharp conflict with each other; and, in that case, a person has to decide, which of them have priority in a specific situation. Such «problems» need to be «resolved» not only by people, so one cannot consider such a «choice» purely rational. A strong-willed decision is at the heart of ones ability to hinder some instincts and follow others.

As a result, a person should, to a sufficient degree, realise his entire complex of instincts, as suppressing even some of them over a long period of time disturbs a person's psychic balance. In fact, the «balanced» fulfilment, to a sufficient extent, of such an individual complex represents the concept of «well-being».

Certainly, every one seeks to realise their instincts and habits not simply to a «sufficient» degree, but to the highest possible level, i.e., 
«to raise their level of well-being». Does this mean that a person aspires «to maximise his monetary income»?

This would be the case if the way and means of such maximisation did not touch upon well-being, as defined above, i.e., if the means (and not just the purpose) of the income earned was an activity that simultaneously served as the means of realising some instincts, without suppressing other instincts.

However, such kinds of activities make up only a small share of all the activities of a person. For the overwhelming majority of people, the single-minded aspiration to maximise their monetary income would lead to the restriction and even suppression of many, if not the majority, of their other instincts. That is why, people, as a rule, do not set themselves such goals. Instead they set themselves the task of earning monetary income, which is sufficient to cover their individual psychophysical balance.

Let us now look at how systems of the psyche «join» the economic system (with the reservation that this will be undertaken in a simplified way, in order to reveal only the principle of such an «inclusion»).

Each national economy occupies a certain place in the world economy. Each economic organisation (firm, establishment, etc.), in turn, occupies a certain place and carries out functions in its national economy. Finally, each individual has a place and function in some organisation.

Ideally, a person occupies a place and carries out functions corresponding to his psyche («inclinations»). Otherwise, either he will not be able to cope with his functions or he will be in a state of permanent stress, suppressing his instinctive «inclinations». In the end, these «inclinations» will find a way through and people with a specific psychic disposition will end up in those organisations and workplaces, which correspond to their disposition.

The same tendency also operates in global migratory streams. Earlier, I mentioned the psychic factor related to the emigration from Europe to America. Something similar can be inferred about the psyche of modern emigrants to Europe from Turkey, Algeria, Pakistan, Afghanistan, Vietnam, etc. As a rule, they make up the active, inquisitive, and courageous part of the population, who have not found in their own countries a functional niche, adequate to their psyche. 
The high level of concentration of high technology manufacturing primarily in the United States, followed by Western Europe and Japan leads people from every corner of the world, who are highly intelligent and genetically predisposed to creative activity, to be drawn to these countries; in contrast, in those countries experiencing the reverse process of a deterioration in their economic structure and a reduction of the relative density of high technology and complex manufacturing in favour of strength in the fuel, raw materials, and half-finished products sectors (as in Russia, a number of other CIS countries, and Eastern Europe), such people are being «squeezed» out.

It is unlikely that countries from which people, psychologically inclined to creative activity, are being «forced» to emigrate will be able to revive or create a competitive high technology manufacturing environment in the near future. On the contrary, the overwhelming majority of the population of such countries will gravitate towards simple types of work for many years to come, until the appearance of a new creative generation; however, by that time there will not be anyone left to train the younger generation in the necessary skills.

\subsection{The Unresolved Problem of the Mechanisms of Memory and Training}

The discovery of the mechanisms of memory and training (in the broad sense of this term) plays a central role in the clarification of the relationship between the inborn and acquired elements of the psyche. In 1923, Ivan Pavlov, proposed the hypothesis that conditioned reflexes, acquired in life, can be transferred genetically to descendants, having been turned, over time, into inborn, unconditioned reflexes. In response, the geneticist, Nikolay Koltsov, sharply criticized it and Pavlov was forced to withdraw his hypothesis. Since then, nobody has managed to shake the barrier, dividing the inborn and acquired features of the psyche. Moreover, the discovery of the molecular structure of the genome has strengthened this barrier even further.

However, this does not mean that there is no link between the inborn and acquired properties of the psyche. This link is implemented by the training process. It simultaneously influences both the 
development (or inhibition) of the inherited properties of the psyche and the acquisition of new properties (requirements and conditioned reflexes). Furthermore, its influence helps in «converging» or establishing a greater conformity between both sets of properties.

The basic distinction consists of the fact that training is capable of influencing the inborn psyche only within certain limits, called the «norm of reaction», and only quantitatively strengthening or weakening the existing inborn properties of the psyche, but, without changing or «erasing» them and without creating new ones. The influence of training on the acquired properties of the psyche is much broader, but at the same time it is more limited, on the one hand, by the ability to learn of the subject, and, on the other hand, by the relative strength and structure of the inborn properties of the psyche.

Thus, what does «the ability to learn» mean, what are the mechanisms of memory? Science has only recently begun to address this issue. The material included in the paragraph below is taken from the article «Genes and Behaviour» written by Leonid Korochkin, a corresponding member of the Russian Academy of Sciences, and an expert in molecular-genetic mechanisms of individual development and neurogenetics.

Korochkin wrote: «We must note that genetic mechanisms regulating behaviour are located, as was assumed at the beginning of the $\left(20^{\text {th }}\right)$ century by the great Spanish neural histologist, the Nobel Laureate, Santiago Ramón y Cajal, in the structure of the neural ensembles, whose features of formation in ontogenesis are governed by genes. Certainly, from the morphological and physiological points of view one or another behavioural action or training process is caused by the formation and closure of new nerve connections. At the same time, as memorisation often occurs instantly, the probable physiological basis of this event is a break of the synaptic contacts between the neurons that had not functioned earlier, included in the performance of the given behavioural reaction. The synapses are preexisting: they are formed as a result of the chemical interaction of the neural cells differentiated in the ontogenesis and, which await their turn, when the functional loads, which have arisen through the course of life, will «include» them in the general, active functioning (in certain conditions) of the neural network.» 
Thus, genes, i.e., hereditary properties, govern the formation of the structure of ensembles of the neural cells of the brain. These cells possess synapses, some kind of potential chemical contacts for establishing connections between neurons. On «loading» the synapses «break out» and through them amongst the neurons there is a chain (network) chemical interaction, causing behavioural actions and actions of memorisation.

Korochkin characterises the role of genetic inheritance in the definition of the ability of the brain to learn and function as a whole: «The distinctions noted, at times, in the activity of the genetic devices or separate genes between the lines of animals, which are easy or difficult to train, are the initial characteristic of the lines of the animals, developed in the course of the differentiation of the brain in ontogenesis and the genetically determined interline differences... One can also name those genetically determined features of the brain, on which the efficiency of its functioning depends:

(1) The mass of the tissue and the number of cells in it, which, in turn, is defined by the relationship of the reproduction and destruction of these cells in the course of ontogenesis;

(2) The ability of neurons to form appendices and synaptic endings - the contacts between the cells: the more appendices and synapses that are formed in the course of ontogenesis and cellular differentiation and the greater the number of links that are established between the cells, the better;

(3) The ability of the formed synapses to function;

(4) The regional features of the distribution of the cells in the organ and the correlation of the neural and auxiliary glial cells;

(5) The adaptive and regulatory capacities of the cells; 
(6) The capacity of certain cells to die at a certain moment in their individual development, in order to allow the surviving neurons to function more effectively.»

Thus, genetics and the development of the morphological and physiological systems of the brain have a defining value for remembering and memory, whereas processes at the molecular level are secondary. At the same time, processes are possible when «molecular events» begin «the cascade of behavioural reactions». In particular, when a specific gene starts to encode special hormones, activating some neurons and inhibiting others, it results in the definitive regulation of the behaviour of the whole organism.

However, Korochkin considers that, on the whole, the molecular and genetic bases of memorisation and the relationships between molecular and morphogenetic processes remain still unsolved. Therefore, the chemical and biological mechanisms of the learning process have also remained undiscovered. The task becomes even more complicated, if one considers that external conditions are capable of strongly influencing the formation of the ability to learn. Human behaviour (both conscious and not conscious) is regulated by the brain. Judging by the number of neurons, the brain is several times more complicated than the genome (in terms of the complexity of the genome according to the number of nucleotides in the 23 DNA molecules, which make up the nucleus of a cell). At the same time, the genome defines $50 \%$ of human behaviour.

Simply speaking, it means that a gene controls $50 \%$ of the functioning of the brain. It controls the brain, primarily, because the structure of the neural ensembles of a brain in ontogenesis is formed in such a way, to allow it to conduct signals from the organs of the senses to the genome and impulses from the genome to the corresponding organs of a person. It probably also controls the fact that the genetically inherited structure of the neural ensembles predisposes specific people to be inclined to certain areas of learning and puts in place the lower and upper limits of memory and learning. Korochkin noted: «... the ability to learn depends ... firstly, on specific genes, and, secondly, on many genes».

However, the remaining factors which regulate human behaviour (beyond the 50\% mentioned above) remain beyond the scope of genetics. Clearly, only evolution, i.e., the interaction between heredity 
and changeability, created a brain, which, in terms of its «resolving power», greatly surpasses the requirement of "servicing the genome». It is also clear that each individual's potential to learn is genetically set.

We know that different parts of a brain carry out different functions. However, the ensemble of neurons of different parts of a brain to some extent are in contact with each other, so, the signals emitted to and from the genes, also affect the storage of memory, accumulated through learning; and, conversely, the «external» impulses, directed to and from this memory, also inevitably affect the biochemical mechanisms of the functioning of genetic memory. This means that the interaction of the properties of the psyche, both inherited and instilled through «learning», are based on extremely complex and mobile networks of neurophysical and biochemical links and interactions in the human brain.

Korochkin wrote: «Learning abilities are formed during the individual development of an organism, which is carried out not only according to the signals of genes, but also through the influence of an environment, capable both of implementing hereditary information and also of inhibiting it at certain stages of the formation of an organism.»

Experiments on mice have shown that «depending on the conditions in which they are kept, descendants of the same parents have been found to have different learning abilities: those that grew up in especially favourable conditions, turned out to be more capable pupils. However, the thickness of the cerebral cortex and the level of learning abilities changed only within certain limits; they could not rise above or fall below certain levels, given to those belonging to a particular line, breed, or species. These limits in variation are called norms of reaction.»

As a result, Korochkin comes to the following conclusion on the potential for significant corrections through education. «The question arises about the role of education in the development of various behavioural characteristics. In other words, the «good» hereditary, structurally functional inclinations of the brain do not, in themselves, ensure their correct implementation in a phenotype - the conditions required, in order to ensure their complete implementation. In the same way, the «bad» hereditary, structurally functional inclinations of the nervous system do not mean that it will be hopelessly spoilt: the 
appropriate favourable conditions can «correct» it within the norms of reaction.» At the same time, these «corrections» cannot apply to «the genetic determinism of different types of characters».

I will raise the question slightly more broadly: about the role of a person's environmental conditions, in the formation of his psychic disposition.

In adverse conditions, positive natural inclinations to learning do not develop and their potential is not fulfilled. As a result, a type of psyche, which finds learning difficult, develops. Moreover, people with this type of psyche not only find it difficult to acquire knowledge, they also find it difficult to acquire the social norms and rules of behaviour, applicable at work, in daily life, and in society in general.

In the behaviour of such people, inborn requirements and instincts are developed directly and are weakly restrained by the superficially acquired social norms, to a much greater degree than in the behaviour of people, for whom learning is easy. For them, mastering these norms (the «socialisation» of the psyche) at best is replaced by the development of a superficial «mechanical» habit.

In order to maintain order in a society, in which a significant part (or even the majority) of the people have difficulties in learning, rigid, formal institutions, backed by compulsory attendance, are required. In such a society, violence from the layer of society, made up of people with learning difficulties, and reciprocal violence from the authorities, become the norm in life.

This implies that society should concentrate its efforts on the creation of conditions conducive to the formation of a person's psyche, and in which the inborn individual potential capacity for learning is developed to its natural maximum for individuals from the very beginning of their lives. These conditions include not only material preconditions, but also the spiritual environment, free from any obstacles (cultural, political, etc.) to the development of the brain, and that stimulate the growth of perception and the processing and mastering of information.

Clearly, the development of the natural capability to learn is inseparable from the learning itself. However, one should not forget that that they are qualitatively different processes and the latter process can both help and hinder the former process (for example, in formal and dogmatic learning). In principle, priority should be given 
to the problem of developing the capability to learn, and the required knowledge that needs to be mastered about nature and society should be presented in such a way that it helps to solve this high-priority problem.

\subsection{Rationality: Abstract or Evolutionary?}

According to genetics, our humanoid ancestors appeared (as a result of a gene mutation) over 5 million years ago (Tarantul, p. 137). This marked the start of the process of the natural selection of psychogenetic types (simultaneously with physicogenetic types), based on survival and their ability to fulfil the necessary functions in a consumer («gatherer») society, and only in the last 40,000 years, in a «producer» society.

It is very important to find out more information about the mutation in the genome, which resulted in the clear divergence of the path of the higher humanoids into two branches, the chimpanzee and apelike ancestors of modern man. However, genetics has still not been able to answer this question.

At the same time, as Tarantul noted, numerous hypotheses have been put forward. According to one of them, the «human gene» appeared as a result of the mutation of a separate gene, i.e., a gene, which millions of years ago ... «endowed humans with speech» (p.284). The value of this hypothesis lies in the fact that it offers a psychogenetic instead of a purely physiological solution to the problem. In this solution, «walking on two feet» and changes in diet and the form of the skull (as stated in anthropology) no longer act as the criteria of the «division». It appears that the mutations resulted in the appearance of genes and mechanisms for regulating them, whose role consisted in the conception and development of two new psychic functions of the organism: articulated speech and creative «innovative» activity.

The origin of these functions is dated to a period, millions of years before human beings started producing the first instruments of labour (i.e., before the neoliths). This means that the psychogenetic complex of ancestors of the human being was born long before the beginning of any «manufacturing», and their inborn instincts were formed in the 
same way as for many other animals, through processes of collecting, primitive hunting, and the struggle for living space. However, there were two decisive additional factors, the capability to develop speech and «non-standard» (creative) behaviour.

It may be that the unique combination of these two characteristics also led to our ancestors developing an inclination to experiment and the rudiments of logical thinking, as a result of which they mastered fire, began to tame animals, and produce instruments of labour; rather than the reverse case of developing creativity and logical thinking as a result of the unconscious manufacturing of instruments of labour. Here, also, Darwin preceded Lamark, and paved his way.

Clearly, «rational decisions» are decisions, which, in the given conditions, resolve the fundamental needs of an individual (community, organisation, etc.) in the best way possible. It is also obvious that the mechanisms of the entire set of instincts, both inborn and instilled and also habits, aim to do the same. In this sense, instinctive behaviour is reasonable and rational. In situations, in which an individual cannot decide, which instinct to follow, he usually chooses the «like everybody» option; i.e., he is guided by the instinct of imitation and the collective instinct.

In other words, «rational decisions» are at heart those decisions, which are dictated by inborn instincts, the experience gained over generations and concentrated in instilled instincts, and the experience of the individual himself, which is concentrated in his habits and skills.

However, the creative instinct and logical thinking allow people to discover such new resources in the «environment» and to create such means of production and ways of increasing the basic pleasures in life, for whose use and further development, instincts and habits alone are not enough; creativity combined with «rational decisions» in the pure state are necessary, i.e., mathematical types of decisions. At the same time, human psychology does not disappear; it sets the initial basis, target function, and the restrictions of the «mathematical model». In other words, purely rational and logical decisions can play a necessary, but intermediary (i.e., not independent) role in the system of economic thinking and action. ${ }^{110}$ Moreover, the importance and

\footnotetext{
110 The Nobel Laureate, John Hicks, recommended people with a mathematical disposition not to become involved in economic science.
} 
complexity of this intermediary role increases with the speed and depth of the changes that occur in society. However, on the whole, social development can never become inherently «rational»; it will always remain conflictory, diverse, and unpredictable. Otherwise, society would long ago have turned into some sort of rational «device», operating like an automatic machine. The human genome allows one to understand why the history of society, despite being «irrational» and unpredictable, nonetheless, constantly repeats itself. This implies that, on the whole, the behaviour of people in general and in the economy, in particular, is rational; not in the sense that it is deliberate, calculated, optimised, and in their best interests, but in the sense that it is acceptable in practice and, in the given conditions, satisfies their requirements to a sufficient level. It can be habitual, rather than deliberate; rely on norms, rules, experience, and imitation, rather than calculations; and be far from the best way of protecting their (the people's) interests.

A different understanding of the rationality of behaviour is contained in George Kleiner's work on «The Evolution of Institutional Systems».111 Here, essentially, rationality is understood to mean the ability to consciously and consistently develop optimal programs of actions, according to the available information. The author justifiably considers that such rationality is inaccessible to the majority of individuals. However, at the same time, two questions remain: the reasons for this «inaccessibility», and whether one can consider behaviour, which does not correspond to such rationality, «irrational». Outlining these reasons, Kleiner reveals numerous such characteristics of the psyche of the majority of people involved in economic activities, which, together and individually, interfere with the acceptance of rational decisions.

Moreover, another Nobel Laureate, Milton Friedman, argued against numerous attempts to investigate and solve economic problems mathematically. William Baumol underlines that economic-mathematical models, including models of the general market equilibrium, macroeconomic models, and models of the theory of games are not capable of giving economically meaningful answers.

111 G.B. Kleiner, "The Evolution of Institutional Systems", Moscow, "Nauka", 2004. (Further, in the text after the quotations, the pages of this book are specified in brackets.) 
Let us keep in mind that this author investigates the psyche and behaviour in general, as well as certain aspects in particular: «... the psychological features of agents (and partly their groups), which exert a fundamental impact on the processes of institutional change are investigated (p. 51).» In other words, those features of the psyche, which are important for understanding the evolution of institutions, are distinguished. The author continues: «Moving away from the fundamental concept of the rationality of the individual, we build a theory of the «organic irrationality» of the majority of subjects, specifying the factors and consequences of a deviation from the principles of rationality. These factors are rooted in the mental features of individuals and the cultural features of the social and economic development of a country (p. 51).»

«The theory of organic irrationality» attempts to offer a scientific explanation for the inability to think rationally, inherent, according to the author, in the «majority of subjects».

In Kleiner's understanding, rational behaviour involves: (1) The establishment of aims; (2) The definition of conceivable alternatives; (3) The selection of real alternatives; (4) The establishment of the criterion valuing alternatives from the point of view of achieving ones goal; (5) The selection of the best alternatives; (6) A definitive choice: «The performance of all these stages in exact conformity with the information available to the subject for making a decision corresponds to the rational behaviour of the subject (p.53).»

Note that the question of the rationality of the aim itself has not been set and the problem of the rational choice of the aim has essentially not been raised.

Further, Kleiner lists the psychological factors of the infringement of the rationality of choice (the ways and means of achieving an aim) and specifies the features of the personality (or the temporary conditions of the psyche), being the preconditions of the occurrence of these factors (p.54).

«(1) An unwillingness to understand and formulate the establishment of an aim in a selective situation («antipathy to target setting») ... The main personality trait, hindering rationality in the process of identifying an aim, is inconsistency.»

«(2) ... «The difficulties in the analysis of conceptually possible alternatives and in distinguishing the realistic ones amongst them («difficulties of differentiating the real from the unreal») ... (p.55);» 
«The character traits, supporting this kind of deviation, are dreaminess, a propensity to fantasise, and an unwillingness to realise the distinction between wishful and real (p. 56).»»

«(3) The difficulties in the comparison of acceptable alternatives («an antipathy to a ranking or rating») (p. 56);» «Some subjects have a lower ability to see qualitative distinctions in alternatives; others are inclined to exaggerate such distinctions, to the extent of considering alternatives only as «acceptable» and «unacceptable».»

«(4) The unconscious propensity to choose extreme or close to extreme alternatives («an inclination to extreme and risky situations»);» «Such behaviour is characteristic for individuals with a preset propensity to danger, extreme situations, and radicalism (p. 58).»

«(5) Unconscious aversion to extreme or close to extreme alternatives... The psychological precondition ... instinctive fear of heights ...»

«(6) A preset preference for alternatives, considered in the beginning/middle/end of the decision-making period ... Here, also, cyclothymia functions as a psychological precondition, i.e., the cyclic distribution of attention during ... «the evaluation session» (p. 58).»

«(7) A preset preference of the alternatives, identified according to their configurational characteristics, in connection with the previous experience of decision- 
making («unconscious associations with the past «).» «The psychological precondition of apperception, i.e., the unconscious influence of the subject's previous experience and aims, on his perception of the real world... (p. 59)».

«(8) The preference for decisions, whose implementations begins/ends faster («an antipathy/inclination to quickly executable decisions»).» «Psychological preconditions impatience and impulsiveness of the person concerned ( $\mathrm{p}$. 59).»

«(9) Preference for decisions, possessing/not possessing novelty signs («an inclination/antipathy to new decisions).» «Psychological preconditions - emotional requirement of the individual for new impressions, excessive trustfulness, exaggerated expectations, experienced in relation to new persons or (more widely) to situations in comparison to known people or situations (pp. 59-60).»

«(10) Preference for reversible/irreversible decisions («an antipathy/inclination to a definitive choice»);» «Psychological preconditions: cautiousness and indecisiveness; or, on the contrary, resoluteness, impulsivenesss, and radicalism (p. 60).»

«(11) Unconscious unwillingness to remain within the set limits of acceptable alternatives («an antipathy to accounting for boundaries»).» «The corresponding psychological 
precondition is a condition of claustrophobia (fear of the closed set in relation to the space offered by alternatives) (p.60).»

«(12) An antipathy to selecting the absolutely best variant («antipathy to radicalism»);» «Subconsciously, such subjects reject maximising variants as developments that are not evolutionary in character. As shown by psychological tests, many people subconsciously aspire to choose a variant, which is in the top third of a rating scale, but not in any way the best (pp. 60-61).» «The corresponding character trait is cautiousness (p. 61).»

«(13) Preference for decisions selected according to known habitual or traditional procedures, not necessarily corresponding to the given situation («persuasive influence of previous experience»).

The corresponding psychological precondition is a compulsive disorder, i.e., actions or inclinations, caused by outdated rituals (routines) that do not correspond to the specific conditions of a situation (p. 61).»

According to Kleiner, some of the psychological features of the agent set forth above, depending on the extent of their occurrence and stability, are «neurotic or psychopathic conditions (fears, phobias, etc.)», i.e., psychic diseases. How prevalent are these diseases? «The presence of some type of phobia, as shown by research on the psychic health of the population, according to various data, is characteristic for $40-70 \%$ of the population in Russia.» ${ }^{112}$ Thus, it turns out that about

112 G.B. Kleiner quotes from the research of Daniel Rancour-Laferriere, "Russian Nationalism from an Interdisciplinary Perspective: Imagining Russia," E. Mellen Press, 2000 and Simon Rosefield's article, "The 
half of the inhabitants of Russia are not capable of rational behaviour just because they are psychically unhealthy. However, the majority of the remaining, i.e., healthy «agents» in any country are not capable of making rational decisions, as one or another of the deviations from the strict psychic «norms» (amongst those listed by Kleiner) exists in almost every healthy person.

Excluding neurotics and psychopaths, the majority of the features of the psyche listed by Kleiner, which interfere with rational targetsetting (according to Kleiner's interpretation) and are inherent in the prevailing majority of individuals, in my opinion, cannot be considered as deviations from psychic norms, as, in fact, they are the norm. According to the data from psychogenomics, the priorities of a very broad series of existential requirements, genetically inherent in humans, vary, depending on the condition of the organism and external conditions. At the same time, the instinct of expediency, in each time interval, forces the selection of the most urgent need and the most effective ways of satisfying it. Consequently, the natural psyche of a person does not compel him to unequivocally define specific narrow aims and certain constant ways of achieving them. Genetically, one may consider that variable goal-setting, which always leaves room for the selection of a new goal, is characteristic for humans. Cultural and institutional factors, defining the instilled psyche of a person, are capable of fundamentally limiting this natural changeability, but are not capable of excluding it.

What are the preliminary conclusions that economists can deduce from the data from psychogenomics? Decisions in the economic sphere are taken by the overwhelming majority of people based not on the aim of maximising monetary income or through purely rational calculations, but on the basis of a complicated set of individual and collective psychological preferences, experience, and intuition of the subjects. The maximisation of incomes and purely rational calculations are «built in» in this «integrated» decision-making mechanism as its elements and intermediate links.

In this case, what lies behind economic progress? All the same genetically inherited and instilled instincts: creativity,

Metamorphosis of Russia: from Yeltsin to Putin", "Economic Science in Modern Russia”, 2002, №4. 
competitiveness, cooperation, rationality, diligence, accumulation of knowledge and culture, and the ability to learn, etc.

However, could the economy disintegrate and break up if each of its subjects does not rationally maximise his monetary income? It will be saved from this by instincts of self-preservation, nourishment, procreation, and others, whose actions «protect» not only biological survival, but also the consumption level achieved and the social status of individuals. At the same time, the norms in society and rules (institutions) are the first line of defence against harmful behaviour.

As noted above, the psychological disposition of individuals is extremely varied, so that some people consider the maximisation of their monetary income as their top priority, thus, limiting and even suppressing other fundamentally important factors and, quite often, even shortening their lives. Such individuals mainly concentrate their efforts in the financial markets (on stock exchanges, in banks, various funds, etc.). However, even they make decisions not purely rationally, and without thinking of «maximising their welfare», but on the basis of their reflexes, experience, intuition, and a combination of genetic and instilled «inclinations» towards appropriation, risk, and game playing that set them in motion.

It is interesting to compare the role of the rational maximisation of profitability with the role of the psyche, by using as an example, the selection of the paths of economic reforms in Russia and China. Western experts on «shock therapy» did not deny that their advice was based on ideological (i.e., in the final account, psychological) motives, instead of economic rationality. The Russian population, also, was not in a position to make rational economic calculations, and was guided by instincts of freedom, appropriation, imitation, inquisitiveness, etc. Only the leading Russian reformers, individuals of a certain psychic disposition, set themselves the rational purpose of maximising their own monetary income, which they achieved, by building billion-dollar fortunes from nothing. In China on the contrary, the leading «market» reformers were guided not by aims of individual enrichment, but by the aim of national benefit, coinciding with the aims of the rational maximisation of the incomes of individuals (families). Therefore, irrational «shock therapy» in China was rejected and, instead, a gradual transformation took place. In the end, this, primarily explains the deep distinction between the national psyche and, in particular, the psyche of the «ruling elite», in Russia and China. 
Does this mean that theoretical constructions of «mainstream economics» are empty, useless, and even harmful (as some authoritative Western critics of this trend believe)?

Certainly not: Their arguments can be substantiated, but only provided that we agree with their initial postulates. Thus, «mainstream economics» is a conditional theory, which describes what the behaviour of people would be, if they were guided only by the principle of selfish and rational maximisation of monetary incomes. In other words, it is the normative theory. Certainly, this is not a new conclusion, as the argument on whether «the neoclassical» theory is normative or positive, has been going on for a century. The novelty lies in the fact that the discovery of the human genome, in my opinion, is capable of definitively destroying the claims of this theory that it is a positive science, reflecting a living reality.

However, the decoding of the genome will force both institutionalists and critics of the mainstream to think again. In the dispute on whether the nature of an individual precedes institutions or vice versa, genetics is clearly on the side of the individual. However, he is an individual, in whose genome, five million years of evolution of the human race has laid the roots of all modern institutions.

\section{Chapter 5}

\section{The Structure and Types of Psyche: from the Socioeconomic Point of View}

Earlier, in the first chapter, we learnt from Hjelle and Ziegler (to our surprise) that psychologists look at the human psyche from the point of view of philosophers. In other words, they are seeking solutions in science to problems, raised in philosophy.

In the second chapter, we became acquainted with the view points on the psyche of some of the leading economists of the past. They were primarily interested in the psyche's place among other social forces, the correlation of different types of human psyche and the socioeconomic structure of society, and the role of the psyche as the engine or inhibitor of economic growth. 
The third chapter, in our opinion, testifies to the extremely pragmatic orientation of the research conducted by leading modern economists; they are interested in the psychological aspects of the functioning of the market and their application in firms, trade unions, and state and international economic regulation.

Finally, geneticists (chapter 4) are interested in those elements of the human psyche, which are predetermined genetically (as opposed to the ones that are «acquired»), as well as the related biochemical and biophysical mechanisms of the ongoing psychic processes, including perceiving, processing, and storing information (the mechanism of the memory).

Generalising the results of chapters 2 and 3, regarding the thoughts of economists, it seems that the psyche of a person interests the economist both as an independent and as a mediating factor in the formation, functioning, and development of economic systems; and also as the factor, directly influencing technology, demography, politics, and culture, as they also are part of the economic process.

If we approach the works of psychologists and geneticists from such an economic point of view, then, one can see in them the «decoding» of those initial, but excessively general and uncertain, concepts, which economists are still using: interests, preferences, wellbeing, etc. In particular, the approach, according to which the wages and requirements of people are defined by the reproduction expenses of their labour force, ignores the independent role of the higher nervous activity and culture, and reduces the economy to an «engineering» calculation, which is pertinent so far as the minimum physical boundaries of consumption and physical production factors are concerned. However, the modern world has repeatedly crossed these borders, and the psyche of people has become the foundation of their behaviour both in the production and consumption spheres, and a major factor both in production and consumption.

All the areas of a person's activities, including economic activities, «emerge» from the existential requirements and possibilities (abilities) of a person, or from his psyche. Furthermore, the psyche itself is affected by this activity, particularly, economic activity. However, if the psyche's influence on activity is direct and immediate, the counter action occurs with a huge time lag, and is mainly carried out through an intermediary. The «vertical» section of the human psyche contains four closely related «layers», which are, however, qualitatively 
diverse: (1) inborn properties (requirements, abilities, and the reflexive mechanisms of their fulfilment); (2) the instilled properties (the suggested requirements since childhood, developed abilities, and conditional-reflexive mechanisms); (3) the habits acquired in adapting to the «environment»; (4) consciousness and will, as the ability to independently process information and regulate ones own behaviour.

Part A - The «Vertical Section» of the Psyche: Unconscious, Preconsciousness, and Consciousness

\subsection{Inborn Requirements, Abilities, and Instincts}

As has been established in modern genetics, the inborn properties of the psyche are programmed in the human genome, including genes and their complexes, defining both the specific properties of the psyche and the biochemical mechanisms of the fulfilment of the corresponding functions of the genes.

The inborn psyche of different people is different, which can be seen in children's behaviour at an early age. For simplification one could have assumed that the set of «psychogenes» in every human being is identical, and inborn distinctions in the psyche of people can be explained by the corresponding biochemical mechanisms. However, genetics offers a more complicated answer to this question: in some cases, the distinction is related to the presence or absence of the appropriate gene (for example, the genes of leadership, genius, motherhood, etc., are not present in everybody); in other cases, it is caused not by the presence or absence of the appropriate gene, but by the different biochemical mechanisms that make it function (for example, the gene that arouses interest in the search for new experiences is available to all people, but its biochemical mechanisms in individuals can differ).

Psychologists relate not only purely physiological but also requirements caused by the structure of the nervous system, such as the requirements for protection, communication, freedom, appropriation, etc., to inborn requirements.

It is clear that inborn physiological and neuropsychic requirements are fundamentally interconnected and form a complex system. This 
system is internally conflicting, as inborn needs appear and develop unevenly. Some needs (such as, the requirement for food) appear immediately at birth, others (such as, the requirement for protection, communication, etc.) develop in infancy, a third group (such as the requirement for freedom, appropriation, etc.) appear in childhood; and, others (such as, the requirement for sexual relations, motherhood, etc.) appear during puberty.

The fulfilment of inborn requirements is carried out by the system of inborn instincts (complex reflexes), whose appearance and development is inseparably linked with the appearance and development of these requirements. This means that both the appearance and development of inborn instincts also occur unevenly, and the inborn instincts of individuals are essentially different.

The human genome, just as hereditary properties in animals, is subject to mutation and selection (in the sense that healthy and physically and psychically strong people, as a rule, have stronger offspring than the weak and sick). However, this occurs so slowly that in its structure (but not orientation), the inborn psyche of an individual person (and of a generation as a whole) can be accepted as something given. Its development in the course of a person's life can proceed under different conditions, so that for some people these conditions may widen (or suppress) the development of some inborn requirements (and instincts), while for other people other requirements (and instincts).

Thus, the inborn properties of the psyche of a certain generation only theoretically represent the «matrix», common to all people; on closer consideration, they differ both structurally and to the extent of the development of separate components, not only in different people, but also in the same person at different stages of his life.

In these distinctions, an important role is played by the psychic energy of an individual. Psychic energy is linked to the physical energy of an organism, but differs from it in that (like a battery that feeds the electric ignition system of a motor), it feeds the nervous system, arousing other organs and controlling their actions. The level of a person's psychic energy influences the functioning of his instincts, and the intensity and results of his actions.

Here, I still do not differentiate between requirements and instincts, excluding the following exception: I distinguish the requirement for development. Psychologists consider the property of «development» 
as one of the inborn psychic requirements of an organism. I believe that one needs to distinguish and set off this requirement against the remaining requirements, since the fulfilment of all the inborn requirements of a person depends on the development of the individual (his physical system and the system of his higher nervous activity).

Geneticists were not the first to consider that a person is born with defined, inherited psychic properties; many well-known psychologists had come to this conclusion much earlier. Although the studies and opinions of psychologists on the nature of the human psyche often contradict each other, the majority of psychologists are convinced that the fundamental (existential) requirements and instincts are inborn; it is the same also for abilities, both general and particular.

I will try to unite those inborn features of the psyche, which have been pointed by psychologists, with those features, which have already been revealed to be genetically determined, and on this basis I will develop the conditional classification of all these features.

Inborn, genetically inherited features of the psyche are the product of natural selection over a period of 5-6 million years of the history of the ancestors of modern man. Therefore, the classification criteria should correspond to the criteria of the given selection - these requirements and instincts are directed to: (1) the survival of the individual; (2) the survival of kin; and, (3) the development of both. Accordingly, I will call the requirements of the first group individualism; of the second group, sociality; and, of the third group, development.

Which of the above-named features (i.e., from the few hereditary features of the psyche that have already been discovered and investigated by geneticists) can be included on the basis of each of the three basic aspects singled out by me? I believe that heightened «anxiety» and an inclination to aggressiveness, criminality, and divorce can be, as a rule, associated with the features of the psyche, which focus it on individualism.

At the same time, the heightened «happiness», developed «maternal instinct», and the inclination to leadership and sociability are those inborn features of the psyche, which focus it on sociality.

Finally, the presence of a "gene of the search for novelty» is a necessary element of the psyche of an «innovator» (i.e., a psyche, focused on development). 
Furthermore, geneticists have established inborn distinctions in the levels of the abilities according to indicators, such as the degree of activeness, intelligence, and memory. In this way, they indirectly confirm Pareto's idea about inborn distinctions in the levels of the psyche, regardless of its dominant orientation.

If we unite the existential requirements and instincts, with which psychologists have already been working for a long time, with those inborn «predispositions», which have been discovered very recently by geneticists, and divide them into three groups, as distinguished above, we arrive at the following general (but far from complete) idea about the structure of the human psyche.

Thus, I include the following amongst the inborn requirements and instincts of individualism: food, sex, self-preservation, appropriation, parasitism, aggression, jealousy, revenge, and hunting. (The instilled instincts of thrift and cleanliness are also related to this group.)

I relate the following needs and instincts to the inborn needs and instincts of sociality: motherhood, trust, kinship, the herd instinct, imitation, cooperation, justice, compassion, communication, hierarchy and leadership. (The following are included in the instilled requirements and instincts of this group: honesty, religiousness, national-ethnicity, and warlikeness).

The following are inborn requirements and instincts of development: freedom, search for novelty, creativity, competition, game-playing, and curiosity. (I consider the following as instilled requirements and instincts: diligence, thinking, goal-setting and selfrealisation.)

The conditionality and inconsistency of such a classification are obvious, as, for example, individual aggression can serve ones «kin» as a whole, whereas the «social» requirement of the individual to take his place within the hierarchy of his kin can be interpreted as egoistical. Nevertheless, the process of natural selection over millions of years has resulted in both individualistic and social (related to kin) requirements and instincts becoming rooted in the human being, in the elevation of these requirements, and in the development of the corresponding abilities, opposing, connecting, and counterbalancing them, but without uniting them and without subordinating them blindly to each other, in the way that individuality is subordinated to the tribe in many species of insects, birds, fish, and animals. 
During the process of natural selection, the interaction of inborn requirements, abilities, and instincts led to certain stereotypes of behaviour, concerning the procuring of food, continuation of kin, the hierarchy within ones kin, the provision of safety, etc., becoming consolidated in the genetic code and being handed down from generation to generation. It is well-known that extremely complicated models of behaviour and «social organisation» are genetically programmed in animals, birds, fish and insects. Therefore, it is no surprise that, from birth, a person «is programmed» to unconsciously gravitate towards certain stereotypes of behaviour.

\subsection{The Instilled and Developed Properties of the Psyche, Adaptation, and Habits}

The instilled properties of the psyche. Human beings, as well as many living organisms, are born with the ability to learn. One can think of this as an inborn requirement to learn together with a learning reflex (and, not merely requirements and instincts for communication, curiosity, and imitation). The requirement for learning is caused primarily by the fact that not all instinctive requirements from birth are programmed in a developed form. For example, one does not need to teach salmon fry, on reaching maturity, where to return for spawning (even though this entails covering a distance of thousands of miles); birds of passage, having barely opened their eyes, are already programmed for seasonal migration; and ants and bees are born with encoded plans of building ant hills and beehives; however, in contrast, although beasts of prey are usually born with the basis of the hunting instinct, they lack inborn hunting «programs» (which can be explained). Their parents teach them the specific hunting reflexes (applicable to the environment in which they live).

A person is born with an instinctive requirement for communication and with a physical inclination for speech; however, adults actually teach a child to speak and, since early childhood, speech, as a means of communication, becomes an instilled instinctive requirement.

Our humanoid ancestors, followed by primitive people, for millions of years lived in herds and then kin, led a nomadic existence, 
and survived by gathering and primitive hunting. By the time that the first rudiments of ancient civilisation began to appear (40-50 thousand years ago) and mankind's development accelerated sharply, the human genome had already fully developed on the basis of natural selection, and inborn instinctive requirements had been defined.

They do not include many gradually varying requirements, without which the continued survival of the human being in conditions of historical dynamism would have become impossible. They appeared and began to be passed from generation to generation through the instilled requirement for distinguishing good from evil and «ones own» from «another's» and the requirement for regular work, honesty, orderliness, etc. Inculcated since early childhood and consolidated by example, games, encouragement, and punishment, these requirements acquired instinctive force.

The instilled requirements and instincts «rely» on the inborn ones, but, as a rule, they do not rely on one of them, but on their «combination». For example, the instilled requirement for a family and the «family» instinct rely on the reproduction instinct, the sexual instinct, the maternal instinct, the hierarchical instinct, the need for belonging, etc. The instilled «proprietary» instinct relies on the inborn instinct for appropriation, but is not reduced to it, as it necessarily also includes respect for another's property, i.e., instinctively reacts negatively to an encroachment of any property, not only ones own but also another's. From this, it follows that the "proprietary» instinct cannot be instilled without the support of the inborn instinct for justice. By the criterion of fairness, in the course of evolution, only such a fundamental distribution of riches could have been accepted, which served the survival and development of kin or society. The requirement for work (and the instinct for diligence) can be instilled only through the support of the inborn instinct to play games, goalsetting, inquisitiveness, imitation, competition, etc. The requirement for cooperation and the instinctive inclination for cooperation can be instilled on the basis of the inborn requirements for communication, justice, trust, empathy, and expediency.

The requirement and instinct for religiousness (belonging to a certain religion) are instilled on the basis of the inborn instinct of «belief» (in the existence of «supernatural» forces), and also on the basis of the inborn requirement for protection, trust, belonging to some hierarchy, and creativity. 
Since early childhood, society (a herd, kin, tribe, family, and society) instils those requirements and instincts in its members, which address the problems of the survival and development of this society, through the experience accumulated by this society. The role of accumulated experience, transferred from generation to generation, sharply increases with the appearance of speech and culture.

Instilled instincts can be aimed at restricting inborn instincts: for example, the instilled instinctive requirement for respectful relations to people is aimed at restricting the inborn instinct of aggression.

The instilled and inborn instincts operate as a general and, at the same time, also inconsistent system. However, the qualitative distinction between them is apparent for individuals in critical conditions, and for society as a whole, during epochs of historical shocks and breakdowns in the system of values and reference points of society. In these periods, the authority of the «educators» (the older generation) falls, people (through their own actions) suppress the moral properties that had been instilled in them since childhood, and inborn requirements and instincts come to the fore and start dictating people's behaviour directly: instincts of self-preservation, aggression, appropriation, the sexual instinct, the herd instinct, etc.

Thus, instilled requirements and instincts have different natures and functions: some serve the development and «specification» of inborn constructive requirements and instincts, others supplement them with new necessary psychic properties, and a third group forms such properties of the psyche, which serve as «suppressors» of the destructive displays of some inborn instincts.

However, they all need to be acquired in early childhood, during the breast feeding stage, through the contact between mother and child, together with the development of speech, through the subjects and phenomena of the surrounding world, through the unconscious imitation of adults, and through the first fairy tales, songs, and images of art with which a child comes into contact.

Adaptation and habit. Habit is usually defined as the unconscious repetition of acts of individual behaviour. Habit can be the result of both inborn or instilled instincts, as well as a consequence of constantly repeating a conscious activity.

For example, an adult who emigrates to another country, tries to acquire local norms and rules of behaviour, and learn the local language. In this case, the already developed psyche of the person 
adapts to the new conditions. This is possible due to the partial elasticity of the psyche. However, consciously acquired new norms and rules cannot become instinctive. At best they remain, as habits that have taken root, on the border between preconsciousness and consciousness. The strength of the adapted habits, depends to the extent that they correspond or contradict the inborn and instilled (in childhood) elements of the psyche.

While instilled requirements and instincts are capable of varying only through the course of several generations, adapted habits can develop and change in the course of a single lifetime (for example, habits of absolute submission, secretiveness, mistrust, etc.).

Let us imagine that a given person is trustful by nature and upbringing but, having arrived in an environment, where dishonesty is widespread, he is compelled to adapt his own behaviour and to transform mistrust into a habit. This does not mean that he, like those around him, does not value trust or that his psyche has fundamentally changed. However, he is compelled to adapt in order to survive. It is possible that he takes the next step, and accepts his competitors' dishonest methods of conducting affairs as his own. In this case, there is a «bifurcation» of the psyche, and if there is a prevalence of such people in society, it becomes economically and politically unstable, volatile and, in the end, unviable.

How significant is the relative role of adapted habits in the psyche? Based on Marshall's ideas discussed in chapter 2, one can conclude that he considered the habits instilled from ones work and social environments, to be the defining «layer» of a person's psyche («character»).

For some people, this can probably be justified, but not for the majority, and not over the long-term.

As noted above, if the habits of a person correspond to his inborn and instilled requirements and instincts, then their «defining» role is apparent; and, essentially, in this case, they are merely the specific psychic form of the fulfilment of requirements and instincts.

If these habits are developed consciously during the adaptation of a person to an environment, alien to his natural and instilled psyche, then they can become a truly defining part of his psyche only under specific conditions:

- If the genetic base of the inborn and instilled psyche in the given individual is weak; 
- If his inborn and instilled psyche is deformed and, in particular, there is a hypertrophied development of the instincts of imitation and hierarchy in contrast to the weak development of some other instincts (freedom, goal-setting, competitiveness, etc.);

- If there is no structural dynamism in the society, i.e., the technical and organisational structure of the economy and the social way of life are stagnant, even though they do not correspond to a number of inborn and instilled requirements and instincts.

In society (as in nature) there are always individuals, who are extremely flexible and have the ability and desire to adapt - the defining feature of the psyche of Polonius in Shakespeare and «Chameleon» in Chekhov.

Equally, there are just as many people, who are not capable of, and do not wish to, adapt (Chatsky, in Griboedov, a character in Gorky's tales). In the times of serfdom, hundreds of thousands of freedomloving young peasants ran from central Russia to its edges to the Cossacks, where everyone was free to live according to his inborn and instilled (since childhood) requirements and instincts, and did not have to acquire habits, contradicting these instincts.

The majority of the members of a society, in adapting, develop habits that partially correspond to, and partially contradict, natural and instilled instincts. If too many contradictions are accumulated, a psychological crisis develops and is followed by a political crisis, which demolishes and brings to an end the system of habits and the entire «habitual» system of life that had developed. ${ }^{113}$

\footnotetext{
113 Lenin believed that socialism will win, when it becomes a habit for millions of people. In the USSR, a set of features, which usually characterise socialism, had truly become a habit for the masses; however, this habit contradicted a number of basic existential requirements and instincts of people and, as a result, was rejected.
} 


\subsection{The Role of Consciousness - Cognitivism}

\section{Consciousness as an integrated and autonomous part of the}

psyche. Consciousness (as the ability to reproduce reality in concepts and to think abstractly) feeds on the inborn and instilled properties of the psyche. At the same time, it is capable of influencing the display of inborn and the formation of instilled requirements and instincts, in the development of habits.

Consciousness should be divided into passive and active parts. Passive consciousness reflects the impulses emitted from the inborn and instilled requirements and instincts, «records» and «ranks» them, and projects an order and ways of implementing them, relying primarily on habits. In this case, consciousness follows the impulses emitted from «preconsciousness» and the unconscious sphere, and acts as their tool and «servant».

Active consciousness is not directly guided by the impulses emitted from «preconsciousness» and the unconscious sphere. Such consciousness «critically studies» the system of inborn and instilled requirements and instincts, including spiritual needs, and develops the basic program of actions, including aims, and the order and methods of their implementation.

Thus, on the whole, active consciousness does not in the least resist the unconscious sphere or preconsciousness; however, it resists some of the impulses emitted from them; being governed by a general strategy, consciousness itself decides, by which particular impulses it needs to be guided in certain conditions, and which impulses should be limited or suppressed. Therefore, active consciousness is inseparable from the will, which is nothing other than the ability to limit and suppress some instinctive impulses and stimulate others, by «contrary» impulses from the will.

Until now, the main discussion was based on the relationship of consciousness to other elements of the psyche. However, as noted in the first chapter, psychologists are primarily interested in the role of consciousness as a mechanism of perceiving and processing information about the external world and on decision-making. However, without taking into consideration the relationship of consciousness to other elements of the psyche, one cannot understand the real process of the work of consciousness. I believe that the topics discussed in chapters two and three testify to the fact that the 
perception and processing of information and, especially, making «logical» decisions, is under the (more or less strong) influence (or even control) of the inborn and instilled properties of the human psyche and habits.

It follows from this that the consciousness of each person aspires to unite the internal impulses, emitted from the unconscious sphere and from preconsciousness, with impulses generated by the information on the external world. In the life of a given subject, the repeated connection of internal and external impulses («agglomerates»), together with the decisions taken and their results, are stamped in the form of images or «logical schemes» in his memory. Later, they can determine habitual behaviour or «automatic» decision-making in similar situations.

«The external information» for the subject is primarily data about the behaviour of other subjects and about the interaction with them. Hence, another's experience in some form is taken into account in the accumulated experience of each subject. Therefore, individual experience is partially also collective experience; the psyche of the subject includes both the individual's and society's origins.

How deeply does society's origin penetrate the psyche of a subject? As the lives of human beings from the very beginning, i.e., over millions of years, were spent in «society» (a herd, kin, or tribe), natural selection has placed on the genetic base of the subject not only individual, but also social, requirements and instincts.

As far as instilled requirements and instincts are concerned, they are defined not only by the individual elements of the psyche of the real educators of a child (parents, nurses, older brothers and sisters, etc.), but primarily by the general culture of the educators. In this case, culture means the material and spiritual experience of a given society, embodied in ideas (values) and images of national and professional creativity.

Consciousness, having actively participated in the creation of the human psyche, and then having used culture for instilling adequate requirements and instincts in it, has played a central role in the historical development of the human psyche.

Each new generation forms its psyche on a partially renewed and «advanced» cultural basis (which does not exclude «failures» in the history of culture and in the evolution of the psyche). The relationship 
of individual, social and «innovative» elements in the upbringing of the psyche depends on the character of the culture.

Consciousness has developed as a result of the speech-mediated activity of people. Unlike thinking, whose simple forms are characteristic also of some animals, consciousness assumes the ability to evaluate oneself and ones past, plan for the future, deal with abstract concepts and resolve complex tasks.

The information that arrives from the sensual organs, both «from the outside» and «from within» an organism, through the primary and secondary signalling systems, is capable of simultaneously influencing all spheres of a person's psyche, including his consciousness, preconsciousness, and his unconscious sphere.

Decisions, which are consciously taken by a person, and the subsequent conscious acts of behaviour reflect the interaction between the following: unconscious requirements and instincts; values and the norms reproduced by the memory from preconsciousness; and the logical correlation of requirements (desires) and norms (institutions) with abilities (resources). According to many psychologists and economists, the overwhelming majority of actions of a person in the economic sphere are turned into routines and regulated by habits, i.e., preconsciousness, demanding the active intervention from the unconscious sphere or from consciousness in case of the infringement of the habitual situation.

The problem, however, lies in understanding what type of relationship exists between the unconscious sphere, preconsciousness, and consciousness in the formation of habits themselves, and also in how these three spheres of the psyche co-operate in the regulation of «non-standard» actions, which are defined not by habits and skills, but by a conscious choice.

With some simplification, one can divide the opinions of psychologists on this issue into three groups. One group believes that preconsciousness and the unconscious sphere (Freudism and neoFreudism) have a defining role; the second group believes that this problem cannot be solved and also has no practical value, as only the empirical link between the external influence on a person and his reciprocal action or reaction (behaviourism) is important; and the third group considers that the main role in the formation of habits and nonstandard decision making belongs to consciousness (cognitivism). 
Cognitivism. In modern economic theory, especially in neoinstitutionalism, cognitivism exerts the greatest influence. Cybernetics and works on the creation of artificial intellect have played a leading role in the appearance and development of cognitivism. As the well-known Russian psychologist, R. Nemov, commented: «This trend has arisen in connection with the development of cybernetics, computer science, mathematical computer programming and, to a certain degree, was a negative reaction to the weaknesses inherent in all psychological concepts that ignore consciousness and belittle the role of thinking in determining human behaviour.» According to cognitivism, everyone has a «scheme», i.e., a plan for collecting and a program for processing information; moreover, the organism has a set of interconnected schemes that function in a dynamic system. «The perception, memory, thinking and other informative processes are defined by schemes in the same way as the structure of an organism is defined by a genotype. Cognitive schemes develop in the individual experience of a person; however, they are also partly inborn.» 114

Both neoinstitutionalism and cognitivism share the view that the human brain contains a resilient program for perceiving and processing information, independent of the character and source of this information. Here, «schemes» are similar to norms and rules, i.e., institutions. The principal difference is that, according to cognitivism, «schemes» reflect individual experience and cannot be general, whereas an institution is a fundamentally social category.

George Kelly, the American psychologist who proposed the theory of «personality constructs» in the 1950s, is the founder of the cognitive aspect of the personality. 115 According to this theory, each person in his everyday life is a researcher and his consciousness is focused on the future. He formulates hypotheses and checks whether they prove to be true or not. From the proven hypotheses, a person composes «understood schemes or models» for himself; these are the «personal constructs». These «constructs» are built on a bipolar principle and are aimed at enabling the subject to distinguish between honest and dishonest, kind and malicious, clever and stupid, etc.,

\footnotetext{
114 R.S. Nemov, "Psychology”, Book 1, M., "Vlados”, 2003, pp. 640-641.

115 See L. Hjelle and D. Ziegler, "Personality Theories", "Piter", M., SPB and others, 2005, pp. 438 onwards.
} 
people and, accordingly to construct his own behaviour. According to Kelly, a person is not controlled by present events (as Skinner proposed) or past events (as Freud proposed), but rather controls events, depending on the questions raised and the answers found.

In other words, in Kelly's concept, cognitivism focuses on the conscious, active, and creative part of the human psyche, oriented on the future. The statement of the question on behaviour in such a way conforms to the orientation of the economic concepts of forecasting (Milton Friedman) and «rational expectations» (Robert Lucas Jnr.).

One has to note that the extreme subjectivity and relativism of Kelly's concepts were subsequently significantly softened and limited by the psychologists and developers of the «social cognitivism» concept, Albert Bandura and Julian Rotter.116 Unlike Kelly, who considered that cogitative schemes were independent of the current influence of the environment, Bandura considered that behaviour, the cognitive mechanism, and the social environment continuously interact and are interconnected, and that learning by observing other people's behaviour plays a central role in the formation of the cognitive mechanism.

Rotter's «The Theory of Social Learning», underlines the fact that the main or basic types of behaviour can be learnt in social situations, and these types of behaviour are connected in a complicated way to needs, demanding satisfaction through the mediation of other people.

One can argue that the main difference in the understanding of the human psyche between the last two «cognitivists» mentioned above and institutionalists consists of the fact that the former do not consider the psyche (the cognitive mechanism) as something steady and constant, whereas institutionalists consider the system of norms and rules, acquired by humans, to be a relatively stable basis of their behaviour. According to Bandura, on any given day, a person's behaviour varies, depending on the changes in a specific situation; while on different days, the same person can behave differently in similar situations; thus, it is impossible to predict his behaviour. This is obviously a weak point in the concept of «social cognitivism», which unilaterally focuses attention on the adapted functions of the psyche (reminiscent of Chekhov's «Chameleon»).

116 See L. Hjelle and D. Ziegler, Quotes, Essays, p. 367 onwards and p. 412 onwards. 
Are personal «cogitative schemes» phenomena of the consciousness or preconsciousness? If they are the result of the «research» carried out by the brain, then they are originally formed in consciousness; however, later on they are stored in memory, i.e., in preconsciousness. Recall that Veblen saw the nature of institutions in «habitual thinking and behaviour». The habitual and habits lie in the sphere of preconsciousness. Thinking lies in the sphere of consciousness. Hence, the concept «habitual thinking» is a process that is on the verge of consciousness and preconsciousness, it is thinking by means of stereotypes that were developed earlier and extracted from memory.

However, how do «constructs» and «schemes» develop? The information arriving in consciousness, cannot be investigated, differentiated, and ordered in the form of «constructs» and «schemes»" without criteria, which are set in the unconscious sphere (existential requirements and instincts) and preconsciousness (the experience of generations, transferred through acquired cultures and habits). One can assume that the relative role of consciousness, preconsciousness, and the unconscious in the formation of «schemes» varies in different people and in different epochs. For example, American cognitive psychologists made observations and conducted experiments, as a rule, in student environments; consequently, the social environment and the age of the respondents could lead to an extremely exaggerated estimation of the independent role of consciousness in the formation of «schemes».

In order to become an «institution» (a norm and a rule for thinking and behaviour), «schemes» need to be the same (common) for a wide range of individuals (a social group, a layer, a class, a nation, etc.). Such general schemes are developed through dialogue and the interaction of individuals. It is obvious that the degree of generality of various schemes is extremely diverse and should be dictated both by the psyche of the subjects, and by the conditions in which they interact. If the psyche of the subjects (for example, employers and workers) is incompatible, then the agreement in force between them as a «mental scheme» or institution (according to Commons, «a going concern») cannot be strong or long-term. One needs to search for the foundations of long-term norms and rules in the generality of the psyche of a given group of individuals, which, in turn, is rooted in common genetics and national culture. Not many employers and 
employees are able to develop common norms of behaviour. Quite often, even members of a family cannot manage to achieve this.

\section{Part B - «The Horizontal Section» of the Psyche: Individualism, Sociality, and Development}

\subsection{The Constituent «Blocks» of the Psyche and its Social Types}

The triangle of the individual psyche. Above, I tried to track the structure of the «psyche tree» - from its genetic roots to the «crown» of consciousness, and discover the interaction of the components «along the vertical». The properties of the psyche are interconnected not only «vertically» but also «horizontally». Psychologists hold extreme positions regarding the systematic properties of the psyche. While some believe that the psyche of a given person is something integral, others, in contrast, consider the human psyche as a set of contrasting properties and mechanisms. For example, Maslow believed that if a person is hungry, then that person as a whole is hungry, rather than only his stomach. Skinner, on the contrary, considered that there are different reflexes for different signals, and, by controlling these signals, one can cause the necessary reactions in the form of specific human behaviour in each specific case.

I believe that those psychologists, who see both the interrelation and relative autonomy of various aspects of the psyche, are right. That fact that, at a given moment, a person reacts to a certain «signal» does not refute the interrelation of various aspects of the psyche. The most sharply perceived requirements transform the corresponding instincts into dominating instincts in the given time interval. For example, the instincts for food, self-preservation, sex, freedom, and even curiosity can become dominating instincts.

The coherence of various aspects of the psyche is caused by the coherence of the fundamental needs of a person's dual nature - as a separate being and as part of mankind, as a functioning and as a developing being. 
The precondition to understanding any system lies in classifying its constituent parts, according to the basic functions of the system. Note that the fundamental functions of a person are the following:

- Maintenance of an individual existence;

- Preservation of an individual as a part of a community of people;

- Development of ones own potential and a developing influence on ones environment.

Accordingly, both inborn and instilled requirements and instincts can be divided into three groups: (1) Individualistic, (2) Societal, and (3) Developing.

This division is conditional, as the same requirement and instinct can simultaneously carry out all three functions. For example, the inborn instinct for competition serves both deeply egoistical and the social requirements of an individual.

Nonetheless, the answer to why nature has included the need for competition in the genetic code has to be as follows: because development is the law of all life, including the human being and mankind as a whole, and competition is a means of development.

In other words, we define one or another requirement and the corresponding instinct in one of the three groups not because they do not fit in the other two groups but, because, in the selected group they play their most important role.

Thus, evolution has placed a fairly rigid set of requirements and instincts in human beings, which demand fulfilment in systems of social, economic, political, and ideological organisations of society. From the point of view of the psyche, these requirements are ambiguous, as, clearly, the named requirements and instincts are contradictory in their relationships with each other, their relative force can vary, and they can form the most diverse combinations, sometimes strengthening each other and at other times weakening each other.

However, in all variants, the inborn trilogy of a healthy human psyche, which is focused simultaneously «inwards» on the individual, «outwards» on society, and «forwards» on development, remains indivisible. This can be considered as my answer to the «alternative 
positions» of the psychologists, philosophically formulated by Hjelle and Ziegler (discussed in the first chapter).

However, there is also another way to state the question on human nature, which is contained in the works of economists and sociologists, and which seeks an answer to questions on how the human psyche correlates with the actual division of a society on the axes of domination-submission, wealth-poverty, and innovationconservatism. I consider this question in the following paragraph.

The types of psyche - an aspect of requirements. In chapters one and two, we saw which types of the human psyche have been distinguished by the leading psychologists and economists. It is very indicative that some of the psychologists, in addition to distinguishing types on the basis of purely psychological characteristics, also distinguish types on the basis of characteristics that clearly have a social and economic background. In other words, in a number of psychologists (Freud and Erich Fromm), the tendency to interpret social types as types of the psyche, can be observed. An even more pronounced analogous tendency is shown by economists, who consider that the social and economic structure of a society is defined by the psychic structure, by people belonging to different psychic types (Veblen, Pareto, and Sombart).

According to a different position (for example, Marshall), the social and economic system is the primary factor, defining types of psyche. In other words, a person from an oppressed class acquires a psyche that is opposite to the psyche of a person from the governing class.

In other words, both for psychologists and economists, the link between the social and economic positions of an individual and the type of his psyche is obvious; there are disagreements only regarding the definitions of the types of psyche and the substance of the specified link.

In order to define my position, two questions need to be answered: (1) How different is the inborn psyche of different people? (2) How compliant is the inborn psyche to social «re-education»?

The inborn psyche of people differs primarily in terms of its energy level. In highly energetic individuals, requirements and instincts manifest themselves with greater force and sharpness, than in individuals with low psychic energy. The inborn distinctions in the level of a person's intellect and willpower are no less profound. These 
(latter) distinctions can be compensated, to some extent, by the subsequent development of intelligence and willpower but, with other things being equal, the inborn distinctions remain. ${ }^{1}$

Hence, inborn distinctions in psychic energy, natural intelligence, and willpower are the first psychological division, leading to the distinction of three types of psyche, within the framework of any social group, class, or nation: individuals with a strong, average, and weak psyche.

The second division is designated relative to the strength of each of the three groups of inborn requirements and instincts that were distinguished: individualistic, societal, and developmental. I refer to individuals, in whose psyche individualistic instincts are relatively strongly expressed, as «egocentric»; those, whose societal instincts are strongly developed, as «socially oriented»; and, those with strong development instincts, as «innovators».

Uniting the two specified criteria («divisions») results in nine types of psyche: a strong, average, and weak psyche in each of the three groups of individuals, i.e., egocentric, socially-oriented, and those focused on development.

Let us consider individuals with a strong psyche, and assume that each of the three types is presented by only one sort of individual psyche:

- An egocentric psyche is aggressive and appropriating;

- A socially oriented psyche is cooperative and fair;

- A psyche focused on development is creative and competitive.

Under which conditions can such abstractly assumed versions of the inborn psyche become truly functioning types?

Firstly, if these inborn characteristics were not suppressed in early childhood by «instilled» instincts; and, secondly, if these inborn requirements and instincts are supported by the corresponding inborn capabilities.

117 It is obvious that the systems of upbringing and education in this aspect should be compensatory, but not levelling; i.e., it should pull up those that are lagging but, at the same time, help leaders to develop further. 
It is obvious that, without being supported by abilities, these requirements and instincts remain chronically unfulfilled (fully or partially) and result in a damaged and defective (to some extent) type of psyche.

Therefore, the question of abilities is no less important in understanding the psyche than the question of requirements. An instinct is a reflex mechanism, which activates certain abilities in order to satisfy certain requirements.

Types of psyche - aspect of abilities. Abilities are understood to mean the following: the inclination of an individual to master knowledge and skills; the skills and qualities that he has already mastered; and the disposition of an individual to fill, develop, and actively use this reserve.

The evolution of the human being, having placed fundamental needs in a person's nature, has, at the same time, also included abilities for their satisfaction. However, between inborn requirements and abilities there exists an initial gap: whereas a number of requirements (for nourishment, protection, communication, appropriation, etc.) already exist in a one-year-old child, the abilities to fulfil these requirements are placed in the form of inclinations, which subsequently demand development.

Is there a fundamental conformity between the level and structure of the inborn requirements of an individual and the inclinations of his abilities? In other words, has evolution harmonised the nature of each individual regarding his inborn requirements and capabilities (i.e., inclinations)? I believe that this is not the case. For example, an individual may have a strong inborn requirement for leadership (the presence of the «leadership gene»), but without the corresponding abilities (organisational, oratorical, analytical, and prognostic). Such a requirement, lacking the corresponding capabilities, can only be fulfilled at the domestic level and, even then, only partially.

Between the general inborn level of requirements and the general level of the inborn potentialities of capabilities, different relationships may exist (in addition to the corresponding case):

A person's requirements exceed his abilities: this results in chronic neurosis and dissatisfaction, which the individual tries to compensate by inappropriate means (for example, resorting to deceit or violence); 
- A person's requirement level is below the level of the potentialities of his abilities; this leads to underdeveloped potential and unfulfilled capabilities.

In the first case, there is an inborn aspiration to develop the general level of abilities from inborn inclinations to the level of requirements. In the second case, the development of the inborn requirements themselves is necessary, which can be reached only in the following level of the psyche, the level of (culturally) instilled requirements and instincts.

In any case, the general level of an individual's fundamental needs is the main force behind the development of his abilities.

The relationship of the structure of the inborn needs and inborn capabilities is also significant.

For example, in an individual, inborn egocentric requirements can be the most strongly expressed needs; while, the most vivid natural inclinations of his abilities could be related to creativity (for example, artistic or technological).

The resolution (or, the form of movement) of such types of contradictions is the division of labour and the social mechanism of exchanging activity, which gives an individual the chance to satisfy his requirements through abilities, which may not be connected with these requirements.

Thus, the contradiction between the structure of requirements and the structure of abilities - the natural source of the division of labour, moreover, the gender division of labour (and social functions in general) - is merely the historically initial form of the manifestation of this contradiction.

In many cases, the structural discrepancy between requirements and abilities becomes aggravated, leading to a psychological conflict, resulting in chronic stress. (For example, an individual, who, through his outstanding abilities in mathematics and physics, participates in the development of a nuclear bomb, which contradicts the socialoriented altruistic nature of his fundamental needs. On the other hand, the egocentric requirements of a person can be in chronic conflict with the outstanding medical or preaching abilities of an individual).

The majority of fundamental needs in a market economy are satisfied through money or with the assistance of money. In this way, these diverse requirements are transformed to a universal 
homogeneous requirement for money. A fetish for money, as an independent and fundamental need, takes place. Such a fetish occurs through the market culture at the level of instilled requirements and instincts. This fetish is supported by the fact that the payment for a person's work, i.e., his fulfilled abilities, are also in monetary form. This payment acts as a regulator of the development of his abilities. On the whole, the system of market prices for goods and services (including resources) serves the task of establishing a correspondence between the structure of requirements and the structure of fulfilled abilities. However, it is not capable of providing a balance between the level of potential requirements and the level of fulfilled abilities.

A person's choice of a field of activity and the place, which he occupies in this sphere, is defined not only by the initial social status of the person, but primarily by the structure of his existential requirements, and also his inborn and developed abilities.

The following rule holds true: the more the structure of a person's existential requirements is balanced and harmonious, the more the place occupied by him in the national economy depends on the level and structure of his abilities, both general and special. (The level and structure of inborn abilities can be significantly transformed by upbringing and training; however, the more such a transformation deflects a person's abilities from their natural basis, the less effective it becomes.) On the other hand, for a person with a psyche, dominated by a certain group of inborn or instilled requirements, abilities develop unilaterally, subordinated to these requirements.

In principle, it is to be expected that natural evolution, over a period of millions of years, should have developed a certain degree of correspondence between inborn requirements and inborn abilities in individuals, as, in the presence of a deep gulf between them, they simply would not have survived (in conditions when the division of labour still had not reached sufficient depth).

However, this «certain degree of correspondence» fluctuates sharply in people. For example, people with a strongly expressed instinct for procreation of kin sometimes turn out to be incapable of producing progeny; individuals with an inborn requirement for leadership can lack the necessary organisational and other abilities; people with a thirst for appropriation do not always possess the abilities to acquire and conserve wealth; fortunately, often, inborn «aggressors» do not possess the physical and intellectual qualities and 
the willpower needed to achieve their aims on a large scale; consequently, they are compelled to limit their aggression within their own household (according to the Russian proverb, «God does not give horns to a butting cow»).

On the other hand, there are also instances, when such abilities are incorporated in an individual in the absence of an existential requirement for a corresponding kind of activity, or for any activity in general (Onegin in Pushkin, Oblomov in Goncharov, Veretev in Turgenev, etc.).

The systems of upbringing and education are closely connected with each other. However, the system of upbringing deals primarily with requirements; it refines and adds to the set of inborn requirements with the requirements of the system, developed in the culture of a society. The educational system deals primarily with abilities, it develops inborn abilities to the maximum, so that they fulfil requirements at the highest level.

For individuals, focused on development, the development of their own abilities constitutes an independent requirement, and can become an end in itself. This characteristic of the psyche of some individuals is sometimes interpreted as the highest step of an individual's development («self-realisation»).

In any case, the psyche of an individual should be considered as a unity of his requirements, abilities, and mechanisms of instincts, habits, and consciousness, which unite these two aspects of the personality.

Further, I will consider some types of psyche as a unity of aspects of requirements and abilities.

\subsection{The «Homo Economicus» and the «Real» Person: Does Everyone Wish to Become a Capitalist?}

Not taking the factor of the psyche into consideration can lead to misleading social and economic conclusions, and even to the construction of whole concepts that correspond to the logic of the «homo economicus», however, are fundamentally unrealistic.

For example, the well-known concept of the Peruvian economist, Hernando de Soto, won the support of many Western economists. His 
concept essentially states that in the majority of the countries of the world (Latin America, Asia, and Africa) capitalism has not developed, and «is losing», because the property rights of the poor (making up the majority of the population) have legally not been registered. Plots of land, houses, workshops, shops, livestock and other property of peasants, handicraftsmen, and small traders are not protected by the law; they form the basis of the shadow economy, maintained by officials and criminal organisations. This property, amounting to huge sums in these countries, cannot be capitalised, since it cannot be used to obtain credit from banks. If the rights of the poor to their actual property were legally registered and protected, it would allow them to obtain credit and join in the process of the accumulation of capital. In this way, the gulf between the prospering capitalism of the West and the decaying capitalism in the rest of the world would be overcome.

A century ago, the Russian economist (widely known in the West also), Alexander Chayanov, on the basis of a thorough and comprehensive study of the peasant economies in Russia, established that the purpose of the overwhelming majority of peasant workers' households was the production of the fundamentally important goods required by a family, rather than the accumulation of capital. This rule can also be extended to other layers of small proprietors in the handicraft, trade, various services, fisheries, etc., sectors; only an insignificant minority among them truly aspired to accumulate money and become capitalists. The majority continued to be the small businessmen that they had become as a result of family traditions, their own aspirations to work independently, or not having found worthwhile work as employees. This is explained primarily by the psyche inherent in the overwhelming majority of people, who were not aspiring to achieve monetary profit, but to reproduce and improve conditions that were of fundamental importance for their families and for themselves.

The conception (common both in the Marxist, and the neoclassical, theory) that almost every small proprietor aspires to become a large proprietor and capitalist, and each employed worker either wants to become the top-manager in the corporation or actively participate in management, have little in common with reality.

Certainly, this is not to belittle the significance of de Soto's practical proposals: the legal registration of small properties would improve the position of many that are hard up and would activate 
credit and private business. However, in order for this measure to result in the same powerful development of capitalism in these countries as has been the case in the West, the population of these countries needs to have a similar desire to attain wealth, consider the accumulation of capital as the central core of life, and possess the abilities necessary to achieve this.

As shown in chapter two, many economists, including Veblen, Pareto, Shumpeter, Sombart, and Keynes have researched the psychological bases of capitalism. Veblen believed that the predatory instinct, inherent in representatives of the ruling class, lies at the heart of capitalism. Pareto included in the «elite» class, successful people (in terms of material success), did not distinguish between honest businessmen and swindlers, and believed that «the manipulative and scheming instinct» lay at the heart of all forms of prosperity. Shumpeter qualitatively distinguished innovative businessmen, who are ready to bear risk from those who are «slaves to routine», afraid of risk, and satisfied with a moderate level of profit (he called the latter «capitalists»). Keynes divided capitalists into gamblers, on the one hand, and optimistic (by nature) investors, on the other hand, and considered the psyche of both these two groups to be extremely unstable.

However, Sombart offered the most detailed analysis of the «capitalist spirit». According to him, the psyche of people, who are bearers of the capitalistic «spirit», originated from two diverse types of psyche, industrial and trading, which then merged into one. The former is rooted in the heroic and predatory psyche of ancient Romans and some German tribes; the latter is rooted in the psyche of ancestors of the Dutch, Swiss, Florentine, and other nations. Industrialism signifies an aspiration and ability to develop and implement largescale plans of expansion; while, trading requires scrupulous calculation, patience, and the ability to accumulate wealth. The dynasties that united the two original branches specified above and handed down this special «capitalist spirit» from generation to generation, constituted an insignificant minority in the population; however, they were the ones, who created the capitalist system.

From this one can make two conclusions. Firstly, the majority of prominent economists agree that capitalists are people, possessing a special type of genetically inherited psyche, whose defining feature is the absolute dominance of the requirements and instincts for 
appropriation and the accumulation of wealth. In a sense it is a variant of extreme psyche. Secondly, the specified type of psyche, depending on the structure of other inborn and instilled requirements and abilities, can appear in fundamentally different variants:

1. The predatory type, the aggressive capitalist, accumulating wealth through the redistribution of what others have accumulated.

2. The innovator, creating new effective combinations of factors of manufacturing and products, and opening new technologies, resources, and markets.

3. The slave to routine, using the existing technologies and methods of manufacturing, following the developed traditions, norms, and economic rules.

4. The opportunist, aspiring to benefit through any fair and criminal means and ready to break any norms, rules, and contracts for the sake of achieving these goals.

It is worth keeping in mind that there are many individuals, possessing the inborn requirements and instincts of capitalists (as listed above), who have not been able to fulfil these requirements and instincts due to a lack of (both specific and general) abilities or because other circumstances have prevented them.

Both successful and unsuccessful capitalists always aspire to maximise their monetary incomes as the dominating goal of their activity. They embody «the homo economicus» described in neoclassical literature.

A type of psychological barrier exists between successful and unsuccessful capitalists, on the one hand, and the remainder of the population, on the other hand. This is not because the rest of the population would not like to maximise its monetary income, but, due to the fact that it does not, at the same time, want to renounce its other fundamental needs, such as looking after family interests, an interest in professional work, an attachment to its habitual living conditions 
and circle of contacts, etc., and also because it is organically not capable of giving up its standard moral norms for the sake of money.

However, this «rest of the population» (i.e., the overwhelming majority) is also psychically diverse and can be divided into four groups:

1. Individuals with dominating individualistic inclinations; such people aspire to become small businessmen, farmers, and as salaried employees, they try to work in an isolated workplace (with an individual machine tool, car, computer, etc.) or become division managers in an organisation.

2. Individuals with dominating sociality tendencies aspire to work in state and public organisations, in organisations in the social sphere, in the media, etc.; they consist of those farmers and small businessmen, who actively support different types of cooperation, and those hired workers, who fight for self-management of their enterprises.

3. Individuals, whose psyche is dominated by requirements for creativity and development, concentrate in spheres of innovative engineering and scientific activities, art, and literature. As a rule, it is not possible to «re-orientate» people with a dominant psyche (i.e., with clearly expressed inborn inclinations): for example, these types of artists, engineers, doctors, and scientists are unlikely to be lured (through the offer of higher incomes), into changing their professions and engaging in (for example) trading, raising animals, working on the stock exchange, etc. 
However, «reorientation» is possible for the fourth and largest group of people, who do not have dominating inclinations, whose inherited psyche is «balanced», and consequently is capable of «fluctuating» from one side to another. Discussions on the behaviour of the «economic person» are focused on these short-term and superficial fluctuations, selecting whether to produce «guns or butter» today. However, regarding deep and long-term inter-sector shifts, the notion «choice» acquires a different meaning, as these shifts touch the structural bases of the psyche of manufacturers. In the USSR, the peasantry was destroyed (during collectivism), as was the type of inborn psyche, which focused on family agrarian businesses. Subsequent attempts to restore the country's agrarian economy on collectivist (1929-1991) bases or individual farm bases (after 1992) turned out to be unsuccessful, and the peasant-farmer estate could no longer be revived.

This example shows that the forced transfer of large masses of people from one field of activity to others can have destructive consequences, both for the psyche of people (as their way of life is destroyed) and for the economy, as people have to change from an employment that corresponded to their psychic disposition, to an employment that may be alien to their nature. The Great Depression in America in the 1930 s confirms this conclusion.

\subsection{The Psyche of the «Elite» and the Psyche of the «Masses»}

«The elite.» Initially, I will raise the question abstractly and will define the natural qualities, required to gain entry to the "governing elite».

First of all, a high level of general natural abilities is necessary: psychic energy, intelligence, willpower, memory, attention, and purposefulness. Natural inclinations of specific abilities are also necessary: organisational, technological, economic, military, etc.

Secondly, one needs to possess that qualitative type of psyche, which prevails in a specific «ruling elite»: a psyche that is clearly focused either on individualism, or on sociality, or on development. This means that the psyche of a person aspiring to become a «member 
of the governing elite» should be dominated by certain existential requirements and instincts.

The specified natural abilities and existential requirements can be developed and strengthened by upbringing, education, and training; however, their absence, i.e., the absence of a high natural level of general abilities, the absence of natural inclinations of specific abilities, a discrepancy between the type of psyche of a person aspiring to join the «elite» and type of psyche of the «elite», or the overall absence of a certain inborn type of psyche, minimises the possibility of becoming part of the «elite».

Earlier, I qualitatively distinguished four types of psyche: one «balanced» (usually prevailing among the population) and three «dominant» and «tendentious»: individualistic, societal, and development oriented. The struggle for power usually takes place among «the elite», representing these four types of psyche. The struggle can be either open or latent in character. Moreover, this is not a struggle of «economic interests» or ideas (these kinds of struggles can take place independently by themselves), but a clash of types of psyche.

Suppose, there is a socialitarian elite in power, which is focused on social solidarity, social stability, relative equality in incomes and in the ownership of property, the provision of free social services, etc. Then, the individualistic elite will be compelled to adapt to the dominant position of the ruling socialitarian elite, hide its natural requirements and instincts, and function on the basis of socialitarian rules that are internally alien to «individualists». Those among the individualist elite, who are able to adapt themselves to these conditions, can, as a result of their abilities and hiding their true nature, rise to a very high level in the hierarchical ladder and establish themselves as part of the ruling (socialitarian) elite.

In a centrally-operated economy, the socialitarian elite finds itself in a contradictory position, as it has to operate an economy that is contrary to its psyche, using material stimuli, trading, and allowing significant differences in incomes and property ownership of various groups of the population. The management of production, construction, trading, property funds, etc. are channels, through which the individualistic elite, by adapting themselves to the circumstances and hiding their true nature, can enter the ruling elite; forming a low, but wide and strong, layer in it. However, this layer occupies such 
initial positions that under favourable conditions it is ready to throw away its mask and fully grasp power, together with the ensuing consequences.

During the dominance of the individualistic elite and market capitalist system, part of the socialitarian elite can also adapt themselves, hide their true nature, and establish themselves amidst the ruling elite, by using their abilities. However, their prospects for achieving this are significantly worse. They are restricted, primarily, to fields of activities, with limited commercial potential, such as education, public health services, social security, the legal sphere, and power structures. As a rule, it is difficult for people with an individualistic psyche to work in these fields, as they cannot fulfil their existential requirement for appropriation, enrichment, and exploitation, without succumbing to corruption. However, persons with a socialitarian psyche are suited to working in these spheres; their difficulty in adapting to the ruling elite and hiding their animosity towards the psyche of this elite hinders the development of their careers and entry into the elite. The concealed socialitarian governing layer in the specified fields of activities is a potential threat to the governing individualistic elite; it is aware of the danger posed by this layer and aspires, on the one hand, to undermine the appeal of these spheres of activities by under financing them and, on the other hand, to involve this layer in commercial activity and to corrupt it, thereby degrading the specified fields of activities.

The antagonism between the individualistic and socialitarian elite is complicated by the fact that the entire population, which possesses a balanced psyche, forms its own elite. This psychically balanced elite is not as goal-oriented as the first two, which both try to use the representatives of the «balanced» elite for their own ends.

The elite, consisting of people with an «innovative» psyche, contains fewer members. In the genetic code of these people, the "gene in search of novelty» dominates the other genes, and controls their psyche. Accordingly, the existential requirement for change and the instinct of creativity dominate their other requirements and instincts. Irrespective of whether an individualistic or socialitarian elite is in power, people with an «innovative» psyche aspire for sweeping changes. Moreover, the process of change, rather than the end results, is of paramount value for them. When highly capable people with such a psyche are united in an organisation, they become 
a powerful force. Nonetheless, their lack of numbers prevents them from independently creating a ruling elite. They are compelled to try to unite with whichever (regardless of whether it is individualistic or socialitarian) non-governing elite is struggling to gain power, in any given period. On coming to power, the non-ruling elite (either individualistic or socialitarian) uses «innovators» to clean the social system of the institutions and politicians that are objectionable to it; however, then, the new elite frees itself from these «innovators», and they again join the opposition.

Pareto has constructed a scheme of the social structure of a society, similar to a truncated dismembered pyramid. It is truncated because, although the «top» of the pyramid exists, it does not govern, but has a decorative (concealing) role in relation to the real power of the ruling elite.

In Veblen «the predatory class» is the governing class; it consists of people, whose psyche is dominated by existential requirements and instincts of aggression and appropriation. While Pareto distinguishes the ability of the ruling elite to enrich itself through scheming (manipulative) activities, Veblen underlines its ability to expropriate other people's property and exploit other people's work in various ways. While in Pareto the elite supports its rule primarily by maintaining an intermediate layer of «clientele», in Veblen this is done through the imposition of an «envious» consumer life style, absorbing the time and energy of the working class.

In all these different approaches the main point is that neither Pareto nor Veblen divides the ruling elite in terms of «economic» and «not economic» characteristics. For them, both the capitalists and the state functionaries, making up the ruling class, are people with the same type of psyche, who, above all else, value personal enrichment as the main goal in life. Therefore, in the behaviour of capitalists and state functionaries belonging to one elite, there cannot be any basic distinctions; only minor and formal differences can exist, as a result of legislation, and even then only to the extent that this legislation is implemented.

The categories, designated by Pareto and Veblen, as the «manipulative and scheming» elite and the «predatory class», in my interpretation are versions of the «individualistic» elite, one of the four possible dominating elite groups. The «manipulative and scheming» version of the individualist elite includes individuals with an 
«innovative» psyche and in general is made up of individuals with constructive abilities; in the "predatory» version of the individualistic elite, the affiliation to a hierarchy is of crucial importance.

At the same time, members of the individualistic elite are selfish, and are constantly fighting amongst themselves for a place in the power hierarchy, the division and redistribution of property, and control over monetary streams.

«The masses.» The majority of the population are people with a balanced psyche, in whom some existential abilities and instincts do not normally dominate others. This majority forms its own «balanced» elite. In normal conditions, this elite group is not interested in transforming society or in radical changes, and supports the gradual improvement of all aspects of the structure and functioning of the social system, so that it meets all existential requirements more comprehensively.

One characteristic of this «balanced» elite is that it is relatively evenly distributed in different spheres of activities according to the abilities (both general and special), whereas representatives of the other three types of the elite try to subordinate their abilities to their dominating requirements and corresponding purposes.

Another characteristic consists of the fact that, in normal conditions, the «balanced» elite is quite passive and does not struggle actively for power, being content to stay in the background. As a rule, this elite is not internally driven to aspire to become the «dominating elite».

However, the position changes cardinally, when the existential requirements of this elite and the majority of the population, from which it emerged, are suppressed. Depending on which requirements are suppressed, the «balanced» elite falls under the influence of one of the three other elite groups, or breaks up into parts, and these parts join the other elite groups. This type of schism cannot endure in the long-term, as people with a balanced psyche cannot follow people with an unbalanced psyche over the long-term. (This is why, so often, there are «reactions» after each round of radical transformations.)

The composition of each of the three elite groups with an unbalanced psyche is non-uniform. In particular, both among «individualists» and among «socialitarians», one can find people, who are aggressive, moderate, radical, and conservative. However, these lines of the psyche characterise a form of behaviour and the method 
and intensity of actions, instead of their orientation. As I am primarily interested in the link between the types of psyche and the character of the system of economic and social institutions of a society, my goal consisted in revealing the social and economic orientation of the psyche.

It is in this way that my approach to the classification of psychic types differs from Pareto's approach. Pareto, as noted in chapter two, divided the elite into two parts, one group, whose behaviour is governed by the «manipulative and scheming instinct» and another group, characterised by the «constant aggregates», in other words, into reformers and conservatives. The first group in aspiring to personal profit seeks novelty and in this way secures economic progress, while the second group preserves traditions and condemns the economy to stagnation.

Although, after Pareto, there is a temptation to identify «individualists» with progressive individualists and reformers, and «socialitarians» with conservatives and traditionalists, this is not confirmed by the history of the $20^{\text {th }}$ century. The aspiration for personal profit is by no means always combined with a search for novelty and progress, and quite often it ends up protecting the status quo and inhibiting development; while «socialitarianism» is quite often related to reforms undertaken to accelerate progress.

As a rule, the coming to power of a ruling elite with an unbalanced psyche is harmful for society, as a whole, and for the economy, in particular, as it is usually accompanied by social shocks, suffering amongst the population and enormous losses for the economy. It can even lead to the collapse of a nation.

The only way for a society to develop smoothly and quietly is under the government of a ruling elite that has a balanced psyche, which is not subject to pressure from dominating requirements and instincts, and does not allow extremists and conservatives, hostile to novelty in general, into its inner circle.

However, it is hard for the «balanced» elite to govern, as world political tendencies and inclinations often change directions and force, the country needs to keep on functioning, while it is modernised and reconstructed, and within the elite there are constant conflicts and calls to replace both policies and the government itself.

The «balanced» ruling elite tries to implement a balanced policy, which simultaneously meets all three groups of existential 
requirements, individualistic, socialitarian and «innovative». However, this is hindered by different types of processes, usually with a one-sided but variable orientation. Demographic shifts, scientific and technical revolutions, technological and natural accidents, and international and internal conflicts all disturb the balance in some way or another; and, restoring the balance requires specific measures, which quite often infringe (either directly or indirectly) the needs of one or another group of the population.

The «unbalanced» elite continuously attacks the ruling «balanced» elite, both openly and in «concealed» ways, and tries to adapt its disguised representatives so that they can penetrate into the ruling elite.

The «unbalanced» elite cannot remain long in power, without resorting to «special types» of measures. If an opposing «unbalanced» elite comes to power in conditions of the breakdown of the psychic balance in society (expressed in the suppression of either socialitarian or individualistic requirements) and successfully corrects the situation, then its further stay in power leads to a reaction in the opposite direction, and society gradually turns against it. This elite can prolong its stay in power, either through force or by creating a psychic climate in society, which paralyzes its normal activities. This can involve intimidating society by warning it of the existence of external or internal threats, arousing its self-preservation instinct, kindling nationalist instincts in a multiethnic society, using religious feelings, etc.

\subsection{The Psyche of Extremists}

Usually, the extreme behaviour of people is considered as an aggravated reaction to external «irritants» in the extreme conditions, in which these people find themselves, due to social, natural, or technogenic factors. Such a reaction can, at times, grip large masses of the population.

However, some people are chronically inclined to extreme behaviour, even in «normal» conditions. This can be expressed in different spheres of life in a wide range of obviously destructive forms 
of behaviour, such as cultural nihilism, religious fanaticism, racism, vandalism, criminality, and terrorism.

Extremists, concealed behind civilised aspirations for general wellbeing and prosperity, who, however, try to impose their own understanding of this well-being and prosperity by deceptive and violent acts, turn out, in the end, to be no less destructive.

That fact that some people gravitate to extreme behaviour, forces one to search for the roots of this phenomenon in the natural bases of the psyche of these people.

Above, I have offered a simplified scheme of the structure of the psyche of a person, having divided inborn existential requirements and instincts into three groups: individualism, sociality, and development. In this simplified structure, the psyche that maintains a dynamic balance between these three groups can be considered as «harmonious» or «ideal». However, often the «domination» of one of these three groups prevails, so, from birth, the psyche turns out to be focused on individualism, sociality, or development. The concept «domination» signifies varying degrees of prevalence, from decisive influence to oppression and suppression.

As long as all the basic existential requirements of a person are satisfied, his psyche remains quite normal despite the fact that some requirements can dominate in it and others occupy a subordinate position. However, when some requirements suppress and supersede others (even the self-preservation instinct can be suppressed), then this psyche becomes one-sided, defective and, in this sense, extreme. Some people are born with inclinations towards such a defective psyche: for example, with a complex of hypertrophied requirements for domination and aggression and weakened requirements for sociality and creativity. Later, these inborn inclinations either develop, or, on the contrary, are limited and weakened, or, are finally «driven deep inside», depending on a person's upbringing in early childhood and subsequent life experience. However, they can manifest themselves later in life in the most unexpected way under a certain confluence of circumstances.

Extremism is justifiably considered as a social phenomenon, as groups and entire levels of the population can fall under its influence. However, before becoming a social phenomenon, it has to exist in the psyche of individual people. 
Dostoevsky is probably the only one among the great writers, who has tried to investigate in detail the origins of extremism in a person's psychology. His «extremist characters» are not compelled to extremism as a consequence of being deprived themselves. Dostoevsky attributes the fact that these «characters» murder innocent (although also «bad») people to the harmful influence of false theories of «permissiveness». Raskolnikov («Crime and Punishment»), Verhovensky («Demons»), Smerdyakov («The Brothers Karamazov») - all of them essentially oppose their «reason» to the teachings of «the Gospel». Dostoevsky himself in his youth was a member of the extremist Petrashevsky Circle and knew at firsthand how the «right» of a person to break laws of universal morals is philosophically justified.

In this way, Dostoevsky's novels try to convince the reader that in relation to certain types of criminals, the question of a direct material or other «motivation» of a crime has no meaning, and only the fact that these people have a criminal ideology is of significance.

Is it accidental that some people choose (or develop) a criminal ideology and adhere to it? Dostoevsky does not take the next step and recognise that some people are born with deformed psychic inclinations and, consequently, require a special upbringing. Recognising this would have contradicted the belief that God creates everyone equal in terms of moral and spiritual values.

If such an upbringing was absent or ineffectual, for the sake of self-preservation, society was obliged to develop and take special measures to detect people with an extreme psyche and control their behaviour. However, such measures have still not been developed, which explains the rise to power and mass public support for individuals with an extreme psyche, such as Hitler, Mussolini, Stalin, Mao Tse Dung, and many others. Moreover, at an individual level, the uniform approach of criminologists to the psyche of different types of criminals, leads to criminals with an extreme psyche being freed (after serving time in prison) and given the opportunity to again commit grave crimes.

In medicine, people with an extreme psyche are recognised as almost healthy and capable of being legally responsible for their actions. This is confirmed by the Nuremberg process that tried leaders of the third Reich, the trial of the «maniac» of Chikatilo in Russia, etc. In fact, the chronically extreme psyche of a person is not a psychic 
disease, but a certain psychic structure, both inborn and developed, in a particular direction. 118

In the economic sphere, literature has provided extreme characters, such as Shylock (Shakespeare), Gobsek (Balzac), Pliushkin (Gogol) and the Avaricious Knight (Pushkin).

The degree of the extremeness of the psyche can vary greatly, from weak to maniacal.

Judging by the social life of countries, in periods of social revolutions, one would be justified in thinking that there are many people (if not the majority) with a chronically extreme psyche. In fact, they constitute an insignificant proportion of the population, without any significant variations; however, during periods of upheaval they become especially active, and the weakened and destroyed institutional system in society allows them to clamber to the top of the pyramid of economic and political power.

\subsection{Psyche and Religion}

Here, I will interpret ideology as an understanding of the origin and the system of internal links of natural phenomena and societies, and the place of the person in this system. In the past (completely) and currently (to a considerable degree), these concepts in the general population were formed by religious systems, based on belief.

With the awakening and development of consciousness, the primeval human was increasingly convinced of two things: firstly, that a link among phenomena exists and human existence is entwined in this link; and, secondly, that he does not understand this internal link. The instinct of «belief» developed from this contradiction, over a period of tens of thousands of years, i.e., the natural psychic readiness to see in each phenomenon not only the natural side that could be perceived by the senses, but also the «supernatural» side, not perceived by the senses, and concealing something unexpected and,

\footnotetext{
118 A. Khinshtein, who named his book, published in 2006, "Yeltsin - The Kremlin. The History of an Illness", was mistaken: it should have been called: "Yeltsin - The Kremlin. An Extremist Psyche in Power". 118
} 
often, threatening. The link of this instinct with the fundamental instinct of self-preservation is obvious. The fact that the human being had developed in himself the ability to be constantly psychically ready to come across not only phenomena that were obvious and clear but also those that were secret and inexplicable, expanded and strengthened the «safety belt» of a person, who possesses the instinct of self-preservation, inherited from his ancestors.

All religions - from primitive pagan to modern monotheistic religions, which are essentially informal institutions, capable of existing, taking roots, and developing over thousands of years, and the churches based on them as formal institutions - are built on the basis of the instinct of belief.

The initial step of a religion - deification (spiritualisation) of the forces of nature in the form of subjects and processes of nature - is both objective and materialistic; here a person starts to recognise himself as a being, opposed to the rest of nature, but subordinated to it both in its «kind» and «malicious» displays.

The next step is polytheism, when the forces of nature no longer act as spiritualised subjects and natural processes, but as humanoids, possessing the psyche of people, but with unlimited power. Here, religion is no longer simply a display of the instinct of belief, but the reflexion in the pantheon of gods of the entire complex of the human psyche, ordered and structured according to the canons prevalent in society.

Finally, monotheism is the concentration of all the power of nature, society, and all the positive qualities of the human psyche in one being, living beyond the tangible and conceptual world, which nonetheless controls the world through its power. This creates a double effect: people receive an «absolute» point of support for instincts of self-preservation, trust, compassion, etc., and simultaneously attribute to the positive features of their own psyche, generalised in the image of God, such power, which the human psyche does not and will never possess.

Thus, religion is a system of images and ideas, filling the vacuum of the «unperceivable» and the «supernatural». At its centre there are beings, both kind and malicious, which reproduce - to some extent the human psyche and its values. The kind Gods encourage the «correct» norms of behaviour (informal institutions) in people, and the 
malicious Gods (demons) push people to breach these norms, for which the kind Gods punish the transgressors.

Can the progress of knowledge and sciences deprive the justification of the instinct of belief? Any step forward in science involves answering one of the universal questions and, simultaneously, raising several new questions, to which there are (at that point in time) no answers. The border between knowledge and ignorance is moved, but it has not been eliminated. Hence, the justification of the instinct of belief has also not been eliminated. The strength of this instinct depends on the psychogenetic types of specific personalities.

Religious systems, unlike their basis - the instinct of belief - are not eternal, but are extremely robust. The stability of religious systems (in comparison with social systems) can be explained by the fact that they reflect, first of all, the overall human psyche, including both its inborn and instilled features; only to the extent of shifts in the dominating instincts and changes in the instilled properties of the psyche is it possible to change religions.

According to Marxism, religion is a fetish, made up of a false reflection of the social system. However, such a point of view cannot explain why specific religions are incomparably more durable than any social systems. Essentially, religion is a creative, transformed projection of the foundation of the human psyche in that infinitely great part of the universe, which is still inaccessible to knowledge and, therefore, remains in support of belief.

In 2008, a three-year research project, «Knowledge, Religion, and Theology», was launched at Oxford University, with a budget of 1.9 million pounds sterling. Its task is to reveal, how natural it is for a person to believe in God, which religions are the most restrictive for human nature, whether belief in gods helped in the course of natural selection, whether it offered any advantages in adaptation and socialisation, whether belief constrained egoistical displays, and whether religion was always a mechanism for ordering some groups of people to use violence over others. Anthropologists, psychophysiologists, neurobiologists, psychologists-evolutionists, cognitive linguists, and theologians (especially those interested in cognitive religious studies) will take part in the project. (See Karin A. Nazaretjan's article, «Belief and Truth», in Moscow State University's weekly journal, «Action» № 3 (86), March 14, 2008, p. 15.) 
Geneticists have not been included in the list of participants in the project. Therefore, I would like to ask the authors of the project whether they understand the concept of «human nature». Clearly, this question cannot be answered without geneticists and it is unlikely that the project will succeed in answering the questions it has raised.

Having raised the question, "why people believe in God», the authors of the project go on to say that «we are not going to investigate the existence of God». However, if, after all, God exists, then this question is no longer relevant, as God created such people. This question makes sense, if one assumes that God does not exist, or that God is not part of «human nature» (which is the same in this context).

Essentially, the authors of the project proceed on this assumption, as they intend to conduct research in the framework of cognitive science on religion, which studies the occurrence, functioning, and evolution of religious views from the point of view of specific applied sciences (see the same source). Moreover, applied sciences deal, as is well-known, with proven phenomena and take nothing on trust.

Below, we consider the issues regarding the occurrence of a specific form of ideology by using Islam as an example.

The appearance and victory of Islam in the Arabian Peninsula in the first half of the $7^{\text {th }}$ century is an example of the interrelation of deep changes in the psyche, ideology, and the social and economic systems of a society, over a relatively short period of time, in a clearly defined geographical space. For general information, we have used the historically documented book, «Mohammed's Life» by V.F. Panova and J.B. Vaxtin. ${ }^{1}$

During this period, the psyche of the Arabian tribes and clans occupying the peninsula was in an excited and pressurised state. The Bedouin herdsmen, who had for centuries been accustomed to warlike freedom, were being squeezed by the burden of being surrounded by inarable land, which was not allowing them to feed the growing population, on the one hand, and the prosperous agricultural provinces of the mighty Byzantine Empire, which had captured Arabia in a wide arch from Gaza to Basra, on the other hand. This led to a growing wave of aggression based on despair, robberies, and attacks on

${ }^{119}$ M. Politizdat, 1991. 
agricultural oases and on the trading caravans, travelling from the Red Sea to the lands of Byzantium.

The dominant instinct of tribal and clan aggression found support in the ideology (religion) of paganism; each clan and tribe worshiped idols and humanoid gods.

The sharp economic crisis confronting nomadic cattle breeding in Arabia, and the psychic crisis connected with it, created a general environment, to which the few agricultural oases and trading settlements of the peninsula were forced to adapt. Within them, also, there was an inter-clan struggle for land and markets, in which the alien communities of Christians and Jews, patronised by separate pagan clans, also participated.

The clannish and tribal pagan society of Arabs was not closed: it had been penetrated by foreign cultural and ideological influences. Due to the trade that had developed, the mobility of the nomads and the «impregnation» of alien agricultural and handicraft communities, it was sated with the cultural and ideological intrusions of Byzantine Christianity, Persian Zoroastrianism, and Judaism. At the same time, it was sated also by elements of the degeneration of these cultures drunkenness, dissipation, bribery, and treachery.

Clearly, in these circumstances, the leading Arab thinkers searched for an ideology that met the basic characteristics of the Arabic psyche (domination of the instinct for aggression, a developed proprietary instinct, individual freedom, developed instincts of clannish collectivism, and a developed instinct of belief) and, at the same time, could harness and restructure the powerful psychic energy of the Arabs. The Arabs had to spiritually regenerate their psychic and cultural bases or disappear as an original ethnos. In other words, they had to transform their inborn natural instincts, which were only partially limited by fear of pagan gods and the institutions of blood feuds and clan solidarity.

Thus, an ideology was needed that would unite Arabs on the already existing basis of a common psyche and language; which would eradicate the separate (different) pagan ideologies; which consisted of uniform, uniting economic and social policies that were applicable to society as a whole, instead of separate tribes and clans; and which would direct the aggressive energy of Arabs outside Arabian society. 
Therefore, an ideology that would have led to the submission of Arabs to any of the already existing ideologies (religions) was clearly not suitable.

In contrast, an ideology that united Arabs and directed their aggression outside their society, had to show its clear superiority over other ideologies and aspire to a higher level of achievement in comparison with all other ideologies, including Christianity, Judaism, and Zoroastrianism.

These ideological requirements fully corresponded to the psyche of Arabs, who, although being much poorer than the Byzantines and Persians and also having a lower general cultural level, nevertheless, were assured of their moral superiority over their neighbours as members of free tribes, which had never been subject to state control, were not attached to land, and were not dependent on slavery or feudalism. They still measured the value of human existence and human dignity by tribal standards.

In the beginning of the 7th century, this was the outline of the new ideology which, the Arabs were psychically prepared to accept (without realising it at the time), either voluntarily or through the application of some initial force to overcome old habits. It is not difficult to describe these outlines retrospectively. However, it needed a genius to «catch» them and fill them with substance during that critical period in Arabia, which was in a tense, troubled, and stagnant state. For the Arabs, this genius turned out to be the Prophet Mohammed.

In the epilogue to "Mohammed's Life», Vaxtin notes that the psychology of creativity has hardly been researched in science, and religious creativity even less. Mohammed is not simply the creator of a religion - he is first of all a spiritual leader, an economic, social, and political reformer, the founder of the Arabian state, and the founder of the Arabo-Islamic civilisation. However, religious creativity provided the main impetus for all his creative activity.

He concentrated and absorbed in his psyche and consciousness all those requirements of the new ideology that were put forward by the spiritual disposition and fundamental needs of Arabs, who were a nation only due to a common language and psyche; however, in order to give a specific answer to these requirements, a person of that period had to take a psychic and intellectual leap forward. In their book Panova and Vaxtin focus their attention on this leap forward as if on 
Mohammed's subjective sensations in surmounting the «wall», separating people from God and his angels.

The many years spent almost incessantly in prayers, vigils, fasts, and contemplation, in the solitude of mountain caves prepared Mohammed for these leaps forward. The leaps ahead occurred during dreams or nervous attacks, similar in outward appearance to epilepsy attacks.

Panova and Vaxtin, interpreting these «leaps ahead» as subjective states, endured by Mohammed as instants when he «felt» himself to be in dialogue with God, do not touch on their objective side.

Meanwhile, the moments of the «leaps ahead», which Mohammed experienced as moments of being in touch with God (through «hearing» God speak), were actually moments of physical and psychic «shocks», releasing his preconsciousness from the shackles of those «instilled» instincts, which were forced on him by an invisible hand and limited the work of his consciousness.

Prayers, fasts, and deep contemplation had prepared him to face these «shocks»: the accumulation of ideas in his consciousness following on from the speculative principle of monotheism, on the one hand, and the accumulation of his preconscious psychic resistance to these ideas, on the other hand. During these «shocks», it seems that the earlier concepts from the preconscious were displaced and replaced by new concepts. The form, in which the commandments of God were later presented by Mohammed, implies that they emerged from the preconsciousness and were only partially «edited» by the consciousness.

The lines of the Koran as they were consistently declared by Mohammed (the sura were composed from these lines later by his followers), were messages from the preconsciousness of the prophet to the preconsciousness of Arabs. Even though, originally, they took shape in another form in Mohammed's consciousness.

Usually, for a human being, the birth of an action follows the following pattern: requirement $\rightarrow$ desire (preconsciousness) $\rightarrow$ consciousness $\rightarrow$ action. For the prophet, the pattern was different: consciousness $\rightarrow$ processing in preconsciousness $\rightarrow$ action (sermon). It seems that an extremely highly developed active preconsciousness (intuition) of the psyche, as a whole, is the main precondition for the transformation of a human being into a prophet. Due entirely to his highly developed preconsciousness, the prophet utters such messages, 
which the preconsciousness of the masses is anticipating and which answer their fundamental needs in life. Thus, the new religion becomes the tool of the institutional transformation of the entire society, including its economic system.

Thus, we can divide individuals into those, in whose psychic structure there is a steady inborn domination (in the form of certain existential requirements, instincts, and potential abilities), and those, in whom there is no such domination.

One would be fully justified in assuming that the latter group is in the majority. In general, these are people with a balanced psyche from birth. However, one can, within certain limits, deform the structure of a balanced psyche by a goal-oriented upbringing and surrounding environment, having transformed individual requirements, instincts, and abilities into dominating ones. However, the psyche of a person, through the course of his life, will inevitably gravitate towards its natural balance.

It is much more important that under the influence of a set of external conditions and, primarily, under the pressure of an organised group of persons with a sharply expressed dominant psyche, which has grasped leadership, the structure of the psyche of the «balanced» majority undergoes a shift; consequently, as a result of «suggestions», «imitation», «contagion», and «competition» the same requirements and instincts become temporarily dominant in this group, as in the leading group. The «pattern» of society changes and people display different sides of their psyche to each other.

The «dominating» psyche of a part of the population is still not an extreme psyche. The latter requires that the group of dominating requirements and instincts necessarily includes aggression and domination among them. This means that in itself dominant individualism, socialitarianism, or creativity does not signify an extreme psyche. However, dominant aggressive individualism, aggressive sociality, and aggressive innovation are variants of an extreme psyche.

Persons with a stably extreme psyche, obviously, make up only a small part of people with a dominating psyche, however, they, as a rule, are extremely active and sometimes talented. In the latter case, 
the actions of such people are capable of repudiating the statement that «genius and evil are incompatible». 


\section{Chapter 6}

\section{Underlying Psychological Background of Institutions and Organisations}

Having a conception about the structure and types of psyche (and, hence, about types of behaviour) allows one to come closer to an understanding of the real variety of the substance of economic institutions and organisations, and economic concepts in general - in particular, the inevitability of the existence of fundamentally different relations both within the institutions of "private property» and «state ownership». There are just as many different behavioural («relational») variants and, hence, different concepts in terms of «capital», «profit», «interest», «savings», «investments», «wages», «unemployment», «market», «economic growth», «firm», «establishment», «budget», etc.

The systematic division of the three groups of existential requirements and instincts and four social types of psyche (with each one being subdivided, taking into account the level of psychic energy and general abilities) can be considered as a step in putting in order the large number of variants of economic behaviour that are still considered chaotic, accidental, and unpredictable. This (or a similar) systematization, after it is elaborated, after being checked and corrected, can serve in the future as a means of working out the psycho-social matrix of a society. Together with the already existing matrix of input-output and system of national accounts, and also with institutional matrices, the psycho-social matrix can contribute to the creation of realistic multi-version «behavioural» models (both of the private and national economic models); the independent variables obtained on this basis can be included in different blocks of prognostic models. 


\subsection{Institutions, Organisations, and Typologies of the Psyche}

In the previous chapters, the nature and structure of the human psyche was considered mainly from the point of view of economists. Before considering the relationship between the psyche and economic institutions, here, one should keep in mind what I mean under the notion of institutions in general and economic institutions in particular. Although a broad range of literature (supporting different positions) has been published on this topic, I will not discuss these positions here as they are not relevant to the problem being discussed. I will start with the most widespread point of view, according to which an institution is the set of informal and formal norms and rules, regulating certain aspects of people's behaviour in a given society. From this point of view, the concept of an «institution» differs from the concept of a «contract» (which only covers the norms and rules established by the specific agreement of the parties involved), and from the concept of an «organisation», (which, basically covers a number of institutions, but also includes specific internal rules and personal power relations). On the whole, in such an interpretation, institutions as standard norms and rules constitute the foundation of contracts and organisations.

In a market economy, economic institutions are understand to be the norms and rules, regulating commodity-monetary (i.e., «equivalent») relations in manufacturing, trading, and the distribution and consumption of goods and services. In society, apart from economic institutions, other institutions (social, political, religious, and military) also exist - i.e., the norms and the rules, regulating the granting of services that are partially or completely paid for at public expense (in other words, «non-equivalent» relations). I will consider those organisations to be economic, whose main objective is to extract profit or increase the incomes of their members, and where, therefore, economic institutions dominate social institutions, which occupy a subordinate position. In contrast, one needs to consider social organisations to be those organisations, in which social institutions dominate economic institutions (i.e., where property relations, the pricing system, wages, etc., are subordinate to the fundamental social mission of a given organisation). According to this line of thinking, the national economy consists of two interconnected, but qualitatively different spheres, the economic and social. Within this framework, 
each organisation operates on the basis of both economic and social institutions.

Now, based on the previous chapters, I will put forward two principles of the mutual interaction between the human psyche on the one hand, and institutions on the other hand.

I name the first such principle as the principle of the greatest possible integrity of the representation of the typical individual psyche at each institution. The aspiration for the integrity of the representation of the psyche explains the extreme complexity of economic institutions - money, property, wages, competition, etc., each of which includes a complex system of norms and rules, corresponding (in the end) to the system of existential requirements and instincts of a person.

The second principle is the redundancy of the content of the psyche in relation to the content of any set of informal and formal institutions. Institutions are norms and rules that are applicable to everyone; therefore, they can only be based on the general basis of the psyche of the members of a society and cannot be considered as the specific psychic attitudes of separate groups, differing in terms of psychogenotypes and social types of psyche and the level of their general abilities. However, in the end, these distinctions also define the distinctions in the efficiency of the organisations (firms, market associations, foundations, etc.), operating on the basis of the same informal and formal norms and rules (i.e., institutions). This leads to an important conclusion: institutional theory in itself cannot explain the distinctions in the effectiveness of the same types of organisations that exist in a given society. Neither can it explain the distinctions in efficiency of the same types of institutional systems operating in different countries. However, nor can any other theory - based on the axiom of the uniformity of social and economic «strata», consisting of identical «atoms», «cells», «work-hours», «utilities», «energy levels», and «economic individuals» - explain this distinction. Supporters of such types of theories (classical, neoclassical, neoinstitutionalism, Marxism, etc.) believe that one needs to explain the specified distinctions by the casual coincidence of circumstances (random in relation to economic theory). They believe that economic theory should deal with laws, and laws reflect certain average characteristics of processes in terms of the market system as a whole. Marx characterised the attempts of representatives of the German historical 
school to find specific laws for the development of separate national economic systems as digging the tomb for the political economy. According to Marx, the specificity of a national economy is not a subject of economic theory; it can be understood only as a result of studying the specific circumstances of the occurrence of «an infinite number of variations and nuances of the united capitalist basis».

The real economic world is indifferent to such an economic theory. It is only interested in selected aspects. For example, Marxist theory is interested in the class struggle, neoclassical theory is interested in market balance, etc. For «pure theory», backward and advanced countries, profitable and loss-making firms, and fast and slow rates of development do not exist; these are areas that should be covered by applied economic sciences, together with geography, history, and sociology. This type of economic theory is a sort of free rider, as it wishes to be accorded the status of a reputable science, without answering the majority of fundamental questions of economic life. It is time to officially introduce a list of such questions to economic theory.

An example of the types of paradoxical conclusions that the initial axiomatics of the neoclassical theory (also applicable to neoinstitutionalism) can lead to is given by «the Coase theorem», according to which the redistribution of property between different owners does not affect the efficiency of an economy. Its paradoxicalness lies in its obvious contradiction with reality and its «proof» is based on a tautology: if one initially assumes that all owners are equally effective (as implied in neoclassical theory), then the redistribution of property will not affect the efficiency of the economy. (In the same way, neoclassical theory assumes that all hired workers are equally effective and interchangeable.)

From the point of view of such a theory, the search for an effective owner is meaningless, as everything is reduced to the definition of property rights: if these rights are outlined correctly, this results in the efficiency of a firm, irrespective of the owner.

Clearly, the theory and the reality differ; the theory deals more with the general, instead of the individual, phenomena. However, if individual phenomena are not uniform, if in their essential properties, they form groups, whose occurrence is not casual but natural, and if it is obvious that the economy forms a system, in which groups of individuals with diverse types of psyche interact, then economic 
theory should take these groups into consideration. This refers to qualitatively different groups of owners, managers, hired workers, small businessmen, government officials, etc.

These are psychogenic groups focused on mutual trust, cooperation, and mutual support as well as groups focused on aggression, the redistribution of property and markets, and control over resources; groups operating within the frameworks of standard informal and formal institutions and groups operating beyond these frameworks, based on a narrow group, and individual, «understanding»; groups aspiring to success through the development of human potential; and groups using opportunistic methods.

The relationships and activities within separate firms, foundations, agencies, and society as a whole depend on the psychogenic group to which individuals, at the head of organisations (in the economic and social spheres and in state organisations), belong.

If we designate the domination of a certain psychogenic group as "the regime» then, in that case, it turns out that the results of their management will be defined less by informal and formal institutions, and more by the social and economic regime.

At the end of the $18^{\text {th }}$ and the beginning of the $19^{\text {th }}$ centuries, concepts, which essentially considered that the basis of social relations was a mutual struggle for survival, were widespread. The principle of the English philosopher, Hobbes, of «dog eat dog» unequivocally defines the psyche and behaviour (including the economic behaviour) of people at that time. This thesis was given additional support by the following theories: Malthus' theories about the inevitable tendency of a reduction in the availability of food per capita; social Darwinism's thesis about the internal struggle within society; Ricardo and Marx's theories about the inevitability of an increase in class antagonism; and Adam Smith's concept of egoistical interest and competitive struggles as unique engines of economic development. Such a one-dimensional model of the capitalist market was described in terms of «egoism», «antagonism», «conflict», and «exploitation». Clearly, such descriptions were well founded in the era of the initial accumulation of capital, followed by the industrial revolution. During this period, groups with a dominant or extreme psyche were prominent and they destroyed the old informal and formal institutions and production structures, with tragic consequences for the vast majority of the population. In the beginning, in Western Europe, the tone was set by 
the baron-robbers and merchant-pirates, who were followed by the opportunist-exploiters, who were in turn pushed aside by uncompromising businessmen-innovators; finally, after the Paris Commune, with the dominance in economic, social, and governmental spheres of groups with a balanced psyche, the epoch of social compromises began. This led to the creation of a balanced system (on a market-capitalist basis) of economic and social institutions, meeting the structure of existential requirements of the vast majority of people and their psyche. Its development was interrupted between 1913 and 1945, but resumed after the end of the Second World War.

\subsection{Shifts in the Psyche and the Transformation of Institutions}

While the relationship between the inborn and instilled elements of the psyche is critical to understanding the human psyche, the key to understanding the link between the psyche and institutions lies in the relationship between the instilled psyche and «habits» (habitual thinking and behaviour).

Institutions are the norms and rules of habitual thinking and behaviour. Habits develop on the border of consciousness and preconsciousness in the course of the adaptation of a person to certain fundamental conditions of life. Clearly, as these conditions change, both habitual thinking and behaviour, i.e., institutions, can also change. Such changes can occur during the lifetime of one generation (both under the influence of changing external conditions and due to age-related changes in the organism and psyche of a person).

This is the main difference between the instilled psyche and habits. Instilled requirements and instincts can fundamentally change (within the permitted limits of the inborn psyche) only over the course of many generations, covering a period of two-three centuries (if children are not artificially isolated from the surrounding social - primarily, family - environment). However, this means that the habitual thinking and behaviour (institutions) can correspond to, and can contradict, the instilled psyche. In the first case, institutions change in such a way that the new norms and rules do not contradict the instilled psyche of the majority of the population, but correct and supplement it. In the 
second case, the new institutions (habits) conflict with the instilled psyche and, as a result, are either torn off or change.

For example, the private-ownership instinct, which has been instilled over centuries, cannot be forgotten or cancelled with the takeover of private property by the state. Such a replacement can only lead to a gradual change of habits (habitual thinking and behaviour) of a population, compelled over a period of years and decades to adapt to a new order. However, such an order turns out to be fragile and eventually falls. At the same time, sustainable development allows a multifaceted transformation of private-ownership norms and rules, in which the division, redistribution, restriction, and addition of property rights with different obligations, takes place. Thus, the habitual thinking and behaviour of owners (institutions) change, however, in such a manner that the private-ownership instinct is not undermined and continues to operate through a modified set of habits (informal and also formal institutions). The same holds true for the family instinct. Throughout history, there have been numerous attempts to «abolish» the family, to introduce a system of «shared wives and husbands» and «shared children», within the frameworks of various communes, both secular and religious. Forecasts concerning the formation of «new forms of family units» have also been made: «incomplete» and «unisex» families, «large families» on the base of «electronic cottages», etc.

I believe that the instilled human instinct of gravitating to a family, consisting of a husband, wife, and their children, was developed over the last three-four hundred years. The habitual norms and rules (institutions) of life in such a family changed repeatedly during this period; however, they did not change contrary to this instinct, but, in the direction of the modification of the forms and spheres of its functioning.

Modern society contains factors that both strengthen and undermine the instinct for domesticity (in the sense specified above). If the latter prevail, the monogamous family can collapse; however, in that case, in exchange, new sturdy social forms for fulfilling the inborn instinct of reproduction and the parental instinct will appear, i.e., new instilled instincts and new habitual norms and rules.

Since concepts, inferring that it is possible to break off stable relations between parents and children, contradict the inborn instincts of the majority of the population, any attempts to «dissolve» the 
family unit are utopian. Hence, one cannot realistically speak about the «cancellation» of the instilled instinct of domesticity, but only about its gradual transformation.

Informal and formal institutions. Norms and rules, corresponding to the normal psyche and shared by the overwhelming majority of people («informal institutions») can contradict the psyche of the minority and be broken by this minority, despite the moral condemnation of the majority. This is the first reason why informal institutions should be formulated in legislative and administrative acts, which have to be obeyed under threat of punishment («formal institutions»).

However, also within the majority of the population, the differences in the individual psyche, interests, and social status lead to distinctions in the interpretation of the standard norms and rules, which demand their legal specification, commitment, and the requirement for them to be fulfilled in a legally binding way. This is the second reason.

The third reason lies in the development and complication of society as a whole and the economy in particular, as a result of which the norms and rules that have developed over a certain period, based on inborn and instilled (since childhood) requirements and instincts, become outdated and need to be replaced by new ones, corresponding to the specific new conditions. Theoretically, informal institutions precede formal ones in content and form. However, historically, informal institutions develop and evolve through the vigorous activity of people, including the creation of standards. New norms (formal institutions) are created and frequently take root long before the formation of standard informal norms, based on the new realities of the culture and instilled psyche. These new formal institutions (corresponding to the psyche of the dominating minority) then either take root, accelerating and facilitating the development of an adequate informal base, or die off and perish, without having received such a base.

This reason is especially important for understanding the logic of reforms. Quite often, an active minority with a dominant and even extreme psyche, having come to power, aspires to impose new formal institutions (in place of the old ones) on the majority of the population, corresponding to the structure of their own inborn and instilled requirements and instincts, which, however, are contrary to 
the psyche of the majority. Such institutions could not exist without the support of specially created structures, including state security structures. At the same time, the dominant minority considers that the population will gradually get used to the new formal institutions, taking into account that adequate cultural conditions (including a technical basis) will be gradually created for the new institutions. The new culture will result in the development of a fundamentally new psyche, and «the New Person» will appear. This was the argument of the Bolsheviks against the Mensheviks in the 1920s. However, in order for new formal institutions to survive, they should not contradict the inborn psyche of the majority of the population. They cannot even be in conflict with the instilled psyche of this majority. The former practically does not vary at all, and fundamental changes in the latter are possible only over the course of two-three centuries. Does this mean that radical reforms of an ancient system of institutions in general are impossible? They are possible, but only such that correspond to the structural bases of the inborn and instilled psyche of the majority of the population. The formal institutions of «military communism» were unacceptable from this point of view, but the new institutions of «The New Economic Policy» of the 1920s were fully acceptable; later, the institutions of «collectivisation» and planned centralisation were again unacceptable. The radical reforms of the 1990s in Russia, having recreated the free market and private property, have restored the conformity between the psyche of the masses and institutions in some aspects, but have at the same time broken it in others, having generated a high degree of psychic tension by the concentration of property in the hands of the few and the destruction of the social sphere. As a result, this led to a defective system of informal institutions and the degradation of the nation as a whole. At the same time, the reforms that have been taking place in China for the past 30 years along the lines of the Russian New Economic Policy, have led to an overall improvement in China.

\subsection{The Psyche and «Human Capital»}

The category of «human capital», which is widely applied in modern economic theory, continues to be topical today; however, it is 
not relevant here. However, I note that during the course of these discussions both supporters of the narrow-economic and supporters of the «holistic» social and economic approaches did not try to reveal a link between this category with the psychology of an individual and society and its structure. I will try to concentrate on this aspect of human capital.

Taking into consideration the material of the previous chapters, I will proceed on the basis that human capital is a set of constructive and creative properties of a person, including the inborn, instilled, and obtained properties, which can be maintained and developed. These properties are classified through the allocation of health capital, the capital of science and education, intellectual capital, social capital (including capital of trust), and cultural capital.

The formation of human capital demands individual and social expenses, so the accumulated human capital is measured by the amount of corresponding investments made in it. Clearly, such a measurement is extremely conditional, since a monetary estimation of the «benefits» that make up human capital is impossible in some cases and is only partially possible in others.

That is why investments in human capital (both for private and for social purposes) can only partially be considered as investments, which yield monetary income to the investor. As a rule, such investments yield significant returns only over decades, and, mainly in the form of steady economic growth, an increase in life expectancy and income levels, preservation of social balance, and the spiritual enrichment of a society.

The bases of the psyche, that is, the natural and instilled existential requirements of people («values») and their natural and developed abilities are formed at the same time as the basis of human capital. Specific displays of the psyche in habitual forms of thinking and behaviour, including the economic sphere, are, at the same time, specific forms of the fulfilment of human capital. This means that the efforts of individuals and society in the formation of human capital take place on two different levels and in two different directions.

The basic level is the level of the formation of positive existential requirements (values), on the one hand, and the constructive development of abilities, on the other hand. The specific level is the formation of habitual behaviour in different activities and situations in an individual, corresponding to the basic values, and the practical 
skills and abilities in the effective performance of industrial and other functions.

Both at the basic and at the specific levels, the formation of human capital takes place in two areas: in the area of the formation of values and in the area of the formation of abilities.

Clearly, in the formation of human capital, it is important to attain conformity between basic values, basic abilities, habitual behaviour, and practical skills and abilities.

A society in which habitual behaviour is not based on the corresponding basic values cannot be stable; a society in which practical skills and abilities are not based on the development of general abilities (physical, intellectual, volitional, etc.) cannot progress effectively; this shows the significance and necessity of the link between these basic values and general abilities and between habitual behaviour and practical skills.

This means that upbringing and education (in both cases, both basic and practical) should form a uniform co-ordinated system and develop together. The market mechanism is not in a position to carry out such coordination; this is carried out by institutions and social organisations, such as the family, public health services, education, science, the media, and other forms of activities, relying on the state and on society as a whole.

The lack of uniformity and contradictions in the processes of developing human capital are connected with different levels of the physical health and psychic energy of members of a society, distinctions in the inborn types of the psyche and natural abilities, and also with the systems of institutions (informal and formal) and organisations (including economic organisations).

If one assumes that all individuals have identical access to all sources of accumulation of human capital (public health services, education, science, culture, etc.), then, due to psychogenic distinctions, a number of tendencies would manifest themselves, illustrating significant social and economic consequences.

Human capital as a whole would accumulate significantly faster in the part of the population, which possesses the higher psychic energy and the higher level of general abilities (willpower, intelligence, the ability to learn, etc.).

Thus, individuals with a socialitarian dominant psyche would accumulate mainly social capital; individuals with an «innovative» 
dominant psyche would accumulate intellectual capital; and individuals with an individualistic dominant psyche would mainly collect health capital.

Thus, people with an individualistic psyche and, in particular, people with an entrepreneurial psyche, would attract first of all those elements of human capital, which are connected not with its basic fundaments, but with its behavioural habits and practical skills and abilities.

I believe that the institutional system of capitalism does not weaken, but, on the contrary, strengthens the unevenness of the accumulation and concentration of human capital, which has natural psychogenic origins. It is also promoted by the entrepreneurial psyche, aspiring to establish control over the accumulation of human capital and use it for capital accumulation in other forms - material, stocks, bonds, and monetary. This is because, unlike these forms of capital, the human capital of hired workers is personified and cannot become the private property of a businessman. At the same time, for the preservation of social balance and sustainable development, society is interested in avoiding a gulf developing between the level and character of the accumulation of human capital between separate groups of the population. Therefore, society and the state should take special measures to avoid excessive differences in the population regarding the level of their health, education, upbringing, and culture, by providing uniform standards necessary for the accumulation of human capital for everyone.

The special support by the state of the higher individual abilities for the accumulation of specific knowledge and skills is expedient only on the basis of this general necessary level.

\subsection{The Market and Organisations: Two types of Relations}

Informal institutions (norms and rules) always concern relations among people, even regarding a person's internal relation with himself or a person's relation to things. Concepts of cleanliness and a protective attitude to nature and to pets always assume a certain norm or a rule that is co-ordinated between the majority of people; beyond this generally accepted norm (excessive attention to cleanliness, pets, 
and plants is detrimental to other fundamental needs, both one's own and others'), these qualities are no longer considered by society in a favourable light.

The free market can be considered as a set of norms and rules, according to which an exchange between members of an economy is carried out under the prices defined by supply and demand. This set of norms assumes fluctuations in all market indicators, but also includes standard notions of admissible limits of fluctuations. Although specific quantitative expressions can change in time, nonetheless, a certain general opinion on the existence of limits of «normal» fluctuations remains.

It is clear that the institutional base of the market and the market's supply and demand depends on the set of factors defining the distribution of wealth and income, and the production, exchange, and consumption of goods and services - in particular, factors such as the existential requirements, instincts, and abilities of various groups of members of the economy, possessing various types of psyche.

On the supply side, people are united in organisations, which act as market agents. As noted above, informal and formal institutions lie at the foundation of the activities of organisations, but only at the foundation, as the direction and character of their activities (both «internal» and «external») are defined primarily by the psyche of those, who control and operate the property of a given organisation (firm, corporation, bank, etc.).

On the demand side also, organisations act as market agents; however, individual buyers, whose psyche can differ sharply from the psyche of the managers of these organisations, also play a significant role.

Two basic types of relations, both between and inside (internal to) organisations are possible: conflictory and compromisory.

If organisations are supervised and controlled by people with aggressive and appropriatory types of psyche, then the relations between and inside the organisations develop in an antagonistic way. The management of such organisations aims to reap the benefits at the expense of its counterparts in the market and the organisations' own employees. The classical, Marxist, neoclassical, and Keynesian understanding of the functioning of the market is based on such a «model» of relations. 
At the same time, the classical and neoclassical theories imply the initial existence of a balance between the forces of conflicting parties, which allows them to argue in favour of the preservation of a mechanism of competitive balance in the long-term. However, Marxism and Keynesian theory reject such a premise and, therefore, their understanding of the future prospects of a market economy is built on the postulate of institutional transformations of the market, tending towards etatisation.

The second type of relations, compromisory relations, occurs when organisations are managed by people, inclined and able to benefit through innovation and cooperation with their counterparts and employees. In game theory, this variant of behaviour is referred to as «co-operative», where the players search together for mutually beneficial solutions. In other words, each side sets itself the task not to deprive its counterparty, but to promote mutual development, and the game turns out to be mutually beneficial.

George Akerlof, one of the leading post-Keynesian economists, has built his theory on wages on such premises: employers aspire to raise salaries and in response, employees try to raise the productivity and quality of their work.

Both types of relations, antagonism and cooperation, are possible on the basis of the institutions of private property, competition, and hired labour. Hence, the maintenance and orientation of these institutions depends on the organisations in which they are included, and the nature of the organisations is defined by the psyche of their managers.

This implies that competition, private property and hired labour, on the one hand, and cooperation, on the other hand, cannot be considered as incompatible concepts. Marshall noted that with the development of the capitalist market (i.e., private property and hired labour), the role of trust and cooperation gradually has increased. However, at the same time, he considered cooperation and competition as opposing mutually exclusive concepts. At the end of the 19th and beginning of the 20th centuries, competition amongst organisations had a predominantly conflictory and antagonistic character. To the extent that it has maintained such characteristics in the 21 st century, it remains incompatible with cooperation. However, today, aggressive and predatory types of managers of organisations have been gradually forced out, and with the change in the nature of 
organisations, an increasingly significant role in their behaviour is played by the symbiosis of competition and cooperation.

This raises two types of questions. Is it possible to consider the aggressive behaviour of the management of organisations as a response to the aggressive behaviour of their internal or external counterparties? In some cases this occurs; however, in the absence of impulses from ones own psyche, the response will, as a rule, be defensive in nature.

The second question concerns the compatibility of management's compromisory behaviour within an organisation with aggressive behaviour in relation to external counterparties. From the logic of economic interests, under certain circumstances, it can suit the management to pursue a conciliatory policy within the organisation and an uncompromising policy outside it, or vice versa. Such a conclusion concurs with the approach used in behaviourism and cognitivism in psychology, and neoclassicism in economic theory. However, in reality, groups of individuals with an aggressive type of psyche are aggressive everywhere. The specific forms of the aggressive behaviour of such people can vary; however, it remains aggressively oriented, regardless of whether it is within the context of relations in families, economic organisations, or in government. Such people are capable of temporarily compromising only when faced with clearly stronger adverse forces, which pose the threat of severe losses.

In many social and economic concepts, questions concerning relations between private property and the psyche are turned upside down. People with an aggressive psyche will always find a way to tyrannise the rest, regardless of the existence or abolition of private property (as noted by Lenin and Keynes). Nevertheless, it continues to be considered that private property «spoils» the psyche, rather than an aggressive type of psyche that uses private property as an instrument of oppression and violence. In order to raise the issue of the correlation between the psyche and the institution of property in a clear and sharp way, I will allow myself to digress slightly. This question is investigated in extreme detail in detective novels. In case of a murder of a millionaire, how is the circle of suspects defined? First of all, it is defined on motives (possible inheritance). In this way, the appropriation instinct (material interest) is immediately put forward as the driving force (motive) behind a crime. Based on this 
motive, some relatives are immediately placed in the circle of suspects. Then, one discovers that all of them are people with a normal psyche, and only one person has an aggressive inclination and a criminal past. This is the person exposed as the murderer.

Thus, material interest in people with a normal psyche cannot be the moving force behind criminal appropriation - such a force is represented by the aggressive psyche; material interest acts as the catalyst, which sets this psyche into action.

Let us also consider another variant: none of the suspects are aggressive, but the instinct of appropriation in one of them is hypertrophically strong: he is greedy and avaricious. Here, material interest turns out to be the moving force behind the murder, however, again, not in itself, but as the catalyst of a deformed psyche. Pliushkin (Gogol), Gobsek (Balzac), and the Avaricious Knight (Pushkin) are not aggressive, but are capable of murdering even their own children for the sake of property.

This digression shows the dependence of relations to property on the psychic type of a person. While for some, appropriation is one of the existential requirements, which exists along with others, for others, it is the dominating requirement.

\subsection{Questions Regarding «Proto-Institutions»}

The relative role of the separate elements and forms in the framework of a developed social system is not necessarily the same as their role in the course of the occurrence and formation of this system.

One can assume that for a significant part of the period covering 5 - 6 million years of the evolution of the human being, his «social» life only slightly differed from that of his close relatives, the primates. In the primates (as in other representatives of fauna), one observes genetically caused «habitual forms of behaviour», including complex behaviour, such as the division of functions in life-support processes, seasonal migrations, and marital and other rituals. If one considers «habitual behaviour» as the «norm», and norm as an institution, then one has to recognise that the lives of (close to) the majority of representatives of fauna is governed by «institutions». 
Human institutions differ from such zoological «institutions» in that they are formed not only as a result of genetic and environmental factors, but also due to two additional factors, consciousness and culture.

Such a «triple» approach to the genesis of human institutions allows one to avoid extremes in explaining their nature. These extremes consist in absolutising the role of one of the three specified factors: genetics, consciousness, or culture. There is no need to repeat the fact that these factors are connected with each other; however, one should not forget that they also have independent lives both within the framework of institutions and outside them. The occurrence, 5-6 million years ago, of a new genotype with its physiological abilities for the development of walking upright, speech, and brain could not help but affect the evolution of its genetically inherited psyche, which gradually started to increasingly diverge from the psyche of other primates.

We have no data to answer the question on the time period necessary for fundamental changes in genetically inherited types of the human psyche. However, if one assumes that changes in the structure of the genetic mechanisms controlling the psyche occur at approximately the same speed, as in the genetic mechanisms controlling the general development of an organism, then it would take not less than several tens of thousands of years. Hence, over 5 - 6 million years, changes in the genetically inherited psyche could be repeated (in the course of natural selection) many times, long before the most primitive consciousness was formed and cultural traditions started to develop. Thus, as noted above, not only elementary «propensities» but also very complex «modules» of behaviour (as evidenced by ethology) in the genetic code of the human being could be fixed and transferred to descendants.

Therefore, there cannot be any fundamental objections against the theory that the «unconscious» part of the human psyche contains certain «archetypes» of perceptions and «archetypes» of behaviour, which appeared there long before consciousness and culture.

However, this means that over a period of millions of years, the individual and collective inborn psyche of people lay at the heart of the organisation of their lives. The kin and the individual cannot be separated from each other or reduced to each other; they are two poles of one natural system; at the same time, «kin» is not a formless mass 
of individuals, but a structured hierarchy (of different qualities of the psyche), whose particles are individuals.

Later on, the organisation of life varied qualitatively, kin became more extensive and united as tribes, tribes broke up into «neighbourhood» communities, nations were formed, direct personal contacts were replaced by mediated links, people were divided into classes and social groups, families and enterprises became the basic «cells» composing society, and vested interests and the market became the driving force and the binding mechanism. The psyche of people became extremely complex under the influence of the huge growth in culture and changes in living conditions. However, just as tens of thousands of years ago, it continues to serve as the main binding mechanism of social organisation, which, despite its different versions, inevitably continues to remain hierarchical (as it cannot exist without a hierarchy).

In this context, I will consider the concept of «proto-institutions», developed by George Kleiner (on the basis of developments carried out by a number of psychologists).120 «Significant institutional changes (the fundamental transformation of old or the occurrence of new institutions) are the result of extremely specific interactions of the available institutions or, in algebraic terms, the final number of operations over some objects, which can be called proto-institutions. As well as the usual institutions, proto-institutions represent institutional norms, rules and forms of behaviour; however, they are perceived and function not so much on the conscious, as on the unconscious individual level (in Jung's interpretation), if the agent is a physical person, and (in a certain sense) at the collective unconscious level, if the agent is represented by a group (an enterprise, organisation, etc.) (p.191). Thus, supporters of the concept of «protoinstitutions» go much further than Jung, believing that the sphere of the unconscious contains not only the «archetypes», but also the set of norms and rules, regulating human behaviour in all spheres of its activity. "In terms of their position in the social-individual structure, proto-institutions are related to processes that are connected with satisfying the basic needs of an individual, including the «fundamental» (requirements for food, water, sleep, protection, and

\footnotetext{
120 G.B. Kleiner, "The Evolution of Institutional Systems. Moscow”, Nauka, 2004, pp. 191-194.
} 
defence), the roles (based on relations with relatives, sexual partners, work, and other hierarchies, etc.), requirements for a fair evaluation, and requirements for self-development (including research interests, imitational-game functions, etc.) (P.V. Simonov and P.M. Ershov, «Temperament, Character, and Personality», M., "Nauka», 1984). Proto-institutions exist for the simplification and streamlining of the individual and collective implementation of these basic (and also some accompanying) requirements, when material resources and individual possibilities are limited (p.192).»

According to Kleiner, the basic archetypical social and economic proto-institutions include the following:

- Institutions of family and related relations;

- Friendship institutions;

- Institutions of trust and agreements;

- Religion institutions;

- Institutions for donations, inheritance;

- Institutions for debt and credit;

- Boycott institutions (exclusion from membership of a certain community);

- Institutions of gratitude;

- Institutions for compromises;

- Institutions of behavioural rituals (for example, greetings on introduction and farewells at partings);

- Institution of hierarchical submission, coordination during group work;

- Institution of collective and individual games (actions in the proposed conditional circumstances), etc., (pp. 192193).

«Proto-norms» lie at the heart of the listed «proto-institutions»: «The norms, which are the core of such institutions, could be referred 
to as «proto-norms», as they are in each specific historical epoch ... prototype norms ... Proto-norm turns into a proto-institution as a result of the process of institutionalisation, i.e., the acquisition of stability and consolidation in the conscious and unconscious structure of individuals, groups, and societies as a whole.» The authors continue: "Thus, the appearance of a new institution is the result of «crossing» the basic proto-institutions and the subsequent selection process or activity on the selection and consolidation of useful results (p.194).»

In my opinion, the movement of institutional theories towards a rapprochement with psychology in general, and with its fundamental principles in particular, is a constructive process; however, at the same time, one needs to be careful, as rapprochement, beyond a critical line, can turn into an identification, reducing an economic science to psychology. In my opinion, such a path is encountered in the concept of «proto-institutions».

Can one consider stereotypes of behaviour, which are perceived and operate at the unconscious level, as «institutions»? If so, then the stereotypes of behaviour of many kinds of animals, birds, insects, and fish illustrate forms of institutions and even institutional systems.

However, if an institution is a concept, related exclusively to human society, then the stamp of consciousness and culture as accumulated experience and knowledge should be pressed on it.

(Here, by consciousness, we understand the ability of people to take decisions not under the influence of unconscious impulses, but based on the analysis of information and its comparison to previous experiences.)

In this context, those concepts which are introduced by Kleiner as «proto-institutions» should be divided into different groups:

The first group of concepts introduced by Kleiner is the genetically transferred existential requirements and instincts, (which, in the human being, can be similar to the requirements of his distant humanoid ancestors) - of kinship, trust, boycott, gratitude, behavioural rituals, hierarchies, coordination, games, etc.

These requirements and instincts can become the natural basis of institutions only under the influence of a culture and consciousness, which transform them into specific historical norms of behaviour.

The second group is institutions, as they are formed, at the same time, naturally and by social history - the family, religion, inheritance, 
credit, compromise, etc. These institutions are not transferred genetically from generation to generation, but by winning over public opinion, through upbringing, education, and example. They can be stored in the preconsciousness of a person, however this is not the genetic but the cultural memory of a generation.

Hence, a qualitative barrier lies between the first and second groups; it is the barrier between the inborn and instilled psyche, which cannot be erased, as it would prevent us from finding out which possibilities are provided naturally in human nature for its historical creativity and by which insurmountable barriers it limits this creativity.

Thus, I believe that there is no justification in considering congenital stereotypes of behaviour as certain archaic institutions or «proto-institutions», and modern institutions as the products of combinations of these proto-institutions. The qualitative side, referred to as culture (in the broad sense of the concept), transferred by means of training and memory mechanisms, lies between genetically caused natural requirements, abilities, and instincts, on the one hand, and institutions, on the other hand,.

Culture cannot be understood without considering its natural psychic basis. However, in itself, culture represents the accumulated experience of conscious activity, transferred either directly from generation to generation through education and training, or through the perception of objects of culture.

Institutions represent the result of the transformation of natural stereotypes of behaviour through the influence of historically defined types of cultures and current conscious activities. Thus, one has to establish the triple-sided (natural, cultural, and conscious) nature of institutions. At the same time, each side of this duality continues to maintain its independent life: culture and institutions unite people through the common norms of behaviour; however, in the psyche of each individual, the general is connected with the specific in a «minisystem», whose core is made up of natural requirements, abilities and instincts.

The human memory is that complex, multilevel sphere of the psyche, where the acquired values, skills, norms of behaviour, and habits, i.e., culture in general and informal institutions, in particular, are stored and from where they can be (if necessary) reproduced in the consciousness. This sphere occupies an intermediary position between 
consciousness and the «unconscious» and is called «preconsciousness» by psychologists. According to the researchers, studying the functioning of the brain, the mechanisms of the memory have still not been disclosed. There is evidence that these mechanisms operate at a fundamentally different biochemical level than the mechanisms of the genes that control the psyche. While the mechanisms of the genes (from the sphere of the unconscious) operate at the molecular level, memory mechanisms (from the preconsciousness sphere) are systems of the interaction (through the synapses) amongst the nervous cells of the brain. For this reason, the contents of the memory are not transferred genetically; only its potential possibilities («reaction limits») are genetically transferred.

From this, it follows that a person genetically inherits numerous fundamental needs, abilities, and instincts, but not culture and institutions.

\subsection{Structures of the Psyche and Social-Economic Systems}

Mainstream economic theory studies the choice faced by the buyer in selecting different goods (and groups of goods), assuming that the supply (i.e., «choice» of the manufacturer) follows demand. Meanwhile, individuals with a «balanced» psyche, given the possibility of choosing the area of their work, can be guided by the criterion of maximisation of their monetary income, as long as this does not significantly disturb the balance between their existential requirements and instincts, i.e., within limited frameworks.

The basic choice made by individuals is a triple choice: selecting a profession, its branch, followed by the «role» of the individual (small businessman, hired worker, manager, member of co-operative society, etc.). As this «triple» choice is in many respects defined by the psyche of individuals, one can conclude that this psyche is an independent factor (along with technology and the environment) in defining the professional, branch, and social structure of an economy (on the national and global levels). In short, it is not structures that create people, but people that create structures in their own model.

I come to a conclusion, which fundamentally diverges from the conclusions of Marx and Marshall, according to which the psyche of 
individuals is formed by the conditions of production and distribution. To the extent that these conditions are dictated not by the psyche of individuals, but by external factors that are outside the psyche, and that contradict this psyche, it results in the occurrence of a triple process in a historically short-term period: conflicts, temporary adaptation, and emigration. Over the long-term, the conditions of production and distributions are brought into line with the existential requirements, instincts, and natural capabilities of individuals.

The entire modern system of social-economic institutions of an economy is the result of the interaction of forces violating and restoring this conformity.

Private property develops on the basis of the evolution of the production abilities of a person and the division of labour; however, it is driven and motivated by the general instinct for appropriation.

Private property is accumulated on a vast scale, by aggressive and capable individuals, whose psyche is absolutely dominated by this instinct and who dedicate themselves to the accumulative instinct, whereas the majority of the population possesses a different psyche.

The interaction of the general instinct for appropriation with the division of labour has generated the market; the interaction of the market and the accumulative instinct has generated trading and usury capital; the market, the trading capital, and the innovative instinct have generated the industrial revolution and together with it market capitalism.

Based on the accumulative instinct of owners, large-scale machine production as a whole has raised the population's consumption level; however, at the same time, it has suppressed many of its existential requirements and instincts. This became apparent through the absence of employment guarantees, the excessive intensity and duration of work and the increased threat to health, the exploitation of women and children in work, the increasingly unfair distribution of incomes, the lack of care for the sick and aged, etc.

Can one assume that private property resulted in the natural psyche of hired workers in industrial enterprises becoming suppressed?

Firstly, even based on market capitalism, relations between owners and hired workers, corresponding to normal existential requirements and instincts, are possible. This can be seen from Robert Owen's experience in England at the beginning of the 19th century, and 
especially the practices prevalent in Western Europe after the Second World War.

Secondly, the experience of the USSR shows that even at state enterprises, the domination of relationships, suppressing the fundamental needs and instincts of hired workers, is possible.

Consequently, in this respect, it is the psyche of the people, who control the enterprises, and the character of the laws and agreements, regulating the relationships of the parties involved, rather than private or state ownership, which matter. These two factors, the psyche of the owners and the character of the institutions that regulate real relations, define the actual nature of the ownership, rather than the reverse. Throughout the last three decades of the 19th century and all of the 20th century, the development of regulatory institutions, called on to bring relations in the economy into accord with the structure of the existential requirements and instincts of hired workers, was carried out in a disputed and uneven way. This process developed in four directions, and led to the transformation of the market-capitalist system into the market-capitalistic-social system.

Firstly, economic institutions within the framework of firms (i.e., a system of norms and rules, focused on maximising profit and in that way fulfilling the requirements and instincts of the accumulative psyche of the owners) were gradually supplemented with «built in» social institutions operating within firms, which reflected the existential requirements of the hired workers (in terms of social safety, protection of health, justice, etc.). This was implemented through these institutions by means of state laws and the conditions specified in the agreements with trade unions (concerning the hiring and dismissal of employees, safety precautions, working hours, salaries, the participation of employees in management, etc.). The social institutions within firms do not suppress the profitability principle as the dominating institution of a capitalist firm, but directly limit the sphere of its activities within a firm.

Secondly, the state and trade unions have gradually created a national «network of social safety», consisting of institutions for the protection of the population in case of unemployment and incapacitance, which aim to support weak groups.

Thirdly, a system was formed for the macro-regulation of the economy by the state, which was socially oriented to maintain employment, stimulate growth and technical progress, redistribute 
incomes in order to support branches and regions that were lagging behind, and satisfy critical social needs.

Fourthly, the social sphere of the economy, including education, fundamental science, public health services, and culture, has developed. Institutions belonging to this sphere aim to address the following three tasks: to form human capital, required for modern production; to fulfil the congenital requirements for justice and development, providing people with equal access to knowledge, medical aid and culture; and to instil the requirements and instincts in people, corresponding to modern civilised life. Organisations in the social sphere (universities, hospitals, theatres, etc.) are capable of carrying out their tasks only to the extent that within them social standards dominate economic standards (without suppressing the latter), and to the extent that their activity is not aimed at making a profit but rendering qualitative and accessible social services.

Thus, one sees that in the historical development of institutional structures of the economy, an expansion in time and space of the structure of the human psyche takes place. Moreover, expansion in two forms - as existential requirements, instincts and abilities of a typical normal individual and as the psyche of the entire set of individuals in all its contradictory variety.

In the set of institutions of the market-capitalist system, the economic norms and rules underlying a manufacturing firm are of critical value. As noted above, they primarily reflect the accumulative instinct of the owner of the firm. Moreover, this owner-accumulator can act in several forms: as a predator, innovator, slave to routine, or opportunist. The type of psyche possessed by the prevailing majority of capitalists holds some significance for the national economy. Does the psycho-typical structure of the capitalist corps develop randomly or does it change under the pressure of circumstances? I believe that the psychic types of capitalists are a steady phenomenon; however, the structure of their corps is capable of cardinally changing, depending on the surrounding institutional environment, and on the individual and collective psyche of the other cooperating «actors».

This question carries great value as an explanation of the technogenic growth of the West and Japan after the Second World War, and for understanding the economic conditions prevalent in countries in the post-socialist area. In order to answer it, one needs to consider that different types of capitalists use different sources and 
methods to accumulate capital. «Predatory» capitalists gather capital primarily through the redistribution (to their own advantage) of other people's property (both private and state-owned) and incomes (private and budgetary) by direct seizure, criminally fraudulent security transactions, monopolistic price inflation, manipulation of state orders and tax payments, plundering natural resources, contraband, etc. They are capable of carrying out these activities through the direct and indirect participation of state structures, deliberately leaving «holes» in the legislation and turning a blind eye to the violation of laws, and through lobbyism and corruption.

Currently, in the West, the prevalence of predatory capitalists has been significantly reduced; however, they still exist as can be seen from the activities of corporate raiders, forced mergers, managers stealing from shareholders, etc. Regarding Russia, where law and order is in the process of being restored, the owners of stolen capital, aware of their criminal past and their semi-criminal status today, tend to move abroad or become involved in financial speculation. Clearly, the gradual replacement of predatory capitalists is connected with the change of the type of politicians and officials that are in power. Instead of «scheming manipulators», who used the pretext of fighting against communism for their own material benefit, state deputies, judiciary appointments, and ministerial posts are starting to be filled by individuals with a balanced psyche, whose instincts of sociality have not been suppressed.

The predatory capitalist, who was not inclined to submit to the state, who, through various open and hidden means even subordinated the state to himself, is being replaced (as the prevailing type) by the opportunistic capitalist, who extracts profit not by large-scale robberies of other people's properties and social revenues, but through «ordinary» and «peaceful» ways. These include avoiding the payment of taxes, systematic underpayment of hired personnel (regarding working conditions, overtime, inflation, etc.), and a refusal to compensate for the depreciation of equipment, pay environmental protection expenses, pay costs related to safety precautions, etc. An «opportunistic» capitalist is not in the least interested in the technological modernisation of production or about increasing the efficiency of production. If «opportunists» prevail, competition dies away, as they aspire not to compete, but to adapt to each other, having de facto divided the market territorially and in terms of 
«commodities». Informal local industrial and trading networks are created, which ensure rising prices. The close association of such capitalists with the local authorities and trade-union bureaucracy, which also mainly consist of people with an «opportunistic» type of psyche, serve as the prerequisites of their success.

While large predatory capitalists can be forced out by the higher organs of government, controlling the numerous «opportunists» is much more difficult, requiring persistent work in each region and with each enterprise (firm).

First of all, one needs to provide conditions of strict competition and, hence, facilitate the access of new firms to the local markets as much as possible. Furthermore, one needs to cardinally change the function of trade unions so that they can consistently achieve wage increases at each enterprise to the maximum level reached in a given sector (as takes place, for example, in Germany). Strong «pressure» from financial and supervisory bodies for the payment of taxes, observance of safety rules, and health and environmental protection is also necessary. In other words, firms should be encouraged to profit through technological and organisational progress, and all other ways of making a profit should be cut off.

At the same time, it is naive to expect the opportunistic capitalist to change his psyche to become an enthusiast of innovations and cease to consider his firm as a means of pumping out capital for investments in country houses, yachts, planes, etc. However, he will be compelled to either sell his firm to someone who is willing and able to modernise it, or transfer practical control to managers with a completely different psyche, who will force the «opportunist» to unwillingly invest the profit in the firm's development. Otherwise, the firm will go bankrupt. However, in any case, in a society in which the legislation is focused on development, with a healthy administrative apparatus and strong trade unions, firms are governed by people with an innovative psyche. Their abilities may vary, but all of them have a dominating requirement for novelty and creativity.

Those that are truly capable of large-scale and deep innovations are in the minority; the others can be considered as satellite innovators. However, they are all company and industrial leaders, who have consistently driven the technogenic growth in the developed countries of the world for the past six decades. As a rule, they have become company heads in these countries not through inheritance, criminal 
seizure of assets, or speculative stock exchange manipulation; but, because society (in these countries) via its legislators, officials, judges and trade-union leaders blocked the channels, feeding predatory and opportunistic capitalists, and supported innovative capitalists.

In the end, the problem of the development and backwardness (an old problem of the "wealth of nations») depends on the quality of the psyche of the governing elite of a society - its legislators, officials, judges, and party and trade-union leaders. If this psyche is the same as the psyche of predatory and opportunistic capitalists, the given country is doomed to backwardness. If this elite is capable of resisting such capitalists as a result of its qualitatively different type of psyche, then, the country has a real chance to follow the path of technogenic growth. 


\section{Chapter 7}

\section{Market Categories: the Psychological Aspect}

\subsection{The Institution of Trust and the Trust Instinct}

The market economy is based on the institution of trust, however neoclassical theory, which is based on rational egoism, cannot explain the presence of trust. The belief that contracts and rules will be implemented is founded on its rational and egoistical motives: on the fear of incurring legal liabilities for the infringement of a contract and on the fear of incurring material losses as a result of the infringer losing his business reputation. One needs to explain such trust (i.e., voluntarily rendered trust in contrast to compulsory trust) by altruism, i.e., by the egoistical feeling of pleasure, which is experienced by some people, in trusting other people, irrespective of whether this trust is justified or not. Altruism is the behaviour of a select few, in contrast with the behaviour of the majority, and cannot be the basis of market relations.

It is well-known that voluntarily rendered trust is very often broken and that in a short period of time people can be repeatedly deceived by their counterparts, partners, clients, employers, employees, etc. However, people continue to restore their trust in others over and over again. This would not be possible, if the majority of people did not feel a fundamental instinctive need for trusting people similar to themselves.

Sociology explains the presence of the feeling of trust through the influence of the surrounding environment, particularly, upbringing. This raises the question (which is easy to answer) on whether this influence falls on inherently neutral, hostile, or favourable grounds. As already mentioned, a certain percentage of mothers, lacking the motherhood gene, do not care for their children and do not deserve their trust. Nevertheless, their children trust them - contrary to 
«objective» circumstances. Such behaviour indicates that the human requirement for trust is inborn.

At the same time, for a child, the need to trust his mother is primary and unconditional, whereas his need to trust other relatives and a broader circle of people is secondary and conditional.

To some extent it can be suppressed in adults by the instincts of self-preservation, aggression, appropriation, and other natural individualistic instincts. In contrast, it (trust) can be strengthened by the socialite instincts.

However, in any case, it is clear that trust is a deeply rooted need in the genetic nature of human beings.

These roots vary, ranging from almost complete trustfulness bordering on dependence, to limited trustfulness, combined with natural independence and early separation from parents and guardians.

Below, I have used the characteristic of trust, given by the wellknown American sociologist, Francis Fukuyama, considering trust as a part of social (public) capital.

According to Fukuyama, one cannot understand the substance of the category of trust from the position of the rational maximisation of individual well-being. He wrote that social capital differs from other forms of human capital as it is usually created and transferred by means of cultural mechanisms - through religion, traditions and historical customs. Economists quite often assert that it is possible to explain the creation of social groups as a result of voluntary contracts between individual entities, who have concluded on rational grounds that cooperation would favour their long-term interests.

However, although the contract and egoistical interest form important bases of association, the most effective organisations include groups, whose members share general ethical values and there is a preliminary moral consensus amongst members as a basis for mutual trust.

According to Fukuyama, social capital, which is required for the creation of such a shared moral community, cannot be obtained through the development and realisation of rational investment decisions, like other forms of human capital. A person can decide to «invest» certain resources in human capital, for example, to study at an institute or training college in order to become a mechanic or programmer; for this, it is sufficient to enrol in the corresponding educational institution. In contrast, in order to acquire social capital, it 
requires a person to adapt to the moral standards of a specific community and master (within its framework) virtues, such as fidelity, honesty and reliability; in other words, social capital prioritises social, rather than individual, virtues. It is much more difficult to attain the propensity to socialisation than other forms of human capital, as it is based on morals and ethics; at the same time, it is also more difficult to change or destroy this propensity. ${ }^{121}$

Francis Fukuyama considers «spontaneous sociability» as a «component of social capital». He argues that the most useful social capital frequently consists not in the ability to operate under the power of a traditional or other society or group, but in the ability to create new associations and to interact within the framework of the rules and conditions established in them. Associations of this type, which arise within the limits of the complex system of the division of labour existing in an industrial society, but, at the same time, are built on the basis of general values, instead of on contractual relations, are related to the category referred to by Durkheim as «organic solidarity». ${ }^{122}$ It is obvious that «spontaneous sociability» and «organic solidarity» designate inborn requirements and instincts of sociality, consolidated by upbringing, culture, and experience.

Fukuyama considers that trust is the fundament that supports not only society as a whole, but also specific branches in the social sphere and in the economy. He wrote that trust is the expectation that members of a specific community will behave normally and fairly and will be willing to help each other in accordance with standard norms. The latter may be related to the sphere of «fundamental values»" regarding the nature of God or justice, but they also cover secular concepts, such, as professional standards and behaviour codes. Thus, we have the right to believe that a doctor will not deliberately cause harm as he is obliged to observe the Hippocratic Oath and specific professional norms.

Historically, specific institutional forms of trust change. The forms within kin and tribal organisations differ from those in neighbourhood communities; the difference is even stronger when compared to the

121 Fukuyama Francis, "Trust: The Social Virtues and the Creation of Prosperity", "The New Post-Industrial Wave in the West. An Anthology", Moscow, "Academy", 1999, pp. 134-135.

${ }^{122}$ In the same place, pp. 135-136.

${ }^{123}$ In the same place, p. 134. 
forms prevalent in the conditions of a market economy (impersonal exchanges). In institutional forms of trust, religion, moral norms, and the state system play a defining role. However, Fukuyama is mistaken in believing that these factors are a source of trust - as the existential requirements for trust and trust among people arose (simultaneously with the need for mutual aid and justice) long before (and not after) the formation of religious, state, and other institutions.

Institutions and organisations, which are based on the inborn requirement for trust and on the instinct of trust, passed through a long historical journey of transformations from the trust of kin and tribal institutions, to the trust of highly developed societies with their institutions and organisations. In particular, the modern trust of the market capitalist system means that individuals trust in the ability of this system to provide them with employment and growing levels of incomes. However, the institutions and organisations of this system are in fluid and conflictory interaction with each other and the trust in them is constantly tested.

Thus, employment and inflation (influencing real incomes) are interconnected. Attempts by the state to increase trust in the monetary system by restricting inflation (by tightening credit) results in slower growth and a decrease in employment. In contrast, credit expansion stimulates growth and increases employment, but results in higher inflation and, at the same time, undermines trust in money and the markets as a whole.

The discussion given below held behind closed doors at the Federal Reserve System in the United States in 1989 about trust in the monetary and credit systems illustrates this.

The pretext for the discussion was the resolution passed in September, 1989 by the chairman of the Subcommittee of the House of Representatives, Nile, on domestic credit policy, according to which the Federal Committee of the Open Market of the Federal Reserve System was to approve and implement a credit policy directed at the gradual decrease of inflation aimed at excluding inflation within five years of this law coming into force, and would later pass and implement a credit policy aimed at maintaining stable prices. ${ }^{124}$

${ }^{124}$ Hali J. Edison and Jaime Marquez, "US Monetary Policy and Econometric Modeling: Tales from the FOMC Transcripts 1984-91". In the collection: 
The statement of the task of reducing inflation to zero highlighted the following question: to what extent was the Federal Reserve's radical anti-inflationary policy compatible with its other targets of maximising employment and supporting moderate long-term interest rates (and, hence, investment activity)? The forward looking models developed by the Federal Reserve indicated that each percentage point of a decrease in inflation during 1989-1995 would result in an increase in the unemployment rate of about $2.1 \%$ to $2.7 \%$, with corresponding losses in GNP, as well as social and political costs. As a result, the legislative initiative of Nile was not supported by the Federal Reserve Committee and was not passed in Congress. ${ }^{125}$

In a discussion of the results of the calculations, the presence of the «costs of deflation» in the model was not called into question. The governors of the Federal Reserve System began to have doubts on the model due to the fact that the model showed that with inflation of 3.9 $\%$ p.a. (the actual level of 1989), its reduction over the following years would incur only costs and no benefits to the economy. The practical intuition of the supervisory bankers and their inclination in favour of monetarism could not reconcile themselves to these results. They asked for five-year forecast calculations, which could be used to find out whether these costs would be reduced over a longer time horizon and the influence of the level of trust on them. In other words, they

F.A.G. Butter, M.S. Morgan (eds.), "Empirical Models and Policy-Making: Interaction and Institutions," London etc., Routledge, 2000 (p. 192).

${ }^{125}$ Quot. Essays, p. 196. Clearly, in this case the opinion of Nobel Laureate, G. Akerlof, that bankers have a psyche, inclined to risky behaviour, and therefore should not be trusted, turned out to be incorrect: Akerlof wrote that the demonstration in behavioural macroeconomics of the fact that it is necessary to pay for very low inflation by a steadily high rate of unemployment and low output, leads to important conclusions on credit policies. The majority of us imagine central bankers as very cautious, conservative, and reliable people. However, he considers many of them to be comparable with dangerous drivers: in order to avoid the oncoming stream of inflation, they drive on the very edge of the road, keeping inflation as low as possible, and unemployment at too high a level. ("World Economic Thought: Through the Prism of Centuries", vol. V, Book 2, p. 465). At the same time, as can be seen from the following text, bankers are instinctively inclined to underestimate the unemployment factor and overestimate the value of price stability. In other words, bankers underestimate the role of social factors and overvalue the role of economic factors in the mechanism of society. 
demanded that the model reflected not only the costs of a policy of deflation, but also the expected positive influence of the given policy on the growth of the degree of trust in economy, and the beneficial influence of this increased trust in the economy.

Director Peri asked how the acceptance (validity) of Nile's resolution and the declaration of a specific long-term course relating to nominal GNP or money would influence trust. Moreover, he wondered if this would not force the acceptance of faster rates of adjustment than provided by the model. ${ }^{126}$

In response, the forecaster, Stockton, was able to base his answer only on past experience. He said that if one looks at the latest data on inflationary expectations, then, for example, in 1979 an immediate reaction to the announcement of changes in the methods of work of the Federal Reserve System would not have occurred. ${ }^{127}$ In other words, one should not expect a quick effect from a change in policy in the form of strengthening trust; furthermore, there are no tools for measuring the «effect of trust».

However, director Hoskins continued the attack on the model begun by Peri by arguing that they were measuring the costs of the reduction of inflation. If they tried to take a decision on whether it was necessary to take this course of action, they needed to measure benefits from a zero rate of inflation over the following 5 or 10 years and, then, to compare these benefits with the transient costs. He said that many of them believed that there were certain benefits that were reflected in the economic indicators, as a result of maintaining price stability. $^{128}$

Director Meltzer also underlined the question regarding the influence of the expansion of the time frames of alternative forecasts in the correlation between the sacrifices and results, and the absence of the forecasters' understanding of this question. He asked about the impact on the sacrifice-result correlation if the time frameworks were broader. He added that he was aware of the effects of expectations, trust, etc. However, he questioned the forecasters' understanding of

\footnotetext{
${ }^{126}$ Quot. Essays, p. 194.

127 Quot. Essays, p. 195.

${ }^{128}$ In the same place.
} 
this issue. He asked whether a time frame of 10 years instead of 5 would significantly decrease the sacrifice-result correlation. ${ }^{129}$

Director Black not only specified the basic methodological weakness of the prognostic model, its focus on the past, but also set the task of reconstructing the model on the basis of the theory of rational expectations. He acknowledged that very few people trust economic measurements; however, he considered that qualitative distinctions between these different lines of thought were important. The model based on the past was the traditional approach, which measured costs excessively highly. He said that if one assumes something similar to forward-looking rational expectations and if one accepts that the public trusts the market system to a certain extent and this trust gives strength, then the costs become much lower. ${ }^{130}$

This material shows that trust in the market system is considered by bankers not as an abstract concept, but as a real factor, which supports the credit-and-monetary mechanism and influences the efficiency of an economy.

Actually, the requirement for trust and the trust instinct make up the psychological basis of all key institutions and organisations of the market system of an economy: money, credit, securities, contracts, banks, firms, and the state itself. Such a psychology originates from the congenital and developed trust of people in each other, and is, in the end, expressed as trust in the market capitalist system as a whole and that this system will provide employment, income growth, and stability. It is difficult for bankers to understand that measures aimed at increasing the stability of credit-and-monetary institutions (and, hence, trust in them) but, at the same time, exerting a negative influence on employment and growth, do not strengthen, but reduce the level of trust in the market system as a whole.

\subsection{Wage Psychology}

The institution of wages, as it is connected with many sides of a person's daily activities, is particularly complex.

\footnotetext{
${ }^{129}$ In the same place.

${ }^{130}$ Quot. Essays, p. 196.
} 
Neoclassical theory believes that wages are defined by marginal labour productivity (measured by the usefulness of the product made by the last employed worker).

The Marxist political economy considers that the value of the commodity, «the labour force», constitutes the basis of wages.

Social and ethical concepts recognise that the level of wages is defined by the correlation of the strength of capitalists and trade unions in the struggle for the distribution of the incomes of enterprises, and the concept of social justice lies at the heart of this struggle.

Keynes believed that wages are based on the developed standard of living of workers and their desire to protect this level in conditions of chronically insufficient demand for labour.

Keynes' followers («post-Keynesians») believe that wage agreements reflect the mutual desire of employers and employees to cooperate on the basis of trust, leading to higher wages and labour productivity (and the abandoning of «surplus» employees, who are not in demand).

Each of these statements reflects one real aspect of the «wage institution».

First of all, the level of labour productivity is a factor that limits the possibility of an increase in wages «from above». However, the statement that the productivity of the last («limiting») employed worker defines (through «attribution») the wages of all of the others ignores both the real conditions of production and the human psyche.

Further, «the value of the labour force», defined by the value of goods, necessary for the reproduction of this labour force, outlines the lower limit of wages. However, the lower limit characterised in this way is too vague, and, can be interpreted as the physical minimum of

131 In this context, the attempt of the Nobel Laureate, R. Solow, to disassociate himself from the theory of "attribution" is typical. He said that a hundred years ago, John Bates Clark considered that distribution according to marginal products was fair; however, no modern or "bourgeois" economist shared this point of view. ("World Economic Thought: Through a Prism of Centuries", vol. V, Book I, p. 585). However, in this case, the problem is not whether the specified way of distribution is fair, but relates to the fact that neoclassicists do not have another theory of distribution. 
goods and services or as the «the minimum» that provides «a reasonable standard of living for the worker and his family».

It would be more accurate to consider that, after Keynes, wages reflects the habitual form and standard of life; as the habitual form of thinking and behaviour in the distribution sphere, wages are the institution, resting on the psyche that has developed. However, Keynes' interpretation also oversimplifies the real relations in this sphere, which was probably connected with the conditions of the Great Depression, prevalent at that time. In the 1930s, in conditions of mass unemployment and falling prices workers were struggling against a decrease in nominal wages, which, according to Keynes, was due to «money fetishism». This referred to the fact that if workers had been confined to defending their real wages, unemployment would not have been as widespread as it was. The «money fetishism» made workers «inflexible», when it was necessary to lower nominal wages after the general fall in market prices.

Akerlof, who developed post-Keynesian «behavioural» macrotheory, believes that Keynes' interpretation of wages was based on an intuitive understanding of psychology, whereas «the behavioural» concept is based on the psychological «theory of prospects» and takes «cogitative frames» into consideration. He wrote that Keynes' assumption that workers were resisting a reduction in nominal wages was based on an intuitive understanding of psychology. This assumption also conforms to the psychological theory and practice. The theory of prospects asserts that individuals evaluate changes in their circumstances in terms of acquisitions or losses concerning some reference point. Experience shows that the individual is more concerned with avoiding losses, than increasing acquisitions. The cogitative frames (the informational designs, defining the formation of an aim - O.) of individuals are not formed in terms of real values as classical economists assumed, but contain elements of «money fetishism».

The post-Keynesian theory of wages began to take shape at the end of the 1960s, in cardinally different conditions in comparison with the 1930s. On the basis of the scientific and technological revolution there was almost continuous growth in labour productivity and, consequently, wage increases. At the same time, from the beginning of

132 “World Economic Thought” (WET), vol. V, Book 2, p. 462. 
the 1970s, higher inflation and unemployment («stagflation») was observed.

These historical conditions were also reflected in this theory. It was developed in conditions when the role of «human capital» had increased sharply, and investments in this capital became beneficial not only for hired workers, but also for employers.

The Marxist theory of wages is based on the aggressive egoism of industrialists, aspiring to reduce the wages of workers to the minimum subsistence level (which was realistic in the first half of the $19^{\text {th }}$ century). The neoclassical theory is based on the egoistical interests of both sides, «arbitrated» by the labour market. The social and ethical theory of wages postulated the existence of standard concepts on the fair distribution of incomes in a society, and urged the state to supervise the implementation of these norms. Keynes proceeded on the basis of a conservative and protective psyche of the trade unions in conditions of fundamental market uncertainty.

The post-Keynesian theory of wages assumes the existence of another psychology both in industrialists and in workers: namely, instead of confrontational psychology, leading at best to a forced compromise (Commons), it assumes a psychology of cooperation, based on mutual trust and general concepts of fairness.

One can explain this change by the fact that changes in the psyche occurred after a change in «objective conditions», and the psyche of industrialists and workers flexibly adapted to the conditions of the scientific and technological revolution and the rapid technical progress at the enterprises.

In part, such an adaptation took place. However, the transition to new relations did not take place in all countries, branches, and firms. Moreover, it was connected not with the distinction of «objective», technological and economic conditions, but with distinctions in the type of psyche of those people that manage firms, head trade unions, and constitute the ruling «political class» of countries.

In the 1950s, a number of American economists and sociologists noted that the type of relationships that existed between employers and workers in large firms in industrially-developed countries began to cardinally change. This phenomenon was interpreted as being connected with the transition of the real power in these firms from the owners to the managers (leading to the term «managerial revolution»). In the 1960s, J. K. Galbraith tried to illustrate the basic difference in 
the psyche of the managers of large corporations from the psyche of the owners: whereas, the latter are focused on maximising profit and restricting employee salaries, the former are interested in the technogenic growth of the firm as the foundation of their career and in providing incentives to employees and, in particular, to «the technostructure» (managers of all levels and experts).

Subsequently, events revealed that Galbraith's interpretation turned out to be mistaken: the owners did not lose control over their corporations. Essentially, the change did not consist of control passing from the owners to the managers, but in the fact that people, who actually became heads of corporations were those, who focused on technogenic growth and on cooperating with the personnel, persons with an innovative and compromising psyche, regardless of whether they were owners, managers, or both; «predators», «slaves to routine», and «opportunists» were forced out of the management of large corporations, regardless of whether they were owners or managers.

Thus, as a result of the scientific and technological revolution, people with a new type of psyche came to power (through a competitive process) and created a new system of relationships in corporations. Moreover, in the new conditions, the managers of trade unions, who no longer saw the need to represent their unions as the «the battle organisations of labourers», actively participated in this process.

However, one cannot consider this shift as either universal or irreversible. Certain technological and organisational conditions are necessary for the maintenance of the new relations: the possibility of raising productivity by increasing salaries, favourable market conditions for a firm, cooperation with trade unions (which depends, in particular, on the inflation rate), etc.

In the absence of such conditions, «predators» and «opportunists» are always looking for ways to return to power in corporations under the pretext of the need to increase their competitiveness by decreasing costs through lower salaries.

In this they can be helped by incompetent or «biased» bureaucrats. Instead of assisting firms in improving their technological and organisational progress, they help predatory businessmen in curbing workers' wages and the rights of trade unions.

From this, one can draw two conclusions. Firstly, each of the mentioned interpretations of salaries can be justified to some extent in 
specific historical conditions. Secondly, during each historical period the actual maintenance of the "wage» institution directly depends on the type of psyche, which prevails among those who manage firms, head trade unions and define state policy.

\subsection{Does the Instinct of Thrift Exist?}

The deficiency of savings in the United States was one of the critical issues noted by Akerlof. He noted that from the point of view of neoclassical theory, such a problem should not exist, as the individual rationally optimises the distribution of his current income, aspiring to maximise his welfare throughout his life.

Keynes wrote about the surplus of savings (over investments), as the population tries to save up (in monetary form) an increasing share from their higher incomes (growing propensity to save). Keynes deduced this tendency from the uncertainty and risk generated in the market economy that was especially characteristic for the 1930 s, when Keynes formed his theory. At the same time, Keynes noticed that people try to save up more, not because they are inclined to worry about the future and are capable of foreseeing it, but based on their current or recent experience, instilling fear concerning the stability of their incomes.

Milton Friedman, in contrast, asserted that the ratio of consumption and savings of a population's income is steady; a surplus or a lack of savings in monetary form cannot exist, as each individual optimally distributes his savings between investments in five forms of capital: material capital (houses, durable goods, etc.), human capital (health, education, culture, etc.), shares, bonds, and money. Friedman wrote about this in conditions of the prevalence of a «middle class economy» in the United States (1960s-1970s), when the problem of a surplus or shortage of monetary savings did not exist. However, with the decline of the economic prevalence of the middle class, this issue became important in the United States.

Akerlof wrote that according to the new classical macroeconomic theory (i.e., monetarism - O.), insufficient or superfluous savings, just like forced unemployment, are meaningless and directly contradict the initial assumption of the model. As savings are the result of the 
individual maximisation of utility, they should be, in the absence of other factors, optimal. In contrast, behavioural macroeconomics has developed theoretical tools and empirical methods that promote the understanding of failing to save as behaviour, inadequately considering the time factor.

The key theoretical innovation, allowing one to carry out the systematic analysis of such «inadequate in terms of time» behaviour, is the recognition of the fact that individuals can maximise their function of welfare, which differs from the achievement of «true welfare».»> ${ }^{133}$ Akerlof believes, firstly, in the applicability of the psychological law, according to which people (and animals) value their current requirements higher than future needs. Therefore, they are not inclined to reduce their current consumption for the sake of maintaining their consumption level in the future. Secondly, understanding, nonetheless, that they need to save, people try to postpone this «unpleasant» process «until tomorrow», believing that tomorrow they will be able to limit their current consumption in order to save - something that they are not able to do today. From the rational point of view, both these psychological conceptions are erroneous, as, firstly, «tomorrow's» needs are the same as their current needs and, secondly, what people cannot achieve today, they will not be able to achieve tomorrow.

According to Akerlof, current consumption is more significant than future consumption, people hesitate to save. The hyperbolic function is very well coordinated with empirical observations: people (and animals) are significantly less willing to forego current pleasures than agree to future restrictions.

Two versions of the procrastination of the necessary refusal follow from the hyperbolic discount function. A «naive delay» occurs when an individual incorrectly estimates the change in his future utility function. He is not in a position to understand that his needs tomorrow will not differ from today's needs, and that «tomorrow» they will be just as important as they are today, as soon as «tomorrow» draws a step closer. A naive delay results from the mistaken belief that tomorrow he will start saving (keep to a diet, exercise, give up smoking, etc.), even though he is not prepared to start taking these measures today, and is then surprised, when it turns out that the

${ }^{133}$ WET, vol. V, Book 2, p. 466. 
sacrifices and restrictions that were put off are again put off tomorrow. A more refined delay takes the form of a «pre-sensation». There is no reason to save money, if tomorrow turns out to be the same in terms of requirements, as today.

Akerlof argues that besides the popularity of social insurance and other programs, which «force» consumers to save, the best evidence in favour of the fact of failing to save comes from the observation that after retirement, individuals, on the average, significantly reduce consumption. $^{135}$

Akerlof concludes that it is indisputable that the majority of people who save do so primarily under the influence of their psychology, rather than rational calculations. However, it seems that the main psychological factor behind a lack of savings is not underestimation of future requirements (in comparison with current needs) or the propensity «to postpone from one day to the next», but the psychological inability of the majority of people to estimate the eventual inevitable decline in their potential to earn income, sufficient to maintain their current consumption level. In other words, the main factor is a «lack of foresight». Moreover, this does not concern only savings. If people were sufficiently prudent, both their private lives and the course of world history would fundamentally change.

One needs to take into account the fact that the inborn psychology of our ancestors was formed, when the average life expectancy was less than 30 years. In other words, the vast majority of people died long before their strength and ability to earn a living were exhausted from ageing. Therefore, even if people led more or less settled lives, they still did not develop the instinct of creating «old age» reserves, as old age (as a condition of the inability to earn a living because of age) was an unusual occurrence.

The kin and tribal systems of the ancestors of modern man, followed by the patriarchal family, ensured joint care for the aged and infirm.

With the destruction of both these systems, and in the absence or insufficiency of the state system of social protection, private savings became the main source of existence for people at an age, when they

\footnotetext{
${ }^{134}$ WET, vol. V, Book 2, pp. 467-468.

${ }^{135}$ WET, vol. V, Book 2, pp. 468-469.
} 
were incapable of working, especially when this age (length of time) gradually increased.

Therefore, with the formation of the market capitalist system, individual prudence («thrift»), indirectly based on the inborn instinct of self-preservation, gradually became a special part of culture.

In their psychological roots, «savings» fundamentally differ from the characteristics of «bourgeois» economic behaviour, such as «appropriation», «exploitation», «accumulation», etc.; the former has a «protective» character, whereas the latter are closely connected with the instinct of aggression. As «thriftiness» does not have its «own» roots in the inborn psyche of a person, as a required feature of the psyche, it needs to be instilled since early childhood or acquired as a habit at a mature age. At the same time, there are grounds to believe that the dominant role is played by upbringing at an early age, when the characteristics of the national psyche are instilled.

Akerlof considers a deficiency in monetary savings in the same way as characteristics of economic behaviour in general. Meanwhile, the savings level is highest in a number of Eastern countries (Japan, China, Taiwan, etc.), followed by Western Europe, with the United States having the lowest level. The population of the United States lives essentially on credit, by drawing credit from the savings of the populations of foreign countries. It is hard to say whether this behaviour of the American population is connected with the absence of an emphasis on «thriftiness» in their upbringing in childhood; however, undoubtedly, the «average» adult American has a long-term habit of living on credit. The formation of such a habit after the Second World War was probably the result of a generally optimistic spirit in conditions of almost continuous technogenic growth and equally continuous growth of inflation in the United States.

The inherent «envious consumption» (according to Veblen) of the American middle classes and their strong desire to live on credit, encouraged by the speculative psyche of the bankers, who were urging on credit expansion in the mortgage sector, led to the financial crisis in the United States in 2007. The inflation of the credit «bubble» in the United States was indirectly also promoted by the investor countries, including Russia, investing their «savings» of hundreds of billions of dollars in American securities.

Thus, Akerlof, having shown that a person, preferring current to future consumption, does not maximise that function of consumption, 
which provides «true welfare», only set the problem of linking the failure to save with the psyche of economic agents. A fuller understanding of this link requires studying the interaction of the inborn and instilled requirements and instincts, and also the specific habits, which have developed over a period of decades in different countries.

Akerlof speaks about the human being in general, without making distinctions in the behaviour among different groups of «savers». In my comments, I was referring to «savers» with a «balanced» psyche (who, in my opinion, in normal conditions, form the majority of the population). At the same time, it is realistic to expect that people with an individualistic psyche, as a rule, are more prudent than people with a socialitarian psyche, and among «individualists», those who «accumulate» save the highest share of their incomes. However, they are in the minority, and for them accumulation is an inborn or instilled requirement, and is by no means a way of providing for themselves a sufficient consumption level in the future. As far as prominent businessmen are concerned, one cannot consider their accumulation as «savings», as it has a significant link with their current and future consumption only at that time, when their consumption itself becomes one of the forms of accumulation (discussed in greater detail in chapter VШ).

\subsection{Psychological Aspects of the Securities Market}

Keynes noted that the participants of a securities market try to guess the responses to each other's behaviour, which is reminiscent of an infinite number of reflexions of an object, placed between two mirrors. Clearly, the behaviour based on such guesses, should generate an extreme degree of uncertainty, volatility, and sharp and unpredictable fluctuations.

Referring to Keynes, Akerlof wrote that securities markets are excessively volatile and responsive to news. Such a point of view on securities markets contrasts with the model of the rational market, in which share prices represent the risk-adjusted discounted value of future incomes. 
Based on a hundred years of observations of share prices and dividends in the United States, Schiller (1981) compared the average standard quadratic deviation of the share-price trend to the average standard quadratic deviation of discounted dividends. He discovered what Keynes had foreseen: the average quadratic deviation of share prices turned out to be five times greater than the deviation of dividends.

For describing one of the mechanisms of these types of «deviations», Akerlof refers to Schiller's book, Irrational Exuberance (1999), which discusses the press coverage of the financial bubble in the stock markets in the 1990s and explains how the concept of the financial markets and the industrial sector supposedly entering «a new era» was inculcated. As share prices rose, the spell of the «new economy» was handed down by word of mouth, and individual investors acted on the prompting of the media, which overestimated the influence of new technological means, such as the Internet, on labour productivity. ${ }^{137}$

In other words, the deviations from the trend, caused by «irrational expectations», i.e., psychological factors, were five times greater than the deviations that could be explained by fluctuations in dividends.

Nevertheless, the huge sums invested by the public (with sharply contrasting income levels) in shares, shows that people are drawn both rationally and irrationally or unconsciously to such types of investments.

The rational side of such mass actions is based on the fact that the real value of the shares of normally functioning firms gradually increases, through expansion, technological and organisational progress, and the accumulation of human capital, which are reflected in the long-term tendency of the rise in the market price of shares exceeding the rate of inflation.

If the shareholders were only small shareholders, who considered shares as a form of savings, providing income that was approximately equal to or slightly greater than the interest from bank deposits, then, these people, possessing (on the whole) a balanced psyche, would not have grounds either for «dumping» shares en masse or for hazardously and irrationally pursuing them.

\footnotetext{
${ }^{136}$ WET, vol. V, Book 2, p. 470.

${ }^{137}$ In the same place, p. 471.
} 
Both these courses become inevitable, with the arrival on the stock exchanges of prominent businessmen with a "predatory» type of psyche, aspiring to transform the smooth curve of a gradual increase in the share price index into a broken curve, with sharp ups and downs. They collect the profit from each hike in share prices and transfer the losses from collapsing prices onto the small shareholders.

Clearly, under any shareholder structure, fluctuations, reflecting different forms of the natural (for the market capitalist system) unevenness of movement, are inevitable on securities markets: unevenness in the time of the general movement of this system; interbranch, inter-regional, and inter-firm unevenness; and unevenness in the incomes of different groups of the population. However, powerful stock-market speculators give these fluctuations a chaotic and essentially unpredictable character.

George Soros tried to theoretically interpret the behaviour of these speculators, using two definitions: «mistakenness» and «reflexivity». Any investments in securities in conditions of inevitable market fluctuations at some instant appear erroneous; moreover, it is logically impossible to define this moment. It is not possible, because the behaviour of speculators is reflexive; they influence each other by each other's example, generating waves of excitement and panic. Based on his own experience, Soros asserts that successful speculators are those, who correctly pick the moment of the beginning of a new upward trend in a particular security, enter it, and then sell it at a high price after the price rise, without waiting for its inevitable decline in price. Soros is criticises attempts to find a specific rational formula for selecting an optimum set of securities, based on features of their historic price performance and other objective criteria.

Soros is right that past experience and rational calculations cannot form the basis for predicting future price movements in securities markets. However, he is clearly underestimating the role of large speculators by describing them as blindly wandering and tentatively feeling their way in turbulent markets, and involuntarily creating convulsive mass movements of investors, first in one direction and then in another, as a result of the «mass» investors imitating and being influenced by the large speculators. Actually they, like Soros, not only skilfully use, but also consciously push spontaneous movements in a direction suitable to them; their actions are driven by strongly pronounced instincts for moneymaking, aggression, and domination. 
However, besides large speculators, there exist thousands of average and small speculators with a similar psyche, who do not have such means at their disposal; this leads me to raise the following question: is a significant part of the population with a balanced psyche not subject to the temptation of earning easy money by risking a part of their savings to play the stock market?

If the aspiration for easy money, connected with risk, is a widespread characteristic of the human psyche, then is it the result of a «market civilisation», or has this civilisation only given a certain form to this characteristic, which has genetic roots?

It is reasonable to assume that over the course of millions of years preceding the appearance of modern man, when his ancestors were vagrant-collectors and primitive hunters, not only the self-preservation instinct but also the instinct to search for the easiest and fastest ways of obtaining a means of existence were established in the genetic bases of their psyche. The absence of reserves demanded that the collectors and hunters exerted themselves to achieve the fastest results, even if it meant taking on great risk. Only in the latest stages of the prehistory of modern man, when his genetic code already existed, was it feasible for man to actually direct his efforts not on immediate, but on more or less remote, results.

This explains, why even those persons, educated and accustomed to patient, ordered, and skilled work, find it so easy to arouse their instinctive interest in fast and easy enrichment, even if it is risky and fleeting. ${ }^{138}$

Certainly, the market system stimulates this interest. However, it did not die away in the period of the planned economy in the former Soviet Union, as can be seen from the existence of bribery, gambling, lotteries, and certain forms of underground businesses. In fact, the privatisation policies implemented in Russia in the 1990s were based on the stimulation and operation of the instinct for easy enrichment.

Theft is the extreme form of display of this instinct, and kleptomania is its pathological form. Thus, paradoxically, in terms of its psychogenetic roots, one of the highest and most complex results of economic civilisation, the stock exchange, is the reincarnation of the

138 According to some of Marx's biographers, he tried to speculate on the Stock Exchange, but was unsuccessful. Keynes, on the other hand, was much more successful. 
psychology of the primitive community of impatient collectors and risk-taking hunters.

\section{Chapter 8}

\section{Psychological Foundations of the General Interrelation of Markets}

\subsection{Partial Markets in a System of General Market Equilibrium}

The term that is referred to as the «market» in abstract theory, actually consists of many diverse interconnected partial markets, which differ not only in the character of the goods that they offer, but also in terms of their institutional and organisational mechanisms and the psyche of the people, who participate in them.

Partial markets are connected by the division of labour (objective and functional), the network of interests of market participants, and their general psychological features. F. Kene, K. Marx, L. Walras, J.M. Keynes, R.F. Harrod, V. Groman, W. Leontief, N. Kondratiev, N. Feldman, etc., all tried to reflect the general connection of the partial markets; however, only Keynes placed emphasis on the psychological factor. In Kene's tables, tenant farmers, land owners, and industrialists (the «sterile class») appeared as people with a different psyche. Farmers and industrialists are labourers, consuming the products of their efforts; land owners receive rent, which is a gift of «nature». Thus, the agricultural and industrial products' markets are united by the division of labour and interests of the owners of «labour» and of land.

In Marx, the markets of the means of production and consumer goods (both for workers and for capitalists), as well as the capital and labour markets, are abstractly presented; they are united by the exploitative capitalistic psychology, interpreted as the reflection of the objectively required form of organisation of the productive forces. The 
capitalistic psychology of intra-branch and inter-branch competition (leading to the formation of «market value» and the «cost of production») acts as an additional unifying factor. According to Marx, the psychology of class solidarity is inherent in workers; competition among them is not considered, although it is implied (in the concept of the value of the labour force).

The theory of «general market equilibrium» has united the partial markets of consumer goods, capital goods, labour services, financial assets, and money in a unified and balanced model. The founder of this theory, Leon Walrus, was the first to propose conditions, in which balance was established in each partial market and on the entire set of the markets. Such equilibrium is based on a flexible («auction») system of pricing, by maximising the usefulness and complete interchangeability of goods and services in conditions of free competition and the transfer of resources among the partial markets.

Keynes was the first, who developed the integral concept of the psychological basis of the interrelation of markets, explaining the general tendency of the markets of consumer goods and resources to disbalance (involuntary unemployment). This general basis is defined by the psychology of people as subjects of consumption, savings, investment, hired workers, and employers; the tendency to chronic disbalance (involuntary unemployment) is deduced from the contradictions in the specified psychology.

Since Keynes, his approach was widely discussed between his supporters and detractors (which was partially discussed in the earlier chapters of this book). One should acknowledge that Keynes himself caused a fair amount of turmoil, by proposing to consider the neoclassical theory of the general market equilibrium as a special case of the «general theory». According to Keynes, this special case turns into reality in conditions of full employment. It turned out that in conditions of involuntary unemployment (and these are the predominant conditions), the market is defined by a completely different set of psychological laws than in the case of full employment. Keynes probably understood the incompleteness and ambiguity of his concepts about the psyche of market participants. However, the discrepancies of these concepts reflect the true heterogeneity of the psyche of separate groups of market participants. Some of them really aspire to «rational» (and risky) maximisation of monetary incomes and thereby cause fluctuations and adjustments of 
the conditions of equilibrium in different markets, while others avoid risk and aspire to protect the attained level of monetary incomes, which limits the elasticity of the market.

The entire range of the human psyche is displayed by market participants, institutions, and organisations, from instincts of appropriation, self-preservation, trust, leadership, competition, and mutual aid, to instincts of exploitation, domination, and aggression.

All these motives stand behind the cumulative forces of supply and demand, therefore, there cannot be any question about a smooth and gradual process for overcoming these imbalances, especially where financial force or administrative resources can be used in a competitive struggle.

However, from the second half of the 20th century, one factor which has a truly universal value in the market, as it is simultaneously the driving force behind development, a competitive instrument, and a mechanism for maintaining equilibrium - has functioned with particular force, breadth, and variety. This universal factor is the technological and organisational progress that has been accomplished as a result of the achievements of eminent people, possessing the psyche of innovators.

Due to continuous, comprehensive, dispersed, penetrative technological and organisational progress, all proportions and economic correlations become flexible and mutually adaptable, so the contradictions, which Keynesian theory specified, are smoothed out or temporarily overcome. As William Baumol emphasises, technogenic growth, rather than the price redistribution of «limited resources» (production factors) within the framework of the equilibrium model, is the real mechanism for optimising the economy. This mechanism functions through the development of new knowledge and abilities (intellectual capital) within branches (firms), and the spill over of knowledge (intellectual capital and information) between branches (firms).

Technogenic growth created the conditions, in which the macrotendencies specified by Keynes, which limit «effective demand» (a decline in the propensity to consume and an increase in the propensity to save, preference for liquidity and excessive attachment to money, weakening the «interest in investment») ceased to operate and were replaced by the opposite macro-tendencies - increased aspiration to consume on credit, flight from liquidity, an excessive interest in stocks 
(instead of money), and a strengthening of the desire to invest, particularly through credit expansion.

Since the 1970 s, the term «market psychology» coined by Keynes has cardinally changed: there has been a transition from «Keynesian» psychology to «Schumpeterian» (or «innovative») psychology.

The fear of the threat of general chronic «overproduction» and underinvestment was overcome for a specific period, however other contradictions in the market system became aggravated, and new difficulties arose. Firstly, the deficiency problem of «Baumol's economy» in branches of the extended social sphere, where productivity cannot grow at the same rate as in the material sector of an economy (or cannot grow at all) and where the incomes of the people employed are paid from the state budget, became aggravated. Secondly, the threat of the global destruction of the environment and the necessity of non-market regulation of technological progress became real.

Thirdly, technogenic growth increased the danger of the formation of huge credit and investment bubbles, which latently ripen and every 5-10 years burst in different parts of the global economy.

All this creates instability in the global markets and generates the necessity for coordinated regulation.

Thus, the system of the general market balance undergoes changes both in the structure of individual markets, and in the character of the interrelations between them.

In the theory of general market equilibrium, mainstream economics usually divide the market into two mutually counterbalanced competitive markets, the market of consumer goods and services and the market of production factors (work, capital, and land). In the first, the sellers are firms and the buyers are households; in the second, the roles are reversed.

The following is necessary in order for the abstract theory of the market to approach, to the minimal necessary level, the modern reality:

1. To present the capital markets as a system of stock exchanges, banks, and investment funds; 
2. To present the labour market as the contractual interaction of the unions of businessmen and trade unions;

3. To build the markets of raw materials and half-finished products realised both between firms and within them (between divisions of large firms) in the block of the «firms»;

4. To divide the consumer goods and services markets and the «final-product» market into a market of private goods and a market of social (sponsored by society and the state) goods and services.

5. To divide the markets of the «new economy» (information products, biotechnology, nanotechnology, etc.) from the markets of the traditional economy.

6. To present all markets as the interaction of large, average, and small sectors; the «final» sellers and buyers and the dealers and intermediaries, having different market strengths; institutions and organisations; and, finally, individuals with different types of psyche, grouped in different markets.

7. To allocate types of national markets, in particular, the markets of developed countries and the BRIC countries.

The mechanism of the general market equilibrium, connecting separate markets, consists of the triple psychological-technologicalprice mechanism, in which the following holds true: (1) The human psyche supports equilibrium in the development of the separate existential requirements and industrial abilities of market participants; (2) The scientific, technological and organisational progress, through 
its universality creates conditions for the alignment of ruptures in requirements and abilities; (3) The price mechanism, through the movement of supply and demand and the spill over of resource levels evens out the relative profitability of homogeneous (interchangeable) input of resources in individual markets.

\subsection{The Standard of Living and the Self-Preservation Instinct}

In order to understand the role of the psyche in competition, on the demand side (buyers) one needs to distinguish consumers (households and the state), on the one hand, and investors, on the other hand. These groups of buyers have different psychic outlooks. In this context, foreign demand (export) is reduced to these two kinds of demand. Consumers demand the satisfaction of specific requirements; investors demand the satisfaction of the requirement for enrichment.

There is a view that natural (genetically inherited) requirements and instincts (the instinct for food, procreation, selfpreservation, etc.) define the consumption of individuals only within the minimal physically necessary limits. Beyond these limits, the structure and form of consumption are explained not by natural, but by social factors (technology, the actions of economic and other institutions and organisations, advertising, etc.).

However, this is not the case. I will consider one aspect of the link between the natural psyche, on the one hand, with the level and structure of consumption, in particular, the average life expectancy, on the other hand. The average life expectancy of the ancestors of modern man was 20-25 years, in the $18^{\text {th }}$ century in Western Europe it was approximately 40 years, and by the end of the $20^{\text {th }}$ century it had risen to 80 years in the developed countries. According to Nobel Laureate in Economics, Robert Fogel, this was due to the improvement in the quality (and quantity) of food, progress in medicine, and improvements in basic living conditions (the provision of homes, clothes, etc.). The improvement in the health of the population (in particular, the increase in the average weight and height of people) has led to an increase in labour productivity and gross national product per capita, which has in turn raised consumption. Fogel attributes half the per capita improvement in the gross national product in Western Europe to the improvement in people's health and 
the other half to technological and organisational progress and improved education.

A deterioration in the quality of food consumed and a decrease in the general consumption level of a significant part of the population eventually lead to poorer health, lower labour productivity, and a reduction in average life expectancy. Therefore, any serious threat on the standard of living of a person with a normal psyche should arouse the self-preservation instinct into action.

The natural needs and instincts of an organism are designed to function throughout its potential lifetime. However, what is its potential maximum limit? Gerontologists have repeatedly lengthened the potential average life expectancy: from 80 , to 90 , to 100 , to 120 , and to 150 years. Some of them consider it may even be 200 years. In any case, it is clear that the following conditions apply to any attained level of average life expectancy:

It is reached under the influence of the set of natural requirements and instincts, and like the life of an organism in general, it is under the protection of these instincts;

It is reached on the basis of a certain level of health and labour productivity, and consequently, consumption, health services, technological progress, and education; in other words, on the basis of a certain level and mode of life.

This explains why the attained standard of living is perceived as natural, and why people are sensitive to threats that could lower it and instinctively (and not only consciously) resist such attempts.

However, can one consider the continuation of an organism's life term beyond its reproductive borders to be natural, or is it the artificial result of civilisation? If this is a natural phenomenon, how does one explain, why nature would create a potential life expectancy term (which is significantly longer than the reproductive term) for the human organism? 
Evidently, during the natural selection process, tribes, made up of people with longer life spans, were better equipped to survive. They not only gave birth and raised children, but also passed on their accumulated experience. Furthermore, with the development of the brain, this experience increased in value. Difficult conditions with a low general level of culture hindered the potential for longevity, placed by nature in each healthy human organism, from being fulfilled other than in the form of the longevity of a few, in contrast to the high overall mortality rate among children.

From this, it follows that one can consider all consumer demand (and not just its physiological minimum) as a result of simultaneously functioning natural-psychological and socialpsychological factors.

Psychogenomics offers the starting points for understanding the shifts in the bases of the psychic structure of a society as well as in some economic structures.

The work of the genes controlling behaviour is connected with the aging of a human organism and its general state of health. As noted above, Fogel has established the law of the biotechnical (not genetic) evolution of the human being, which, over the last 200 years, has led to a sharp increase in the average height and weight of people, in the doubling of life expectancy, and an increase in labour efficiency and productivity. This shift in living conditions and work has not changed the genome of a person, but it has sharply raised the relative density of older people in the populations of developed countries and the term of a productive life. In my opinion, this should affect their dominating instincts and the forms in which they are displayed. In particular, at a young age, the genes of gender behaviour, aggression, leadership, inquisitiveness, and happiness are more active. In the elderly, there is a greater tendency towards feelings of uneasiness and the selfpreservation instinct becomes more pronounced. With age, the roles of experience and habit increase together with the role of rational thinking. On the whole, in comparison to younger people, the reactions of the elderly population to economic impulses are fundamentally lower.

On the whole, with age, the roles of preconsciousness and consciousness increase in the structure of the psyche and the role of the unconscious decreases. According to social psychology, in the change of the value system defining human behaviour, the changing of 
the generations has a considerably greater influence, than a change in the average age of people. This means that an increase in the average life expectancy is a factor that slows down the change in highly valued priorities and raises the level of institutional stability in a society.

In the United States, between 1850-1950, life expectancy increased from 40 to 68 years and in the last half century, it has increased to 80 years (and continues to grow). The same has occurred in Western Europe and Japan. This should have a stabilising impact on institutions, including the economic institutions, in these countries.

However, the aging of the population inevitably increases the need for social services and social protection. However, it does not mean that the psyche of people becomes less individualistic and more social. The relationship amongst the types of psyche distinguished by me (individualist, socialitarian, innovative, and harmonious) remains, in general, unchanged in an aging population. However, undoubtedly, the contradiction increases in society between the absolute and relative increases in the requirement for social protection and social services, and the maintenance of the role in the psyche of the population of the inborn and instilled instincts of individualism.

\subsection{The Boundaries of Interchangeability}

The exchange value of goods (their relative price, i.e., the price expressed in terms of other goods) is defined, on the one hand, by the costs of resources used for its manufacture, and, on the other hand, by the usefulness of the given goods (in comparison with the usefulness of other goods). Usefulness (consumer value) is the ability to satisfy human needs. Hence, the degree of usefulness of the goods depends on the persistency of the requirement, which these goods satisfy, and the correlation of usefulness (which means, the exchange value of the goods) depends on the correlation of these requirements.

If, for the sake of simplification, one imagines that each utility (good) is capable of satisfying only one requirement, then one can say that utilities are interchangeable (comparable) only to the degree that requirements are interchangeable (comparable). To what degree are guns and butter interchangeable? They are interchangeable only to the extent that it is possible to replace safety requirements with food 
requirements and vice versa. (For example, one can demand «a little bit more food and a little bit less safety», or the contrary; moreover, this is quite realistic when circumstances change). However, when such a substitution of requirements is not possible, then the exchange of goods on the basis of their relative usefulness is also not possible. Then, society distributes its resources between the production of butter and arms manufacturing in a way such that - in specific circumstances - an optimal correlation is attained, satisfying the requirement for food on the one hand, and safety on the other hand. This optimum can be attained according to a plan, and on the basis of empirical market iterations.

However, in any case, it is not «a consumer choice», and the example of an «indifference curve» also does not apply, as the two requirements cannot be reduced to each other, and are externally set not only qualitatively, but also quantitatively (by the food allowance and by the scale of the threat).

The level of the development and satisfaction of needs has developed historically and for each individual forms a system, called the «mode of life». Thus, at the heart of an individual's «mode of life» lie the structure and degree of development of his genetically inherited and instilled requirements and abilities. Therefore, everything that affects a person's «mode of life», also affects his psyche, causing positive or negative reactions. Thus, a person can be psychically injured not only by a reduction in his income, but also by a shortage of consumer goods or services that he is used to, or even simply by an unexpected change of furniture in his apartment.

All this means that usefulness is capable of being included in the definition of the exchange value of goods only to the degree that the following are interchangeable:

1. Different requirements - (inborn and instilled);

2. Different goods satisfying the same requirement;

3. The same good is capable of satisfying different requirements.

Thus, markets are more competitive, when requirements are more interchangeable, goods are more interchangeable, and each product is more universal in satisfying different requirements. Moreover, the 
more exchange proportions are controlled by correlations with usefulness, the more they are, in the end, controlled by the requirements of people as consumers.

However, the same requirements limit the influence of utility on the exchange value. To the extent that the requirements are not interchangeable (are irreducible), they form a rigid frame, predetermining the necessity of an exchange of goods, based not on their relative usefulness, but on costs. For such an exchange, it is also necessary that different goods are not interchangeable in satisfying one requirement and one product cannot satisfy different requirements.

If, in his lifestyle, a person annually spends the same amount on car maintenance as he does for the payment of utilities, on three complete sets of clothes and on food, it does not mean that these groups of goods and services are equally useful for the person - they are simply not comparable and mutually replaceable, in the way that an engine, chassis, or body of a truck are.

It is obvious that the degree of interchangeability varies deeply for different groups of requirements and goods, and that is also the reason why pricing factors (costs and usefulness) in different markets operate differently.

This means that the main basis of the interrelation of partial markets is not due to the interchangeability of goods and services, but the result of the system of requirements, fulfilled in a historically developed mode of life, on the one hand, and the system of fulfilled abilities, supporting this mode of life, on the other hand. Moreover, in the end, the crucial point is that the price system, which depends on specified requirements and abilities, is the historically developed price system.

\subsection{The Psychological Determinants of the Structure of Demand}

The structure of a person's psyche as a consumer in specific historical conditions is formed by the set of those specific goods and services that satisfy all of his requirements and instincts. 
The natural and instilled psyche of a person has resulted in the requirement for a separate habitation for a family. The attempts by some religious sects and communes to replace the isolated family habitation with a joint form of habitation invariably ended in failure, despite the economic advantages of many families living as one unit.

In the United States and some other countries, families in cities prefer to live in separate houses rather than in apartment buildings. At the same time, in Western Europe, families with the same level of incomes as in the United States prefer to live in apartments. I believe that the main (although, not the only) reason for this lies in the specificity of the national psyche of Americans, in whom instincts of individualism are much more deeply rooted than in the psyche of Europeans. This also explains the enormous accumulation of different types of arms in private hands in the United States, greatly exceeding the real needs of individual self-defence.

A privately owned car occupies a special place in the satisfaction of a modern person's requirements. The need for movement is one of the main requirements in the human psyche, inherited from our nomadic ancestors. The freedom of movement is one of the main manifestations of the instinct of freedom. A privately owned vehicle offers the means of satisfying these and some other requirements and instincts. No amount of development of the public transport system is capable of replacing a privately owned vehicle, which fills many with a feeling of possessing additional strength and value. At the same time, as a means of transportation, a versatile and well-developed public transport system is clearly much more economical and ecologically beneficial than private vehicle ownership. The conscious unwillingness as well as the inability of the Soviet system to mass produce cars for the population was one of the fundamental reasons of deep discontent with this system.

The media serves as the modern means of satisfying the instinct of curiosity; any restrictions imposed on them, regardless of their rational or material (monetary) basis, hinder the fulfilment of this instinct. In order to prevent these restrictions causing irritation, they need to be based primarily on psychological motives (in particular, on the selfpreservation instinct, the family instinct, etc.)

The consumption and mode of life of the majority of big businessmen (excluding innovators) included villas, yachts, personal airplanes, expensive cars, sports clubs, thoroughbred horses, 
receptions, parties, festivals, ski resorts, diamonds, fashion models, stewardesses, etc. The highest cultural step of a capitalist is a life surrounded by art objects, in ancient palaces and castles (that have been modernised), among paintings, sculptures, and ancient porcelain and furniture.

It is a direct return to the extravagant epoch of barons, marquises, and dukes. It is paradoxical that many feudal lords were ruined by such a mode of life, while the nouveau riches are enriched by it.

As the number of multimillionaires and billionaires all over the world has increased sharply, so has the demand for, and prices of, country houses, castles, luxury goods, and art; thus, the consumption of modern capitalists simultaneously provides them with highly profitable investments.

One can deduce the following law: the richer the capitalist, the greater the degree his mode of life is a function of the instinct for accumulation, and the more he surrounds himself with those forms of material riches, which promise the highest profitability.

At the end of the $19^{\text {th }}$ and the beginning of the $20^{\text {th }}$ centuries, Thorstein Veblen (as noted in chapter 2) underlined not the accumulative, but another, the demonstrative, function of consumption of the leisure class. This fulfils a dual aim; it shows the power of predatory capitalists and pushes the rest of the population, especially, the middle class, and to a certain extent the lower class, to imitation, envious consumption, and the acquisition of expensive and prestigious goods and services that serve no useful purpose.

The institutions of imitation and envy, which are urged on by advertising, continue to play an important role in the formation of the structure of the consumption of the population and in the stimulation of its economic activity, and they remain instruments with which to control society.

Nevertheless, after the Second World War, the middle class made up $70 \%$ of the population, whose requirements and instincts in consumption were formed independently and were shown in relatively similar forms. This does not mean that these requirements and instincts are uniform. On the contrary, the middle class includes individuals with a balanced psyche, as well as those with an individualistic, socialitarian, and innovative psyche. Small businessmen and farmers, managers, engineers, teachers, highly 
skilled workers of large firms, people in humanitarian professions, the basic personnel in the social sphere and official bodies, etc. - all of them fulfil their requirements and instincts on the basis of a relatively similar level of development of abilities and, accordingly, similar level of incomes. Their living quarters (house or apartment), together with home appliances and the car, form their physical capital, demanding constant expenses for their maintenance and renewal. However, depending on the psyche of the owner, his residence can be a comfortable «bunker» of a family of an individualist, or an open platform for social dialogue, an appendage to a creative workshop, or it can be a mixture of all these characteristics.

Physical capital provides income in the form of necessary services to its owner; however, this income is not in monetary form; at the same time, this physical capital demands a monetary outlay (less than the amount that would be required for the rental payment) for its maintenance from its owner.

A family's human capital is formed by the investments of an individual mainly in education and in the maintenance of good health, and also demands continuous expenses for maintenance and development. The income on human capital (making up the basic part of the wages of the middle class) is a monetary source of the completion and expansion of physical capital.

The possession of considerable human capital is the main economic characteristic that distinguishes the middle class from the upper and lower classes. A number of psychic properties, without which one cannot be part of the middle class in a modern society, lie at the heart of this possession: the presence of the requirement for selfdevelopment, in mastering new knowledge and abilities; diligence; and the required level of activity of socialitarian (status) instincts and the competitive instinct. All this is required, together with the presence of the necessary level of general and special abilities.

The complexity and development of the economy make increasingly higher psychic demands on the middle class, which are not always met adequately. During the 1980s-1990s, in connection with the informatisation, the growth of the multinational technological corporations, and the transfer of production from the United States, there was a stratification of the middle class: the incomes of the upper middle class rose sharply and strengthened its position, while the 
incomes of the lower middle class either remained the same or decreased.

At the same time, the psyche of the members of the middle class and those who hoped be part of it, forced them to keep and support a certain status in their mode of life. In order to achieve this, credit was used, especially mortgage credit, which was not supported by their actual income. The total amount of mortgage debts of American households grew by approximately $60 \%$ in $2001-2006$ and reached almost 10 trillion dollars (75\% of the GDP of the United States) by April 2007. At the same time, the total sum of poor quality mortgage debts increased to 0.8 trillion dollars. ${ }^{139}$ This was the origin of the credit crisis in the United States at the end of 2007 and the beginning of 2008.

In this crisis, there was a clash of three tendencies, each of which had a psychological basis: the general tendency of the American middle class to live on credit, the enormous growth of speculative global capital (based primarily on petrodollars), its propensity for risky investments, and the aspiration of the lower middle class to maintain their mode of life, despite insufficient income.

Previously, the middle class in the United States had an ample safety cushion: apart from physical and human capital, there was financial capital - divided into three forms: cash, stocks, and bonds. However, as a result of the structural shift in the middle class, a significant part of this cushion was lost.

Taking into consideration the propensity of American consumers to increase their debts, the growth of speculative global capital, and an increase in the proportion of individuals with a «middle class» psyche, who, however, lacked the corresponding incomes, one can see how the United States was transformed from being the main centre of stability in the global economy prior to the 1990 s to the main centre of instability, especially financial instability, in the beginning of the $21^{\text {st }}$ century. Moreover, this did not happen because the United States faced the most severe economic problems, but due to the psyche of a significant part of the population, which did not allow it to live within its means, by adapting to changes within the United States and globally; and, also because the United States currently occupies an excessively high relative density in the global economy.

139 “Economic Questions”, № 12, 2007, p. 6. 


\subsection{Social Requirements and the Markets of Social Goods}

In consumption, an important role (sometimes as much as $50 \%$ ) is played by the goods and services making up the social values, whose consumption (fully or in part) is (directly or implicitly) financed by the state budget and special funds, i.e., from tax and insurance deductions.

In economic theory, a great deal of attention is paid to the question on why the usefulness of social goods does not find adequate expression in solvent market demand from individuals.

As the reasons for insufficient (or a total absence of) demand vary in relation to the different groups of social goods, the classification of these goods also depends on these specific reasons.

However, a general reason has also been put forward. A.J. Rubinstein wrote: «I assume that the majority of people have no concept about common good.» A.D. Nekipelov considers that «there is, most likely, a special breed of people, who alone can correctly estimate the real needs of individuals not included in its structure.»

It is useful to begin with the most general question - from the division of monetary incomes of citizens into the part, which they spend in the market, and the part, which they pay as a type of tax and social security contributions for financing social goods. In a democratic society, such a division of incomes is voluntary and is based on the trust of the state and in solidarity with the majority of the members of society. This is based on the belief that certain types of requirements should be satisfied not according to the preferences and incomes of separate members of society, but in order to support and develop society as a whole (at a given GDP).

Such solidarity is based on socialitarian instincts (sympathy and mutual aid) and instincts of development (related to self-realisation and creativity) that are genetically inherent in people, and on instilled instincts of national complementarity (in terms of language, culture, and psyche).

For the part of the population with a balanced psyche (i.e., the majority of the population), there is a certain balance between the proportion of monetary income used by individuals for private goods 
and the proportion, transferred to the state for financing social goods. The correlation between individualistic requirements and instincts, on the one hand, and socialitarian requirements and instincts, on the other hand, lies at the heart of this balance. As the correlation varies historically and in different countries, the role of the state in providing the population with social benefits varies from country to country: in particular, at the beginning of the 21 st century, it is much greater than it was at the beginning of the 20th century, and in Europe it is considerably larger than in the United States. It would not be possible to determine an optimal share of social goods in the GDP, and especially the optimal distribution of this share for the needs of separate groups of social goods (education, science, public health services, culture, social security, defence, law and order, etc.) for an individual as a member of society, if he had to resolve this issue from scratch, supported only by his income, market prices, and intuition. It would be similarly difficult for any branch of government to resolve this. However, this distribution has developed historically, so the annual budget revision only corrects the previously developed ratio, taking into account empirically revealed discrepancies from the previous period as well as new tasks and possibilities.

Mainstream economic theory, as noted above, classifies goods satisfying not private but social (public) requirements, depending on the position of the latter in the market, into «public», «meritory», «Baumol's», and «mixed» goods.

Public goods (for example, achievements in the basic sciences or various cultural achievements) by their nature are open to the masses and can be used by everyone. However, not all users are ready to voluntarily pay for the maintenance of science and culture and take advantage of these services for free. As a result, other users also do not wish to pay for these services voluntarily. Therefore, the state is forced to finance these benefits through taxes. The same applies to the construction of major road networks, drainage of malarial bogs, etc.

Contradictory psychological factors lie at the heart of the financial allocation for these public goods. If, in a given society, there is a relatively high proportion of individuals with a developed parasitic instinct, on the one hand, and, individuals with a developed instinct of justice, on the other hand, then the solution consists in the introduction of taxes, equalising the varying (for each category of tax payer) subjective values of social goods. 
The concept of meritory goods is included for that group of social benefits, which an individual considers he does not need, or requires to a clearly insufficient degree (from the social point of view). These are services related to education, public health services, culture, and social security. The lack of demand or insufficient demand (from individuals capable of paying for such services) can be explained either by a lack of information or an excessive inequality in incomes. In fact, the «lack of information» is due to the lack of development of the requirements of a certain part of the population, caused either by an insufficient level of income (according to Maslow) or by the type of psyche (for example, carelessness). The state is obliged to finance (fully or in part) these services (free of charge or for partial payment) and, in some cases, makes it compulsory for its citizens to use some of them (secondary education, vaccinations, etc.)

The state also has to subsidise those kinds of activities, where the growth of labour productivity is either absent or significantly lags behind the national economic growth rate, which, in turn, results in lower incomes (theatres, museums, the arts and crafts sector, etc.).

The reasons for this again turn out to be psychological. For example, if stage actors are paid low salaries, why do they not change their profession and why does the number of theatres not decline until their services start to be adequately paid?

Economists answer these questions by asserting that the state (society) considers it necessary to maintain a certain number of theatres as a way of preserving culture.

However, the history of theatre shows that the number of theatrical companies and actors can vary, without significantly influencing their income levels. Changes in income levels affect employment levels in individual sectors in different ways. In other words, the level of the supplies of services, for example, in education, public health services, and culture can remain at their former levels for a long time (several years) even after the salaries in this sector in real or absolute terms, or in comparison to other sectors, have declined by $50-70 \%$. This was experienced in Russia in the 1990s. Recent events in the United States show that demand for public health services has remained at former levels, even when the prices for these services have grown one and a half to two times faster than general inflation and faster than real income. 
This demonstrates that in the sectors mentioned above, employment (as the supply of work) and the requirements of the population for the corresponding services are relatively weakly dependent on prices, as in these sectors, the psychological factor of being attached to a certain trade, on the one hand, and the attachment of consumers to certain services, on the other hand, are especially strong.

Here, the state (through financing and grants) aims, firstly, to maintain the quality of services, secondly, their availability, and, thirdly, the sociopolitical loyalty to the governing party of those employed in the social services sector.

\subsection{Types of Psyche and Forms of Competition}

As already noted, classical and neoclassical theory linked the competition among commodity producers to human nature, but believed this nature to be uniform and invariable, and characterised by both egoism and rationality. Distinctions in the conditions of competition in different markets and during different historical periods have been explained: by the number of participants, the presence of barriers to enter and exit, the difference of a product, and the presence of information. In other words, they were explained by different objective conditions, in which the participants competed and fulfilled their uniform and invariable nature. The fact that the behaviour of the participants of a competition can be fundamentally different (under the same objective conditions) began to be considered only in the second half of the $20^{\text {th }}$ century, by the development of the theory of games, which required taking into consideration the possibility of not only the uncooperative but also the cooperative behaviour of the participants. In the latter case, each participant restricts his own interests by taking into consideration and respecting the interests of his competitors and counterparties. This clearly demands from the market participants a psyche that is willing to compromise, instead of a psyche that unilaterally pursues its own maximum benefit. However, on the whole, in neoclassical theory such a compromise between competitors is considered as a type of exclusive (monopolistic) arrangement, which is not realistic in a competitive struggle. Competition is a 
struggle of sellers for buyers, which is waged by the sellers simultaneously on many fronts (prices, costs, quality, modifications of goods, advertising, information, servicing, financial control, etc.); consequently, compromises on some issues are likely to provoke or aggravate disagreements and conflicts on other issues. For the buyers (and society) the end result of the struggle and compromises between manufacturers (sellers) is important - the optimal combination for the buyer of the price and quality of a product and its enhancement.

In order to understand the nature of competition and the market capitalist system, it is not enough to proceed from the premise of the egoism and rationalism of an «economic person».

In reality, an egoistic and rational economic person in certain conditions can decide that, in order to maximise his well-being, it is quite acceptable to avoid competition and become monopolistic; moreover, to forego private property in favour of public property.

In the $19^{\text {th }}$ century, the Russian revolutionary democrat, Nikolai Chernyshevsky (after Charles Fourier), based his concept of socialism on the principle of rational egoism. In the middle of the $19^{\text {th }}$ century, one of the founders of the neoclassical synthesis, the Nobel Laureate, P. Samuelson, proved that the optimal price system develops in conditions of market socialism, when economically independent enterprises compete with each other, while, at the same time, remaining in public ownership.

Based on this, two decades later, another Nobel Laureate, the neoinstitutionalist, James Buchanan, declared that the preceding stage of the development of the neoclassical theory was «socialist» and underlined that private property rather than rational egoism should form the initial principles of economic theory.

From the psychological point of view, this is correct. Both psychologists and economists agree that the economic and general behaviour of a person is $90 \%$ defined not by rational calculation, but by habits and intuition. The natural instinct of competitiveness, which functions together with the natural instincts of appropriation, aggression, cooperation, freedom, creativity, etc., lies at the heart of competitive behaviour. Each psychogenetic type of market participant introduces his own meaning to the competition.

The Marxist understanding of the capitalistic psyche recognises that this psyche is defined by capital functions in specific conditions and changes together with these conditions. Thus, in the industrial 
revolution and the rapid accumulation of capital, the typical capitalist was a miser and ascetic in all aspects of personal consumption and his mode of life. As capitalism developed, he was already capable of prodigal consumption. With normal profits, private capital (and its embodiment, the capitalist) came alive, as the rate of return grew, he became more active and aggressive, and when there was the prospect of receiving profits of $300 \%$, the capital (i.e., the capitalist) was ready to break all laws and moral standards and commit any crime. In other words, market conditions are capable of transforming a respectable businessman into a criminal.

The theoretical logic is the following. At first, the category «private capital» is deduced from the genesis of capitalism «exhaling blood and sweat from all pores» as the antagonistic «relations of production» of two classes are inevitable at the given step of the development of production. Then, this class relation is personified in the figure of the capitalist, who becomes a certain personality cover of this relation. It turns out that specific people, both businessmen and workers are merely powerless puppets in the invincible and callous mechanism of exploiting "production relations».

This logic seems realistic as in Western Europe in the course of the 500-year multistage development of capitalistic institutions, the structure of the natural psyche of society and economic conditions interacted in such a way that causes and effects repeatedly changed places. Paradoxically, the key to understanding the basis on which capitalistic institutions arise and operate was given by events in Russia in the 1990s. These events have exposed the following simple and obvious fact: except for the psyche of a certain part of the population, no other significant basis existed for the formation and spreading of capitalistic institutions in Russia. The research conducted by sociologists has established that an overwhelming part of the large industrialist class of Russia in the 1990s consisted of former Soviet bureaucrats, who until then had formally been engaged in spreading communism and instilling communistic morals in workers. These people, who had been a part of the communist party system and managers of economic and security forces, enterprises, scientific institutions, and the top layer of the Soviet and Komsomol, whose psyche was potentially dominated (but, which until this time had been repressed) by the requirements and instincts of appropriation, moneymaking, and aggression. As soon as the pressure of the formal 
institutions of state socialism disappeared, this group of former Soviet bureaucrats and politicians rushed to plunder the defenceless state property, and, whenever possible, to transfer stolen capital abroad.

At the same time, the formal institutions that were formed were essentially urged to protect and legalise the informal institutions (concepts), which reflected the liberated predatory psyche of the new capitalists.

The initial growth and then fading away of small business in Russia, which is based for the most part not on the instincts of moneymaking and the thirst for money and aggression, but on the psyche of the individual freedom of action, had a completely different nature. The small business sector attracted that part of the middle class of Soviet society (trade workers, engineers, teachers, professionals in liberal professions, skilled workers, etc.), whose psyche was dominated by the requirements and instincts of individualism, freedom, competitiveness, and creativity. However, small business growth in Russia - in the absence of effective state protection and support - was suppressed by the actions of strongly capitalised companies, organised crime, and local bureaucrats. In approaching the market as a competitive mechanism, which provides for the exchange of goods in the economic system, through the interaction of the supply and demand forming the prices, one should take note of the basic psychological heterogeneity of the market participants, from the point of view of both sellers and buyers, and the variety in their activities.

Predatory capitalists aspire to maximise their incomes for relatively short-term periods, either by inflating the price of goods and lowering the prices of resources purchased by them (through a monopolistic arrangement), or by removing their competitors (through a short-term reduction of sales prices, demand for resources, advertising, etc.). That is why capitalists with a predatory psychic disposition usually concentrate in those markets that can be controlled and where large quantities of homogeneous goods are traded, whose prices can fluctuate sharply and frequently: namely, the oil, coal, metals, cement, grain, meat, fruit, etc., markets. The same also applies to the market related to the mass construction of residential dwellings, as well as the securities and currencies markets. Price volatility in similar markets is partially caused by the influence of conjunctive factors, and to an even greater extent by the psyche of the market participants. George Soros has illustrated this in his books about stock exchange mechanisms. 
However, in describing the psyche of players on the exchanges from within, based on his extensive experience, Soros naturally did «not notice» the specificity of these types of capitalists, in particular, their «naturally» predatory behaviour. Of course, one can consider that stock exchanges represent just one type of typical capitalistic activity, which on the one hand, promotes inter-branch and international capital flows and the adjustment of rates of return, and, on the other hand, rewards successful firms and punishes the inefficient ones. However, fluctuations in market prices are several times more volatile than the fluctuations in the real profitability of the corresponding manufacturers and their efficiency, are no means always connected with them, and are therefore basically a display of the actions of large speculators, whose psyche made them select such a path to potential enrichment.

Hostile takeovers are a particularly predatory activity, prevalent in the stock and debt markets. This involves taking over the ownership rights to a firm at a low price with the aim of their further resale at significantly higher prices (entirely or in parts). Inefficient firms that are on the verge of bankruptcy, and quite healthy and successful firms, which have fallen into temporary financial difficulties either for conjunctive reasons, or as a result of the deliberate manipulations of the corporate raiders, are particularly vulnerable to hostile takeovers.

In a hostile takeover, to a greater or lesser extent, banking capital is used, both directly and indirectly. The indirect use of banking capital takes place through the crediting of large stock exchange speculators and raiders, in speculative (uncovered) crediting of some branches of the economy (housing construction, transport and communication, oil drilling, etc.). The direct use of banking capital involves the direct participation of banks in large speculative deals on the stock exchange.

The struggle for large amounts of capital, controlled by individuals with a predatory psyche, causes the market in the sectors mentioned above to become extremely unstable and transforms it into a source of shocks for the economy not only of individual countries but also for the global economy. This is why Soros has demanded the establishment of strict restrictions on the activities of financial capital on a global scale and international bodies for regulating its movement.

The technically complex, high technology production markets ( «the innovative markets») have a completely different nature. They 
are composed of industrialists with an innovative psyche, who also compete intensely against each other. However, the character of the competition in this sector is fundamentally different in comparison to the competition in the markets, dominated by predatory capital. In contrast to the predatory markets, where the substance of the competition centres around the redistribution of wealth and pushing aside ones competitors, in the innovative markets competition involves outperforming competitors in the development of products and the newest technologies.

The cardinal distinction between the psychology of capitalists, dominating the two types of markets discussed above, dramatically manifests itself by the opposite price movements in each of them. If one takes a typical product for each market, with specific consumer characteristics (for example, a particular oil brand or grain of a certain category, on the one hand, and a car or a computer, on the other hand) - in a predatory market, regardless of whether there is a boom or a decline, the general tendency of price rises is clearly visible, but in an innovative market there is a general tendency of falling prices.

One needs to keep in mind that both types of capitalists aspire to maximise their return on capital. However, the distinction between them lies in the fundamentally different methods used, which are defined by their psyche. Moreover, the distinction in the methods leads to a difference in the nature of the capital itself - depending on whether the capital's origins are destructive or constructive.

Predatory capital, in addition to fulfilling some socially useful functions, also has destructive consequences. Innovative capital is basically constructive. However, critics point out the superfluousness of the technological progress generated by it (in terms of developing expensive features that are not required by the majority of consumers). One can consider such a tendency as a negative consequence of the intense competition between innovators (manufacturers); however, it is strictly limited by consumer choice. While, price rises on raw materials, the housing markets, etc., as a rule, are limited by crises, when the cumulative suppression of demand takes place.

The majority of businessmen, whose psyche turns them into «slaves of routines» work in branches, where technologies develop slowly and production properties change very gradually. This includes, for example, the food, textile, sewing, shoes, the polygraphic industry, the services, and public utilities sectors. 
In terms of the rates of change of technologies and properties of a product, these branches find themselves between the raw materials and innovative branches; however, here, the ferocity of the competition amongst manufacturers is weaker than in the raw materials and innovative sectors.

One can assume that the competition in the intermediate branches is less severe than in the innovative sectors, since, in the innovative sector, the capacity and complexity of technologies and products increase much faster than in the intermediate sectors. However, in relation to the raw material sector, a different set of factors apply: in the intermediate branches, the distinctions among products are incomparably stronger, than in the raw materials sector; furthermore, product differentiation results in the division of the market into groups of sellers and buyers, connected by certain tastes and habits.

In the intermediate branches, price rises (in this type of production) mainly occur due to higher energy and raw material prices.

From this, it follows that development and dynamics (instead of redistribution in a static condition) are the main means of maintaining the general market balance and, consequently, are inseparable from it. At the same time, balance is an attribute of the existence of the system and its development.

The stability of the general market equilibrium depends on the stability of each of the markets and the character of the communication between them. At each historical stage, the configuration of the markets and the structure of their participants vary, distinguishing «dominating» and «dependent» markets.

In the modern American market system, the financial markets (and within its framework, the stock exchange) occupy the leading position. The total value of stocks, bonds, and other financial tools is four times greater than the GDP of the United States. This gives us an approximate scale of the possible short-term deviations of stock exchange profitability levels from those in the real economy. Profitability on the stock exchange depends on expectations, i.e., forecasts, in which a company's forecast profits are only one of the components, and the estimation of the future behaviour of other market players (a psychological factor) plays the dominant role.

Due to its size and independence, the American stock markets exert a defining impact on the overall economic system not only of the United States but also of the world. The Russian economist and 
banker, M. Ershov, wrote: «There are cases, when the financial markets, being derived and secondary relative to the economy, exert a decisive influence on the economy. Moreover, currently, the financial markets are frequently in a position of exerting a greater influence on the economy than the economy can exert on them (as has happened on more than one occasion both globally and in Russia). On the stock markets themselves, an even more inconsistent interdependence has been noted quite often. From the overheating of the stock markets of the new economy in the United States in 2000, one can draw the following conclusion: the global economy to a great extent depends on the condition of the American economy, which, in turn, depends on the American stock markets, which, in turn, are significantly dependent on 10-15 companies (mainly from the new economy), whose place in the market was disputed by many (this was followed by the crash on NASDAQ, which lost more than $60 \%$ of its market value).»

Although this is, on the whole, reasonable, it does raise some questions: firstly, the clearly out-of-date thesis about the secondary financial market. Actually, it is a major branch of the general market. In it, the ownership rights to firms (controlling rights) are fulfilled. On this market, a firm, combining material and human capital, is evaluated primarily on its ability to yield income to the owners over an undefined period of time. This estimation depends on many variables, which are not defined exactly, which is why the evaluation is, to a great extent, dependent on the psychology of the market players. Secondly, in 2007-2008, events in the United States have shown that it is the uncontrollable greed of the owners of big banks and financial funds, and not the companies of the new economy, which is the main source of the current instability of the global economy. 


\section{Chapter 9}

\section{Modern Innovations: the Conflict of Different Types of Entrepreneurial Psyche}

\subsection{N. Kondratiev's «Waves» and R. Foster's «Eras»}

The question of the interaction of technology and the psyche of a person can be stated in the following way: what demands does technological progress make on the human psyche? However, technological progress is not a mystical external (in relation to people) force, but the product of their technological creativity, and, hence, of the human psyche. Thus, it would be better to pose the question differently: what type of psyche is the driving force behind technological progress?

Some people drive and develop technological progress, others only adapt to it and use its benefits, and others, deliberately or otherwise, resist it; thus, the concept becomes complicated and technological progress appears as a mechanism of the influence of some types of human psyche on others in the technological and organisational sector of the economy.

Marxism promoted a concept of technological progress that was not personified. According to it, private capital represents an impersonalised force, continuously «revolutionising» production in pursuit of profit. People's talents and will are only material for the callous Moloch of capitalist progress, who grinds human creativity into profit and new investments.

Schumpeter proposed a fundamentally different approach, dividing economic decision makers into innovative industrialists and capitalists, who are slaves to routine. The former transform production and the economy as a whole, creating new types of resources and new systems of relations, while the latter are content with the existing production methods and institutions. At the heart of this division lies a 
psychic divide between those capitalists, whose behaviour is dominated by creative instincts and a readiness to overcome institutional barriers and habits, on the way to creating new technological and organisational systems, and those capitalists, who are slaves to customs and habits and aspire to avoid risk, preserving the existing level of return on capital.

Both kinds of capitalists are financially motivated by the aspiration to profit; however, this profit differs in terms of its sources and methods through which it is obtained, and the motivations of these two kinds are qualitatively diverse. The depth and historical significance of the gulf in the psyche between capitalists, who are slaves to routine, and innovative capitalists is even deeper than that presented by Schumister. He believed that this rupture underlies the distinction between stationary circulation and the dynamics of an economy in general. However, he did not think that two qualitatively different systems of capitalism are possible: one dominated by slaves to routine and the other by innovators. He believed that large corporations transform innovation into bureaucratic routine. However, he was mistaken, as he clearly underestimated the forces of competition and the potential of the scientific and technological revolution in the advanced countries.

In his division of nations into capitalistic-industrial and pettybourgeois, Sombart came closer to understanding the intra-national significance of the gulf between the types of psyche. However, Sombart did not link this division to the nature of technological progress. During the epoch of Schumpeter and Sombart (from the end of the $19^{\text {th }}$ century to the first half of the $20^{\text {th }}$ century), technological progress was made through the industrial revolutions occurring (approximately, once every 50 years), at first in the advanced countries, which then caused waves of capital expansion worldwide. Therefore, in their concepts of business and innovation, they emphasised new combinations of resources and the opening of new markets (and the corresponding aspects of the psyche of businessmen). At that time, the continuous competition for new technologies and products had still not become a permanent and basic form of the existence of business in the developed countries.

This new form of capitalism, which has grown through almost continuous technological self-upgrading and, thus, by the creation of 
new markets for itself, started developing only after the Second World War, in the second half of the $20^{\text {th }}$ century.

This form of capitalism assumes not only the existence of a great number of innovative businessmen at all levels - large, average, and small - but also the existence of a great number of engineers and workers, continuously ready to be retrained and adapt to new technologies and organisation of production. It also assumes the existence of consumers, who are ready to frequently change the range of products used by them and to almost continuous changes in their way of life; i.e., it assumes the existence of nations, whose economies are run by talented, resolute, and competent leaders, and whose populations possess an elastic psyche and high potential for retraining.

The book of the American scholar, Robert Foster, «Innovation: The Attacker's Advantage» (New York, 1986), explains the mechanism of modern technological progress in the conditions of advanced capitalism. The author analyses this mechanism by the use of specific examples from the competitive practice of dozens of the largest American and international corporations. Although the author does not specially aim to reveal the psychic bases of modern technological progress, in my opinion, the book clearly shows that the specific psyche of the industrialists, personnel, and consumers represent such bases. The value of Foster's book lies in the fact that he uses his long-term operational experience in a consulting firm in the corporate management sector and, in particular, his experience gained from discussions with higher-level managers. Psychologists would classify the book as field research (at least, partly).

From Foster's book, it follows that different periods of technological development exert different demands on the psyche of the companies' managers.

Foster, based on Kondratiev's theory of 50-year cycles of conjunctures and referring also to Schumpeter, distinguishes «four waves of innovations» from 1790 to 1990. The first (1790-1840): new technologies in the textile industry as well as coal and steam power; the second (1840-1890): railway transportation and mechanisation; the third (1890-1940): electric power, chemistry, and the internal combustion engine; the fourth (1940-1990?): electronics. It is possible that the fourth wave will merge into the fifth wave $(1990-\ldots ?)$, in which biotechnology will be one of the bases. 
In his book, Foster concentrated on the fourth wave (electronics), whose specificity consists of changes at speeds unknown earlier. The time from realising the need for a new product (the presence of demand) until shipment of this product in large quantities has been reduced on average to half a year.

However, the innovations of the fourth wave were not developed uniformly and are inconsistent. Whereas in the 1950s, there was a boom in research and development, the 1960s were disappointing as scientists and technologists were not interested in consumer inquiries, and corporations did not earn the profits that they expected. Consequently, interest in research and development, as well as in technologies fell, and attention was focused on marketing and customer inquiries. The managers, who had turned away from technology, came to power. Scientists with degrees became taxi drivers and companies started to search for diversification. The era of conglomerates had arrived. The third era (within the fourth wave) started in the 1970s, with the «rehabilitation» of technology as a means of competition and became the object of «strategic management».

Foster considers that such an approach could work in conditions of continuous and gradual technological changes and it is not suitable for fast and spasmodic shifts. Such shifts are characteristic for the fourth era (within the fourth wave), which began in the 1980s. This was an era of the management by «technological breakthroughs» (which was understood only in some corporations). This era required managers with the psyche of innovators.

The periodisation of Foster is interesting for Russia, which, from the failed technological euphoria of the epoch of Gorbachev rushed into Yeltsin's marketisation, and in the midst of the severe technological backwardness that had developed, tried to find ways of competitive technological development. However, innovative businessmen were still not visible on the horizon of Russian production. However, there was a surplus of innovators in the sphere of the redistribution of property and incomes. 


\subsection{Conservatism and Innovation in American Corporations}

The large modern American corporation, which is the moving force behind technological progress, was the main subject observed by Foster. The overwhelming majority of such corporations are conservative, i.e., their management and personnel are conservative. This does not mean that they are against technological progress - in fact, the opposite is true. The management annually invests millions of dollars in technological progress and the personnel modernise production methods and upgrade production. However, these efforts are spent almost entirely on the improvement of technology and production that has already been mastered, and funds for the search for high-quality alternative technologies and production are not allocated. Such an initial starting position can be considered conservative; however, when a technological alternative appears on the horizon of competitors, and the given corporation continues to ignore it, then the conservatism of that corporation poses a potential threat to its own existence.

The conservative adherence of corporations to technology that has already been mastered is not a deviation from normal behaviour; according to Foster, such behaviour should be considered typical. This has been supported by numerous sources.

First of all, the technology that has already been mastered and that has become habitual influences the perception of new information, and forces one to negatively interpret data on technological alternatives and to focus attention on their shortcomings rather than their potential advantages.

The management of large corporations, which have won a considerable share of the market with the help of technology that had once been new and effective, are disdainful and arrogant in their relations with smaller competitors' alternative technologies.

The link between a specific technology, and large capital investments in the capital, both human and physical, is an important source of technological conservatism. A radical change in technology leads to a considerable part of the accumulated knowledge, experience, and corporate equipment becoming outdated. Such a change demands new investments, both in retraining personnel and in 
new equipment. At the same time, there is a significant risk of a fall in the market value of the company.

An equally deep influence on the conservatism of a corporation is exerted by the close connection of the familiar technology with the social status of a company's directors and managers. Their positions, as well as the prospects of career growth throughout the company's administrative hierarchy, are connected with the use and perfection of the technology to which they have become accustomed.

Finally, (and this needs to be noted especially as Foster's central idea), technological conservatism is supported by the fact that the link between the evolutionary cycle of a specific technology and the economic cycle of a corporation based on this technology is deeply hidden. It is mediated by the functions of many diverse factors, internal to the corporation as well as external ones, which are not directly related to technology. Therefore, the financial and economic well-being of a firm can, for a long time, mask the approach of its technological crash.

Thus, the psychology of technological conservatism of corporations is supported by different «layers» of the human psyche: by habits, orientation to hierarchy and status, the self-preservation instinct, and the protection of a standard of prosperity.

This leads to the emergence of behaviour characteristics in the management of a corporation, such as a distorted perception of technological alternatives, the perception of the technological evolution of a corporation in the context of its financial position, pride, arrogance, and risk avoidance. From here, one can also see that the specifically developed abilities of the directors and staff of corporations are an integral part of their psyche; they specifically influence their preferences, and their chosen behaviour in the economic (technological and economic) and social spheres.

So far, I have discussed the internal sources of technological conservatism in corporations. However, there are also external sources. One needs to relate to them, firstly, the habitual behaviour of consumers, who have become accustomed to a corporation's products having certain characteristics. Consumers usually wait for improvements in products that are already known to them, instead of replacing them by completely new ones. This applies to individual consumers, firms, and state organisations. Secondly, when there is a basic change in technology and production, one needs to partially or 
completely change ones current suppliers, and once again agree to new parameters, conditions, and terms of deliveries. In other words, one has to change the entire developed system of external relationships of the corporation. At the same time, one needs to persuade the sceptically inclined (to innovations) financiers to support the innovative activities of the corporation.

Perhaps, conservatism or, more precisely, evolutionary conservatism is the best technological policy for the corporation, corresponding not only to the psychology of the personnel but also to the objective logic of technological progress?

The American economist, Devendra Sahal, in his book «Technological Progress: Concepts, Models, and Valuations» (English edition, 1981; Russian translation, Moscow, 1985), has characterised the evolution of views on the nature of innovations in the following way. Whereas Schumpeter and a number of other authors treated technological progress as an exogenous parameter, possessing a noneconomic (psychological and sociological) nature, from the end of the 1950s, technological progress began to be considered as a completely economic phenomenon. He wrote that, while, previously, it had been considered that the process of technological shifts is independent, now technological shifts are considered to be dependent on the social and economic system. He considers that neither of these points of view can be considered as proved and that the process of technological shifts is neither fully chaotic, nor fully controlled. Moreover, he doubts that the nature of technological shifts will ever be explained in a completely unambiguous way and that the question on whether the process of technological innovations is independent is fundamentally impossible to answer.

According to Sahal, the development of technology is defined by the action of two major factors: (1) training in the course of production and operation, and (2) a change of scale of the technology in order to give it a structure, corresponding to certain applied tasks. The evolution of technology passes through critical points, where invariable basic constructive schemes are formed, which are then gradually modified for many decades (pp. 330, 333).

In other words, cumulative processes of synthesis (including at critical points), mutual additions, modifications, and the perfection of already saved up technical knowledge and experience are strongly dominant. 
Whereas Sahal's conception of technological progress in some way is reminiscent of the construction of an ant hill, for Foster, modern progress in science and technology is primarily a battle ground among leaders of different corporations, equally inclined to profit, but possessing different types of psyche. Foster wrote that according to the majority of researchers, the introduction of innovation is a unique process demanding a creative approach, talent and, perhaps, even greatness. They consider that this process cannot be managed or predicted, and one can only hope that it will occur, and, perhaps, one can accelerate it. In contrast, Foster considers that innovation is something more. According to him it is a fight in the market between innovators, or between those who attack and aspire to profit by changing the order of things and those who defend by protecting their current incomes.

Thus, technical innovation is not only a unique creative action, demanding «greatness». It is an attack on the developed order of things and on those who protect it.

Foster is convinced that the conservative management of corporations is doomed to defeat as it is mistaken in its thinking.

According to Foster, the first characteristic mistake is the belief that the evolutionary approach to technology will fully justify itself. The second mistake is that the majority of companies do not know how to measure technological health; instead, they measure their economic health. The trouble with this is that economic health is the result of the action of many factors which, in fact, do not depend on the deep technological health of a company. The third error occurs, when the company is convinced that it understands the needs of the consumer. The fourth error consists in the incorrect understanding of the size of the market. One needs to fairly deeply understand the technology of ones competitor, which is not always possible.

Foster believes that any specific technology within the limits of a corporation develops under the same law. At the first stage, the investment in developing a new technology increases much faster than returns, and during this period it is important to define the potential of the new technology. At the second stage, the returns from the new technology greatly exceed the expenses for its perfection, and during this period the corporation generally achieves the greatest economic benefit. At the third stage, expenses for the perfection of the production method, which has already become a habitual method, 
again start to increasingly exceed the return, which means that the economic limit in the development of the given technology has been reached.

For example, in the construction of the engine of an airplane, the main technical indicator is the ratio between the tractive force and the weight of the engine. At a certain stage, the expenses for the perfection of piston engines ceased to provide substantial improvements, which resulted in the necessity of changing to a fundamentally new technology, the turbo-jet.

Hence, for a corporation it is critical to be aware of the limits of the possibilities of the effective perfection of the technology used by it.

However, we will assume that experts have revealed these limits in good time, and have informed the management of the necessity to begin the search and development of new technology. The tragedy of many corporations consists in the fact that during this period the old technology still provides a high return, and the economic and financial indicators of the corporation are extremely high.

Foster noted that in general the time required to prepare for the transition to new technologies is often overlooked, and large corporations concede their leading positions in the sector to their competitors, who are frequently small companies in the beginning, which use fundamentally new technology.

Foster gives examples, demonstrating that heads of large companies do occasionally carry out a fundamental reorganisation of their company (in good time) on the basis of completely new technology. However, this occurs very rarely. Foster compares this to the legendary ability of the phoenix to burn to ashes and then arise from the ashes.

Such an innovative leader needs to possess many qualities, which conservative leaders lack.

Firstly, he needs the ability to perceive information adequately, without inertial preconceptions.

Secondly, he requires knowledge of the tendencies of the development of technologies in his branch and in associated industries and the ability to see both the basic distinction and the link between technology and the economy.

Thirdly, he needs experience and intuition in evaluating potential market demand as well as the potential of competitors.

Fourthly, he needs organisational talent. 
Fifthly, he needs willpower and courage, the ability to risk his reputation and position, and the ability to undertake strict and painful measures.

According to Foster, the redistribution of resources is a painful procedure. However, in order to cope with technological gaps, the company should tear its ties with the past and part with technology, which quite often has only just entered its most productive phase of the S-shaped curve. The essence of the fourth era of the management of technology, which companies should enter, is contained in this dilemma. Technology management requires knowledge, analysis, and the capability of detecting limits. It demands the conviction and boldness to recognise that harsh measures are sometimes necessary.

Are the managerial qualities listed above sufficient for the radical reorganisation, from top to bottom, of a huge corporation in which tens (and sometimes hundreds) of thousands of persons are employed?

It seems that Foster feels that these qualities are not sufficient; for, among the listed qualities, there is only one that is capable of serving the innovative leader as a motive for a radical transition to an alternative technology - the instinct of self-preservation, aroused by an awareness of the prospect of the company crashing and generating a feeling of alarm and fear. However, the innovative leader is hardly likely to allow fear to act as his primary motive.

Foster, therefore, puts forward another motive, the profit motive: the transition to a fundamentally new technology promises to raise a company's profits many times over. However, Foster notes that the costs of such a transition are very high, the risk of heavy losses is also great, and the chances of failure are far greater than the chances of success in the attempt to implement a fundamentally new technology.

For innovators, who have successfully developed a new technology (and who have been mentioned in Foster's book), maximising their profit was not the main driving motive. Industrialists, who are driven mainly by the motive of fast personal enrichment (the appropriation instinct), select fields of activities that are not connected with production, but with the redistribution of property: corporate raiding, speculation on the stock exchange, real estate transactions, etc.

In order to understand what motivates innovators, one needs to bear in mind that innovators are people with a special type of inborn psyche (which is developed throughout their lifetime). They are people, whose psyche is dominated by the existential requirement for 
creativity and who are guided by a powerful creative instinct. In innovative corporate managers, this requirement and instinct are supported by inborn and highly developed technical and organisational abilities.

Certainly, constructive creators are realists, who aspire to secure for their creation (in this case, a company, based on new technology) durability and financial and economic conditions for its further development, i.e., a certain level of profitability. However, the main objective of their management of a company does not lie in their own or the shareholders' enrichment, or in altruism towards company employees or society as a whole, but in the development of the corporation as an updated system, based on the most modern technology. In this case, profit and share-price growth are merely a by-product, as the market evaluation of the efficiency of their innovative activity.

Profit and personal enrichment are the main motives of evolutionary conservatives.

The rupture between the habitual and alternative technologies characterised above, the domination of conservatives in large corporations and the specific psyche of innovative managers are the three factors that explain why, in most cases, new technology is initially implemented in small companies, especially in small companies led by innovators, rather than large corporations.

In these firms, innovators do not encounter the resistance that they face in large corporations. On the contrary, here, the innovator can create a group of like-minded people and benefit from its support.

However, small innovative firms face a significantly greater number of external obstacles than large corporations. First of all, they suffer from a shortage of capital, especially at the initial stages of developing a new technology, when expenses greatly exceed returns.

Secondly, the absence of links with the market and the uncertainty of the sales of new products also pose problems for small firms; especially, when large and financially powerful competitors lower the prices for their traditional production in reply to the release of the new production.

Thirdly, there is a high level of risk associated with the development of the new technology.

Thus, it is not surprising that the majority of average and small firms, aiming to compete through the use of new technology, are 
ruined; however, those that survive, win against large and wellestablished firms, and, as a result, grow into large and famous companies themselves. Foster considers that in traditional military strategy, the defending party is considered to have the advantage. This view has also been applied to the economic sphere, in the belief that the defending party, i.e., the competitor with the largest market share and the greater knowledge in production and sales, has the advantage in the struggle for market share. Foster considers the opposite to be true. Logically, the defending party is at a significant disadvantage. The attacking party is often much stronger than it seems and it is better mentally prepared to fight.

This shows the qualities of the psyche that are required of an innovative industrialist: a fanatical devotion to the new technology and confidence in its superiority; tenacity and patience; the ability to transfer these qualities to ones partners and the ability to organise production in a new way; the talent to persuade bankers and other creditors; market intuition; and an understanding of the psyche of the consumer.

In other words, the innovative psyche is a combination of unique existential requirements with unique general and specific abilities. It is an energetic psychic structure, in which the requirement for creativity is dominant, and which depends on well-developed technical, organisational, and communicative abilities.

According to Foster, only three out of every ten large corporations manages to introduce new technology in time and, as a result, remain among the leaders. Only these three leading companies are found to have managers, possessing the psyche of innovators. Even when the upper management of companies realise the requirements needed to maintain their leading positions, only a handful possess the desire and ability to fulfil these requirements. The will to carry out fundamental changes is inherent in only a few of them, and these are the managers, who lead companies through fundamental technological changes. Moreover, they have caused these ruptures to take place. The question remains, whether many of us are capable of following their example.

A handful of innovative managers, possessing the desire, ability, and will to carry out changes have played a leading role in ensuring that technological progress became the main engine for developing capitalism. It goes without saying that many other preconditions, making up the system of advanced capitalism, are also required. 
However, those capitalist countries that do not possess such innovators in charge of at least some corporations are bound to lag behind.

Foster describes some ways, used by large corporations to attract leaders, possessing the psyche and experience of innovators.

One way is to acquire a small firm, which already possesses the new technology. The management of the (former) small firm are then given the opportunity to reorganise the entire corporation.

Another way is to invite scholars and experts from universities, research centres, and other firms (i.e., from outside the company) in the role of innovative managers.

Finally, a third way is to search for and cultivate innovators from among the experts of the corporation. However, this can only occur in corporations that are not predominantly conservative.

In any case, the transformation of a corporation from an organisation, which has limited itself to perfecting technology that already exists, into an organisation which also develops fundamentally new technologies as an alternative production base, depends on the presence of an innovative manager (leader). Moreover, a person who is conservative by nature cannot become a true innovator.

\subsection{Conservatism and Innovation in Science}

The collision of the conservative and innovative psyche is characteristic also in the development of science.

It is well-known that there are two basic concepts for the development of science: Robert Merton's concept of the cumulative accumulation of knowledge and Thomas Kun's concept of a change of scientific paradigms. The first concept is essentially evolutionary and conservative and the second concept is innovative in a revolutionary way. Merton's concept is based on the existence of a special social institution and scientific community, whose members possess special ethics dedicated to truth. It assumes also a special type of psyche. (Merton's concept was subsequently further developed in the works of the sociologist of science, Michael Polany).

Unlike Merton, Kun believes that the scientific community is not uniform and, just as in any other sphere of knowledge, is divided into 
those who support the old paradigm (thus, protecting both their social status and income) and, reformists, who, relying on the new data, oppose the old theoretical paradigm and try to replace it with a new one.

Although the scientific sphere is not the object of Foster's research, he notes that Kun's book, "The Structure of Scientific Revolutions» led him to the idea of perceiving the development of technology through «ruptures» between old and new production methods.

In his book, Foster quotes statements, characterising the technological conservatism of some outstanding scientists, as well as the innovation of others.

In 1902, the well-known astronomer, Simon Newcomb declared that flight through the use of machines that are heavier than air is impractical, senseless, and impossible. (The following year, the Wright brothers succeeded in making the first manned flight.)

In 1923, the Nobel Laureate in physics, Robert Milliken, confirmed that it is inconceivable that human beings will ever be able to use atomic energy. (Two decades later, in 1945, the United States tested a nuclear bomb. Later, in 1954, an atomic power station was built in the USSR.)

Having quoted these statements (and noting that it would be possible to quote hundreds of similar statements), Foster then explains the origin of such blunders. He argued that these scientists, based on reasons, connected with technological limitations, came to incorrect conclusions. They lacked the open-mindedness and ability required to look beyond the nearest restriction. Submitting to the tyranny of numbers, they, probably, would have come to the wrong conclusion about the potential of the miniaturization of the transistor.

The problem probably lay not only in a lack of open-mindedness. A scientist, who makes a forecast in a specific branch of natural (and social) sciences, should know the possibilities and limitations of the existing technology in this branch. However, he should not be psychologically attached to this technology. On the contrary, he should be psychologically prepared and motivated to search for alternative technologies, with broader possibilities and limits. He should possess a psychology that is similar to the psychology of people such as Archimedes, Copernicus, Columbus, Korolyov, Oppenheimer, Henry Ford Senior, etc. 
The danger to the scientific community (based on old paradigms), posed by innovative discoveries in science, can be seen from the following example given by Foster in his book. Joseph Priestley, the discoverer of oxygen and a member of the English Royal Society in the $17^{\text {th }}$ century, speaking about the dangers which he foresaw for the Royal Society, stated that they were engaged in placing «gunpowder» under an old building of errors and prejudices, which can blow up from a tiny spark, causing an explosion that will result in the whole temple, constructed over many centuries, to fall at once, and it will be destroyed to such an extent that it will not be possible to recreate it. Foster argued that this also applied to modern technological transitions.

I note, however, that there can be no definitive winners in the war between scientists with an evolutionary and conservative psyche, and scientists with an innovative psyche. Since, in the development of science, both evolutionary and revolutionary processes are intertwined, and not only conflicts but also constructive interaction can take place between the followers of different paradigms.

\section{$* * *$}

Foster considers technical and organisational innovation as an instrument of the competitive struggle of corporations and its derivative. In fact, the role of innovation is much wider and its roots lie deeper. It raises the productivity of labour and the efficiency of the economy as a whole to new levels, develops requirements, and in this way creates the possibility for increased well-being and an improvement in the quality of life; acts as a means of balancing interbranch and macroeconomic proportions; and is capable of resolving global economic and demographic problems.

Technical, organisational, and scientific innovation arose long before the formation of corporations, and its roots lie both in the inborn psyche of a certain part of the population, as well as in those cultural aspects of society, which encourage novelty and resist routines. 


\section{Chapter 10}

\section{The National Psychology and the National Economy}

\subsection{Understanding the National Psyche}

In the widely accepted interpretation of the concept of a «nation», two different groups of phenomena are mixed: the factors forming a nation, and the properties of a nation as a system-defined entity. The authors of «The Sociological Encyclopaedia», having made the reservation that there are different approaches to defining the term «nation», nevertheless, go on to state that the presence of unifying factors such as a common territory, historical destiny, a literary language, culture, commodity-market relations, traditions, a state system, and a national consciousness is a characteristic sign of a nation. ${ }^{140}$

Historical experience, however, has shown that a nation continues to exist even when a common territory is shared between different states with different political and economic systems. Moreover, the association of different nations on one territory under a common political and economic system does not lead to them merging and forming one nation.

Certainly, a common territory, historical destiny, a state system, and commodity-market relations serve as necessary factors for the formation of a nation. However, after the nation is generated, it forms an independent organism that is capable, depending on its basic needs, of actively influencing the state, the economy, and the territory.

A nation that is formed is not a conglomerate of different types of links that are defined by the state, the market, and its borders. On the contrary, a nation uses the state, the markets, and its territory for its own purposes, namely, survival and development. The terms

140 “The Sociological Encyclopedia”, vol. 2, "Misl”, Moscow, 2003, p. 35. 
«national state», «national market», and «national borders» are used in this context.

From this, it follows that a nation is a historically formed community (unity) of people in terms of language, culture, and psychic disposition. (This definition includes «traditions» and «the national consciousness»» as elements of the culture and psyche.)

In this context, the statement that nations arose «during the formation of the capitalist system» is a simplification. ${ }^{141}$ In many parts of the world, nations appeared many centuries prior to the capitalist system.

In relation to my theoretical position, I understand a national psychic community, primarily as a more or less uniform relationship in the majority of the members of the community in relation to three groups of existential requirements and instincts: individualism, sociality, and development. As will become clear later, these correlations (i.e., structure of the national psyche) vary amongst the representatives of different nations: some nations are focused to a greater degree on individualism, others on sociability, and some others on development. If, for example, individualistic requirements and instincts dominate in a nation, it does not mean that it neglects development. However, the requirement for development is fulfilled only so far as it does not restrict an individual's requirements for consumption, appropriation, safety, etc. The same can be said about cases in which the requirements for sociality and development dominate.

Further, the national psychic community should manifest itself in the character of the interaction between different levels of the psyche - the consciousness, preconsciousness, and unconscious (in other words, in the functioning of the psychic system). Members of the community should relatively uniformly perceive external information and react to it in more or less the same way.

Both for the structure of the national psyche and for its functioning, the dominant psyche (in the current historical period) of «the elite» is of crucial importance. As it will become clearer later, since nations are formed historically rather than genetically, upbringing, as a means of transferring traditions and culture, is of critical importance in the formation of the national psyche. The

${ }^{141}$ In the same place. 
dominating elite has the greatest (but not unlimited) potential influence on the process of upbringing, and thus imparts some features of its own psyche to the national psyche.

In what sense can one speak about the genetic roots of the distinctions in the psyche of individual nations?

According to geneticists, modern man (Homo sapiens) appeared (as a result of a long chain of mutations in the genome of his ancestors over a period of 5-6 million years) over 180 thousand years ago in East Africa. All nations (people) of the modern world originate from one foremother (or a group of foremothers closely related with each other through blood relationships). During the last 40-50 thousand years, modern man gradually settled along the coasts of the Mediterranean, in Mesopotamia, India, and China.

There are no grounds to assert that during this period (40-50 thousand years), shifts in different directions occurred in the genomes of separate migrating groups of mankind, which fundamentally affected the structure of their basic existential requirements, instincts, or inborn capabilities. A child, born in an African tribe, but brought up in a European family from infancy, has the same structure of psychic properties and the same level of learning abilities, as European children.

However, both mankind as a whole and each tribe separately (as mentioned earlier) consist of individuals belonging to different psychogenetic types (moreover, from a social and economic point of view, I divided them conditionally into four such types).

Through the process of the mass migration of people and through conquests, individuals of a certain psychic type were selected. For example, the numerous groups of Normans, who won significant parts of the occupied land in Western and Eastern Europe, were composed of only the most aggressive, rough, and greedy members of the North German tribes. People of this kind clearly affected the genetics of the ruling layer of some West and East European countries.

Another, later example, concerns the mass resettlement (in England) of Protestants, who had been hounded in continental Europe by the Catholic Church. As a rule, they were the most active, creative, and capable people, who genetically strengthened the population of England and aspired to conduct free enterprise. 
A similar selection occurred in the mass resettlement from Europe to the United States, Canada, Australia, and Southern Africa, which clearly influenced the national psyche in these countries.

Thus, national distinctions in the psyche have partly genetic roots, but they remain within the framework of the universal structure of the psyche and concern mainly the dominant inborn inclinations of the population. As far as the level of inborn abilities is concerned, the distinctions should be less pronounced, as abilities are distributed relatively evenly between different psychogenetic types.

The famous Russian sociologist, Pitirim Sorokin, rejected the existence of a specific national factor. With his paradoxical way of thinking, he called into question even the obvious fact of the existence of nations and nationalities as special communities. However, his point of view implicitly identifies the problem and provides the clue to resolving it in a different way.

He argues that none of the signs indicating the existence of nations (or nationalities, as Sorokin does not make a distinction between these two concepts) put forward in the literature, in themselves, characterise them as a group of people, united by a specific link. Sorokin shows that a common blood line (race) and language or shared economic interests, historical destinies, or outlook cannot achieve this. Similarly, the psychological acknowledgment of belonging to an organisation, such as a state, church, etc., also does not serve this purpose.

One has to agree with such an argument, as any form of human interaction consists of forces of attraction and repulsion. Sorokin studied this question during a period of deep national dissent in Russia, when the alienation of social forces, both interclass and intergroup, had clearly prevailed, and the national community in everyday life turned into a shadowy ghost. That is why his categorical conclusion also appears extremely pragmatic. He argued that nationality as a uniform social element does not exist, in the same way that a special national link also does not exist. According to him, the current (at the time) meaning of this word was simply the result of a lack of analysis and superficial understanding of the concept it denotes. $^{142}$ In other words, if one severs economic, political, ideological, and territorial unity, then a nation will cease to exist, as

${ }^{142}$ Pitirim Sorokin, "Man, Civilization, Society”, p. 248. 
the special national link no longer exists. For example, that is why, according to Sorokin, there is no Polish nation.

One cannot reject such a conclusion, as nations really are formed on the basis of diverse links, and by nature are not eternal. Nevertheless, as history has shown, they are much more durable than economic systems, classes, ideologies, and states (although they are less durable than global religions). The fact that the potential of national unity is capable of remaining in existence despite the actual rupture of specific forms of national links, forces one to search for a basis of this unity at a deeper psychophysical and psychosocial level. Moreover, this search depends on Sorokin's methodology.

In order to understand the forces that create and destroy a national community, in my opinion, one needs to return to the theory of instincts. Earlier, a limited number of basic instincts had been mentioned; actually, there are many more that were not mentioned. As stated in the previous chapters, the basic instincts can be provisionally divided into three groups. The first group consists of the instincts of individual survival (digestion, procreation, self-preservation, ownership, hunting, and aggression). The second group consists of instincts of individual development (freedom, expediency, competitiveness, playfulness, self-expression, and inquisitiveness). Finally, the third group consists of social instincts, which in this case refer to the psychic reactions, expressing the social requirements of a person in a collective co-existence (sympathy, cooperation, imitation, the herd mentality, hierarchy, etc.). A characteristic of the instincts of this last group consists in the fact that their action is capable of transforming an individual reaction of a member of a group to any irritation (for example, indignation at the lack of freedom, fear, or aggression) into a group reflex, in which all the members of the group react uniformly and at the same time.

This shows that the human psyche (as well as the psyche of many kinds of higher animals) is an area in which an extremely complex system of contradictory instincts interacts. If only the mechanism of inborn instincts functioned, then specific acts could be defined by the influence on the psyche of that instinct, which manifests itself with the greatest force at a given moment, as (at that time) it is most aroused in terms of internal needs and is the most suppressed in terms of external restrictions. This occurs in extreme conditions of hunger, panic, and in resistance to natural disasters or 
aggression; moreover, both the individual and group actions of people of all nations are practically identical. However, in normal conditions, such a direct and uniform display of inborn instincts in the actions of people has not been observed.

If, for simplification, one assumes that such displays are regulated by the consciousness, then one fails to take into consideration two mediating layers of human psychology. One of them, relatively inert, is formed by the transfer of the experience of older generations through example and advice to their children. Another, more superficial and consequently more mobile layer, develops as the set of the habits that are obtained at an older age.

The first mediating layer is created by the images embodied in the subconsciousness and the concepts, which together act as a code, «automatically» estimating, ordering, and regulating the displays of the inborn instincts. However, what are the origins of this code that is used to regulate behaviour? Clearly, it originates from the centuriesold experience of a given people in family life, the economy, hierarchical relations, religion, and other fields of activity, strongly expressed in the norms of daily and religious ethics, and in the images and themes of the national culture. Sorokin is right, when he shows that deducing the concept of a nation from a community of people in one or more of the listed fields of activity allows one to decompose it into components and thereby prove that it does not exist as an independent concept. However, such a deduction, as already noted, is a confusion of the process and the result.

What exactly enters the receptive memory of a child in the period that he is breast fed? Primarily, the concepts of good and evil, usefulness and harm, and fear and love, the ways in which one may satisfy ones needs and the ways in which one should not, how to relate to people and nature, etc. In other words, the code for the regulation of natural instincts (a system of ethics, in which components of a person's way of life are presented in a processed and integrated form), which guides the adults surrounding the child, takes root in the subconsciousness of the child.

Hence, one cannot compose a national community from its individual elements or decompose it into separate parts, in the same way that one cannot create a living organism from oxygen, hydrogen, carbon, and calcium, or decompose a living organism into its constituent parts. History has shown that attempts to merge different 
nations into a uniform state by the creation of an economic, political, cultural, and religious community usually end in failure. Moreover, in the end, the division of nations during civil wars and the establishment of borders also end in failure: nations time and again are reborn in their integrity and relative isolation. Sorokin has not offered an explanation for this phenomenon; however, he has specified the inconsistency of the theoretical approaches based on «compartmentalisation».

It turns out that a national community is a certain «imperceptible spirit», which cannot be «felt»? Although it is impossible to «feel», historically, it has played a primary role. Furthermore, in itself, this «spirit» has an entirely material basis in the form of a special layer of higher nervous activity, in which both constructive subconscious conditioned reflexes (national pride and complementarity) and painful reflexes (nostalgia and xenophobia) take root.

The independent and indivisible essence of a national community of people lies, primarily, in the fact that it is a specific set of real ethical standards that through their changes reflect interwoven centuries-old fundamental processes of a given people, which are indelibly embodied in the human preconsciousness. This community is shown in the specificity of the psychic reactions, both individual and collective, in various real life situations.

Thus, the specificity of such an intertwinement and interaction is of primary importance, and should be explained in the beginning, based on the background of a specific nation. The nature of a living organism is defined by its origin, and not by the elements from which it is composed; the design of a carpet cannot be understood by studying the colour and quality of its threads. The common national features of the separate people of Western Europe were formed from practically the same elements, but were combined in different ways and with different interactions. As a consequence, there are notable distinctions in the norms of behaviour of Swedes, the French, the English, and Germans.

Another reason for the independence of the concept of a national community consists of the fact that its code is imprinted in the preconsciousness and cannot be erased by current events. Only deep-rooted changes in the fundamental life of a nation over a number of generations can cardinally changes this code. Especially, as it is 
introduced in childhood, the code cannot be changed throughout the life of a person, regardless of where he lives (after childhood) and the habits he acquires.

It is important to understand that the concept «community» applied to a nation does not necessarily have a complimentary meaning of mutual liking of people belonging to it. For example, the workers of one country can relate much better to workers of another country than to local industrialists. Nevertheless, the fact that ones own (local) industrialists and workers are part of the same way of life, whereas the foreign workers, despite being from the working class, are in some way different, is indelibly impressed in the preconsciousness. Psychologically, a national community is a preconscious attachment of people to a specific centuries-old way of life as a whole, even though they are aware of all the defects of their country and their attachment does not extend to everyone living according to this way of life, or to all aspects of this way of life.

The integrated concept «national community» logically precedes the concepts «national requirement» and «national interest», which are related to specific spheres of fundamentally important functions of the nation - the economy, politics, culture, etc. From this, it follows that the «national idea» always expresses the main interests of a nation at a certain historical stage from the point of view of its unity and original development in the global system of nations.

Thus, nations are historically developed communities of people in terms of their language, culture, and psyche, with a certain unity in the psyche of all their representatives. However, at the same time, each nation, as I established earlier, includes groups of people with essentially different types of psyche. (One needs to underline once again that I have allocated psychic types under a defined social and economic point of view. The typology of the psyche under other points of views, for example, political, military, gender, pedagogical, medical, etc., can vary, for here other criteria for the allocation of type-forming signs will be required). ${ }^{143}$

143 For example, in the selection of workers, who work (outside) on skyscrapers, the primary importance is given to psychic features, such as resilience and cheerfulness. 
Is there a contradiction in the fact that individuals belonging to one nation, at the same time, have different types of psyche? Clearly, there is a contradiction and it is a real contradiction in the system of any national psyche. However, natural selection, having placed the foundations for psychic variety in the human genotype, at the same time, has also given it the ability to develop common norms of behaviour, without which society cannot exist. These instilled national norms of behaviour, reflecting the natural, economic, political, and common cultural conditions, in which over the course of centuries a specific nation was formed, should reflect the psychotypical structure of groups entering its structure. The unique, national-specific complexes of norms are called on to regulate relations between individuals with different types of psyche, within the framework of each specific nation.

\subsection{The Genetic Roots of the National Psychology: A. Marshall and J. Priestley}

Marshall's understanding of historical, including economic, events is stated in the Appendix to his book «The Principles of Political Economics», entitled "The Growth of the Free Industry and Business»». ${ }^{144}$ This understanding can be reduced to three points: (1) The immediate causes of these events lie in the actions of separate persons; (2) Their sources are institutions, national qualities, and physical nature; (3) These sources, in turn, are rooted in the genetic qualities of their forefathers and in the physical (natural) conditions of the remote past. He argued that although the closest reasons of fundamentally important historical events should come to light in the actions of separate persons, nonetheless, the origins of the majority of conditions, which have made it possible for these events to occur, can be traced to the influence of the inherited institutions, national qualities, and physical nature. However, national qualities themselves are mainly the result of the actions of individuals and physical factors

144 A. Marshall, "Principles of Political Economics", III, Publishers "Progress", Moscow, 1984. Further references to pages (after quotations) are given according to this edition. 
from the distant past. A strong nation often actually, and according to its name, originates from a certain forefather, possessing an exclusively physical and spiritual force. Traditions, which strengthened a nation in times of both war and peace, were often the result of the wisdom of a few great thinkers, who interpreted and developed its customs and rules, possibly, on the basis of formal precepts, or possibly by exerting a calm and almost imperceptible influence. However, none of this is of use, if the climate does not favour the manifestation of human energy: the gifts of nature define the character of the activity of the nation and thereby set the tone for its social and political institutions (p. 143).

Thus, according to Marshall, the «physical and spiritual force», being passed on from the «forefather» of a nation is of crucial importance for the foundation of a «strong nation». Psychologically, «strong nations» possess a higher psychic energy, will, and intellect, transferred (both genetically and through traditions) from distant distinguished ancestors.

However, Marshall does not name such ancestors in relation to the English nation; on the contrary, he believes that this nation, firstly, was formed relatively recently (since the Middle Ages) and, secondly, developed from the strongest representatives of the strongest nations. He argued that the geographical position of England has led to it being occupied by the strongest representatives of the strongest nations of Northern Europe: the process of natural selection brought to only the most resolute migrants, who relied on their own strength, arriving in England (pp.165-166).

In other words, the English nation had emerged not from uniform roots, but from the intertwining of many very powerful roots. In this way, Marshall informs us that from its beginning, the English nation was stronger, in terms of its psychic energy and intellect, than other West European nations - due to the fact that the strongest forces of these nations were concentrated in England and formed the English nation.

Marshall attributes exclusive intellectual and moral qualities to the English, which predetermined the special and orderly course of English history. At the same time, he ignores famous historic events, in particular, the bloody reformation in the $16^{\text {th }}$ century and the even bloodier civil war in the $17^{\text {th }}$ century. Marshall wrote that the English were resolute in their resistance to tyranny, but submitted to authority, 
when it suited them. He stated that each of the revolutions carried out by the English had a specific purpose. He stated that even in revising the constitution, they observed the Law; and only the English, apart from the Dutch, knew how to properly combine order and freedom; only they have united a deep respect for the past and a strong stimulus to live for the sake of the future, instead of the past (p.166).

Marshall connects the multi-rooted structure of the English nation to the individualist orientation of the psyche of the English. He wrote that the new nation of businessmen consisted mainly of those who independently created their own fortunes, i.e., strong, resolute, and enterprising people, who, beholding the results obtained through their own energy, were inclined to assert that the weak and poor should be blamed for their own misfortunes instead of feeling sorry for them. They were opposed to state interference in economic affairs and considered that full economic freedom and competition would result in progress and allow the strongest to fulfil their potential. They glorified individuality of character and were in rush to find a contemporary substitute to replace social and industrial links, which had united people in the past (p.178).

Marshall explains the negative attitude of the English to traditions and their orientation towards novelty and innovation in terms of their individualism. He argued that England had attained an exclusive position in the world thanks to the speed with which it adapted to new economic movements; in contrast to countries in Central Europe, which adhered to old-fashioned customs, and, thus, could not take advantage of the vast natural resources of their countries. Therefore, English businessmen were inclined to consider that the influence of customs and sentimentality is harmful to conducting business (p.193).

Marshall links the backwardness of the West European nations in comparison to England with the presence of uniform ancestral roots in each of these continental nations, with the maintenance of strong social links and loyalty to traditions. According to Marshall, these features of the psyche are especially characteristic of the German nation. For a German, regardless of how resolute and strong he is, it has always been extremely difficult to release himself from the bonds of customs and from ignorance. The heartiness and faithfulness, which gave him special strength, inclined him to excessively value institutions and customs of his family and tribe. No 
other great race of conquerors has shown such limited abilities to gather new ideas from more cultural (although also weaker people), which had been subdued by them. They were proud of their brute force and energy, and they cared little for knowledge and arts (p. 157).

Some years later, the rapid development of militaristic Germany shows that «loyalty» and «brute force» can live hand in hand with the ability to accept new ideas and with respect for knowledge. In fact, in the $19^{\text {th }}$ century, in creating its empire, England widely applied «brute force», and the English repeatedly showed their «loyalty» to their nation and the crown in the European and colonial wars. It seems that the work of the scientist-economist was also motivated in this case by patriotism.

It is interesting to see how Marshall connects the specificity of economic science in England at the beginning of the $19^{\text {th }}$ century with the national psyche. Marshall sees the specificity of English economic science in the overvaluation by this science of the role of individualism and competition, and its underestimation of the role of collective actions, as well as national and class psychology. Marshall explains this by four groups of factors. The first three are directly connected with the psyche of the English. Firstly, the economists were directly influenced by the utilitarian philosophy of Jeremy Bentham. Secondly, they (together with Bentham) were enthralled by the «spirit of the epoch» of free enterprise. Thirdly, economic research was undertaken by people, who did not have the proper training and depended mainly only on their personal experience.

Marshall conceded that there was some element of truth in the charges, which were often put forward against English economists in the beginning of the 19th century; namely, their research was superficial, they did not sufficiently acknowledge the role of group actions rather than individual actions in the economic and social sectors, and they exaggerated the strengths of competition and the speed of its influence. These shortcomings were partially due to the direct influence of Bentham and partially because they were connected with the spirit of an epoch, whose spokesman he was. However, to a certain extent they were caused by the fact that economic research was in many respects conducted again by people, whose strengths lay in vigorous actions rather than philosophical reflection. At first glance, it seemed likely that their connections in real life, their broad experience, and their vast knowledge of life should have helped them 
in conducting deep and wide-ranging research in the economic and social spheres. However, according to Marshall, those who are educated only through practical life are frequently inclined to quick generalisations on the basis of their personal experience (pp. 194-195).

The fourth group of factors bears a special, not typically English, character: the intrusion in the English empirical-inductive science of the Semitic genius, David Ricardo and his followers, with their abstract-deductive constructions. This intrusion led to the specific shortcomings of English economic science (the overestimation of the role of individualism and competition, the absolutisation of English institutions, and the underestimation of the role of the psyche of different nations and classes) being sharply exposed, which became an obstacle to understanding economic processes internationally and in England. According to Marshall, while the English economists of Ricardo's school stayed within their own sphere, their works were magnificent. The monetary circulation theory represents that part of an economic science, in which only minor harm can be done by refusing to take into consideration any human motives, except the aspiration for riches, and the brilliant school of deductive proof headed by Ricardo, appeared in this case in a safe zone (p. 195).

Thus, the essence of the mistake committed by English economic science, which was aggravated by Ricardo, lay in its refusal to take into consideration any human motives, except the aspiration for riches. The English economists proclaimed the general principle of human activity to be connected with business, and Ricardo (also a businessman) transformed this into the starting postulate of his deductive concept. Marshall wrote that people considered Ricardo as a typical English person, but he was not at all typical. His powerful constructive originality is a sign of high genius for all nations. However, his repulsion to induction and his delight in abstract proofs was the result not of his English upbringing, but, as Walter Bagehot noted, his Semitic origin. Almost each branch of the Semitic race had a certain specific genius, allowing them to address abstract issues, and some of them had a propensity for abstract calculations, connected with financial trading and its modern development, and Ricardo's ability to reach new and unexpected results was unparalleled. However, even for the English it was a difficult path to follow, and his foreign critics, as a rule, could not define the true direction and purpose of his work (p. 195). 
Whereas the direction and purpose of Ricardo's research was really difficult to define (for he is unlikely to have set himself the task of proving the irreconcilability of class interests in a capitalist society), it was not difficult to reveal the orientation of the work of his followers. Marshall implicitly includes Marx amongst Ricardo's followers. Based on Ricardo's abstractions, his followers believed that specific distinctions between people of different countries are superficial and inevitably subject to elimination. The one-dimensional concept of global economic developments based on the English example was deductively extracted from the abstraction of the one-dimensional «economic person». According to Marshall, Ricardo and his followers knew that inhabitants of other countries had their own specific features, which deserved to be studied, but, probably, considered such distinctions superficial and inevitably subject to elimination, as soon as other nations become familiar with the better way of life, which the English were ready to teach them. The same thinking, which pushed English lawyers to imposing English civil law on Indians, forced English economists to develop theories, assuming that the world consists of townspeople. While this caused a small amount of damage, when it was a question of considering monetary and foreign trade problems, they ran astray on the question of relations between various industrial classes. It forced them to speak about work in the same way as about goods, without trying to comprehend the point of view of the worker and without stopping to consider his human passions, instincts, habits, likes, dislikes, class hatred and attachment, and aspiration for knowledge and desire for having the possibility to act freely and resolutely. Therefore, they attributed a much stronger mechanical and systematic influence to forces of supply and demand, than was the case in real life, and proposed laws, concerning profits and wages, which turned out to be invalid even for England in their own time ( $p$. 197).

This sounds extremely topical if one replaces England by the United States and Ricardo by the modern monetarists, who borrowed from Ricardo and his followers the «imposition» of their own institutions on other countries, the neglect of «the worker's point of view», the clear overvaluation of the «forces of supply and demand», and the promotion of «ineffective laws» on profit and wages (ineffective even in England at that time!). 
The reader is left in no doubt about the obvious contrast between how Marshall characterises the psyche of the English nation and how he evaluates English economists of the first third of the $19^{\text {th }}$ century. Whereas «the individualist» psyche of the English, in his opinion, is incomparably superior to the «tribal» psyche of German and other nations of Central Europe as the driving force of economic development, the concepts of English economists of this period were weak, on the one hand, in their narrow outlook and superficial practicality, and, on the other hand, in their abstract doctrine. It turns out that economic theory suffers, when it falls under the direct influence of the national psyche, even one, which has proved its efficiency in economic practice. (This leaves much to reflect on for many modern American economists.)

Marshall drew his conclusions in the late $19^{\text {th }}$ and early $20^{\text {th }}$ centuries, when England still maintained its economic superiority. However, already in the beginning of the $20^{\text {th }}$ century, it became clear that features of the German national psychology, such as adherence to traditions, order, and submission to discipline had allowed Germany to catch up with England economically, and then surpass it.

Thus, Marshall, who criticised English economists and Ricardo for exaggerating the role of individualism and market competition in economic development, himself became a prisoner of this defective approach, in explaining the success of England and its superiority over other countries.

A comparison of the history of England and Germany shows that Marshall was right to note the individualism of the English and the sociality of the Germans. However, neither of these factors caused the rapid rise initially of England, and then Germany. The real reason was the concentration of the unprecedented innovative potential of the human psyche at first in England and then in Germany; in the latter it grew out of the unification of the country and the state's vigorous activities in developing education, science, and business.

It is useful to compare the views of the authoritative English writer and publicist John Priestley (1894-1984) with Marshall's views on the specificity of the national psyche. In his essays, «America: The Dream and the Reality» (1967) and «The English» (1973), Priestley stated his own observations on the distinctions of the national psyche between the English, on the one hand, and Americans and some nations of 
continental Europe, on the other hand. ${ }^{145}$ From Marshall's statements mentioned above, based on the paramount value of the fact that England was formed from the strongest representatives of different nations of continental Europe in understanding the psyche of the English, one could draw the conclusion that the psyche of the American «immigrant» nation (the United States) is close to the English psyche. However, Priestley came to the opposite conclusion.

At first Priestley wrote about the Americans that one has to admire such vigorous, healthy, and reasonable people. However, later he wrote that Americans do not seem to be real people in the same way that the Chinese do not seem to be real people. However, since they speak and look like people rather than porcelain or shiny statues, he considered them as something like ideal robots. He wrote that he could not see live personalities in them. He thought it appropriate that it was the Americans who established behaviourism, the theory, in which consciousness is abolished and the human being is explained through his behaviour - reactions and stimulus. He wrote that to him Americans seemed to be the same. He found it hard to believe that they also were allocated a consciousness and that their brain worked unceasingly and furtively. He wrote that he cannot imagine how they can consider themselves as persons (p. 154).

Thus, Priestley compares Americans to robots programmed to behave in a certain way, depending on transmitted signals (stimuli). These robots lack independence, «personalities», and «consciousness». ${ }^{146}$ Such an interpretation is close to cognitivism (which, unlike behaviourism, having studied only signals and reactions, tries to explain how programs that control a person's behaviour are formed in the brain). Americans are distinguished from the English by their straightforward responsiveness and uniformity in behaviour. The psyche of the English, as well as of other West Europeans, «is more individualised» and inert, in the sense that it

145 John Boynton Priestley, "Margin notes", Moscow, "Progress", 1988. Further, links to pages (after quotations) refer to this edition.

${ }^{146}$ While Priestley is, to a certain extent, right concerning Americans, he is not justified in comparing them with the Chinese. The behaviour of the Chinese can be explained by deeply rooted traditions, whereas Americans are characterised by a weakness in traditions and strength in their "standard" of pragmatism. 
reacts more weakly to external stimuli, and allows a person to lead his internal life to a greater degree. However, according to Priestley, even among the nations of Western Europe, the English are obviously distinguished by their aversion for strict rationalism. In his essay, «The English», Priestley, set himself the task of coming as close as possible to the essence of the English. He wrote that it was necessary to go deep into their mind and this justified asking for the assistance (at least for a while) of a psychologist, specialising in studying the depths of the human soul - however, he made it clear that he needed Jung's help rather than Freud's. It seemed to him that inside the soul of an Englishman the border between consciousness and subconsciousness had been washed away, was weak, and not at all clear - so that at times it was not possible to distinguish them, as if they were two neighbouring counties with an indistinct border. According to Priestley, in England people rely more on intuition than in other countries of Western Europe. He did not consider the English to be reckless, however, at the same time, he wrote that they are seldom judicious; they were almost always distrustful of precise, rational judgments, and preferred judgments to be left unfinished. Priestley wrote that essentially the English do not permit their mind to go where it wishes, and resolve all complex issues by subjugating their mind to their intuition. Priestley wrote that he did not mean to imply that the English were better or worse than other Europeans, simply different - and this has been noticed by many foreigners (pp. 378-379).

Priestley did not see the specificity of the national psyche of the English in the same features as Marshall: not in individualism, willpower, or intellect, but in the special character of the interaction between consciousness and subconsciousness, i.e. in the structure of the psyche. According to Priestley, this specific structure of the psyche led to the special flexibility that existed in the social institutions in England. Priestley uses examples from the political, legal, and social-class history of institutions in England; however, this can also be applied to economic institutions. Their psyche, in which experience and intuition prevail over the «rational judgments», has allowed the English to learn from the English revolution of the $17^{\text {th }}$ century and overcome conflicts in an evolutionary way through compromises and reforms. 
Priestley felt that the Spanish-American philosopher, George Santayana, came closest to solving the riddle of the English spirit, when he wrote that the English are governed by «their internal atmosphere», which is «the weather» of their soul. He also wrote that the English establish in themselves a certain content and balance, and this bastion of «correctness» effortlessly examines all values arising on their moral horizon (p. 392).

Here, they underline the thesis that I arrived at above: psychic balance is an essential criterion for an individual to exist in his optimal condition; this happens to be true not only in relation to the English. However, the English are inclined towards a balanced state to a greater extent than other Europeans. Priestley wrote that neither he (nor anyone else, in his opinion) knew how the English had found this spirit. He considered that perhaps Celts, Saxons, and Danes, played some role in this (but not the conquerors - the Normans, whom he argued had adapted to the English, just like all the conquerors before and after them) (p. 393).

Did the psyche of the English nation really offer the economic advantages about which Marshall wrote? Priestley was not sure if this was the case. He wrote that many foreigners consider the English to be extremely practical, especially in comparison to other nations. Priestley strongly disagreed with this. He conceded that the English understand business better and are more sober than many people/nations from Egypt to Tahiti. However, he felt that the most practical nations were the French, the Dutch, the Swiss, the Germans, and the Swedes. He argued that this myth probably arose at the end of the 18th century and at the beginning of the 19th century, and gained strength with the success of «the industrial revolution». It may seem that those who control such markets will necessarily be considered practical. However, one cannot apply this to the nation, on the whole. Napoleon made exactly the same mistake, when he called the English a nation of «shopkeepers». According to Priestley, this was not the case; it would have been much easier for the English if they conducted both small and large-scale trade better. Priestley goes on to state that the French, in his opinion, were reminiscent of brainy shopkeepers both in appearance and mentality. Priestley considered that the best among the English have created and invented, and the worst among them have used and traded the fruits of their creation (p. 381). 
Note that Priestley divides the English into the «best» and the «worst»; the former are creatively inclined people and the latter practical traders. If one ignores Priestley's emotional arguments, it is clear that Priestley was convinced that the primary source of the successful development of England in the $19^{\text {th }}$ century was provided by the activity of creative types of people, whereas traders abounded both in France and other European countries.

It was not the individualism and trading talents of the English, or the sociality and organisation of the Germans that allowed first England and then Germany to make rapid progress in economic development; in these countries, it was the existence of a sufficient number of highly creative, innovatively oriented people, living in conditions that allowed them to use their talents, which generated «the industrial miracle» first in England, and then in Germany. Here, the author, Priestley, is closer to the truth than the economist, Marshall.

Priestley noted that the evolutionary (conciliatory) model of development of England led to the formation of a widely decentralised system of organisation of society in the political and legal spheres. A complex estate (but not «caste») formed the social basis of this «network» of the organisation of society, corresponding to the psyche of the English, who preferred a narrow circle of daily contact and closed groups, clubs, and communities. Priestley recognised that after the Second World War the divisiveness of the English estate system caused more harm to the development of the English economy than the loss of their empire.

Below, I have summarised some of Priestley's ideas on the English estate system. For the uninitiated, the English estate-network system is difficult to understand. A foreigner will only begin to distinguish amongst the estates after having lived in England for many years. As England ruthlessly (and, in Priestley's time, successfully) began to be restricted by other industrial countries, its estate stratification, together with its surviving aristocratic traditions, seriously hampered rapid development. Priestley partly blamed it for the lethargy that set in and considered its consequences to be much more significant than the loss of the British Empire. Unlike others, he did not think that the estate system was imposed from above, from the duke downwards. He felt that this system was natural for the majority of the English and an integral part of the English spirit. If the nobility had suddenly disappeared, stratification would have remained; it would even have 
become more marked amongst simple people. He felt that supporters of democracy failed to appreciate that the majority of the population in England preferred the estate system to the introduction of an egalitarian society. He wrote that it is harmful for almost everyone when the customary stratification is sharply replaced by another form of stratification, which is usually connected with wealth, success in business, and monetary power. The majority of the people were not tormented by ambition and fame. Even if this attitude did not promote industrial development, Priestley noted that people were on the whole happy with their lives. The example of post-war England shows that satisfaction with life and economic progress do not always go hand in hand.

\subsection{Capitalistic and Non-Capitalistic Nationalities $-\mathbf{W}$. Sombart}

In chapter 16 («The Predisposition of Separate Nationalities»), in his book, «The Bourgeois», Sombart raises the following question: «How should we now - purely biologically - imagine the origin of these equally or diversely distributed capitalist variants?» (This is in reference to variants of «proportions of the mixture of different components of the capitalist spirit» (pp. 233, 234). $)^{147}$

He answers: «One can exclude the possibility that the predisposition to the capitalist spirit was acquired through the course of history, i.e., that the training in capitalism eventually entered the blood stream and caused changes in the organism. Such a hypothesis contradicts the accepted fact that nothing can be trained, for which earlier there was no «predisposition».» He continues: «Thus, we are forced to accept the initial assumption, or we could call it the predisposition of nationalities (p. 234).» «Some of the tribes or nationalities, forming the European family, possess a higher than average predisposition to capitalism and others, a lower than average level. However, even those people who possess a below average level, also embody capitalist variants (we assume this, as there are no

147 Sombart, "The Bourgeois", published by "Misl", 2005; Further in the text, the pages shown in brackets refer to this edition. 
nationalities, in whom the capitalist spirit could not be developed at all), however, to such a small extent and with such an insignificant strength of the predisposition that the development of the capitalist spirit is blocked by the first obstacles that it encounters. The people possessing an above average capitalistic predisposition, embody numerous and strong capitalist variants and, all other things being equal, the capitalist spirit develops faster and deeper in them ( $\mathrm{p}$. 234).»

Further, Sombart classifies nations according to their natural predisposition to the spirit of capitalism. «I rank the Celts and some German tribes, for example, the Goths, among the nations with a weak capitalistic predisposition (it is completely unacceptable to consider German nations as essentially possessing the same predisposition .... I do not know of a greater distinction in the predisposition to capitalism, than, for example, between the Goths, Langobards, and Frisians) (p. 235).»

Sombart believes that descendants of the ancient population of Western Europe, the Celts, to the extent that they remained or emigrated to America, have proven themselves to be unsuitable for economic activities. Thus, the descendants of the Celts, the Irish, are not suitable for entrepreneurial activities and are not profit driven, and even after arriving in the United States, «aspire to escape to the safety of any state service that they can find» (p. 235). Sombart also explains the French national soul's propensity to pursue administrative posts as a consequence of their «Celtic blood». (The Celts, living on territory bordering modern France, were called Gauls).

Descendants of the Celts in the Pyrenees, the Iberians, made up a considerable part of the populations of Spain and Portugal and together with the Westgoths, fighting against them, they subsequently prevented the expansion of the capitalist spirit to these countries (which was being spread in this region by the Moslems and Jews).

Sombart pays considerable attention the European nations with strong capitalist predispositions. He divides these nations into two groups: «those people particularly inclined to violence and robbery on a large scale, and, those, who were peaceful traders and who also had 
... a propensity towards petty-bourgoisness. I will name the first group, heroes, and the second, traders (p. 236).»148

Sombart primarily relates the Romans and their descendants in Italy, Spain, Gaul, and Western Germany, where they make up a significant part of the national population, to the «heroic nations». Their commercial activity is based on violence and on the idea that economic success should also be won by force. «The Romans were then joined by some of the German tribes, who were clearly motivated by the same spirit: these were primarily the Normans, Langobards, Saxons, and Francs. The Venetians, Genoese, English, and Germans owe their predatory and landowning entrepreneurship to them (if not to the Romans) (p. 237).»

Sombart considers the Florentines, Scots, Jews, Dutch, and the Swiss as «nations of traders». They have the ability to benefit from the peaceful conclusion of contracts, written in their favour or transferred from generation to generation of skilful calculations ( $p$. 237).

This ability was transferred to the Florentines from their Etruscan and Greek ancestors and from the natives of Western Asia.

The Scots and Dutch inherited their trading instincts from the German tribes of Frisia. (Thus, the English inherited heroic, i.e., predatory inclinations from their Roman-Saxon-Norman ancestors, and the inhabitants of lower Scotland inherited their trading instincts from their Frisian ancestors. Note that the inhabitants of the mountainous part of Scotland are descendants of the Celts and consequently Sombart does not consider them to be inclined to capitalism.

${ }^{148}$ Here, Sombart argues against supporters of the idea of the equality of people and nations: "That these contrasts were not of "a social nature" as it is assumed without verification in all similar cases by fanatics of "the environment" (no distinctions should be rooted in blood, otherwise it will be impossible to fulfil in the future the beloved ideal of equality), can be seen from the history of these people [p.236]." Here, Sombart clearly mixes the concept of "equality" with the concept of "similarity". Some people can surpass others in some natural qualities, but yield to them in others. Thus, the idea of equality does not exclude differences, including natural differences. Besides, superiority in "robbery" does not bring honour (in terms of Christian ethics). 
According to Sombart, the Swiss are descendants of the German Alemanni tribes, who were traditionally traders.

«However, the primary predisposition is, of course, only a starting point from which biological development originates. It is well-known that with each generation, people's (nations') inclinations change, as each generation is constantly exposed to the two forces of conversion: selection and the intermingling of different blood lines (p. 239).»

«In trader nations, the process of selecting the most viable variants, i.e., those possessing the best trading abilities, is carried out quickly and thoroughly (p. 239).»

«Amongst other nations (people), the selection of different versions of capitalism is carried out just as inevitably, but at a slower pace. It appears to take place in two steps. At first, non-capitalistic versions are removed; then, from the capitalist versions, trading variants are selected. This selection process is perfected as the most capable people from the lower class become (capitalistic) industrialists. Since these people, originating from the vocational and lower classes, could supersede others as a result of their skills in trading and other spheres of the economy (pp. 239-240).»

«In the same way as selection, the intermingling of blood lines, which began in the Middle Ages and, from the $16^{\text {th }}$ century onwards in countries such as France and England, was given increasing importance. This was based on the assumption that the crossing of aristocratic and bourgeois blood lines benefitted the latter (p. 240).»)

«... Each additional capitalist version, by its occurrence, necessarily strengthened the capitalist spirit (p. 240).»

«The representation of the nature and origins of the bourgeois are as follows: the basis of all development, which we should consider eternal and original, is unique in terms of its separate members and the structure of its group of nations, which has created the European culture since the fall of the Roman Empire. In these people, we find the origin of two powerful motivational forces: the thirst for gold and the spirit of enterprise, which quickly merge together. From this unification, powerful economic and other organisations are formed, as well as, the modern state and together with it an important way of spreading the capitalist spirit: heresy, whose precondition, however, is another basic feature of the European national soul - a strong religious requirement (pp. 243-244).» 
Thus, according to Sombart, three «fundamental» requirements are initially characteristic of the «European national soul»: gold, entrepreneurship, and religion.

Sombart assumes the following stages in the development of the capitalist spirit. " .... If the entrepreneurial spirit appeared at the beginning of its activity mainly among the upper classes and as a result was associated with violent methods, over the course of time, in wider national layers, there was an aspiration to earn money in some other way through economic enterprises: without the use of force, through the negotiation of peaceful agreements. Here, there is an understanding that in this undertaking the economic spirit, which is based on savings and keeping accounts, can play a significant role.

While this petty-bourgeois trading system and trying to live through peaceful means was gradually accepted by all nations, there were some tribes, in which this general spirit developed quickly from the very beginning. These were the Etruscan, Frisian and Jewish tribes, whose influence increased rapidly, especially as the type of the spiritual structure of the capitalist industrialist changed and moved closer to the petty-bourgeois trading structure.

While, initially, the various currents flowed by one another, at a later stage they merged into one another: the hero, the dealer, and the petty bourgeois merged into the capitalist entrepreneur. However, the further the stream flowed down the valley, the more it acquired the aspects of the petty-bourgeois trader, while the heroic aspect disappeared. This happened due to a number of reasons: the development of a professional army; the authority of moral forces, particularly, religions, which supported the peaceful petty bourgeois and, not least, the intermingling of blood lines, which led to the prevalence of the shopkeepers' blood. In general, heroism is inherent only in a small minority and in order to turn it into a generality it needs to be based on the instincts and abilities inherent in the masses (p. 244).» Sombart quite justifiably raised the problem of the historical interrelation of large economic events of the bourgeois nations with military violence and direct robbery. I note that the book «Bourgeois» was published in 1913, a year prior to the beginning of the First World War, and in the decades preceding it, there were numerous colonial wars and takeovers by force. It was considered self-evident that military violence was the only way to resolve conflicts of the market capitalist economy. At the same time, some believed that the given 
historical, i.e., transitory, form of economic relations generates international military aggression; while others attributed the eagerness of nations to wage war to the aggressive genetic nature of people in general, regardless of the forms of economic relations.

Sombart poses the question differently. Firstly, according to Sombart, the spirit of military robbery existed long before the existence of capitalism, in the conditions of the tribal system, and it became an essential component of capitalism. Secondly, not all tribes were predatory in «spirit» (or, in other words, made up of «heroic people»). As a result, Sombart divides the people of the epoch of capitalism, the genetic successors of ancient tribes and people, into three different types of groups: those that used military strength for the resolution of economic problems; those who solved these problems by peaceful negotiations and trade; and those who did not take part in capitalist development.

However, Sombart does not explain why the predatory «spirit» is present in some tribes (and their successors) and absent in others. He merely ascertains this as a historic fact and states that it is not possible to develop something for which there is no «predisposition» (i.e., genetic roots).

I will try to clarify the problem of the link between the economy and military force in intertribal and international relations, proceeding from those concepts of the structure of the psyche of an individual and society, which have been stated in the previous chapters.

The aggression instinct is peculiar to people, it is transferred genetically from the ancestors of the modern human being. This instinct is inherent also in most types of animals. However, even the most violent predators - lions, tigers, wolves, etc. - only in rare instances use their canines and claws in an intra-species fight. Cases of intra-species conflicts, leading to serious injuries or death among primates are especially rare. This implies that nature and natural evolution has excluded the instinct of aggression as a defining factor of the intra-species behaviour of animals.

At the same time, archaeological and ethnographic evidence is available, indicating that the entire epoch of the tribal system was a period of almost continuous and bloody intertribal wars. How does one explain this, if one recognises that the natural instinct of aggression cannot be considered as a factor defining the behaviour of 
the overwhelming majority of people, and that economic intertribal conflicts (over territory) could be resolved peacefully?

Communities of people, since the time of nomadic groups, kin, and tribes always consisted of individuals belonging to different psychogenetic types. If the head of even one kin or tribe turned out to be a strong individual with a psyche dominated by the instinct of aggression, it inevitably caused a chain reaction in the neighbouring clans and tribes. The self-preservation instinct demanded strong, aggressive individuals as leaders of such communities. Consequently, clans and tribes became aggressively oriented. Newly born children acquired aggressive-militant instincts in relation to people from other tribes.

Thus, the aggressive instinct and the potential capability to kill members of other tribes (who are similar to oneself) as a factor that steadily defined the behaviour of people in intertribal and international conflicts, is not inborn (in the overwhelming majority of cases), it is an instilled instinct.

Why do aggressive individual animals, capable of killing similar types of animals, always remain in the minority, why have ethologists not observed bloody fights between prides of lions, herds of elephants, and herds of sharks of the same type, and why are there no known instances of one pack of wolves fighting to the death with another?

This is probably due to the fact that our ancestors from the very beginning differed from animals and from other primates by their immeasurably greater ability to learn. Consequently, the role of instilled instincts in the behaviour of the ancestors of modern man was always qualitatively different in comparison to animals. An aggressive upbringing early in life and an orientation against other tribes (and subsequently nations) gave way to a natural instinct of aggression.

Different tribes (and subsequently nations) possessed sharply different levels of aggressive militancy and force, therefore, the role of military force in their economies varied significantly. This was reflected in Sombart's concept. However, I believe that he overestimates the role of genetics in dividing nations into those that possess the predatory, trading-petty-bourgeois, or a non-capitalistic spirit, and underestimates the role of upbringing and traditions. After all, a spirit of militancy in the masses can be instilled not only through the support of the natural instinct of aggression, but also through the natural instincts of self-preservation, appropriation, competition, etc. 
On the other hand, the instinct of aggression can be restricted and channelled to a non-aggressive area.

Nevertheless, even if the genetic factor did not play a role of crucial importance in the definition of the specificity of the economic development of individual nations, its influence should not be ignored. In the course of a long evolutionary process, even a secondary but constantly present factor can fundamentally influence its development.

$$
* * *
$$

In the light of the typological structure of society offered in this book, how can one characterise those comparisons of the national psyche, which are considered by the authors in this chapter?

Marshall distinguishes three criteria: the level of capabilities, orientation on individualism or on the community, and orientation on innovation (development). Moreover, he believes that there is a link between the high level of abilities of a nation, its orientation to individualism, and its innovative qualities: a «capable» nation is focused on individualism and innovation.

Note that Pareto puts forward roughly the same criteria, with the basic difference that he does not refer to the nation as a whole, but to its ruling elite. If a nation is led by a «scheming and manipulative» elite, it focuses the nation on individualism and development; whereas, a conservative elite focuses the nation on traditional social values and economic stagnation. At the same time, Pareto does not divide nations into those that are inclined naturally to «scheming and manipulation» or to conservatism. Which elite group is in power, depends on its ability to organise its members, free itself of those, who are not useful to the group, and attract new capable members from outside the elite. In other words, those nations that are led by such a «scheming and manipulative» elite party, which is capable of continuously renewing itself, are the ones that prosper over the longterm.

Pareto's concept is on the whole supported by Priestley, who, based on historical material, has shown that the ability of the ruling elite of England to renew themselves in the $18^{\text {th }}$ and $19^{\text {th }}$ centuries was the main condition of England's successful development. At the same time, the strongly pronounced individualism of the English caused excessive social fragmentation between the estates of its society, 
which, according to Priestley, slowed down the economic development of England in the $20^{\text {th }}$ century.

Sombart does not operate on the basis of «elite» and «non-elite»; he relates the characteristics «heroic» («predatory»), «shopkeeper», and «non-capitalistic» to separate ethnic communities («tribes», «nationalities», «nations») as a whole. In his conception the ethnos, making up the initial basis of modern nations, had different types of psyche and, in varying degrees, this was probably the case.

It is important to note that when Sombart wrote that some Germans were «heroic robbers», he meant «robbers and organisers of the economy»; and, when he wrote about other Germans as «shopkeepers», he was referring to their aspiration and ability to create capital through peaceful trading and money-lending. However, they are both united by their thirst for gold and their aspiration and ability to accumulate wealth in different forms (primarily, in monetary form).

From Sombart's argumentation, one can make an important conclusion, which Sombart himself did not make. The basic distinction (from the point of view of economic psychology) between the native people of Western Europe, the Celts and Iberians, on the one hand, and the Romans and Germans, on the other hand, does not consist in the fact that the former were not inclined to trade and develop market relations, and the latter were. The fundamental difference between the types of their psyche consisted of the fact that the former were not afflicted with a thirst for gold and enrichment, and the latter were.

The fact that the markets existed and developed for centuries among the Celts, without generating capitalism (in its primitive forms), and were subordinated and partially destroyed only after the invasion of the Romans followed by the Germans, by the conquerors' thirst for gold and other riches, fully corresponds to Fernand Braudel's concept mentioned above, about the qualitative distinction between local, national and world markets. 


\subsection{Modern National Models of the Economy in the West - the Psychological Aspect}

The Rhine model against the Texan model. In his book, «Capitalism against Capitalism»" ${ }^{149}$, the modern French economist, Michel Albert, analyses various development models and explains the basic distinctions within the group of industrially-developed countries. He selects two extreme, mutually contrasting, models, the Rhine and new American (or Texan) models. The Rhine model relates to postwar Germany, Austria, and Switzerland, and the Texan model relates to the United States (since the 1980s). The models of other industrial countries fit in between these two extreme versions. Thus, the Scandinavian countries, Holland, and Japan are clearly closer to the Rhine model, and England (since the 1980s), to the new American model. Albert considers that this distribution is dynamic, and since the end of the 1980s, a number of countries that had previously been closer to the Rhine model started to move towards the new American model (Sweden, France, Spain, and some other countries).

The following question is the basic issue addressed by Albert: why is the Rhine model, which is superior to the new American model in terms of economic and social efficiency, being forced to concede its position? Albert's answer, that it is due to aggressive advertising and dexterous economic policy, is partial and superficial. This was because the empirical and descriptive methodology, which allowed him to convincingly raise the problem, turned out to be insufficient to solve it. Albert begins with the formulation of ten practical problems, which are evaluated and solved in fundamentally different ways in the two models mentioned above (see Table 10.1).

149 Michel Albert, "Capitalism against Capitalism", SPB, "Economic School”, 1999. 


\begin{tabular}{|c|c|c|}
\hline Problem & Rhine model & New American model \\
\hline $\begin{array}{l}\text { 1. Relations to } \\
\text { immigration }\end{array}$ & Negative & Positive \\
\hline $\begin{array}{l}\text { 2. Understanding of } \\
\text { poverty }\end{array}$ & As a social phenomenon & $\begin{array}{c}\text { As a personal problem } \\
\text { of the poor }\end{array}$ \\
\hline $\begin{array}{l}\text { 3. Social security and } \\
\text { development }\end{array}$ & $\begin{array}{l}\text { The former promotes the } \\
\text { latter }\end{array}$ & $\begin{array}{l}\text { The former hinders the } \\
\text { latter }\end{array}$ \\
\hline $\begin{array}{l}\text { 4. Differences in } \\
\text { salaries }\end{array}$ & Need to be limited & Need to be increased \\
\hline $\begin{array}{l}\text { 5. Taxes should } \\
\text { stimulate }\end{array}$ & Savings & Debt \\
\hline $\begin{array}{l}\text { 6. State regulation or } \\
\text { court regulation }\end{array}$ & State regulation & Court regulation \\
\hline 7. Bank or exchange & Bank & Exchange \\
\hline $\begin{array}{l}\text { 8. Who controls firms: } \\
\text { shareholders or } \\
\text { management and staff }\end{array}$ & Management with staff & Shareholders \\
\hline $\begin{array}{l}9 . \text { The role of the } \\
\text { enterprise in training staff }\end{array}$ & Main & Minimal \\
\hline 10. Insurance & $\begin{array}{l}\text { General protection for } \\
\text { the future }\end{array}$ & Market activity \\
\hline
\end{tabular}

\section{Table 10.1}

The fact that the Rhine model is economically more effective is testified by its higher income levels with lower labour costs and the international rating of the competitiveness of Germany. The extremely low incidence of strikes and relatively even distribution of incomes testifies to its social stability. The Rhine model is focused on the longterm and on the future, as can be seen from the high level of savings of the population, and investments in education and innovation.

The new American model, in contrast, is focused on the short-term financial effect and quick ways of enrichment, it allows for frequent changes of ownership of enterprises, and firms aspire to minimise costs at any cost; consequently, relations in the work place are harsh, and there is great inequality and social tension in society.

Relations between the two models are characterised by the fact that the United States systematically uses a significant part of the savings accumulated by the populations of Western Europe and Japan for its own development. Control of large American industrial firms is increasingly more often being transferred to German and Japanese 
corporations. However, at the same time, the United States continuously proclaims the supposed superiority of its system.

After the publication of Albert's book, in the first decade of the $21^{\text {st }}$ century, it has been discovered that in many areas this superiority is not so imaginary. For example, in computer science, space, biotechnologies, audio-video production, etc., the American model is extremely flexible, universal, fast, capturing the newly opening global high technology markets and placing itself in the service, and organising the intellectual and material resources of many countries. In this way, the United States was able to significantly improve its employment rate, whereas in Europe employment levels decreased.

On the whole, Albert has accurately and convincingly depicted the features and contrasting tendencies of the two basic social and economic models of modern developed capitalism. In order to estimate the prospects of this confrontation, one needs to define the depth of its historical roots, and how the modern processes of globalisation are capable of affecting it.

Let us begin with the fact that although the factors that have led to the formation of the two models are connected by a chain of historical causality, nonetheless, they are different. Albert notes that the sources of the Rhine model go back to events that took place at the end of the $19^{\text {th }}$ century - to the social laws of Bismarck, the encyclical issued by the Pope, «Rerum Novarum» (Of New Things), and the activities of social democracy. This concerns the development of the spirit of social responsibility, social cooperation, and social peace. However, how does one explain the victory of a similar spirit in Japan? Here, Albert offers a different explanation: defeat in war forced the people of Germany and Japan to transfer their energy to creative purposes. In other words, certain preconditions for the Rhine model arose prior to the First World War, but it needed the catastrophic defeat suffered in the Second World War for this model to be implemented in Germany and partly in Japan.

However, Albert's position in explaining the sources of the new American model (which he considers was formed in the 1980s) with the economic policies of Margaret Thatcher and Ronald Reagan is less clear. Up to this point, all developed capitalist countries, despite the significant distinctions between them, on the whole, were following the Rhine model; however, the United States and Britain (to a lesser extent, though it started to change course slightly earlier) abruptly 
turned away from the course started by Roosevelt and continued by Kennedy. Albert does not offer a satisfactory explanation of this about turn, but notes the following factors in relation to the United States' change in direction:

1. Strengthening of the heterogeneity and cultural dissociation of the ethnic structure of the American population after the Second World War, and a weakening of its aspiration to social solidarity and responsibility;

2. The intensification of the Cold War with the USSR and fear of making concessions to socialism; since 1989, the fall of communism, which struck a severe blow to social democracy;

3. The appearance of a new generation of financiers and managers («the golden boys»), aspiring to quick enrichment and success in the corporate ladder;

4. The possibility of parasitising on the savings of the population of the countries following the Rhine model.

Having evaluated the future tendencies, Albert does not exclude the potential victory in Europe of the new American model over the Rhine model, with strongly negative consequences for the European countries. The main source of this danger lies in the position taken by the government of the European Union in Brussels, consisting in encouraging member countries to compete among themselves by reducing social expenses, restricting the rights of trade unions and employees at enterprises, weakening the links between banks and enterprises, and strengthening the role of stock exchanges. Albert considers the strengthening of European social solidarity and responsibility (amongst all European countries) and the integration of positive elements of both models (as some multinational corporations have done) - as a viable alternative.

As evidence of the acute and open character of the stand-off between the two models, Albert refers to the protest against the 
Americanisation of Germany that took place in Bonn in 1990, in which 300,000 people took part. The mass protests in Britain were also caused by the harsh social policies adopted by the Thatcher government. However, in the United States, Reaganomics did not encounter significant resistance, and the attempts of the Clinton administration to strengthen the social security system failed. Why?

It seems that there are basic distinctions in the national psychology of the United States, on the one hand, and the West European countries, on the other hand.

Firstly, over the course of three centuries, most of the people who emigrated to the United States possessed strongly pronounced inborn instincts of individualism, and had felt chained by the formal and informal regulations of Europe.

Secondly, over a period of 150 years, the nation's psychology was formed under the influence of «frontier borders», which were almost continuously extended as a result of the semi-spontaneous guerrilla war (aggression) in the «Wild West» and the Mexican South.

The ideal American is an aggressive (but magnanimous) individualist, practicing a cult of personal strength (moral, physical, and financial) and haughtily looking down on weakness as inferiority.

For such a nation, the Texan model (this is the more correct of the two terms used by Albert) is a fully adequate form of displaying the inborn and instilled instincts, prevalent in the American national character. As far as elements of the Rhine model (which had been introduced in the United States in the 1930s-1970s) are concerned, the Americans had been forced to accept their limited introduction under the pressure of internal and external circumstances, and partially withdrew them as soon as circumstances improved.

In the national psychology of West European countries and Japan, the inborn and instilled instincts of individualism are, in general, in relative balance with the instincts of sociality. This is predetermined by the more or less homogeneous and constant ethnic structure of the population of each of these countries and by their common twothousand-year history. In all essential features (the social market in Germany, the social partnership in Austria and Holland, the welfare state in Sweden, the clan economies in Japan and Italy, the half dirigisme in France, etc.), the national models of these countries tend towards the Rhine model with its social solidarity, responsibility, and defence within national borders. 
National models in Western Europe. At the same time, within Western Europe throughout the post-war period, despite all the changes, there remain fundamental distinctions between national economic models. ${ }^{150}$ They concern the degree and character of the state's participation in the economy, taxation systems, social security, regulation of relations between labour and capital, ownership structure, the relations between owners, managers and employees of enterprises, etc.

As a result of the integrational activities of the EU, its members managed to make significant progress in unifying the separate important elements of their economic systems - the replacement of their national currencies by the euro and the foundation of the European Central bank. Previously, foreign trade barriers for EU countries had been unified and, within the EU, duties, quotas and other obstacles for the free movement of labour, capital, and goods and services had been cancelled.

However, this unification does not fundamentally concern the existence of national social and economic models, but the conditions in which they function. Rapprochement and convergence of the models is taking place, but extremely slowly and inconsistently; the EU clearly would prefer to move ahead by strengthening the coordination between the national models and maintaining autonomy, rather than by way of unification and centralisation.

It is important to note that the unification of national models would not guarantee identical results in production, consumption, employment, etc.; on the contrary, it is more likely to deepen the ruptures already existing amongst the countries; in contrast, preserving the original national models in practice promotes the gradual (although, slow) overcoming of inequality. Therefore, for the EU, the development and gradual implementation of a system acceptable to all countries of the Union, in terms of social and economic policies - full employment, increased prosperity, steady growth, social justice, social stability, etc. - are urgent priorities.

${ }^{150}$ These distinctions are investigated in detail in the collection, "The West European Models of Social and Economic Development", edited by V.P. Gutnik, the Russian Academy of Sciences, Institute of World Economy and International Relations, M., 2000. 
They are not interested in creating a unified or centralised social and economic model, applicable to all countries. I think that in the foreseeable future it would not be feasible to implement such a centralised system, as the distinctions in the national psychologies, cultures, and historical experience of the nations included in the EU are too deep. As an example, I will compare some of the institutional foundations of the social and economic models in post-war Germany and France.

In both these countries, the bases of social order and the national psyche had been shaken and destroyed by the Second World War; however, in different ways. The centralised German state and the system of industrial cartels closely connected with it, which within a quarter of a century had caused two world wars, had fundamentally discredited themselves. In order to prevent revanchism, the post-war German economic model was built on the basis of the deliberate negation of German centralism and cartelism, and on the equally conscious or, perhaps, compulsory, introduction of a new social and economic system of principles of economic freedom, decentralisation, the greatest possible restriction of the role of the state, and a restriction of the frameworks of cartelism. The old German principle that «order is more important than freedom» (Goethe) was replaced by the new principle of «freedom through order» (Walter Eucken), or more precisely, «freedom through democratic order».

It is important to note that the post-war German social and economic model, «the social market economy», was not in the least a product of spontaneous self-development; moreover, it was also not a product of only one pragmatic experiment. This model was originally developed theoretically by the ordoliberals Walter Eucken and Franz Böhm, the neoliberals Willem Röpke and Alexander Rüstow, and the social liberals (social-Catholics) Alfred Müller-Armack, and others. ${ }^{151}$ Later, important elements of the social democratic concept were included in this model of a "third way».

Thus, the social market economy is primarily a system of new rules of law, originating with the acceptance by the German nation, amidst the ruins of the third Reich, of a new system of values. Certainly, these rules of law and values were supported by many elements of habitual behaviour that had been preserved. According to V. Gutnik,

${ }^{151}$ In the same place, p. 28. 
the social market economy model «united in itself elements of Protestant ethics, the social Catholic doctrine, the so-called Prussian socialism, ideas from the Enlightenment, romanticism, rational criticism, and individualistic liberalism. These sources of the present model are, in essence, not simply historical roots. They are also factors - even if not defining ones - of the current socioeconomic life of the German nation. At the same time, the mentality of the German people is defined by its diligence, love of order, and thrift». ${ }^{152}$ I believe that one can distinguish the following main institutional bases (including both newly introduced and traditional) of the German social market economy:

The principle of the economic freedom of the individual, implemented through free competition (by powerful state support of small and mid-sized businesses, small property ownership of all kinds, the rigid restriction of cartels, and openness to foreign economies);

The principle of legal economic order, reached by the detailed development of the law and its strict enforcement;

The principle of high employment, high salaries, and a high share of savings from incomes;

The principle of social justice and stability, provided through the maintenance of a free market, the state support of weak groups, the real participation of employees in management through advisory and supervisory boards, and a system of independent tariffs;

${ }^{152}$ In the same place, p. 77. 
The decentralisation principle (federalism and subsidisation) in the participation of the state in the economy;

The principle of economic efficiency and the technogenic development of the economy, realised primarily through the support of the corresponding activity of large and small enterprises (in the field of innovation, decreased costs, and professional training), and also special programs.

The theory of the social market economy proved (and 50 years of practice has on the whole confirmed this) that these principles, in general, do not contradict each other. In the areas where these principles partially conflicted with each other, priority was given to the principles of efficiency and technogenic development; other elements of the system were obliged to be transformed, without losing their institutional content.

One of the criticisms of this model is connected with the relatively high level of wages proposed, which do not leave businessmen with sufficient means for modernising enterprises and for investment. However, the same wage level allows the population to maintain a relatively high level of savings, which through savings banks and other financial institutions are deposited in banks and offered to the same investors for domestic and foreign investment. Certainly, this partly limits the freedom of action of the businessmen and places them under the control of banks which, thus, obtain a key position in this model. The system as a whole becomes less flexible and reactive, but more reliable and focused not on short-term but, on long-term, success.

Let us now address the institutional bases of the French social and economic model. War forced the French to revalue their belief in the strength of traditional patriotism and the unity of the nation. In France, the moral authority concerning conservative financial and industrial patronage, as well as the entire ruling elite, was always low, and during the war it became negative. At the same time, in France, unlike Germany, the traditional values and institutions of individual freedom 
and democratic statehood traditionally were preserved and did not need to be spread anew.

However, the traditional German adherence to order and organisation is not inherent in the French character. On the other hand, French officials had for a long time enjoyed authority and were considered effective and able to combine professional skill and severity within the frameworks of democratic legislation.

Thus, in order to overcome the national crisis (national dissent, loss of values, collapse, and chaos), the French, as the main support of the post-war social and economic system, had to use the centralised democratic state to directly regulate and direct the market and all other relations.

In France, the construction of a new national economic model was based on a solid theoretical basis in the form of the concept of dirigisme, which was developed primarily by French institutionalism, which in turn continued the traditions of solidarity. Francois Perroux's thinking - according to which the role of the state is predetermined by the necessity of the harmonisation of growth in conditions of the uneven allocation and dynamics of financial and industrial centres of strength in the market economy - had a significant influence in this process.

In the French social and economic model, for a period of about four decades, a defining role was played by the state system of «indicative planning», consisting in the development and implementation of intermediate-term national plans for the modernisation and development of the economy. "Indicative planning» was supported, on the one hand, by the extensive public sector, including big banks and key industry sectors (power, transport, metallurgy, part of the chemical industry, the motor industry and aircraft engineering, electronics, etc.), and, on the other hand, by the state support of those private enterprises, whose activities were guided by the plan's indicators.

The state regulated relations between trade unions and businessmen on a national scale, through a tripartite system; it introduced advisory bodies that participated in hiring personnel for the management (of social aspects) at the enterprises. The state created an extensive and reliable system of social insurance and security, supported by an equally developed system of state produced social services. 
While the interaction of the competitive and non-competitive institutions on the micro- and mesolevels is crucial to understanding the mechanism of the German social market economy, the decisive role in the understanding of the French dirigisme models, in our opinion, is played by the political mechanism for the acceptance and implementation of sociopolitical decisions. Strong, independent political parties with precisely defined programs of practical actions, and the active participation of trade unions and the majority of the population in mass demonstrations allowed them to reveal, in a democratic way, the real social and economic priorities of the nation and, on this basis, to develop and, at the right time, correct the «indicative plans».

Over the past 50 years, French dirigisme has undergone a deep transformation in terms of the weakening of centralised, and the strengthening of competitive-market, principles. The state sector has been reduced as a result of privatisation, «indicative plans» have been terminated, and attempts to limit the state system of social security and insurance have been undertaken. Nevertheless, the foundations of dirigiste models have still been maintained. The state's role in France's economy is still much stronger than in any other EU country, for which France is continuously exposed to criticism.

This criticism is based on the conception about the same ideal «Homo economicus», who, free of all kinds of state regulation, is capable of creating economic miracles. However, in Germany the economic miracle has not been created by the «Homo economicus», but by real Germans with their traditional inclination for order and self-organisation, and with their persistence, consistency, and scrupulous calculations. France has been almost as successful as Germany, however, as a result of different qualities - through democratic rallies and social solidarity, and through their ability to concentrate national resources in critical sectors. This has been made possible due to the traditional confidence of the French in their ability to supervise and direct state activities, and thus guarantee the preservation of their freedom.

The comparative analysis of national economic models, conducted by modern economists, confirms the conclusion made by Marshall and Sombart that the features of the national psyche, which have developed over centuries, are the important factor defining the 
institutional and organisational structure of its economy, its dynamism, and its efficiency. The most successful nations in terms of economic development were those nations, in whose psyche the primary role was played by the requirements and instincts of innovative activity. 


\section{Chapter 11}

\section{The Specificity of the National Psychology in Russia}

Despite all the ethnic variety of Russia, neither domestic nor foreign authors doubt the existence of a specific Russian national psyche. However, all of them underline its discrepancy, and sometimes its heterogeneity. I will try to find out how this specificity is manifested and connected with the correlation of the basic psychogenetic types in the population, with the historical distinctions in the psyche of the elite and non-elite, and how it influences the structure and functioning of the economic system. Obviously, in this chapter, as was the case in the previous one, I can only state the problem and suggest some hypotheses.

\subsection{History of the Country and the Contradiction in the National Psychology}

The writer, Ivan Bunin, in his diaries «Cursed Days» (1917-1918), representing essentially social-psychological research, noted: «There are two types in the people. In one the ancient Rus, and in the other Chuds and Merya, prevail. However, in both, there is extreme variability in moods, shapes, and «unsteadiness», as they used to say in olden times. The people have said about themselves: «from us, as from wood, both a cudgel and an icon can be formed» - depending on the circumstances of who processes this wood: Sergius of Radonezh or Emelka Pugachev». Bunin writes about the «awful carelessness inherent in us, our levity, our lack of habit and unwillingness to be serious during the most serious moments ... Light hearted, carefree, the whole of Russia even celebrated the beginning of the revolution $\ldots »{ }^{153}$. At another point he wrote: «Klyuchevsky notes the extreme

${ }^{153}$ I.A. Bunin, “Cursed Days”, M.: Soviet writer, 1990, pp. 62-63. 
repeatability of Russian history. To our great misfortune, nobody has paid the slightest attention to this repeatability. The liberation movement was created in an unbelievably light hearted manner, with excessive optimism ... «. ${ }^{154}$ Bunin writes about the psychology of the representatives of the liberation movement: «Herzen was a thousand times right: «We have deeply broken away from the existing ... We indulge in whims and do not wish to face reality, we constantly exasperate ourselves with dreams ... Our misfortune lies in the dissolution of theoretical and practical life ... ««. ${ }^{155}$

In 1932, another Nobel Laureate, the physiologist and psychologist, Ivan Pavlov, formulated his thoughts very specifically: «I have to state with sadness that the Russian possesses such a weak brain system that he is not capable of perceiving reality as such. He can perceive only words. His conditioned reflexes are not coordinated with actions, but with words.» ${ }^{156}$

From the statements quoted above of Bunin, Pavlov, and Herzen, one is tempted to conclude that the typical Russian is merely pliable material for processing and that he has no independent core. However, in that case, how does one explain the «extreme repeatability of history»? Surely, it cannot be explained from the fact that these sacred thinkers and leaders process the Russian, sometimes as an icon and at other times as a cudgel? However, can it not be that such a core, nevertheless, exists?

When Bunin tries to draw together the social psychology of Russians from all periods of Russian history, and not just from its «cursed» years, he offers a less pessimistic evaluation. «The point is that any Russian riot (and especially the current one) primarily proves the extent to which everything is old in Russia and how much she thirsts primarily for formlessness. From time immemorial, there were «brigands» from Murom, Bryansk, Saratov, fugitives, cranks, rebels against everyone and everything, drunkards, beggars in taverns, heretics, and sowers of lies, unrealisable hopes, and quarrels. Rus is the classical country of the brawler. At the same time, there was a holy person and a builder of a tall, but harsh fortress. However, what a long and incessant struggle they faced against the brawler and the

\footnotetext{
154 The same place, p. 113.

${ }^{155}$ The same place.

${ }^{156}$ Quoted in the Independent newspaper, 1999, 29 January, p. 8.
} 
destroyer, with all sorts of revolts, scuffles, and bloody «disorders and nonsense»»!» ${ }^{157}$

Here, the question is no longer of pliable «wood» or about the «weakness of the brain», but about two struggling and extremely specific and rigid psychic ways of life of people: the brawler-destroyer and the saint-creator. However, it is again not possible to define general characteristics of the psychology of the Russian nation. Therefore, I will try to address its history.

The specificity of the Russian national community and, thus, its national psychology can be explained by the presence and intertwinement of a series of processes in the preconsciousness of the population, including:

The centuries-old development of wild and barelypopulated forests in the valleys of the upper Volga and Oka, with their severe winters and short summers;

Its orthodox roots, the struggle against paganism, Catholicism, and dissidence and its coexistence with Islam;

Two and a half centuries of Tatar-Mongolian domination;

Three and a half centuries of serfdom, five centuries of autocracy and dictatorship and its struggle with «fugitives», Cossacks, division, «Freemen», «the class enemies», and opposition;

Its long history of rural communities and also its paternalistic and collectivist forms of economy and life;

Five centuries of territorial expansion and the inclusion (both peacefully and through the use of force) into its orbit of influence and close interaction with many diverse

${ }^{157}$ I.A. Bunin, “Cursed Days”, p. 165. 
ethnoses from the Baltic and the Carpathians to the Pacific Ocean;

Note that I have not mentioned various wars, for all nations were at war, and militancy is not a specific but a common feature of the character of all large nations.

As far as the specificity of the Russian psychology is concerned, it can be described as a unique combination of contradictory features, such as the following: forbearance and persistence, with a refusal to endure monotonous rhythmic burdens; preference for collective (requiring the urgent participation of everybody available) methods of work; broad ethnic tolerance in connection with the sharp tearing away of «non-conforming» religions and ideologies; a patronising attitude to other ethnoses; the formation of links between people not on the basis of laws, but through force, community agreements, and traditions; opposition between law and justice; and alienation from power and at the same time counting on its help and protection. There is a lack of respect for human and property rights both from the authorities and the people themselves. An aggravated sense of justice and suffering lives together with an acceptance of hierarchy, dependence, and violence. The typical Russian is not impressed by rationality and efficiency, but admires verve (on a grand scale), risk, and luck. An inclination for general mistrust is combined with an equally naive faith in leaders, concepts, and a bright future. The Russian - regardless of whether he is an oppressed martyr, soldier, merchant, hero, villain, in authority, or a rebel - as a rule, is a person, whose character is more romantic and reflective than the global average and is well below the average in terms of sober realism.

In other words, the national psychology shaped by the «hammer» of Russian history, has repressed or disoriented those natural instincts of the individual, which are especially important for economic development, the instincts of individual self-preservation, appropriation, freedom, expediency, and self-expression. However, such psychology was not only a product but also a precondition of the centuries-old struggle of the Russian nation for survival, formation, and expansion. Based on the law, respect of human rights, and priority of individual freedom and private property, it would not have been possible to build national statehood, having become a colony of the Gold Horde, to endure the exhausting struggle on its western and 
southern borders, and to transform the Volga region, the North Caucasus, and Central Asia from posing a threat to Russia's security, into becoming partners in general development. Those features of the Russian character that Bunin (and Tolstoy, Gorky, etc.) referred to as unsteadiness and instability, from a historical point of view, can be interpreted as variety, flexibility, and mobility, which were, however, within certain limits, dictated by the historical process. Certainly, it is not moving, but also there is nothing to regret. Our history is our treasure, and may we be forgiven the history that God has not given us.

However, at least two issues still need to be discussed in this context: Bunin's accusation that a considerable part (if not the majority) of the Russian people, possess the psychology of destroyers; and the almost equally grave accusation of Pavlov, who wrote that Russians are not capable of comprehending real life independently.

The «cursed days» and years of the destructive Civil war, of imposed collectivisation, and industrialisation gave both these outstanding Russians the grounds to draw such conclusions. However, their arguments contain a critical flaw: they directly observed a display not of the Russian national character but of the universal psychological illness called «revolution». In order to understand the essence of the revolutionary mentality of the masses, one needs to consider the works of Pitirim Sorokin.

He showed that revolutions occur when, as the result of a long period of oppression of the basic instincts of a significant part of the population, its behaviour starts being governed not by historically developed psychological norms, but directly by natural reflexes. In other words, the historical armour of national norms breaks down, a biologisation of social behaviour takes place, and people appear in a new, previously unknown to them, form. Here, again, the distinctions between the Germans, the French, and Russians are truly erased: the revolutionary Frenchman is roughly similar to the revolutionary Russian or Hungarian. ${ }^{158}$ At the same time, revolution attracts counter-revolutionaries in the sphere of the direct action of biosocial

${ }^{158}$ The coming to power of fascism in Germany, Italy, and Spain can also be considered as a revolution carried out through militant racism, the destruction of the national psyche, and not only the baring of the animal foundation of the psyche, but the transformation of this foundation into an official cult of "the blond beast" (and "beasts" in general). 
forces and ones enemies. This is the objective meaning of Bunin's exclamation: «In what can one trust, after such an inexpressibly terrible truth about human beings has been revealed?» ${ }^{159}$

Pitirim Sorokin, basing his conclusions on comprehensive historical material, wrote (about revolutionary periods) that the disappearance of the majority of habits, interfering with the satisfaction of repressive inborn instincts, frees them from restrictions and promotes their liberation. At the same time, it also eases conditioned reflexes, which previously constrained people from the fulfilment of certain acts of violence, such as theft, murders, sacrilege, etc. ${ }^{160}$

As noted above, Sorokin did not consider it possible to single out a particular national factor and considered revolutionary psychology as the destruction of general civilised ethical standards. However, historically, these norms are developed in the context of a specific national psychology and in their pure form can only be proclaimed, but do not function. If one conditionally accepts the well-known precepts of Christianity (conditionally, as there exist similar precepts of Buddhism, Islam, etc.) as these norms, it is hardly possible to find in history one country or even a community, where they ever were fully implemented. However, they operate to the extent that they are entwined in the specific «fabric» of national norms of behaviour (the «fabric» of conditioned reflexes). They also break off together with this «fabric».

«The terrible truth» about a destructive person, whose behaviour can be manipulated easily, is in fact the truth about the psychological bases of a social revolution. If this revolution is deep and long and if it is accompanied by civil war, it is capable of causing a number of irreversible shifts in the psychology of the masses. Certain features of the national character can be lost or weakened, others can be strengthened, and new features can appear. Not only scars, but also raw wounds (moreover, not only of the guilt of the masses, but also of the insults and latent exasperation of the masses) are rooted in the national psychology. Morally, such revolutions are truly the «engines» of history, but they drive civilisation backwards.

\footnotetext{
${ }^{159}$ I.A. Bunin, "Cursed Days", p. 91.

${ }^{160}$ Pitirim Sorokin, "Man, Civilization, and Society”, p. 274.
} 
Sorokin described the mechanism of psychological shifts after a revolution breaks out as human behaviour being guided by biological laws. The repressed instincts, having destroyed the conditional filters of behaviour, start to exert pressure on all other instincts. The balance between them is disturbed, and the instincts on which pressure is exerted, are displaced. This leads to a new series of shifts in the conditioned reflexes and results in the «biological» behaviour of people to an even greater extent and further disinhibition in the fulfilment of antisocial acts. ${ }^{161}$ From the point of view of the classification of the inborn instincts presented in this book, it is conceivable that, in these circumstances, the instincts of individual survival suppress the development instincts (of freedom, selfexpression, etc.) as well as certain social instincts (of compassion, hierarchy, etc.), and, at the same time, release the herd instinct.

Sorokin notes that suppressed instincts alone are insufficient for a revolutionary explosion to occur; it also requires the absence of powerful and effective resistance by the authorities and the governing party. According to Sorokin, practically all governments in the prerevolutionary period are characterised by anaemia, powerlessness, indecision, incompetence, dissoluteness, corruption, immorality, etc. He wrote that the degeneration of the elite in society is the second reason (and its occurrence is not merely coincidental but indicative) why revolutions occur. The degeneration of the power of the ruling classes if their position is exclusive and class-based becomes, sooner or later, inevitable. It is caused by the action of biological and social factors. ${ }^{162}$

In fact, this refers to the independent historical role of the developed institutional forms of the nation and about those social strata, which these forms are urged to directly support. Their degeneration, decomposition and division imply the breakup of the state, and together with it (in case of the suppression of the basic instincts of a significant part of the population), the impossibility of civilised transformations. If the government and the groups, guarding the maintenance of order, are not capable of preventing the disintegration of the state, the «revolution» in people's behaviour begins immediately: the conditionally accepted clothes of civilised

\footnotetext{
161 The same, pp. 274-275.

${ }^{162}$ Pitirim Sorokin, "Man, Civilization, and Society”, pp. 288, 291.
} 
behaviour are instantly torn apart, and in exchange the «beast» is released in society. However, as soon as the type of behaviour of the masses changes, inevitably, the entire social order changes with it. ${ }^{163}$ In other words, the hope that revolution can be civilised is a dangerous illusion and an enticing deceit.

\section{2. The Elite and Non-Elite: the Genetic Roots of Psychological Alienation}

In classifying people according to the degree that they are bourgeois, Sombart does not mention Slavs in general and Russia, in particular. Meanwhile, the economic history of Russia, considered from the point of view of Sombart's concept, also appears in the form of the interaction of diverse natural beginnings: heroic (or predatory), trading, petty-bourgeois, and non-capitalistic.

To what extent can one conclude from history that the spirit of predatory heroism and profit - which, according to Sombart, characterised the ancient Romans and the majority of the German tribes of the early Middle Ages, including the Normans (and also, I add, the Arabs, the Tatars from Mongolia, the Ottoman Turks, and a number of other nations) - was alien to the ancient East Slavic tribes, such as the Polans, Vyatichs, Dregovichs, Krivichi, etc.

According to Sombart, the petty-bourgeois spirit for accounting and moneymaking - inherent in Greeks, Etruscans, Frisians, the Alemanni, and in their successors, the Florentines, the Scots, the Dutch, and the Swiss - was also alien to the East Slavs. Consequently, in spirit, the East Slavs were reminiscent of the peaceful Celtic farmers and hunters, belonging to the indigenous population of Western Europe.

However, a different spirit reigned in ancient Slavic Novgorod (whose population consisted of a significant number of foreign traders from the West).

This city of the Ilmenski Slavs was located on the route from Varyag to Greece, one of the main trading routes of the Middle Ages, connecting Greek traders with «the heroic Normans» (according to the terminology of Sombart). Since ancient times, Novgorod (with its

163 The same place, p. 275. 
ushkuiniks), had combined trade with conquests, and had created a sort of empire from the White Sea to the Northern Ural Mountains. Thus, the Variagians (Normans), invited by the Ilmenski Slavs in the $9^{\text {th }}$ century, differed little in spirit from the people of Novgorod. Based in Novgorod, the Variagians resolutely moved south to possess the land of the Polans and based themselves in Kiev, having transformed it into the largest military and trading centre in East Europe. ${ }^{164}$

In the $11^{\text {th }}-12^{\text {th }}$ centuries, under the pressure of the steppe nomads, the centre of the Russian statehood began to gradually move from the Dnieper to the northeast, between the Oka and upper Volga rivers, occupied mainly by the Vyatichs.

Genetically, there was a division right from the start in the newly formed Russian nation: the aggressive Normans led by the Rurik Dynasty formed its ruling elite, and the labourers were mainly from the peaceful Slavs. I stress that this is a genetic split not because

${ }^{164}$ Note the (deliberate) synchronic expansion of the Variagians in Western and Eastern Europe and the underestimation of the consequences of this expansion in both parts of Europe.

Incidentally, Priestley (as mentioned earlier) rejected the participation of the Normans in the formation of the English psyche. Meanwhile, the conquest by the Normans of Northeast England in the $9^{\text {th }}$ century and French Normandy in the $10^{\text {th }}$ century, followed by the Norman Conquest of all of England, as a result of which, the Duke of Normandy, Wilhelm I, became the King of England, could not have left the English completely untouched.

Possibly, the Norman Conquest did not fundamentally impact the culture of the conquered Anglo-Saxons, and did not leave an appreciable trace in the genofund of the entire population. However, the Normans became an essential part of the ruling elite of England, and their (and their descendants') aggressive-militant customs were repeatedly shown in the Christian Crusades, in the Hundred Years' War in Europe, in colonial wars worldwide, and in their barbarous bombardment of civilians at the end of the Second World War (which Priestley also mentions). Their methods of conducting economic affairs also made an impact: the slave-trade in the $17^{\text {th }}-19^{\text {th }}$ centuries, military and piratical maritime operations, the expulsion of peasants from their lands in England, severe exploitation of the colonies, etc.

Note that if the overestimation of the historical role of the Normans in Western and Eastern Europe is erroneous, ignoring this role is doubly mistaken. Ignoring their role leads to misunderstanding the genetic aspect of the participation of the Normans in the formation of the psyche of the ruling elite of the countries conquered by them. 
one group is North German and the other Slav, but because the psyche of the newly arrived Variagians was dominated by the inborn instincts of the love of power, aggression, and appropriation, and the psyche of the Slavs was dominated by the instincts of self-preservation, hierarchy, and cooperation.

A similar division existed in some other countries also; for example, between the Francs and Celts (Gauls) in France and between the Arabs and the indigenous population of North Africa. However, there was an essential difference: in these two cases (the Francs and the Arabs), the ruling elite was more or less homogeneous. In Russia, the ruling elite remained genetically homogeneous (to a certain extent) only for a period of two-three centuries, then the process began of its rapid replenishment by foreign mercenaries with an aggressive psyche from the West and the East.

In the official family tree in the «The Velvet Book», assembled by the government of Tsarevna Sophia, 930 surnames from the basic body of Moscow's serving class or high nobility are listed. Of these surnames, 33\% are Great Russian, 24\% are Polish and Lithuanian, 25\% are German and other West European, and 17\% are Tatar and other Eastern. ${ }^{165}$ I believe that the Russian surnames among the high nobility are primarily of the Rurik Dynasty and their relatives, and also descendants of numerous Variagian militias.

Later, the psychogenetic division between the ruling elite and the simple mass Slavic-Finnish population continued and became even more marked, even resulting in severe forms of serfdom of the peasantry.

The Romanovs did not belong to the Rurik Dynasty, however, the founder of their numerous houses, Andrei Ivanovich Kobyla, was a Prussian native (N.I. Kostomarov). The Romanovs received this surname and were raised from ordinary noblemen to boyars, when the daughter of Roman Zaharin, one of the descendants of Kobyla, Anastasia, became the Tsaritsa (Ivan Grozny's first wife). (Note that Grozny's mother originated from the Tatar-Lithuanian Glinskii clan).

The entire House of Romanovs (including the young Michael, the future tsar) had been severely persecuted by Boris Godunov, who himself was a descendant of the Tatar Mirza Chet, christened in the $14^{\text {th }}$ century in Horde.

${ }^{165}$ V.O. Klyuchevsky, Russian history, Moscow, EKSMO 2005, p. 232. 
Under Peter I, and then Anna Ioannovna, the inflow of people from the West entering the Russian ruling elite sharply increased, and under Catherine II, her son Pavel I and grandson Alexander I, the Imperial House of Russia became completely German, in terms of its genetic roots. In general, one can draw the conclusion that, to the extent that genetics has an independent meaning for the psyche, the people and ruling elite in Russia had been psychogenetically separated; a common culture (including religion) and language united them only partially. To a great extent, this explains their permanent and uncompromising opposition in the economic sphere.

The genetic heterogeneity of the elite, can explain (even if only partially) the aspiration for «autocracy» and «a personality cult», for the alternate was a destructive struggle for power amongst the elite (as observed during the weaker periods of the tsar's power). Pareto did not take into consideration the genetic heterogeneity of the ruling elite in a number of countries, when he wrote about the decorative character of the top layer of the ruling elite.

In summary, one can state that the genetic basis of the psyche of all nations develops from the same components noted earlier: existential requirements and instincts of individualism, sociality, and development. At the same time, in different nations, the correlation between the four selected groups of people (focused mainly on individualism, sociality, development, and people with a balanced psyche) varies.

It is very likely that as a result of the hard living conditions over a period of many hundreds and even thousands of years, a relatively high proportion of individuals among the Normans, through a process of natural selection, turned out to be inclined towards aggressive appropriation and combined the qualities of disciplined warriors, pirates, and traders. Individuals with this type of psyche were sent on the Viking campaigns overseas. Some historians characterise groups of Variagians, who had arrived on the lands of the Polans and the Dregovichs, as gangs of robbers - until their acceptance of Orthodoxy by Prince Vladimir (Voldemar) and the christening of the population of Kievan Rus at the end of the $10^{\text {th }}$ century. In many cases, this was probably true. However, long before the christening, Prince Oleg brought, by sea and land, an organised Variagian army (calling itself «Rus»), consisting of many tens of thousands of warriors, to Constantinople, and forced the emperor to pay tribute. Sviatoslavic, 
the father of Prince Vladimir, crushed the Khazars and waged war against the Byzantine Empire in Bulgaria. Thus, they were not gangs, but powerful and well organised ruling elite, consisting of warriors and slave traders with an aggressive psyche, inclined to appropriation. ${ }^{166}$ The fact that their psyche was strongly oriented towards individualism is evident throughout the history of the Rurik Dynasty (in the period before their christening and subsequently), the majority of whom fell not in foreign wars, but against their own brothers, uncles and nephews, in the struggle over prisoners, property, cattle, and individual power.

Thus, structurally, the Russian nation was composed of two genetically diverse layers: the predatory and individualistic Normans and Germans (followed by the Norman-German-Lithuanian-Tatar) dominating elite and the socialitarian-labour Slavic-Finnish non-elite. At the end of the $14^{\text {th }}$ century, a wide and expanding region of freeCossacks was formed, from the (mainly) Slavic population (made up of fugitive peasants with a psyche of freedom-loving individualists), who from the end of the $16^{\text {th }}$ until the end of the $18^{\text {th }}$ centuries constituted the main driving force of the peasant wars in Russia, and turned into the third independent element of the nation. (This can be seen in the formation of a special Cossack Military Service Estate and 11 separate Cossack armies.) As a result, the formation of the Russian nation took place in conditions of partial psychic incompatibility and estrangement between the elite and non-elite, on the one hand, and between the Cossacks and the rest of the population, on the other hand. (The latter intensified during the «Time of Troubles» in the early $17^{\text {th }}$ century).

I believe this explains the especially rigid (and severe) forms of relations between these three groups in Russia, both in politics and in the economy; a common religion and language only partially softened

166 According to the historian, V.V. Sviatlovski, the basic wealth (and the main motive of the wars) of the ruling class of Kievan Rus (princes, boyars, combatants, and monasteries) was slave ownership and the capturing of slaves. Prince Vladimir Sviatoslavic was a large slave owner. The main goods in the trade between the Variagians ("Rus") and the Greeks were slaves (Slavs and other people). (See V.V. Sviatlovski, "The History of Economic Ideas in Russia", in the collection "The History of Russian Economic Thought", V.V. Sviatlovski, M.I. Tugan-Baranovsky, V.J. Zhelezov, Moscow, "Nauk" 2003, pp. 21, 25.) 
this conflict. Riots and mutinies have taken place and continue to occur throughout the world. However, «May God forbid you from witnessing a Russian riot - it is senseless and ruthless» (Pushkin). ${ }^{167}$

The mutual psychic antipathy and the ability to communicate with each other only through force and cunning between the dominating elite, on the one hand, and the non-elite, on the other hand, has turned into a long-lasting tradition in Russia.

In chapter 2, in analysing Pareto's views, an intermediate layer (class) was mentioned, which serves as a tool for governing for the dominating elite. The cruelty of the elite is consolidated in the habits and mentality of this class and can continue even after the ruling elite has been replaced by a new elite.

Russian fairy tales often depict a harsh tsar with servants confronted by Ivan the Fool with magical powers; the tsar forces Ivan to carry out dangerous tasks to secure certain benefits for him; in return, Ivan tries to outwit the tsar, dethrone him, and become the tsar himself.

In chapter 5, I noted that trust is one of the foundations of the market. The famous French economic historian, Fernand Braudel, noted the basic distinction between the three market layers - the local, national, and global. The local markets are the centres of people's economic life; average-scale business transactions take place on the national markets; and large amounts of capital, closely associated with the state authorities, operate the global markets.

Clearly, the economic development of the country depends on the constructiveness of the interaction of the transactions being conducted on these three levels. Obviously the transactions on the local, national, and world levels differ not only in scale, but in the type of psyche of the entrepreneurs and on the types of psychic interactions.

On the local markets, the exchanges are, to a great extent, of a personal character as producers, sellers, and buyers know each other and trust each other. The national markets are composed of capitalists, motivated by profit, but, nevertheless, who need to trust their long-

167 I think the thousand-year old psychogenetic dissociation between the descendants of the Gauls (the peasantry and the bourgeois) and descendants of the Francs (the nobility and clergy) also impacted on the particular cruelty of the Great French Revolution. 
time partners and clients. Finally, the capitalists on the global markets require levels of support and protection, which only the strength and authority of the state can provide.

If the relations between the different layers of market participants are governed by opportunism instead of trust, i.e., by aggressive and deceptive behaviour, which is consolidated and strengthened by the fact that the state supports, and is allied with, the upper layers of groups, whose interests are concentrated abroad, then it is unlikely that the national economy will develop efficiently.

Thus, although the national psyche is formed mainly in early childhood, together with learning to speak and mastering the rudiments of culture, its formation is fundamentally influenced by the nature of the genetic roots of those social groups and ethnoses, on which the nation is formed. If both the elite and non-elite have different types of genetic roots and, if, moreover, these roots vary in different groups within the elite and within the non-elite, then the instillation of a uniform national psyche becomes more difficult, internally inconsistent, and complex. Can one consider that genetic heterogeneity weakens the role of a common national psyche as a binding force of the nation? One needs to take into account the fact that a common national psyche is formed as a requirement for survival, dictated by the pressure of natural, economic, and political conditions. It is not formed as a result of the free choice of people, living in safe conditions. The heterogeneity of the genetic roots of a common national psyche can be compensated by the strength of the instilled features of this psyche. However, where the main substance of a common national psyche, the common instilled existential needs and instincts, weakens and is destroyed, there genetic heterogeneity begins to act as a destructive force.

With regard to the Russian nation (and, more broadly, the different nations contained in the Russian Federation), both series of factors came into play at the same time - genetic heterogeneity and historical pressure directed towards a common set of instilled existential needs and instincts.

This partially explains the sharp conflicts in relations not only between the elite and the non-elite, but also within the elite and the non-elite, and, at the same time, the especially severe conflicts in Russian history as a whole. This poses a specific danger for the survival and development in the Russian nation of all economic, 
social, political, and ideological measures, which weakens the foundations of a common national psyche (as well as a common national culture and language).

\subsection{Specific Features of the National Psyche and the Economic Behaviour of Russians}

How do the specific features of the Russian national psyche affect the economic behaviour of Russians and Russia's economic institutions (both informal and formal)?

Note that here particularities (specific features) denote those common features, which are peculiar to the psyche of the majority of the representatives of a given nation, and which distinguish it from the psyche of other nations.

As already noted above, the national psyche is not the inborn, but the instilled, psyche, transferred from generation to generation (primarily from the adult environment to children). However, this transfer takes place on a specific genetic base and in a specific naturaleconomic and social-cultural environment.

The main specific feature of the national psyche of Russians can be considered the circumstance that, whereas the majority of people (in each nation) possess a balanced psyche, in Russia the «balance» of this majority is traditionally excessively elastic, unstable, and shaky.

The norms and rules of behaviour, which are acquired by Russian children from an early age, are vague and inconsistent, and are primarily a reflection of the psyche of the adults. In terms of the socio-economic aspect, this is primarily a contradiction between element of individualism and elements of sociality in the psyche of the majority of individuals. These inconsistent elements can be in a calm and mutually balanced state, and can also be in an unstable, excited, and slightly unbalanced condition. The latter condition is characteristic of the psyche of the majority of Russians.

This can be related to the fact that in Russia, historically, an excessively influential role was played by people with a dominant psyche focused on individualism, on the one hand, and on sociality, on the other hand. The active and permanent opposition of these groups 
has excited the psyche of the vast majority of the population and has destabilised it.

The instability of the psyche results primarily in ambiguity and changeability in the formation of priorities amongst existential needs, and from there leads to the instability of the system for evaluating the criteria of behaviour. This instability hampers the system for establishing goals, and it becomes difficult for a person to behave rationally, realistically, and practically. Such a person either loses all interest in the system of establishing goals, or becomes absorbed in the search of a system of values that is not connected with the real fundamentally important needs of life (for example, by searching for «the meaning of life»).

In the first and second paragraphs of this chapter, I wrote about the historical factors that formed the structure and specific features of the national psyche in Russia. Here, I have noted those factors that continue to affect the relative instability of the psyche of the majority of Russians today:

The heterogeneity of the genetic roots in the ethnoses and the social groups making up the Russian nation;

The distinctions in the cultural and religious bases of the instilled psyche;

The sharp differentiation of the natural and economic bases of the instilled psyche according to the regions of the country.

The well-known literary critic, J.M. Lotman, noted in Soviet society a propensity of people to take polarly opposite positions, and explained this propensity by the absence (unlike in Western countries) of a civilised kernel of society, capable of pulling together and reconciling contrasting opinions. I believe that it is not a question of the absence of a kernel, but in the properties of the kernel; in Western Europe and Japan, the psyche of the majority of the population is steadier, as it is based on a higher degree of genetic, social-cultural, and inter-regional uniformity than in Russia. 
In modern Russia, a higher level of social, political, and ideological (essentially, psychological) stability is often connected with the prospect of the formation of a large middle class, covering up to $70 \%$ of the population and consisting, primarily, of small businessmen and social groups associated with them). It is considered that the ownership of property and an independent business and earning a reasonable income positively influences the stability of a person's psyche.

Note that Marxism is based on the opposite view; the intermediate social strata (between the bourgeois and the proletariat) are psychologically the least steady layer, as their position in the economy is shaky and a significant part of this layer is ruined (bankrupted) every year. It is not simply a coincidence that in many European countries in the 1920s-1930s, it was the petty bourgeois that easily fell under the influence of fascism and provided it with the support of the masses.

In reality, all classes of society contain individuals with both a stable and unstable psyche. Certainly, conducting business demands that a person is strong-willed and possesses a stable psyche; thus, in the business environment, people with an unstable psyche do not survive for long. However, this does not mean that working as a small businessman stabilises (or destabilises) a person's psyche. Simply, each profession tends to select people with a certain type of psyche. If the majority of the population consists of individuals with an unstable psyche, one cannot hope for significant development of the small business sector.

In a country, where the majority consists of individuals with a stable psyche, informal institutions (primarily, norms and rules of behaviour instilled since childhood) form a firm foundation for the functioning of formal institutions and for the functioning of organisations (both in the commercial and social spheres).

However, if the psyche of the majority is unstable, then this leads to an increased role of such formal institutions, which are based essentially on the state and on organisations, and whose efficiency depends on the individual qualities of its managers.

Contrasting the stability of the national psyche with the instability of the national psyche is an oversimplification. Actually, there is a gradual transition from one condition to the other. However, can one define a limit, beyond which instability begins? 
From the social and economic point of view, the relationship to property can serve as a sort of «litmus test». If the majority of the population supports public property for the basic means of production and natural resources, but after a short time interval the same majority appears in favour of private property, and then subsequently again changes its opinion, then it clearly does not have a stable psyche.

The relationship to corruption can serve as another criterion. If the population resolutely condemns corruption, however, at the same time, actively participates in it (and, frequently does so voluntarily), such an internally inconsistent psyche cannot be considered stable.

Significant fluctuations of the vast majority of the population from excessive trust to excessive distrust in relation to political and economic institutions are equally indicative. Fraudulent financial structures, such as the «pyramids» of state credit obligations, the MMM Ponzi scheme, etc., thrived on the excessive trustfulness of the population; at the same time, because of excessive mistrust, the population avoids appealing to the courts and to bodies of the Ministry of Internal Affairs or investing in private banks, individual insurance, and securities.

Isn't the lack of stability of the psyche contradicted by the presence of one of its characteristics, such as patience? Patience (as the ability to bear relatively strong physical and nervous burdens over a lengthy period of time) can be combined with a stable psyche, but only on condition that the contents of these burdens correspond to the given type of psyche. If the uncertainty and instability of priorities is inherent in the psyche, then patience serves as a compensating property, allowing it to adapt to external circumstances and to develop the corresponding habits. These habits can turn into a sort of replacement of the instilled internal priorities, just as, for a turtle its shell fulfils the role of a spinal column. However, unlike the shell, such habits can only be temporary, until the next change in priorities.

If the instability and range of the fluctuations is a specific feature of the Russian mass psyche, and patience and adaptable flexibility another feature, the third is the aspiration to search for and find unexpected ways of resolving fundamentally important issues outside of the previously accepted norms and rules (I have named this aspiration as the «complex of the lefthander»).

Thus, the majority of Russians are changeable with respect to their dominating inclinations and values, patient, and inventive. 
The norms and rules instilled in childhood play a relatively smaller role in the Russian psyche, and unconscious impulses and fundamental habits a relatively more significant role, than in the psyche of many other people. Russians usually demonstrate a great deal of patience in relation to formal norms and rules imposed externally on them, however, at the same time, inventively find ways to avoid obeying them.

The instability of the instilled norms of behaviour complicates self-organisation in economic life and, at the same time, lowers the efficiency of formal institutions. In other words, in the development of market institutions in Russia, one should not rely excessively either on initiatives from below or on legislative activity. In such an environment, the organisational work of the executive authorities in the creation of market economic structures and the selection of capable and responsible leaders is of crucial importance.

In Russia, the extent of the danger of relying on individual initiatives, interests, and awareness in the economic sphere was shown by the tragic accidents in the Kuzbass mines, which resulted in the loss of hundreds of lives in 2007 alone. The latest English alarm system to warn against dangerous levels of gas had been fitted in one of the new mines, which had been modernised. However, this system was turned off by workers (with the connivance of management) as it «lowered their productivity» - the alarm sounded too soon. As a result, there was an explosion, and not only workers, but also most of the management team of the mine, who had gone down the mine before the explosion to demonstrate the highly efficient work of the miners to foreign visitors, lost their lives.

Throughout the country, the equally reckless methods of welders and other repair and construction workers in unprepared workplaces regularly cause fires, the collapse of structures, catastrophic explosions of ammunition warehouses, etc., with incalculable losses. The brave attempts of airplanes and helicopters to fly over a thunder-storm or fly blindly, with the purpose of saving fuel and time, end in additional losses.

Cars have become a special sphere, where the Russian national character is on display. "Is there a Russian, who does not love driving fast?» exclaimed the classic writer. However, at the same time, he did not forget to mention that «fools and roads» are the main problems of Russia. The combination of a reckless love of speed and a 
lack of good roads results in more than thirty thousand deaths and hundreds of thousands of injuries annually. In addition, many thousands are sentenced to prison terms.

All these figures are several times greater than in Western Europe, after adjusting for the number of inhabitants.

The peasant in Chekhov's novel, «Malefactor», explained to the judge that he did not unscrew the nuts on the rails in succession, but deliberately, every other one: in this way, he obtained sinkers for fishing and the rails remained connected. This characteristic of the Russian psyche, the inability and, critically, the obvious unwillingness to draw an accurate distinction between good and evil, and between what is admissible and unacceptable, has remained unchanged for a hundred years.

Only during critical moments in national history - in 1380, 1480, 1612, 1812, 1917, and 1941- did this distinction become clear and unambiguous for the majority of Russians.

As far as economic development is concerned, it has always progressed, overcoming the obstacles posed by the psychic uncertainty of the majority of the population.

It is obvious that in the conditions of modern technical systems on which production and the entire way of life of modern people are based and in the conditions of fierce international competition, which has been intensified by globalisation, the instability and uncertainty of the psyche of the majority of the population poses a threat to national survival. Russians have to prevent themselves from voluntarily and, in democratic conditions, killing themselves through preventable accidents in mines, on construction sites, in car accidents, shortening their lives, reducing consumption, becoming alcoholics, and giving birth to sick children and leaving to the mercy of fate the healthy.

As it is unlikely that the psyche of the population will change in the $21^{\text {st }}$ century, the nation should have the courage to take the harsh measures required - rigid maximum permissible specifications - in the field of safety, life expectancy, and the minimum acceptable standard of living. Moreover, it should build a system of market relations only on this firm natural base. Those variants of the market system, which undermine this base and contradict it, should be resolutely rejected. 


\section{Chapter 12}

\section{Psychological Factors of the Institutional Transformation and Economic Development of the USSR}

In previous chapters the psyche's links with economic institutions in normal evolutionary conditions were discussed. However, society has always been periodically impacted by wars and revolutions. Being to a great extent a result of processes in the structure of a normal psyche, wars and revolutions, in turn, generate long-term shifts in this psyche, which are capable of forming a foundation for deep and different types of changes in the culture and institutional system of nations and, at the same time, in their economic development.

The investigation of the interaction of the psyche and institutions in periods of military and revolutionary catastrophes and their consequences is an extremely complex challenge, even within the framework of one country and a limited period of time. Therefore, in this chapter, I merely intend to raise this issue and outline it.

The psychological foundation of the construction of a system of state socialism in the USSR was formed by the First World War, the revolutions in February and October in 1917, and the civil war in 1918-1921.

One needs to keep in mind that the restoration of the economy, destroyed by the world and civil wars, and the creation of a system of state socialism took place between the two world wars, in a short period lasting less than 20 years. Throughout this period, nobody in the USSR doubted the inevitability of the Second World War, moreover, the global crisis at the beginning of the 1930s and the coming to power of fascist and militant governments in Germany and a number of other countries signalled the imminence of war in the next few years. Thus, the process of the institutional and economic transformation of the USSR occurred under the pressure of a double psychological stress, the stress left over from the recently endured wars and the stress from the expectation of the war that was drawing closer. 
This foundation was strengthened by the Great Patriotic War in 1941-1945 and strengthened by the ensuing forty-year Cold War. State socialism failed, as soon as the factors that generated and supported the psychological foundation, weakened or ceased to exist.

However, there are no guarantees that new catastrophes, regardless of their origins, will not again generate, in these or other countries, deep shifts in the psyche of the population and, at the same time, the aspiration of the masses for the establishment of a centralised economic system, in some modified form.

\subsection{Pitirim Sorokin on the Psychology of the Revolution of 1917}

There are two types of social sciences (and two types of scholars) the science (scholars) of calm periods and the science (scholars) of tempestuous periods. The former studies an object in a state of relative balance, during quiet, slow, evolutionary changes. The latter deals with epochs, in which cracks are revealed in latent structures, and the roots of social systems are discovered.

Scholars of calm periods concentrate on the metabolism of a system, its functioning, and the role in its evolution of incremental and marginal changes. Scholars of tempestuous periods primarily investigate the structure of society, its contradictions, and the reasons for the cardinal shifts in its foundation.

Pitirim Sorokin is one of the leaders of the second type of science. $\mathrm{He}$ is a theoretician of the Great Russian and global revolutions in civilised countries in the $20^{\text {th }}$ century. Moreover, this is not because he was a revolutionary. On the contrary, he hated revolutions. However, while some intellectuals eulogised revolutions and others condemned them, he analysed them on a strictly scientific basis. This analysis contributes greatly to understanding the deep foundations of human behaviour and the mechanisms for the transformation of social and economic systems. The famous historian of economic thought, Ben Seligman, noted that economic science cannot exist without concepts about people and psychology and that this remains one of the acute 
problems of economic science. ${ }^{168}$ Seligman stated this half a century ago, but it still remains true today. The problem of the psychological basis of economic theory cannot be scientifically resolved on the basis of subjective and descriptive psychology. In his book, Seligman quoted over half a dozen psychological models of behaviour of economic agents that contradict each other, and today an even greater number of such contradictory models exist.

The classification, description, and interpretation of the behaviour of various subjects of the market are useful exercises, especially for those who use this behaviour for their own purposes. However, when the base of the economic system has been shaken and the negative energy of the masses has accumulated, ready to again blow it up, deeper issues emerge on a larger scale. Russia, as well as some other countries, is experiencing such a period.

Nine decades ago, when Russia was at the epicentre of a revolutionary breakdown, it possessed powerful national schools in the major areas of fundamental science - physiology, physics, mathematics, sociology, economy, etc. Pitirim Sorokin, was a pupil and assistant to the great Russian sociologist, Academician Michael Kovalevskiy, a pupil and colleague of the Nobel Laureate of 1904, the physiologist and psychologist, Academician Ivan Pavlov, and the of founder of reflexology and social psychology, Professor Vladimir Bekhterev. ${ }^{169}$

168 B. Seligman, "Main Currents in Modern Economics", M.: "Progress", 1968, p. 344.

169 Pitirim Alexandrovich Sorokin (1889-1968) came from a family of itinerant artisans from Vologda; since his early years, he was an active worker, and subsequently became one of the party leaders of the Right Esers. After the revolution in February, 1917, he became the secretary of the prime minister of the provisional government, A.F. Kerensky, a deputy of the Constituent Assembly. In 1918, he left the party of Esers and devoted himself to science and teaching. In 1920, his two-volume work, "The System of Sociology", was published. In September, 1922, as a professor at Petersburg University, he was among two hundred outstanding Russian social scientists, who were sent abroad. In 1930, Sorokin headed the recently founded sociological faculty at Harvard University (USA) and worked there until his retirement in 1959. The fundamental research and innovative ideas stated by Sorokin in more than fifty books and numerous articles won him a reputation as the leading sociologist of the $20^{\text {th }}$ century. 
Synthesising the achievements of Russian sociology (being based, in turn, on the historic, ethnographic, and philosophic achievements), on the one hand, and the results attained by scientists of the Psychoneurological Institute, created by Bekhterev, on the other hand, Sorokin developed a concept that explained the general bases of human behaviour. Later, one of the most prominent economists of Russia in the $20^{\text {th }}$ century, Nikolai Kondratiev, used it as a reference point in the construction of his theory of economic statics, dynamics, and genetics. $^{170}$

Sorokin came to the conclusion that human behaviour is based on psychophysical reflex-type mechanisms, and the life of a society is an infinite chain reaction of actions-reactions, whose interaction underlies historical processes. ${ }^{171}$ At the same time, the collective reflex acts as the integrating moment. ${ }^{172}$ Thus, the mechanisms of action and reaction operate not only at the individual but also at the group and society levels.

Society progresses according to the following pattern: normal development - revolution - normal development. ${ }^{173}$ However, revolutions, instead of being the «engines of history», are destructive explosions, representing the reaction of society on its infringement of the psychophysical foundations of its own ability to live. Sorokin resolutely underlines that the intensification of the suppression of the basic instincts of the majority of the population was always the main reason and the direct precondition of any revolution. ${ }^{174}$

This relates to the following basic instincts: the digestive instinct; the proprietary instinct; the instinct of self-preservation (both individual and collective); the sexual instinct; the instinct of freedom; and the instinct for the self-expression of inherent abilities. ${ }^{175}$ In other

${ }^{170}$ N.D. Kondratiev, "Main Problems of Economic Statics and Dynamics", M. "Nauka", 1991, pp. 31-71.

${ }^{171}$ P.A. Sorokin, "The System of Sociology", vol. 1, M. "Nauka", 1993, p. 62.

172 P.A. Sorokin, "General Manual of Sociology. Articles from Different Years", M. "Nauka", 1994, pp. 62-70; "The System of Sociology", vol. 1, pp. 260-415; vol. 2, pp. 12-28.

${ }^{173}$ Pitirim Sorokin, "Man, Civilization, Society", M.: "Politizdat", 1992, p. 268.

${ }^{174}$ The same source, p. 272.

${ }^{175}$ The same source, pp. 272-289. 
words, hunger and impoverishment, fear and compulsion, and the impossibility of establishing a family and finding employment corresponding to ones abilities - these are the main initial sources of revolutions.

This immediately raises a series of questions. First of all, is this not reductionism - an attempt to reduce social phenomena to physiological phenomena? Firstly, note that in this context, Sorokin speaks of the psychophysical bases of the behaviour of people, instead of the social mechanism as a whole (an issue, to which I will return). Secondly, one needs to remember that it is characteristic for both individuals and society to present themselves as more advanced in terms of social progress, than has been the case throughout history in general and in the $20^{\text {th }}$ century, in particular.

Another possible question concerns the fact, whether such an approach erases the boundary between the behaviour of animals and humans, who can act not only impulsively but also consciously, take future prospects into consideration without being limited to momentary needs, and are even capable of self-sacrifice? The instincts of many animals are orientated towards maintaining future requirements: squirrels, mice, and bees create food stocks; birds and fish are instinctively aware of routes, which are thousands of kilometres long, leading to the locations of their nests, where they spawn, etc. Moreover, those animals, in which the instinct of collective self-preservation functions more strongly, are capable of individual self-sacrifice. Certainly, unlike animals, humans can act consciously. However, are these actions directed against their instincts or for their fulfilment?

Instincts are difficult complexes of inherited or obtained reflexes, automatically reflecting the requirement of an organism and focusing its abilities on its satisfaction. Requirements and, consequently, instincts, can compete with each other and suppress each other, and here the conscious will plays a significant role in the selection of priorities. However, at the same time, consciousness merely chooses whom to serve in the first place. Can consciousness suppress all instincts? It can. This is testified by the relics in the underground cells in the Kiev-Pechersk Lavra.

Not all conscious activity is premeditated. If a person, based on his needs, selects a plan and tries to achieve it, but then, moved by hunger 
or fear, turns and runs in the opposite direction, his flight is fully conscious, although not premeditated.

In normal civilised conditions, a person consciously considers and realises his requirements, and the link between separate instincts and specific acts is often not obvious. Instincts are usually in a latent, drowsy condition, forming the general psychological background and framework for conscious activities. However, even if one important requirement remains unsatisfied to the extent that it has become accustomed to being fulfilled, the instincts are aroused and pressure is exerted on the nervous system.

The suppression of the basic instincts as a result of the impossibility of satisfying the essential requirements of the majority of the population creates direct preconditions for revolution. However, the link between unsatisfied requirements and revolution is self evident, so what is «new» in Sorokin's discovery?

Sorokin's discovery, which, in my opinion, has still not been given its due appreciation, is that that revolution assumes a deep and steady shift in the psychophysical bases of the behaviour of the masses, which generates a chain reaction of structural changes in the mechanisms of the interaction of the basic instincts, individual and collective, resulting in destructive consequences for society in general and the economy in particular (this process should be named after its founder, Sorokin).

Thus, revolutionary society is characterised by special psychophysical laws and destructive energy, which gathers secretly, and then starts a cumulative chain reaction. One needs to remember that destructive processes in society and the economy, once they begin, do not lead to the elimination of the reasons which caused them, but to increasing the compulsory restriction on the requirements and suppression of the basic instincts, and the latter biologises mass behaviour and makes it (until its exhaustion) increasingly aggressive.

The destructive energy of revolution can be used in certain ways, it can be directed, but it is very difficult to regulate; those, who open the path of revolution, cannot then control it or stop it half-way. That is why revolutions have been compared to monsters that devour their own children - and not only their own.

Now, I will discuss Sorokin's theoretical conclusions, which are of great practical interest for modern Russia. In discovering the destructive potential of revolution, Sorokin did not consider the 
alternative in the preservation of the status quo, but in reforms. However, I stress that reforms themselves carry the danger of sliding into revolution, if they violate the psychophysical basis of society and the system of its collective reflexes.

In order to avoid this, reforms should meet a number of fundamental imperatives. First of all, reforms should not trample on human nature and contradict its basic instincts. Further, careful scientific research of specific social conditions should precede any practical implementation of reforms. Besides, each reconstructive experiment should be tested in the beginning on a small social scale. Finally, reforms should be put into practice through legal and constitutional methods. ${ }^{176}$

Thus, Sorokin formulated four canons of evolutionary reforms, whose violation renders each attempt at social reconstruction futile, and has clearly contrasted them with revolutionary reforms. He states that people follow canons, when erecting bridges or for the cultivation of cattle. However, often it is considered that for the reconstruction of society, there is no need to follow such canons. An ignorant person frequently becomes the leader of revolutionary reforms. Consequently, these revolutionary methods lead to failures in revolutionary reconstruction and an unacceptably high number of deaths. ${ }^{177}$

From the point of view of the criteria stated above, the «shock» economic reforms in modern Russia are more revolutionary than evolutionary. Undoubtedly, they have had a destructive effect on the psychophysical basis of society. However, it remains to be seen how deeply and whether they have triggered Sorokin's cumulative processes.

\subsection{Extremism as the Prepotent Psyche of the State's Socialist Transformations}

The biologisation of the psyche noted by Sorokin originally entered different layers of the population in Russia to a very different degree. To the greatest extent, it gripped the soldiers, involved in the

\footnotetext{
${ }^{176}$ Pitirim Sorokin, Man, Civilisation, Society, p. 271.

${ }^{177}$ The same source, p. 271-272.
} 
butchery of the First World War and the poorest peasants and the majority of workers, whose positions had sharply deteriorated in conditions of war and acute food shortage.

Confronted with the aggressiveness of a growing proportion of the population, the ruling elite had to quickly and cardinally change their traditional behaviour: to move away from their monopoly on power and surrender a significant part of their wealth; to include the governing elite from the opposing group, the Right Esers and the Mensheviks, in their structure; and withdraw from the war. Such attempts were undertaken, but were not supported by the nobility. In the environment of the Russian ruling elite, there was no leader of the scale of Peter I, who could, at the critical moment, break its traditional psyche of domination for the sake of maintaining the social status quo. In other words, this elite appeared incapable of searching for an exit from this extremely deep national crisis in social and economic innovation.

The Russian elite returned the aggression of the lower class with their own aggression, by starting a civil war, which led to the biologisation of the psyche of the elite itself. As a result, this war (like the majority of civil wars) turned into mutual destruction and psychosocial genocide, which caused an irreversible shift in the psyche of the whole generation, affected by the war. This generation remained active until the 1960s-1970s, and left the scars of social irreconcilability on the psyche of the nation for decades ahead.

The ruling elite of Russia, having involved the country in World War I, hoped to consolidate the nation on the basis of the instilled ethnic instinct of patriotism, but the result turned out to be directly the opposite - a deep split in the nation. The Marxist-class terminology in Lenin's rhetoric only outwardly covered the basic strategic target of the New Economic Policy - by the creation of a multilayer market economy, which would provide the economic conditions required for the restoration of the psychic balance and unity of the nation and its further development. Essentially, Lenin's innovative idea was to create a pluralistic institutional system, suitable for a normal state of the psyche of both the individual and the entire population. However, the economy was not able to overcome the extreme psyche of the new elite and the steadily aggressive syndrome of the part of the population following it. 
The extreme psyche demanded the suppression and replacement from society of all those, whose psyche resisted the aims of dictatorial collectivism. Collectivisation, industrialisation, and the Gulag were ways of continuing the civil war. This constituted the social innovation of Stalin and his party.

In a normal, evolutionally developing society, the formation under the influence of culture - of instilled existential requirements and instincts occurs, in general, in line with the proportional increase in the population of individuals with a balanced, steady, and harmonious psyche. Revolutionary societies with undermined moral standards and destroyed systems of values and institutions, where biological instincts rule, are characterised by a sharp proportional increase in the population of individuals with an unstable psyche, dominated by instincts of aggression and self-preservation. The part of the population, which has an unstable psyche, can be easily manipulated and its aggression directed against any of the opposing parties. In these conditions, organised groups of individuals with a stable psyche of the extreme type are able to acquire a great deal of force and influence. Note that an extreme type of psyche refers to a psyche, in which, on account of both its inborn and instilled properties, certain existential requirements and instincts not only dominate, but also suppress, others.

The Bolsheviks were such a group. They had an extreme psyche, the heart of their organisation consisted of revolutionaries underground workers, recognising only radical methods of action and insisting on absolute irreconcilability with those, who had different ideas to them, i.e., people, whose psyche did not correspond to revolutionary and extreme criteria. In 1924, Stalin spoke sincerely, when he said near Lenin's coffin: «We, Bolsheviks, are people of a particular type. We are created from a special material.»

This kernel (of Bolsheviks) consisted of two thousand people at the time of the Revolution in February, 1917; by the time of the Revolution in October, it had expanded to 40 thousand, and during the years of the civil war and the system of military communism, it increased several-fold, taking into account the commissars and commanders at the front and the rear lines. The basic psyche of the Bolsheviks consisted of the expression of the social instinct in its extreme form, taken to a level of extreme negation of the individual origins of the person and the negation of the existential requirement 
for freedom. In the Bolsheviks, the existential requirement for a person to belong to a collective and to society was taken to extreme limits, where the individual becomes ruthless in relation with himself and other individuals, and instinctively appropriates the absurd right to assert on these individuals comprehensive and total demands on behalf of society (in this case, on behalf of the proletariat). The consecutive implementation of the principle of full collectivism leads either to destructive anarchy, or to the individual dictatorship of that individual, who has the greatest capability of exerting control.

Lenin's psyche was created from the same extreme and uncompromising substance. However, he possessed ingenious mental abilities and an iron will, which allowed him to suppress in himself his inclination for extreme collectivism in 1921, when, in desperate conditions of ruin, hunger, and peasant revolts, he made the decision to recede from the position (that was so close to the psyche of the Bolshevik) of military communism to a position of a multilayer and compromising New Economic Policy, and, using his great authority in the party, convinced its leaders and members of the necessity of a cardinal shift: the transition from a revolutionary and violent way of development to an evolutionary and reformatory way. Moreover, he recognised that this new position (which, essentially, denied the extreme psyche) demanded «changes of all our points of view on socialism».

However, this new ideology and politics, despite the obvious success of its implementation in practice, remained alien to the extreme psyche of the majority of party members, and was discarded by this majority, as soon as the internal economic and external position of the country improved. The psyche won over reason. Starting gradually and covertly in 1926 and more openly and resolutely from 1929, the revolutionary ideology, suited to the extreme psyche of the Bolsheviks, had returned and was again being followed. This psyche, which had been compromised in the days of the New Economic Policy, had freed itself of these restrictions and manifested itself without compromise. People, whose psyche was incompatible with the psyche of extreme collectivism, were persecuted: this included peasants, small businessmen, the intelligentsia, and even a significant part of members of the Bolshevist party itself.

In practice, the development along the line of a proletariat dictatorship resulted primarily in the dictatorship of the party over the 
working class, and within the party it accelerated the process of bureaucratisation and the establishment of an autocracy in the form of a cult of Stalin's personality.

The extreme psychology of the ruling elite in any variant (collectivism, nationalism, racism, religious fundamentalism or anarchic individualism) always leads to individual dictatorship. In Russia, in the 1920s, the mechanism for the establishment of a dictatorship consisted, firstly, in the struggle for individual power between Trotsky, Zinovyev, Kamenev, and Bukharin, and, secondly, in the continuous strengthening of the role of the party apparat in the actual management of the party and the country. The general technical secretary, Stalin, was at the head of the administration and, under the party charter, could influence its policy only to the extent that he was one of the members of the Politburo of the Central Committee of the Communist Party (moreover, not the most influential member). However, the charter is a formal institution, and the actual relations were defined by the psyche (including the ability) of the specific people concerned. Already in the early 1920s, Trotsky stood up against the domination of the party apparat (which, since 1922, had been headed by Stalin), but Lenin stopped him, having proposed the slogan «Hands off the Party!». However, shortly before his death, in 1923, Lenin suddenly (and, probably, with a sense of embarrassment) found out that his protégé Stalin, as the head of administration, had concentrated immense power in his own hands, which he was capable of using without due care, and demanded to have him transferred to other work. However, it was already too late.

The $13^{\text {th }}$ Congress (in 1924), prepared by the party apparat, contrary to Lenin's demand, left Stalin in his former post, and, at the same time, sharply condemned Trotsky and his supporters. This was the first step in the confirmation of the cult of Stalin. However, in strictly centralised parties, as was the case with the Bolshevist party, the cult of leaders has always been dominant.

The cult of the personality of the leader as a social phenomenon, as the behaviour of the masses, is repeated from millennium to millennium, from century to century, from decade to decade, and from country to country. Depending on the epoch and the country, this phenomenon appears in new guises and with new themes. However, they contain common features, which are connected with the fundaments of the universal psyche, with inborn and instilled 
existential requirements and instincts, and also with the abilities of a person.

First of all, as a rule, it is characteristic for individuals to need to belong to a society (kin, a tribe, a family, a community, a nation, different organisations, etc.) and to trust people with whom they enter into direct or indirect contact. In addition, the herd instinct and the instincts for hierarchy and imitation are also inherent in people. These are the sources of the initial demands on the leader: he should arouse in people the desire to belong (together with the leader) to one group, trust him, and subjugate themselves to him as members of the hierarchy; he needs to possess qualities, which the people would like to imitate.

Due to the action of the instincts, it is characteristic of people (as well as for many kinds of «social» animals) to constantly try to find and select a leader, whom they can follow and who demands their subjugation. However, unlike animals, the instinct of belief is inherent in people. In early paganism, the phenomena and objects of nature were idolised; later, people were attributed with supernatural properties - wizards, priests, prophets, leaders, and emperors.

At the same time, the opposite (in comparison with those mentioned above) requirements and instincts are also inherent in people - the desire to dominate over others and make them (the others) submit to their will. These requirements and instincts are dictated by the deep logic of the genome. The activity of each genome, as is well-known, is directed towards self-preservation and self-reproduction through the creation of a specific organism, support of its activity and the genetic transfer of the genes of the given genome to the next generation of similar organisms. The more successfully this transfer is carried out, the better the given organism adapts to existence among (primarily, similar) organisms. In the animal world, variants of such adaptation exist: submission, domination, cooperation, and their combination. For millions of years, the ancestors of modern man developed similar properties in themselves. As a result, some people possess such genetic mechanisms, which dictate their aspiration to dominate and subordinate the behaviour of other people to their will. This property of the psyche cannot be reduced simply to «leadership», for it also includes aggression concerning the individuality of other people, i.e., the aspiration to deprive them of their individuality and transform 
their (the other people's) individuality into conforming with their own psyche. Such behaviour can be considered as a perverted aspiration to extend ones own psychogenetics on all mankind.

Certainly, the inborn aspiration to dominate the psyche of others is insufficient. One needs to have the ability to attract people, touch their feelings, inspire them to trust themselves, and be one of them and, at the same time, possess outstanding abilities and spiritual qualities. In other words, in order for a person to become the object of the cult of personality, he needs to possess a rare and contradictory combination of psychic properties, including existential requirements and abilities. Finally, the ability to hide ones aspiration not only to dominate, but to be transformed into the Great Inquisitor, plays an important role.

When the genetic aspiration of a large mass of people to find the object of the cult of personality comes across an individual, truly capable of becoming such an object, it results in the emergence of conditions suitable for rallies and powerful actions, both destructive and creative.

However, not everyone has a psyche, compatible with a cult of personality. Those, with sufficiently developed instincts of selfpreservation, freedom, creativity, expediency, and compassion cannot be adapted to the hierarchy of the cult of personality and cannot be tolerated; for the cult of personality is primarily a system of mass psychic terror, which does not tolerate individuals, who are sure that «the King is naked». It inevitably leads to «psychogenocide», through the imprisonment or physical destruction of people possessing a psyche that differs from the psyche of those, who participate in the cult of personality. At the same time, this process occurs regardless of the initial political system, from democracy to monarchy and military dictatorship.

The cult of personality is a phenomenon, covering not only the psyche, but also all aspects of life - the economy, the social sphere, politics, ideology, etc. However, the emphasis on the psychic bases of the cult of personality is necessary because there is a mistaken belief that one can avoid the danger of the occurrence of such a cult by changing the economic and political system, social conditions, and ideology. History has taught us otherwise. Qin Shi Huang-di in Ancient China, The «Divine» Augustus and Nero in ancient Rome, Genghis Khan in Mongolia, Tamerlane in Central Asia, Savonarola in Italy, Cromwell in England, Napoleon in France, Hitler, Mussolini, 
Stalin, Mao Zedong, Mahatma Gandhi in India, Nasser in Egypt, Castro in Cuba, and Khomeini in Iran - all these figures were objects of blind mass cults which had different and, in many cases, catastrophic, consequences.

Therefore, in any historical conditions, there is only one way of preventing a cult of personality: one needs to block at the earliest possible stage the path of the charismatic leader to power, if this leader possesses an extreme psyche.

A nation, which wants to avoid spiritual and physical violence on its territory, military adventures, and social shocks, should firmly bar the way to power to any leaders with an extreme psyche, and especially those, who are capable of becoming a cult object. History has shown and continues to show that the culture of the majority of nations and its preventive measures (against the development of a cult) through the formation of instilled requirements and instincts were absolutely inadequate to the task of suppressing the inborn attraction of the majority of people to the cult of charismatic people, including extremists.

However, I will return to the psychological aspects of the economic history of the USSR.

Who were the delegates at the $13^{\text {th }}$ Congress of the Bolsheviks, who, in 1924, laid the first stone in the formation of Stalin's personality cult? This party, which had only recently emerged from the underground, had a total of just two thousand professional revolutionaries and their closest supporters in February, 1917; at the end of 1917, it already had 40 thousand members. During the civil war, and then as a result of «Lenin's call-up», after Lenin's death (in January, 1924), the party expanded to a half-million members. The overwhelming majority of party members had little education, were often semiliterate, and came from working class and the poorest peasant families. They were united by revolution and war, and by their «class unity» or, to be exact, by their shared extreme psyche, and they blindly followed Lenin. Stalin also had lower class origins, which were visible in the rough simplicity of his conduct and his dislike of the intelligentsia, which he maintained, despite working closely with the intelligentsia for decades.

In 1923, Stalin in his conflict with Nadezhda Krupskaya clearly let it be known that he was weighed down by the burden of protecting the ill Lenin and thirsted for power. Nevertheless, Stalin had learnt the 
lesson, taught to him by Lenin in his address to the $13^{\text {th }}$ Congress, and he therefore took into consideration the mood of the delegates at the congress. Henceforth, we deal with two Stalins. One wears a mask, shown to all, of a good-natured, benevolent, and modest «father of the people», and an advocate of justice and tolerance. The other is resolute and harsh, who goes underground, from where he deals ruthlessly with anybody, who stands in his way to individual power, using other people to carry out his treacherous plans and creating a psychosis of a «class» war in society.

The following stage in the history of the «cult» is seen at the $17^{\text {th }}$ Congress (1934). The type of delegates arriving at the congress is about the same, as ten years previously. With the difference that the people are more competent, after having experienced at first hand Stalin's industrialisation, collectivisation, dekulakization, and mass hunger. On the one hand, they were already aware of the hypocrisy and damage caused by Stalin's management; however, on the other hand, the delegates had passed through fire in the careful selection process, based on the criterion of personal loyalty to the leader. In his report, Stalin flatteringly named the delegates (and they included almost all the entire top political layer of the country) as «victors» in the struggle for socialism. However, in the elections for membership in the new Central Party Committee, about a third of these «victors» selected by Stalin, voted against him (in favour of Kirov unanimously).

What was Stalin thinking after the votes had been counted, outwardly preserving a good-natured and benevolent expression, as he looked at the delegates in the hall from the presidium? He saw them as traitors, prostitutes, enemies of the Party, Judases, spies, etc. This is roughly the lexicon that appeared in Stalin's resolutions on the lists of the executed in the second half of the 1930s. Almost all the delegates of the $17^{\text {th }}$ Congress were repressed during this period. It became clear to Stalin that the entire party needed to be reformed, and it was reformed. Henceforth, acceptance to the party and promotion came to depend, in practice, on only one criterion - personal loyalty to the Secretary General. These were people with a different type of psyche, characterised not by instincts for aggression and collectivism, but by instincts for hierarchies and adaptation. With such an adaptive psyche, which was «flexible within the framework of the hierarchy», the Party 
continued to exist for another half a century, right up to its disgraceful and meek dissolution in 1991.

The shrewd Stalin was, of course, aware that such people can be used, but cannot be relied on. Therefore, the entire institutional system in the country was constructed on two ancient principles: a combination of the stick and the carrot, and mutual rivalry and mutual control («divide and dominate»). Simply speaking, the Party apparatus and primary organisations supervised each step of the activities of the economic and «Soviet» leaders from top to bottom. Besides, the entire Party was engaged in «educational activities», i.e., introduced the cult of the leader in their environment, the army, and the masses, and this was watched vigilantly by the ubiquitous bodies of the KGB; the entire Party apparatus was under their control.

At the same time, the Central Committee of the Party, the Council of People's Commissars, the KGB, and other state bodies were, in practice, not allowed to take political decisions. These decisions were taken by Stalin, surrounded by a narrow circle of his trusted colleagues (who had taken part in the repressions of the 1930s). The entire party and state «engine» of the USSR possessed the psyche of an adaptable executor and was organically not capable of developing new independent solutions. Its political feebleness was fully manifested in the second half of the 1980s, when such decisions were required for its own survival.

\subsection{Dynamics of the Psyche and Institutional Adaptation in the Economy of the USSR after the Second World War}

The main driving force (in light of the weak material stimulus) concerning the fast growth of industrial (primarily military) production in the USSR after the Second World War - according to state propaganda was provided by the enthusiasm of the masses directed by the Communist Party of the Soviet Union (CPSU), whereas foreign critics of state socialism argued it was through state coercion. Accordingly, the formal system of economic institutions was interpreted by the Soviet ideology as the implementation of informal «relations» of cooperation and mutual aid of people, free from 
exploitation; and, which, critics considered as a mechanism of noneconomic compulsion to work.

Both parties interpreted the transformation of the specified formal institutions as the result of a change in the internal and external conditions, primarily, financial and technological, in which the informal institutions operated. With the essential difference that official propaganda was based on the fundamental permanent conformity of the Soviet Union's formal and informal institutions with each other and with the surrounding material conditions, and critics based their arguments on their equally fundamental incompatibility with each other.

In both these arguments, one can find three weaknesses. Firstly, the statement about «enthusiasm» was applicable only to a part of the workers in the USSR, mainly to the young workers, and, not to all of them. ${ }^{178}$ Similarly, the statement regarding the coercion used is also applicable to only a minority of workers. Up to the 1960s, the majority of workers were conscientious and diligent - habits that they had developed in the 1930s-1940s, based on a fear of military threat and

${ }^{178}$ In the second half the 1920 s, the writer, V.V. Veresayev, over a period of one and a half years studied "from within" the lives of workers of Moscow's rubber shoe factory, the "Red Hero", and, on this basis, in 1931, finished writing his novel-research book, "Sisters". This is what was written in this novel about the enthusiasm for work: "Not all the workers, in contrast to what is written in the newspapers, and not even the majority of workers, are enthusiastic. For one reason or another only $410-450$ of the 6000 workers at the factory actively participated in competition and led the masses forward. They were made up of different types of enthusiasts, those that put all their strength of body and mind in their work and others that were different types of chauvinists - self-praising, careerists, and boasters. There were Party members, working precisely as a result of their discipline. Many were attracted by the rewards promised, and others by the publication of eulogies to them and their photographs in newspapers. From these diverse motives both light and dark - the Party has managed to shape one hard steel spring, which pushed and drove the will of all in one direction - to implement a huge, and almost unbelievable plan. At the same time, slowly and with difficulty, they instilled a new relation to work in the working masses. (V.V. Veresayev, "Literary Portraits, Moscow, Publishers", "Republic", 2000, pp. 489-490.) It is true, that it is "new", but what this "novelty" consisted of, became clear considerably later. 
trust in the future of communism. This majority in general supported (for the most part, passively) the official economic policy and trusted their ability in improving the existing system. It was on this basis that the USSR was able to transform itself into a superpower.

Secondly, these approaches, ignoring the dynamism of the psyche, make it impossible to understand the historical evolution of the system of state socialism, which at first launched it forward, and then to stagnation and destruction.

Thirdly, attempts at explaining long economic booms or deep declines in specific countries and the transformation of their economic institutions by references to the moods of only parts of the population, of state coercion, propaganda, and diverse specific circumstances are only superficial descriptions.

The analytical approach assumes the detection of internal motives of individual and collective behaviour and their changes, in other words, its psychological factors. Here, there is no need to reconsider direct and reverse links between requirements, the psychological mechanisms of their occurrence, economic interests, rational decisions, and real actions (behaviour). One needs to keep in mind that the psychophysical basis of behaviour is formed by the inborn (unconditional) instincts limited, supplemented, and directed in a given specific ethnos by the historically developed hierarchy of values, system of customs, moral standards, and behaviour stereotypes, many of which are essentially complex conditioned reflexes (instilled instincts). To this, one needs to add the ability of people to psychologically adapt to changing conditions, to acquire habits, and also to break away from them. This multilevel, internally inconsistent, tense, and varying (together with changing external conditions, but much more slowly than them) world of psychology also forms the basis of those irrational or «partly rational» decisions, with which economic theory (and other theories) operate. The historical practice of the creation and reorganisation of formal economic institutions - norms, rules, and the organisations founded on them - is based on the same grounds.

Let us try to look at the basic stages of post-war transformation of Soviet economic institutions from these points of view.

The totalitarian stage. In his speech on February 9, 1946, summing up the war and defining the basic course for the next two or three five-year periods, Stalin underlined two points. On the one hand, 
he underlined that the war had been won due to the Soviet political system, its social order, and the armed forces. This can be considered as his instruction on the necessity of preserving, in principle, the basic formal system of institutions, including economic institutions, developed in the USSR before and during the war, and "exporting» them to countries of the newly created Soviet Bloc. On the other hand, he made it clear that the safety of the country was under threat and that «in order to protect itself from any accidents», it was necessary to sharply increase the production of metal, coal, oil, and electric power as the foundations of the country's ability to defend itself.

One would have thought that after the most bloody war in history, resulting in the loss of over 27 million Soviet lives and tens of millions of invalids, in conditions of complete ruin, and the impoverishment and exhaustion of the population, he needed to emphasise the development of agriculture, the food and light industries, construction, and market relations. Such a policy was successful after the civil war in the 1920s. However, Stalin, contrary to logic, counted on the further militarisation of the economy and strengthening centralisation for managing it.

Furthermore, in his work, «Economic Problems of Socialism in the USSR» (1952), Stalin implied the gradual termination of those elements of market relations, which still existed in the country, and their replacement by a system based on «the exchange of products».

What was Stalin's reasoning in going against, apparently, obvious economic logic? Was he counting on the «enthusiasm of the masses»? Was he thinking of «state coercion»? He had a much stronger and wider basis for carrying out his policy, provided by the developed mass psychology of the population. One can consider Stalin as a leading expert in this area. As a result of the enormous number of victims, burdens, and exasperation caused by three revolutions, the First World War, and the civil wars (in 1905-1921), many centuriesold moral standards and customs were broken, the formal institutions that had been developed were undermined and destroyed, and the «biologisation» of human behaviour had taken place (Pitirim Sorokin). The actions of people were being governed by instincts, and, primarily by the instincts of survival and self-preservation, as well as by the instinct of aggression, which was closely connected to them everything, which is the basis of the psychological condition, called the «revolutionary consciousness». 
Stalin was a leader, who took advantage of this psychology in order to force industrialisation and collectivisation and, at the same time, carried out mass repressions, and created a centralised planned system and a collective-state-farm system. Later, Stalin himself indirectly acknowledged that the creation of collective farms was required for the supply of bread to the military-industrial complex. The confrontational relations that existed at that time between the USSR and its neighbours, instead of being soothed, were deliberately aggravated to increase the feeling of militancy within the country, which was in turn used to transform Soviet institutions into a rigid centralised structure.

Why does the psychological condition, which is characterised by a struggle for survival and the dominant role of the instincts of selfpreservation and aggression, justify the transformation of institutions into a centralised system of planning and management? Because, such a system gives direct guarantees of survival to the majority of the population by the relative equality of distribution of the limited amount of goods available and the introduction of a general «work obligation», and at the same time, increases the military strength of the nation.

In order to support the dominant role of the instincts of selfpreservation and aggression, which with their intensity suppressed other important natural instincts - expediency, freedom, appropriation, etc. - in the years after the Second World War, the policy of a «creeping» civil war was continued in various forms: mass ethnic cleansing of populations in the liberated territories, the deportation of some small ethnic minorities to uninhabited regions, repressions against former Soviet prisoners of war, the Leningrad case, the struggle against cosmopolitism, the Doctors' plot, etc.

However, after the war, the grounds for social antagonism, which Stalin had used for support, began to fade away.

The Second World War caused a shift in the mass psychology of all the countries that had taken part in it, especially those that incurred the greatest human losses. The «natural militancy of people» and their aspiration to aggression and dominance sharply weakened, and, in contrast, the congenital requirements for cooperation, mutual aid, dialogue, justice, freedom, and self-fulfilment became much stronger. In the West, this found expression in the development of democratic institutions and regulated markets, and in the creation of organisations, 
focused on multilateral rapprochement and the regional, economic, and political integration of nations.

Internationally, the most dramatic manifestation in the shift of the psyche of the masses from animosity to solidarity was the creation and activities of the United Nations (the UN) and its specialised institutions.

In the USSR, the shift in the psyche of the population consisted in overcoming the civil war syndrome, mutual «inter-class» bitterness, and the revolutionary consciousness; and there was a unification of the people on the basis of the national sense of community, which had developed during the Great Patriotic War. In the perception of the adult population, which had endured the war, Stalin's cult of personality had been irrevocably undermined. It was clear to the majority, that Stalin was responsible for the enormous losses and defeats that occurred in the first one and a half years of the war.

Stalin, aware of this, feverishly searched for a base to consolidate his individual power by again stoking antagonism within society. However, in the changed conditions it was no longer possible to frighten the people by the threat of internal «class enemies». Instead, he found an «exit» in the «struggle against nationalism». Even during the war he had deported ethnoses in the eastern and northern regions of the country: the Germans of the Volga region, the Crimean Tatars, the Chechens, the Ingushes, and the Karachays. After the war, Stalin locked many hundreds of thousands of released Soviet prisoners of war in concentration camps, sent a significant part of the intelligentsia in Western Ukraine and the Baltics to Siberia, prepared (but did not have time to carry out) the mass deportation of the Jewish population to the Far East (which is why he organised the «struggle against cosmopolitism»), and the «Doctors' plot. However, the destruction of the «great Russian nationalism» was the most important «front» for him. During the war, a whole galaxy of young and talented leaders, ready to replace the compromised upper layer under Stalin were brought forward. The Leningrad case (the case of the «Russian bureau of the Central Committee»), as a result of which two thousand people were executed, was specially concocted in order to execute them.

The «cold» war, together with the various «hot» wars (in Korea, Vietnam, Angola, Somalia, the Middle East, Central America, etc.), was the most influential post-war factor that affected the psyche of the masses. The Cold War was fought by two sides. In this way, the West 
tried to isolate from the USSR, and weaken, the strengthened procommunist movement in Europe and other parts of the world, and economically destroy the USSR. In the Cold War, Stalin saw a means of strengthening his individual dictatorship, by creating the conditions of a «besieged fortress» within the country and thereby justifying his new waves of repressions.

It seems that by these actions, which were absolutely against the interests of the population, during and after the end of the Great Patriotic War, Stalin laid the deepest and longest-term foundations of a policy, which ran counter to the new condition of the basic (at the unconscious level) psyche of the population of the country. This resulted in a very deep and irreversible rupture between the people as $a$ whole and the authorities (this rupture also occurred within the party itself), which no amount of correctional and reconciliatory measures were able to overcome, and which manifested itself 35 years after Stalin's death in the collapse of the system and the disintegration of the country. The people can forgive the authorities everything however, only at the level of consciousness and habits. At the level of instilled values, long-term memory, and preconsciousness - nothing is forgotten. Stalin had mocked the people of the USSR and had shown that he did not care about the terrible suffering that they had endured in winning the harshest of wars.

It is difficult to say with certainty whether Stalin understood this, although it is very possible that he did. In any case, he knew of the Chechens, Ingushes, and Latvians. He did not trust the others either. Moreover, this was not due to his maniacal distrustfulness, but as a result of the astute and sober estimation of the scale of the harm done by him.

However, like almost any dictator with an extreme psyche, he was not in harmony with time, he believed that time would obey him and that it can be compressed and stretched. It seems that he was convinced that the Third World War (with his assistance) would break out in the near future, that the imperialist countries would squabble amongst themselves, and that he would transfer it onto the path of a «revolutionary struggle». This latest global revolution would result in a huge number of casualties and would extinguish all memory of past repressions and regenerate mankind for a new life. In his imagination, Stalin saw himself on the border of the new and old worlds, rising eternally to the sky. 
During the first post-war five-year period, the population continued to work as hard as it could, at the same pace as it had during the war. The economies of the republics and regions to the West of the Volga that had been destroyed completely were restored, the army was reequipped, and nuclear-rocket potential was created. Huge material aid was rendered to allied countries in East and Central Europe. However, the conditions of extreme pressure and deep psychological deformation were not natural and could no longer be maintained. In the early 1950s, the crisis of the totalitarian model began to manifest itself openly and the growing discontent of the population began to corrode the party. In October, 1952 in his address to the re-elected members of the Central Committee, immediately after the $19^{\text {th }}$ Congress of the CPSU, Stalin recognised that the party was split from top to bottom, and strongly criticised the leftist Molotov and the rightleaning Mikoyan. The thesis about the implicit split of the party was confirmed immediately after Stalin's death in March, 1953, with the beginning of the struggle for control over the various strategies of economic development and institutional reforms (closely connected with the race for power).

The «partisation» of the Soviet economy. In the system of formal institutions and organisations of a totalitarian system, based on the exploitation of the instincts of self-preservation and aggression and the psychological syndrome of a cult of personality, the police forces and security structures - the KGB, the Ministry of Internal Affairs, and the Ministry of Defence - occupied the central positions. They not only supervised the activities of all economic organisations, from the State Planning Committee to the enterprise, but also directly operated key sectors of the economy, such as power stations, transport, the defence industry, the huge economic complex of the Gulag, etc. «The Supervisory and governing role of the CPSU» was fiction; actually, after the purges of the 1930s, the Party had been turned into a controlled economic and propagandistic educational tool of individual dictatorship. The punitive bodies supervised the entire state system and the Party itself. A clear example of such control can be seen in the outrage, committed by Beria (in 1949) against the Chairman of the State Planning Committee and a member of the Politburo,Voznesensky, for having shown independence.

Stalin's death (in March, 1953) represented a psychological crisis, which had been maturing for a long time in the people, who were tired 
of the endless and continuous pressure, morally united in the war against fascism, and did not wish to be involved in the new creeping civil war, which had been triggered by Stalin and was slowly gathering pace. The absolute power of the punitive bodies had been shaken. It is extremely indicative that the chief of these bodies, Beria, was the first to announce the need for revising the domestic economic and foreign policies immediately after Stalin's death. However, he failed to propose the abolition of the total control of the punitive bodies, which led his colleagues in the Politburo and the generals to suspect that Beria intended to maintain this control and take over as Stalin's successor.

The liquidation of Beria (as an «agent of imperialism»), a sharp restriction of the powers and functions of the KGB and the Ministry of Internal Affairs, and the dissolution of the Gulag were the first significant strides in reforming the system of formal institutions of the totalitarian system in all spheres, including the economic sphere.

The following act of the post-Stalin institutional drama involved the race for power between the Chairman of the Council of Ministers, Georgy Malenkov, and the head of the Party Apparatus, Nikita Khrushchev, (from autumn 1953 to the beginning of 1955). Malenkov believed that one cannot «assign the entire weight of building communism to one generation», which was interpreted to mean a reduction in capital investments and increased consumption, a restriction in the growth of the heavy industries (primarily, the military), an acceleration in the growth of the light and food industries, and increased self-financing and material stimuli.

At first, Khrushchev did not reveal his strategic plans (which just consisted of «building communism in a period of 20 years») - he took advantage of Malenkov's rough miscalculations. Firstly, Malenkov clearly was in too much of a rush to clean the Augean stables of the Party Apparatus, mired in drunkenness and formalism; secondly, he proclaimed, without justification, that the grain problem had already been resolved in the country; and thirdly, he encroached on the inner sanctum of the military industrial complex - uncontrolled military expenditure.

As a result, Khrushchev was able to have Malenkov removed from the post of Chairman of the Council of Ministers and replaced by the «neutral» Marshal Bulganin. However, the battle for leadership between the Party Apparatus and the State Apparatus continued, and 
in 1956, at the end of the $20^{\text {th }}$ Congress of the CPSU, Khrushchev outmanoeuvred his opponents by denouncing Stalin's personality cult.

In his report, Khrushchev did not essentially discredit the personality cult in general, but Stalin's cult, by placing special emphasis on opposing Stalin to the commanding officers of the army. In the end, Khrushchev's position on this issue turned the outcome of the struggle in his favour. Initially, the military commanders did not openly interfere in this struggle. However, when the ruling clique (the Presidium of the Central Committee of the Party, composed of the leading ministers) displaced Khrushchev from the post of First Secretary of the Central Committee in 1957, hundreds of members and candidates of the Plenum of the Central Committee were delivered to Moscow from the regions by military planes, and about half the places in the hall were occupied by generals, led by the Minister of Defence, Marshal Zhukov. «The anti-Party Group» (Molotov, Kaganovich, Malenkov, Voroshilov, etc.) was crushed.

Soon the State Apparatus lost its main support of the branch ministries. Instead of the liquidated ministries, management of the enterprises was transferred to the regional and republican economic administrations, and in the Apparatus of the Central Committee of the CPSU powerful branch departments were created. Full power, including economic power, was transferred to the Party Apparatus in the centre and locally.

It was a revolution of the institutional structure of the economy and revived the spirit of the system, which was dominant in the1920s and the early 1930s, when the economy (as well as the entire country) was governed by the Party. However, the Party had now completely changed, and Khrushchev was in a hurry to change its structure and spirit even more, having welcomed into the Party different types of «administrators», most of whom were ideologically and politically spineless.

Khrushchev's revolution of the institutional structure cannot be considered as a revolution of the upper layer of the Party Apparatus, as, in every way, it reflected a deep shift in the psychology of the masses, as a result of which the instincts of self-preservation and aggression ceased to dominate the behaviour of the masses.

One cannot consider the psyche of the population to be in a normal state, when one or two instincts suppress all the other instincts, in particular, the instincts of freedom, expediency, individual well-being, 
appropriation, and creativity. The normalisation of the psyche of the masses led to the replacement of the formal economic institutions, based on rigid specifications and centralised orders and control, with others, permitting material interest, initiative, and decentralisation.

However, these instincts formed the psychological basis of Khrushchev's reforms in a very limited way. The struggle for the full power of the Party in the centre and locally, which was conducted by Khrushchev as the head of the Party Apparatus, was carried out under a banner, promoting the accelerated pace of the construction of communism. Therefore, the main psychological support of these reforms was provided by the instincts of sociality - mutual aid, justice, hierarchy, and competition - rather than the instincts of individualism. The increase in the salaries in the collective farms and state farms was accompanied by a sharp restriction and, in some cases, failure of the household economies of collective farmers and workers, which generated widespread discontent in the agricultural population and sharply aggravated the problem of food production in small cities and settlements. The psyche of workers, who came out in a mass demonstration against higher prices and lower salaries (in Novocherkassk, in 1961) and were suppressed by the army, was also disguised.

On the whole, the psychological condition of society by the end of Khrushchev's epoch (1964) can be characterised as unbalanced (although, not as tragically, as it was at the end of Stalin's rule). The conflict between the instincts of individualism that were aroused to action but had been suppressed, on the one hand, and the unsuccessful implementation of the instincts of sociality, on the other hand, had become greater. The Cold War with the West had been aggravated by the political and border conflict with China, which reanimated the USSR's externally directed instincts of self preservation and aggression and strengthened the role of the military industrial complex in the institutional structure.

However, the main significance of the result of Khrushchev's transformations consisted of the fact that the Party Apparatus to which Khrushchev had transferred full power and given the task of constructing communism by 1981 , in its psyche was no longer communist, but conservative and bureaucratic. By the time Khrushchev realised this, it was already too late: he himself was overthrown by this apparatus in 1964. 
Kosygin's reforms - the search for a dynamic balance. Khrushchev's overthrow actually put an end to the "construction of communism». It was followed by a serious attempt to combine the institutions of a centrally managed economy with market institutions. It had been implicitly recognised that instincts of sociality could no longer remain as the main basis of economic institutions. Kosygin's reforms ensured that the production program of enterprises was made up of two parts: the mandatory state order and deliveries under contracts, voluntarily concluded with other enterprises and trading organisations. At the enterprises, funds were established for the development of production, social development, and material incentives for workers, which should be supplemented from profits.

Thus, reform was based on the instinctive aspiration for individual well-being and freedom, and also on the instinct of appropriation, evident, in particular, in the broad scale sale of cars and co-operative flats to the population. Kosygin's reforms encouraged the formation of the «group egoism» of labour collectives, which essentially is the combination of the instincts of individualism and fundamentally differs from the instincts of sociality. The latter (together with externally directed instincts of self-preservation and aggression) remained the psychological basis of a centrally controlled economy.

Concerning the psychological aspects of Kosygin's reforms, it would be useful to make a historical digression.

First of all, the tendency to construct an economy on two different bases has been observed for centuries in Russian economic history. Thus, in the times of Ivan Grozny, the country was divided into zemshchina, with a prevalence of large boyar estates, and the Oprichnina, where the former were destroyed and replaced by the estates of the minor nobility. These reforms significantly contributed to ruining the country and the subsequent difficulties at the end of the $16^{\text {th }}$ and beginning of the $17^{\text {th }}$ centuries, which divided and opposed boyars, noblemen, peasants, and the Cossacks. The subsequent division of manor estates into the «masters'» land and the peasants' land kept Russia in a state of backwardness for a long time. Later, the same dual approach was reproduced in Stolypin's reforms, in the Soviet collective farms, which were also poorly managed.

Military communism (1918-1921), with its comprehensive compulsory standardisation, was an attempt to construct a system of economic institutions, which completely suppressed the aspiration to 
individual well-being and appropriation. This system psychologically started with the biologisation of behaviour during the civil war, and after its termination, was unable to continue functioning.

It seemed that «normal» communism, based on the psychology of sociality (i.e., on the natural instincts of compassion, mutual aid, justice, the herd (instinct), imitation, hierarchy, etc.) and on the instilled instincts of loyalty to a social group, could serve as an alternative to military communism. Moreover, both during the civil war and after its termination, both in villages and in cities, there were many different types of communes. However, as the numbers of communes increased, two facts became clear: firstly, in the majority of cases, communes themselves could not be considered as factors of development of the economy or as an economic foundation of the state; secondly, though instincts of sociality, as well as instincts of individualism, are general natural instincts, there is no justification in considering them as dominant instincts in relation to the instincts of individualism and development (i.e., in relation to instincts of appropriation, freedom, expediency, creativity, inquisitiveness, competition, etc.) . In other words, attempts to use the psychology of sociality as an economic basis contradicted both the economic interests of the state and the psychology of the overwhelming majority of the population.

This leads on to Lenin's conclusion: the economy should not be built on the enthusiasm of the masses, but on personal material interest, using «revolutionary enthusiasm» as a supporting lever. Moreover, as far as communism as a form of collectivism is concerned (i.e., according to Marx, as a «system of self-operating communities»), Lenin did not consider such a variant even as a remote prospect. Lenin believed that these revolutionary masses themselves should be re-educated, so that everyone becomes used to working not for himself but for all society and, then, society (instead of a separate community) will take care of the requirements of its members. However, in his later articles, Lenin proposed that socialism should be considered in a new way, as a system of «civilised co-operators», but this applied specifically to socialism and not to communism (I will return later to the psychological aspect of the contradiction between the «community-oriented» Marx and the «statesman» Lenin).

The New Economic Policy marked the creation of a system of economic institutions based, on the one hand, on individual material 
interest, and, on the other hand, on state centralism. The psychological basis of the former lies in instincts of individual prosperity, and of the latter primarily in the externally directed instincts of self-preservation and aggression. As far as the «communistic» instincts of sociality and collectivism in the economy are concerned, they were firmly pushed aside to supporting roles and reduced to a semi-suppressed state.

In practice, the New Economic Policy has clearly shown that the construction of economic activities on different types of psychological bases in a society, which lacks a powerful and relatively homogeneous social «kernel» with a common psyche, inevitably leads to economic contradictions developing into political contradictions, and a struggle for power. The industrialisation which followed the New Economic Policy and collectivisation, and the ethnic cleansing and liquidation (of the kulaks and other classes) connected with them, from the psychological point of view can be considered as a cyclopean effort to create such a «kernel», through social and economic transformations and the elimination from society of all those individuals, who did not stay within the Procrustean bed of the unified psychological model of «the Soviet person». Marx and Lenin's slogan «socialism is the elimination of classes» was not fulfilled, as the destruction of one class was accompanied by the appearance of a new class; however, the actual purpose of the transformations - to achieve the formal unification of behaviour of the overwhelming majority of members of a society - was reached, at least, for a certain period of time. This psychological condition was officially called the «moral and political unity of the Soviet people».

Kosygin's reforms, as well as the New Economic Policy, combined personal material interest and centralism; i.e., it was based on diverse natural instincts, however, in a completely different social, economic, and psychological environment. That is why the contradictions had a different substance and orientation. Whereas, in 1927, the grain surpluses of the peasants were the specific axis of the struggle, after 1965 , the financial funds of enterprises, which started to be managed under new conditions, became this axis.

The success of the reforms led to significant growth in profits (and, thus, in the funds) at these enterprises, which immediately led the State Planning Committee and the Ministry of Finance to centralise a significant part of these means in the planned budget. As a result, enterprises lost the stimuli and the financial independence, which 
these reforms would have provided them. Later, Kosygin declared: «The State Planning Committee and the Ministry of Finance ruined the reform.» Although he could not say so openly, the contradictions lay deeper than the struggle between formal institutions.

This was a collision of people with different types of psyche between people focused on modernising society and increasing individual well-being (some of the directors of the enterprises, the intelligentsia, and workers), and, those who represented social conservatism (the party and state apparatus, the military and industrial complex, and various «clientele»).

Although the partial market decentralisation carried out during the reforms, to a certain extent, liberated the instinct of freedom only in the economic sphere, it soon became clear that this liberation would inevitably manifest itself in the political sphere also; moreover, it would occur with greater force, as it had been suppressed more deeply in this sphere. The events in Czechoslovakia in 1968 had deeply frightened the Party Apparatus and the military and industrial complex in the USSR; under their pressure, the reforms were gradually withdrawn (by the State Planning Committee and the Ministry of Finance), and the military standoff against the West was strengthened.

The epoch of stagnation: an increase in the psychological rupture. The 1970s and the beginning of the 1980s, which are usually considered to be a period of stagnation, were, in fact, a period of the rapid evolution (directed towards greater liberalisation) of the psychology of the masses and the system of informal institutions of society, while the formal institutions either remained unchanged, or were transformed in the opposite direction. This resulted in a growing rupture between the formal and informal institutions and the alienation of the latter from the former.

In this context, one needs to dwell on the specificity of the psychology of the governing elite, which does not always correspond to its own interests. The behaviour of people, social groups, and the nation as a whole, as a rule, can be explained in terms of their perceived interests; and behaviour, which clearly contradicts these interests, can be explained as mistaken, deluded, and short-sighted. However, when these «mistakes» are monotonously repeated and take on a menacing character over a period of many years, it becomes obvious that the behaviour of the person, social group, or even of the 
nation is psychologically «programmed». The behaviour of the Soviet elite in the 1970s confirms this.

The ruling layer of the official institutions of the centralised Soviet system (the Party Apparatus, the security forces, the economic ministries and departments, and the management body) recruited people, whose individual psychology corresponded to the principle of centralism. The heightened instincts of hierarchy and imitation; an equally strong aspiration for self-preservation and improving their social status; extreme adaptability, with weak or suppressed instincts of freedom, inquisitiveness, and creativity; and the ability to temporarily suppress their own predatory instincts - all these qualities of its members, resulted in the elite, as a whole, being opposed to significant innovations, risk, bringing in new personnel, or discussing sensitive problems even within their own circles. The maniacal aspiration to preserve the status quo and hermetic closeness (isolation) of the elite led to its sclerotic degeneration, gerontocracy, and transformation into a national laughing-stock.

In many respects, the psychology of this elite explains its painfully inadequate, primitive, and aggressive reactions to external threats (both real and imaginary), expressed in clearly excessive measures, and involving military expenditures that the country could not afford, such as the introduction of troops in Czechoslovakia and later in Afghanistan.

The instinctive tendency towards self-preservation of the ruling group forced it to consider the centralised economic system as an important lever of power over society. Therefore, in the $1970 \mathrm{~s}$, the perfection of the economic system was considered from the point of view of strengthening its centralised planning, to which the material stimulation and self-financing of the enterprises, as a whole, should be completely subordinated. During these years, planning methods were significantly developed - balanced mathematical models of the national economy, national accounts, forecasting, and programming were applied, a universal system of specifications and economic «passports» for enterprises were developed, and demands were made to unlock their industrial potential. As far as the stimulating role of wages was concerned, it was sharply reduced, by increasing the minimum wage, restricting the difference between the maximum and minimum levels, depending on production, to 30-35 percent, and reducing bonus payments. 
However, during the same time, the evolution of the economic psychology of the masses was proceeding in the opposite direction. The instinctive aspiration for individual prosperity, economic freedom and creativity, and «profit» - that were partially and temporarily, however, officially - liberated by Kosygin's reforms, continued to strengthen, as they did not experience the psychological pressure of the instincts of self-preservation and aggression. This pressure was partially exerted on the psyche of the population prior to the beginning of the 1970s, when relations with Europe remained extremely tense and the war in Vietnam was still being fought, and many people in the USSR (and also in the United States) thought that an even more serious military conflict could take place.

As these factors faded away, and, in particular, with the agreements between the USSR and the United States on the nuclear missile balance, the last powerful stimulus of fear for the population usually, leading to a dominant role of the instincts of self-preservation and aggression - disappeared. At the same time, for the majority of the population, this meant that the psychological justification for the continuation of rigid centralised control over the economic behaviour of individuals, and the economic system as a whole, had disappeared. Moreover, the process of the psychological dismantling of this control became widespread and acquired various forms.

In the psychological environment of the1970s, opportunistic forms of behaviour and unplanned activities developed rapidly, a system of informal and semiformal economic institutions, partially covered by the concept of «the grey economy», began to take shape.

"Opportunistic» activities took place not only outside the planned system, but also within it, and (thus) started decomposing this system. Within the system, repeated downward adjustments of annual plans (without reducing salaries and bonuses), excessively long-term construction, the acceptance and payment for objects that were, in practice, not ready for operation, cost cutting by lowering the quality of production, raising prices by the fictitious announcement of «new» production, unplanned bartering (which was officially forbidden) between enterprises, etc., became the rule.

Outside the system, underground production at the state enterprises and its illegal sale through state trading organisations, trading in scarce goods (i.e., the majority) under the counter at inflated prices, fraudulent reception of money for fictitious deliveries of raw 
materials, etc., became widespread. Corruption and nepotism were rife in many branches of the apparatus of the economic ministries and departments.

Everywhere, the discipline of supplies and work discipline deteriorated from year to year and the efficiency of the economy declined. However, on the whole, the vast mechanism of the centralised economy continued to function, and even, through inertia, grew - although at a slower rate. It resulted in some improvement in the living conditions of the population: during the 1970s, the consumption level, conditions of daily life, and the social and cultural condition of the population improved. The government gathered a false sense of confidence in the economic policy that they were following. At the same time, they ignored the growing apathy of the population, their cynicism and discontent with the formal system, which was clearly inadequate to the psychology of the masses.

Rebuilding the economy: a bet on the wrong horse. The plans of the new reforms were developed by Nikolai Ryzhkov and Mikhail Gorbachev on the instructions of Yuri Andropov, who had become the Secretary General of the Central Committee of the CPSU at the end of 1982. They started to be implemented in January, 1984 (already after Andropov's death), and were referred to as «a large-scale economic experiment». Essentially, it was a return to the reforms of Kosygin, with their concepts of the partial independence of enterprises, and orientation towards profitability and material stimuli for workers. However, at the same time, the direct planning of the ministry, centralised pricing, and the growth of military expenses, were again preserved. After being selected as the Secretary General in March, 1985, Gorbachev at first supported an «acceleration program», which, in relation to the economy, meant primarily modernisation through the concentration of capital investments in the automation of production and management. This expensive program (which, soon failed) also did not promote economic reforms.

The deterioration of the economic situation, «accelerated» by poor harvests, earthquakes, falling oil prices, the catastrophe at Chernobyl, etc., finally forced the government to resort to drastic measures. During their semi-annual discussions, which split the Politburo into two groups, reformers and conservatives, in the summer of 1987, the Law on Enterprises was developed, envisaging the curtailment of state planning and ministerial control over enterprises and the introduction 
of elected directors. However, at the same time, it preserved the obligation of enterprises and ministries to fulfil the tasks assigned in the $12^{\text {th }}$ five-year plan and maintain firm planned prices. Therefore, the introduction of the law in January, 1988, started the struggle for the preservation of centralised control over enterprises, which is considered as the immediate cause of the «slowing down» and, in the end, the failure of this reform also.

Gorbachev (subsequently) considered that it was a mistake to delay the implementation of economic reforms in comparison with political reforms; his main economic adviser, a member of the Politburo, Vadim Medvedev, identified the mistake more specifically - not having the courage to release control of retail prices. In my opinion, the main idea of the Law - of actually transferring enterprises into the hands of «labour collectives» and maintaining state ownership, and thus not assigning real responsibility to «labour collectives» - is flawed. This can be seen in the unwillingness of the authors of the Law to understand the psychology of the social group called a «labour collective».

As already mentioned earlier, whereas the theoretician, Marx, associated the «construction of communism» with the dying off of the state and the appearance of self-governing communities (and Engels saw their prototype in the kin/tribal system of North American Indians), the pragmatist, Lenin, came out basically against real (instead of declared) self-management in general and selfmanagement of «working collectives», in particular. His position in the debate with the «workers' opposition» can be briefly summarised, thus: to transfer the state enterprises into the control of the worker means opposing their group egoism with the interests of society and the state, and this is mortally dangerous to socialism. The worker should be re-educated, so that he became accustomed to working not for himself personally or for the group, but for society as a whole; therefore, the trade-union organisations should be not self-regulating bodies, but «schools of communism».

What are the psychological factors in the relations between individuals, collectives, and society? In the inborn instincts of a person, whose formation basically came to an end with the transition to barbarity, there exist instincts belonging to kin and tribes (forcing a person to be guided in his actions not only on individual, but primarily according to the interests of his kin); however, this does not mean that 
they extend to the neighbouring community or fellow labourers. The instinct of belonging to a «labour collective» can only be instilled and, as paradoxical as it sounds, instilled since early childhood, in the hereditary working-class environment of a given enterprise.

When such an upbringing is absent (and, it has already not been present for a long time in most cases), the application of «the psychology of collectivism» to the enterprise represents a complex local intertwinement of inconsistent inborn and instilled instincts and habits, including the inborn instincts of individualism and sociality, and also a range of "conditioned reflexes» instilled by the social environment. The economic behaviour of a «collective» depends on which instincts of its members, at a given stage, will dominate.

In this context, one can see that there were elements of realism in the theoretical characteristics of co-operative societies in Marxist literature, when it was confirmed that the nature of co-operative societies can be fundamentally different; however, this distinction was made dependent on who controlled political power, banks, railways, etc. This is the type of mechanical interpretation, extended to «socialist collectives», which fooled the authors of the Law on Enterprises.

In the conditions, which had developed in the second half of the 1980s, the instincts of individual prosperity, appropriation, and freedom became increasingly dominant, and suppressed the instincts of sociality and expediency; the behaviour of «labour collectives» became a form of individualistic behaviour, and came to be referred to as «group egoism». "Collective» did not limit the negative aspects of individualistic behaviour; it only multiplied the force, directed against the interests of society as a whole. Among «the instilled» social instincts, the instincts of hierarchical order, belonging to a social class, and national patriotism were increasingly superseded by instincts of egoistical nationalism. The psychological factors constraining the inborn instinct of aggression, weakened.

In the economic sphere, it turned out that «labour collectives», not bothered about the efficiency of the enterprises or capital investments, drew profit and income for the enterprises from the forced sales of their stocks of raw materials and other reserves in order to increase their wages funds. As the latter, on a national scale, could not supply commodity provisions without significant shifts in the entire structure of the economy, there was a severe shortage in the consumer market, 
which set off real inflation. The maintenance by the government of fixed retail prices, while the wholesale prices were inflated by the enterprises, led to the collapse of the state retail trade.

The government's attempts to limit the destructive group egoism by annulling the law of electing directors had a double effect; first, it turned many «labour collectives» into ardent enemies of the government and, secondly, it presented the existing directors and their associates with ample opportunities for plundering the resources of the enterprises, especially through the creation of many thousands of fictitious co-operative societies directly in the enterprises, and also in the form of intermediary co-operatives.

On the newly formed psychological grounds, the slogans of the «national-communistic» Supreme Council of the Russian Soviet Federative Socialist Republic and Yeltsin strongly encouraged the enterprises and local authorities not to pay taxes to the Government of the USSR and «to appropriate as much sovereignty, as you can digest».

Shifts in the psychology of the governing elite had already been taking place for a long time, in line with the general changes, although at a different speed. The prevailing reformatory part of the elite instinctively wished to be released from the centralised control over their behaviour, aspired to personal enrichment and to improve their personal social status. At the same time, within the elite, opposing groups of egoistical interests were formed. The «Moscow» group naturally tried to maintain its positions of command and control of the budget, having grasped the privatised (in practice) banks, importexport firms, «natural monopolies», and power in the branch associations of enterprises. The regional elite strongly opposed the «Moscow» elite, and after a lengthy struggle, finally won under the banner of national-liberal radicalism.

The instincts of freedom, appropriation, individual prosperity, and nationalism were confirmed as the dominant instincts among the population of the USSR. The natural psychological balance between instincts of individualism, on the one hand, and instincts of sociality and development, on the other hand, was again fundamentally broken - this time, in favour of the former. The country had, with little effort, been divided by the national groups of the elite. In Russia and the majority of other independent states that were formed on the territory of the former USSR, an institutional economic system was formed on 
a specific psychological basis, which the reformers themselves characterised as clannish-criminal-bureaucratic capitalism (Yegor Gaidar), or as «oligarchic capitalism» (Vladimir Putin). Society fell into an «institutional trap», where it was enticed by individuals possessing an aggressive, liberal, and egoistic psychology.

Thus, the fundamental defect of all the Russian economic transformations of the $20^{\text {th }}$ century (except for the New Economic Policy), consisted in the fact that they were not aimed at the creation of a system of economic institutions, based on a natural psychological balance; in contrast, one institutional system, breaking the given balance in one direction, was replaced by another, breaking the natural balance in the opposite direction. As a result, the psychological basis of the nation has been shaken to its roots, and it is still not clear whether these cyclic transformational convulsions in the economic sphere have begun to decline. 


\section{Conclusion}

Having discovered the human genetic code and having deciphered its molecular structure, science has taken a decisive step in disclosing the main secret of the human being and of human nature and, at the same time, in understanding the valid laws of the structure and development of society.

Science has known for a long time about the dual, biosocial character of human nature, but only research on the genome gives indisputable grounds for the differentiation of the natural and social boundaries in this nature, and for understanding the natural origin as an invariant basis for the developing social «superstructure».

In the research of the human psyche and behaviour, the success of genetics allows us to distinguish its defining and accurately directed «genetic-social» core from a broad and vague «biosocial» concept. It opens the way to a systemic understanding of the structural components of the psyche - existential requirements, abilities, memory, instincts, and consciousness.

The understanding of a genetic, inherited basis of our psyche is necessary not in order to be surprised at how much there is in common in the behaviour of humans and animals and to admire how far millions years of evolution have taken the human from his apelike ancestors. This understanding is necessary, so that after having got rid of ones illusions, to consider the real structure of the inherited basis of the psyche, both of the person, and of society as a whole, to develop the constructive components of this basis, and to limit and suppress the destructive components. For this, it is necessary for society to consciously correct its culture, and informal and formal institutions. And most importantly, society needs to supervise the psychogenetic structure of the ruling elite by democratic methods. Otherwise the Sword of Damocles of terrorism, dictatorship, wars, and a nuclear catastrophe will constantly hang over society. Moreover, this will happen, regardless of the level of the culture.

This problem - control over the structure of the ruling elite - is extremely intractable, as its solution demands accurate criteria and the presence of self-control from the members of society. Progress in psychogenomics is capable of helping find such criteria; the 
development of civilisation will end in a catastrophe, if society is deprived of self-control and then entrusts leadership to figures with an extreme and inadequate psyche.

The distinction of genetically and socially determined types of psyche is the main problem for understanding the social system and its economic component. The psychological laws of the interaction of these types (of freedom and domination, mutual aid and selfpreservation, cooperation and exploitation, competition and hierarchy, appropriation and justice, trust and aggression, etc.) underlie the formation of institutions, the activity of organisations, classes, nations, and world society as a whole. These laws help us to understand not only the historical movement of various civilisations and social and economic systems in different natural and technogenic conditions, but also the functioning of the modern microeconomic system with all its transformations, technogenic booms, and collapses in times of crises.

The current economic crisis, which began in 2008, has once again confirmed that the real free market is not capable of crisis-free selfregulation; the neoclassical theory continues to merely assert the opposite - because it starts from a truncated and deformed concept about the psyche of market participants and their real behaviour. Adherents of this theory try to justify their inability to explain crises by arguing about the «mistakes» of the market participants. However, a stratum of powerful people with a certain type of the inborn and instilled psyche, who Veblen called «predators», stand behind the «mistakes», made deliberately over a period of many years on a global scale. These people came into power in the United States in the 1980s, and the international expansion of monetarism and «market fundamentalism» is connected with this.

The rise to power in the United States of a political elite with a different type of psyche could begin the restoration of a regulated market and a gradual displacement of bankrupted filibusterers from positions of authority in the economy. As far as mainstream economics is concerned, its representatives (who also are people and possess a certain type of psyche) will probably want to continue their abstract mathematical exercises, however, they will no longer have an audience. Alternatively, the mainstream current will have to change its direction.

The crisis has sharply strengthened the «division» of the psyche of the modern Russian ruling elite. Not only because they consist of 
different people; as can be seen from this book, even the psyche of a completely normal person is fairly contradictory and internally strained. However, sometimes these contradictions become aggravated to such an extent that it becomes impossible to take reasonable decisions.

The reformatory elite of Russia, which came to power in August, 1991, were originally supported and sustained by IMF and American funds, and its psyche of individualism and egoism fitted perfectly with the ideology of «market fundamentalism» and «globalism». Its aspiration to consolidate the power seized by it and also the high export prices for oil, gas, metals, and wood have led to the formation of comprador «oligarchic capitalism», supported by foreign capital, exports, and «offshore centres».

The current crisis and the military conflict with NATO in Georgia have revealed the extent of the unreliability of these supports of the Russian authorities, and the damage caused by the ideology of «liberal-globalism». The ruling elite of Russia are, however, still viable (unlike the Soviet elite of the 1980s), and their instinct of selfpreservation requires the construction of an economic system, focused on national values. The «division» of the psyche of the elite lies in the fluctuations between an individualistic orientation and an orientation on national values. The principle of a multi-polar world corresponds to national values. However, for Russia, this principle will remain merely a wish, if it is not supported by the creation of a sizeable and regulated national market. Probably, such an orientation is unacceptable for the predatory psyche of comprador capital; therefore it proposes as «national» values, the principles of a free global market: competitiveness, diversification, and currency and financial polycentrism.

However, a high level of competitiveness and diversification do not rescue enterprises and the financial centres from a global crisis, if they are not based on a developed domestic market of resources, goods, services, capital, and strong human capital.

The predatory Russian oligarchs, who scour the world in search of export markets, cheap raw materials, and cheap capital and are always ready to emigrate to their foreign residences, do not need such a market.

The «division» of the psyche is characteristic not only for the Russian ruling elite, but also for various strata of the population. The 
crisis has exposed the extent of the unreliability and instability of the increased welfare, based not on the growth of productivity of national labour and on the output of an entire spectrum of high-quality and high technology production, but on the participation in the unmerited and instable incomes of oligarchs from the export of natural resources at inflated prices. The requirement for justice, self-expression, and a debt to posterity is, on the whole, genetically inherent in a nation; therefore, it rejects the «free rider» psyche. However, the system of oligarchic capitalism has put Russians in the position of «free riders», by «squeezing out» intellect from the country, taking out capital, and depriving them of the possibility to master high technologies and release high technology production, leaving only one way of increasing incomes - by participating in super-profits from exports. Now, as the crisis has blocked this source, the time has come for the nation to present the bill to Russian oligarchic capitalism for the loss of 16 years of national economic development and for the plundered natural resources. The psyche of the well-known «care-free rentier», Leonid Golubkov, will be rejected and the «division» of the psyche will be overcome in favour of the need for dignity and the self-esteem of national labour. The moment of truth will come.

The question is whether the Russian ruling elite will manage to separate itself psychologically from the oligarchs, counterbalance its own egoistical inclinations by socialitarian inclinations, and nominate people who think creatively and are capable of innovation to manage the economy. Otherwise the fight against corruption can turn into a farce resembling an endless game for children. In order to implement the new tasks, cadres with an adequate psyche are necessary - not only insiders from «Petersburg», officers from the security services, and sport stars.

In conclusion, I will quote some clauses of the Constitution of Russia, reflecting the normal nature of the psyche and experience of European civilisation.

«Fundamental human rights and freedom are inalienable and belong to everyone from birth (item 17, part 2).»

«The realisation of the rights and freedom of a person and a citizen should not violate the rights and freedom of other persons (item 17, part 3).» 
«The Russian Federation is a social state, whose policies are directed at creating conditions, providing a dignified life and the free development of a person (item 7, part 1).»

«In the Russian Federation, private, state, municipal, and other forms of ownership are acknowledged and protected equally (item 8 , part 2).»

It is unlikely that anyone would assert that these and many other clauses of the Constitution of the Russian Federation are compatible with the system of oligarchic capitalism, based on the domination of persons with a defined and well-known, from Russian and world history, type of human psyche. 